Florida International University

FIU Digital Commons

FIU Electronic Theses and Dissertations

University Graduate School

$11-17-1995$

\title{
Determination of hydraulic conductivity and dispersivity in the Biscayne Aquifer, Taylor Slough, Everglades National Park
}

Jose Dioscoro Altomia Guardiario Jr.

Florida International University

DOI: $10.25148 /$ etd.FI13101611

Follow this and additional works at: https://digitalcommons.fiu.edu/etd

Part of the Geology Commons

\section{Recommended Citation}

Altomia Guardiario, Jose Dioscoro Jr., "Determination of hydraulic conductivity and dispersivity in the Biscayne Aquifer, Taylor Slough, Everglades National Park" (1995). FIU Electronic Theses and Dissertations. 1215.

https://digitalcommons.fiu.edu/etd/1215

This work is brought to you for free and open access by the University Graduate School at FIU Digital Commons. It has been accepted for inclusion in FIU Electronic Theses and Dissertations by an authorized administrator of FIU Digital Commons. For more information, please contact dcc@fiu.edu. 
FLORIDA INTERNATIONAL UNIVERSITY

Miami, Florida

\title{
DETERMINATION OF HYDRAULIC CONDUCTIVITY AND DISPERSIVITY IN THE BISCAYNE AQUIFER, TAYLOR SLOUGH, EVERGLADES NATIONAL PARK
}

\begin{abstract}
A thesis submitted in partial satisfaction of the requirements for the degree of MASTER OF SCIENCE

IN

GEOLOGY
\end{abstract}

by

Jose Dioscoro Altomia Guardiario Jr. 
To: Dean Arthur W. Herriott

College of Arts and Sciences

This thesis, written by Jose Dioscoro Altomia Guardiario Jr., entitled Determination of Hydraulic Conductivity and Dispersivity in the Biscayne Aquifer, Taylor Slough, Everglades National Park, having been approved in respect to style and intellectual content, is referred to you for judgement.

We have read this thesis and recommend that it be approved.

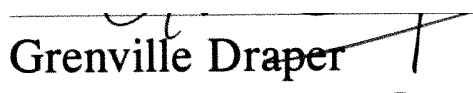

Michael R. Gross

David P. Genereux, Major Ppofessor

Date of Defense: 17 November 1995

The thesis of Jose Dioscoro Altomia Guardiario Jr. is approved.

Dean Arthur W. Herriott College of Arts and Sciences

Dr. Richard L. Campbell

Dean of Graduate Studies

Florida International University, 1996 
This thesis is dedicated to my parents, my wife, Cristy, and my children, Kae, Jay, Nikki and Anne, for their love and understanding. 


\section{ACKNOWLEDGEMENTS}

I am grateful to all who provided valuable help in making this thesis a success: Dr. David P. Genereux, my major professor, for his support, encouragement, and confidence in giving me this project; Dr. Grenville Draper and Dr. Michael Gross for their helpful comments and guidance; Dr. Fred Molz, Auburn University, for his valuable advice and information on the electromagnetic flowmeter; Tom Beasley, Lois Geier, and Diane Pirie for assisting in the acquisition of field supplies and equipment; Mark Stewart for his unwavering assistance in all aspects of the field and laboratory work; Dr. Robert Fennema and Freddie James, Everglades National Park, for providing field logistics; Dr. Florentine Maurrasse, for his valuable information on the geology of Florida and in going through with me on my petrographic slides, and Dr. George Dalrymple, Biological Sciences, Florida International University, for allowing me the use of the scanning electron microscope. Financial assistance for this project was provided by the Everglades National Park. 


\section{ABSTRACT OF THE THESIS \\ DETERMINATION OF HYDRAULIC CONDUCTIVITY AND \\ DISPERSIVITY IN THE BISCAYNE AQUIFER, TAYLOR \\ SLOUGH, EVERGLADES NATIONAL PARK}

by

Jose Dioscoro Altomia Guardiario Jr.

Florida International University, 1996

Miami, Florida

\section{Professor David P. Genereux, Major Professor}

Knowledge of the properties of the Biscayne Aquifer is critical to the understanding of groundwater solute transport problems that affect the Everglades region. To add to our knowledge of the aquifer, geologic logging of cores and hydraulic conductivity measurements were performed in 18 fullypenetrating wells using an electromagnetic borehole flowmeter. Corelogs, ambient flow profiles, and hydraulic conductivity $(\mathrm{K})$ values measured in the study site indicate that the Biscayne Aquifer has a hydraulic conductivity with a geometric mean of $0.18 \mathrm{~meter} / \mathrm{second}$ and a variance of 2.5 , and can be divided into two distinct layers: the Upper Biscayne Aquifer and the Lower Biscayne Aquifer, which are separated by a 33-centimeter hard limestone layer. The hydraulic conductivity of the Upper Biscayne aquifer has a geometric mean of 0.29 meter/second and a variance of 1.9 , whereas the Lower Biscayne Aquifer has a geometric mean of 0.056 meter/second and a variance of 2.1. The best estimate of longitudinal macrodispersivity for the full aquifer is $0.93 \mathrm{~m}$, while the Upper and Lower Biscayne Aquifers show values of 0.97 and $0.20 \mathrm{~m}$, respectively. 


\section{TABLE OF CONTENTS}

ACKNOWLEDGEMENTS $\ldots \ldots \ldots \ldots \ldots \ldots \ldots$. . . . . . . .

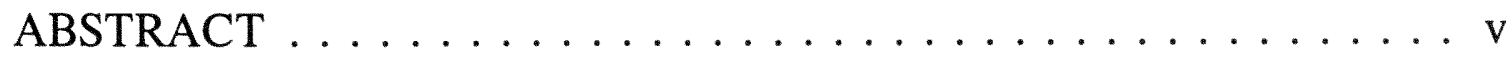

LIST OF FIGURES $\ldots \ldots \ldots \ldots \ldots \ldots \ldots \ldots$. . . . . . . . . . .

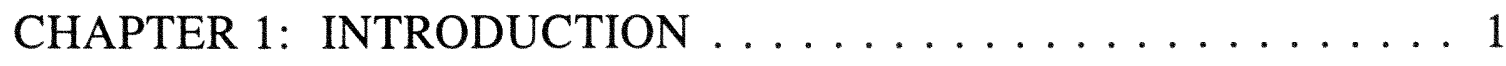

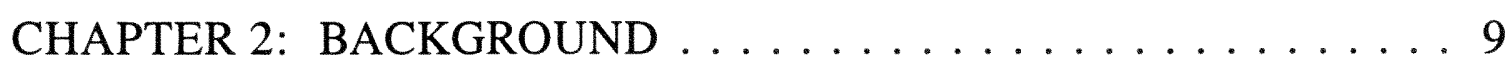

2.1. Advection-Dispersion . . . . . . . . . . . 9

2.2. Determination of Dispersivity . . . . . . . . . 11

2.3. Determination of Hydraulic Conductivity . . . . . . . 15

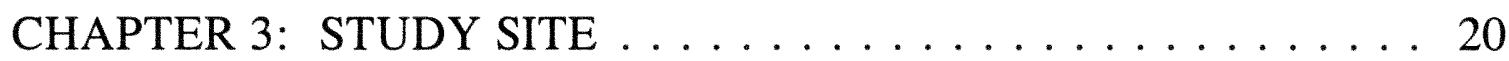

3.1. Regional Setting . . . . . . . . . . . . 20

3.2. Site Characteristics . . . . . . . . . . . . 21

CHAPTER 4: FIELD AND LABORATORY METHODS

AND RESULTS . . . . . . . . . . . . . . . . 27

4.1. Well Location and Drilling . . . . . . . . . . . 27

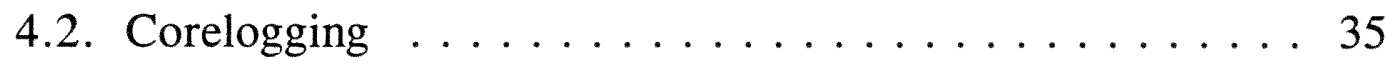

4.3. Core Recovery . . . . . . . . . . . . . . . . . . . . . 39

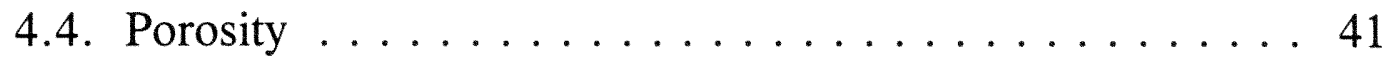

4.5. Flowmeter Setup and Calibration . . . . . . . . . 46

4.5.1. Ambient flow measurements . . . . . . . . . . 50

4.5.2. Induced flow measurements . . . . . . . . . 53

4.5.3. Discharge Rate . . . . . . . . . . . . 56

4.5.4. Layer Hydraulic Conductivity Calculation . . . . . 57

4.6. Geostatistics . . . . . . . . . . . . . . . . 60

4.6.1. Frequency Distribution . . . . . . . . . . 60 
4.6.2. Semi-variogram . . . . . . . . . . . . 67

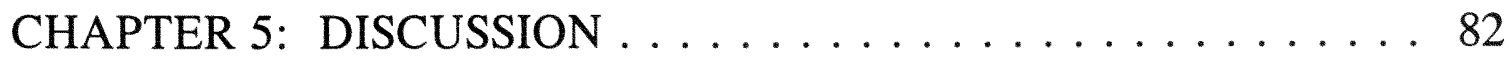

5.1. Hydraulic Conductivity Distribution . . . . . . . . . 82

5.2. Hydrostratigraphy $\ldots \ldots \ldots \ldots \ldots \ldots \ldots$

5.3. Macrodispersivity values . . . . . . . . . . . 91

CHAPTER 6: SUMMARY AND CONCLUSIONS . . . . . . . . 96

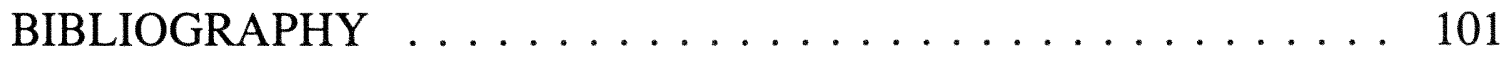

APPENDIX I: Borehole $25-5 \operatorname{Logs} \ldots \ldots \ldots \ldots \ldots \ldots$

APPENDIX II: Flowmeter Calibration and Calibration Curves . . . 112

APPENDIX III: Estimation of Average Hydraulic Conductivity . . . 121

APPENDIX IV: Computation of Layer Hydraulic Conductivity . . . 124

APPENDIX V: Ambient, Pump, and Induced Flow Rates . . . . . 127

APPENDIX VI: Discharge Flow $\left(\mathrm{Q}_{i}-\mathrm{Q}_{\mathrm{a}}\right)$ and Hydraulic Conductivity 146 APPENDIX VII: Flow and Hydraulic Conductivity Profiles . . . . . 166 APPENDIX VIII: Determination of Pseudo-Steady State Conditions 185 APPENDIX IX: Calculation of Macrodispersivity . . . . . . . 188 APPENDIX X: Logistical References . . . . . . . . . . . . . 194 


\section{LIST OF FIGURES}

Figure 1. Kissimmee-Okeechobee-Everglades watershed . . . . . . 2

Figure 2. Hydrogeologic profile in the vicinity of the study site . . . 3

Figure 3. Location of the research site . . . . . . . . . 5

Figure 4. Data acquisition and analysis flow chart $\ldots \ldots \ldots \ldots$

Figure 5. Field data on longitudinal dispersivity $\ldots \ldots \ldots \ldots 12$

Figure 6. Schematic diagram of borehole flowmeter equipment . . . . 18

Figure 7. Topographic map of test site $\ldots \ldots \ldots \ldots \ldots \ldots . \ldots 22$

Figure 8. Soil thickness map . . . . . . . . . . . . . 23

Figure 9. Bedrock elevation $\ldots \ldots \ldots \ldots \ldots \ldots \ldots$

Figure 10. Well location map at the test site $\ldots \ldots \ldots \ldots 28$

Figure 11. Groundwater flow direction monitoring wells . . . . . . 30

Figure 12. Relationship between rainfall, pumping rate, water levels, and the regional groundwater flow azimuth $\ldots \ldots \ldots 31$

Figure 13. West-east vertical section along 18 fully penetrating wells . 33

Figure 14. Core recovery, porosity, groundwater discharge, $\operatorname{lnK}$, and lithology in borehole $25-5 \ldots \ldots \ldots \ldots$

Figure 15. Core samples from borehole $25-5 \ldots \ldots \ldots \ldots$

Figure 16. Core samples within the Fort Thompson Formation . . . . 40

Figure 17. Fabric-selective types of porosity in the study site . . . . 42

Figure 18. Gravimetric porosity in relation to imbibition porosity . . 45

Figure 19. Relationship between $\operatorname{lnK}$ and porosity . . . . . . . . 47

Figure 20. Schematic diagram of the flowmeter calibration set-up. . . 49

Figure 21. Calibration line for correcting flowmeter readings $\ldots . .51$

Figure 22. Temporal variation in the slope of the calibration line $\ldots 52$ 
Figure 23. Ambient, induced and discharge flow rate profiles of borehole $2 \mathrm{~W}$.

Figure 24. Cross section showing the ambient flow profile from

18 fully penetrating wells $\ldots \ldots \ldots \ldots 55$

Figure 25. Cross section showing the induced flow profile from

18 fully penetrating wells $\ldots \ldots \ldots \ldots \ldots \ldots$

Figure 26. Hydraulic conductivity distribution along the study transect 61

Figure 27. Distribution of natural-log of hydraulic conductivity $\ldots 62$

Figure 28. Frequency distribution of hydraulic conductivity values within the full Biscayne Aquifer . . . . . . . . . . . . . 64

Figure 29. Frequency distributions of hydraulic conductivity values in the Upper and Lower Biscayne Aquifer . . . . . . . . . . 66

Figure 30. Search parameters used in horizontal semi-variograms . . 74

Figure 31. Global experimental variograms $\ldots \ldots \ldots \ldots \ldots$

Figure 32. Vertical and horizontal experimental semi-variograms of the full Biscayne Aquifer . . . . . . . . . . . 76

Figure 33. Vertical and horizontal semi-variograms based on the "multiple-interval" approach $\ldots \ldots \ldots \ldots$. . . . 77

Figure 34. Vertical and horizontal semi-variograms based on the "single-interval approach . . . . . . . . . . . 78

Figure 35 . Hydraulic conductivity along the study transect . . . . . 83

Figure 36. Contours of the natural-log of hydraulic conductivity . . . 84

Figure 37. Hydrostratigraphic profile along the study transect. . . . 8 86

Figure 38. Temporal variations in ambient flow profiles $\ldots \ldots \ldots 88$

Figure 39. Water levels and groundwater flow direction during borehole flowmeter measurements. . . . . . . . . . . . 89 


\section{CHAPTER 1 \\ INTRODUCTION}

The Everglades is a vast, shallow sawgrass marsh at the southern end of the 28,205 square-kilometer Kissimmee-Okeechobee-Everglades (KOE) watershed system which ranges approximately $450 \mathrm{~km}$ from Orlando to Florida Bay and $100 \mathrm{~km}$ east to west (Figure 1). Prior to land development and construction of canals for drainage, the natural flow of water in the $\mathrm{KOE}$ system was generally southward, with the Kissimmee River discharging into Lake Okeechobee and groundwater and overland flow continuing toward Florida Bay and the east and west coasts. During wet seasons, lake overflows may provide additional inputs to areas south of Lake Okeechobee (Light and Dineen, 1994; Whalen et al., 1992; Nordlie, 1990). Over a large part of the Everglades, the water table rises above the land surface. The rocks and sediments from the land surface down to the intermediate confining unit (Figure 2) comprise the surficial aquifer system, the top of which is the unconfined, highly permeable Biscayne Aquifer (Whalen et al., 1992; Fish and Stewart, 1991).

At the start of the century, canals were dredged and dikes were constructed which disrupted the natural flow of water from Lake Okeechobee to the Everglades. This paved the way, however, for agricultural and urban development in southern Florida that was accomplished at the cost of immense damage to the Everglades ecosystem. The upland restrictions of fresh water flow resulted in changes in the magnitude and timing of water fluxes into the Everglades (Davis and Ogden, 1994; Light and Dineen, 1994), as well as changes in water quality (Browder et al., 1994). The 


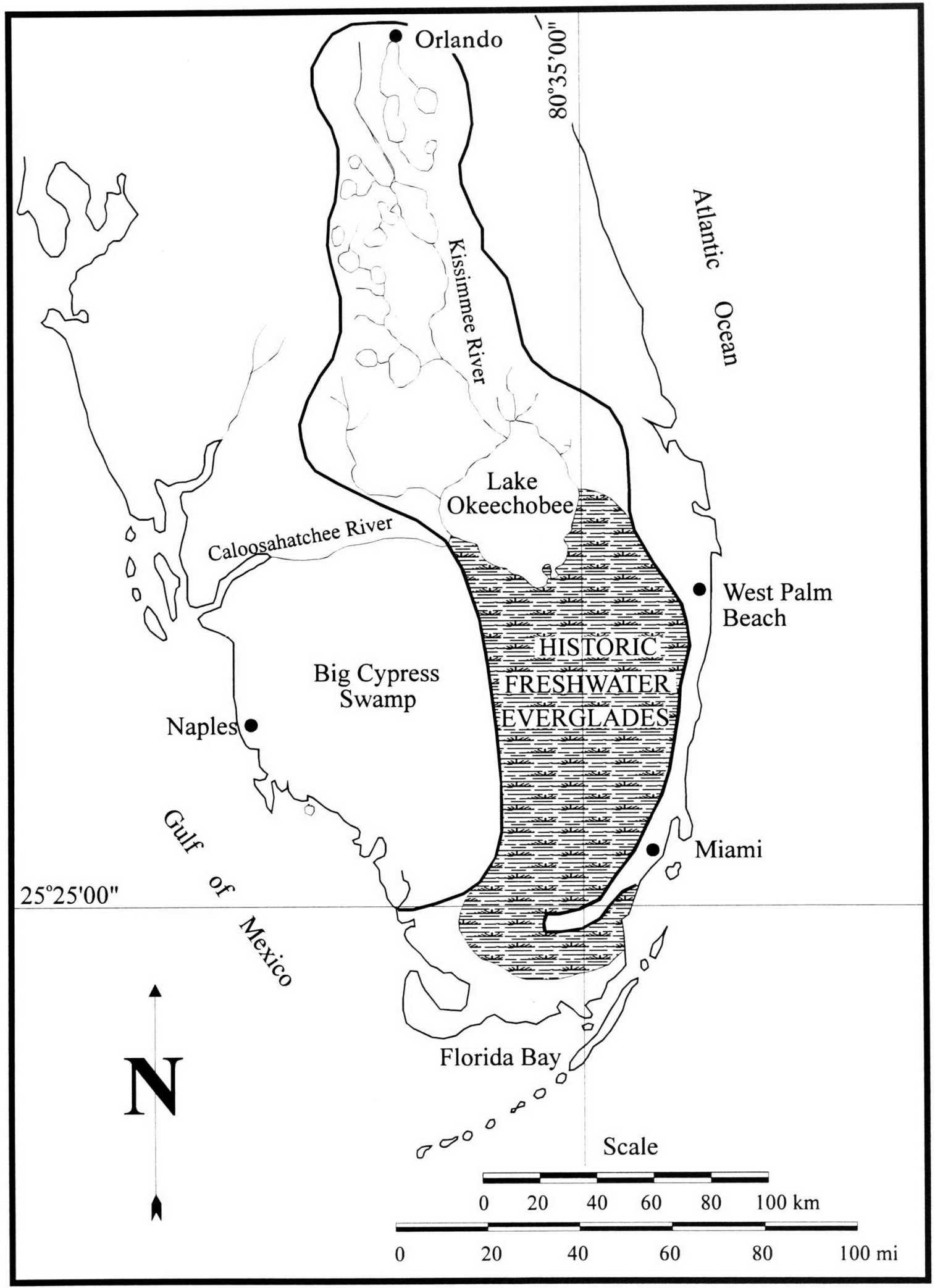

Figure 1. Location of the Kissimmee-Okeechobee-Everglades watershed in south Florida (after Light and Dineen, 1994) 


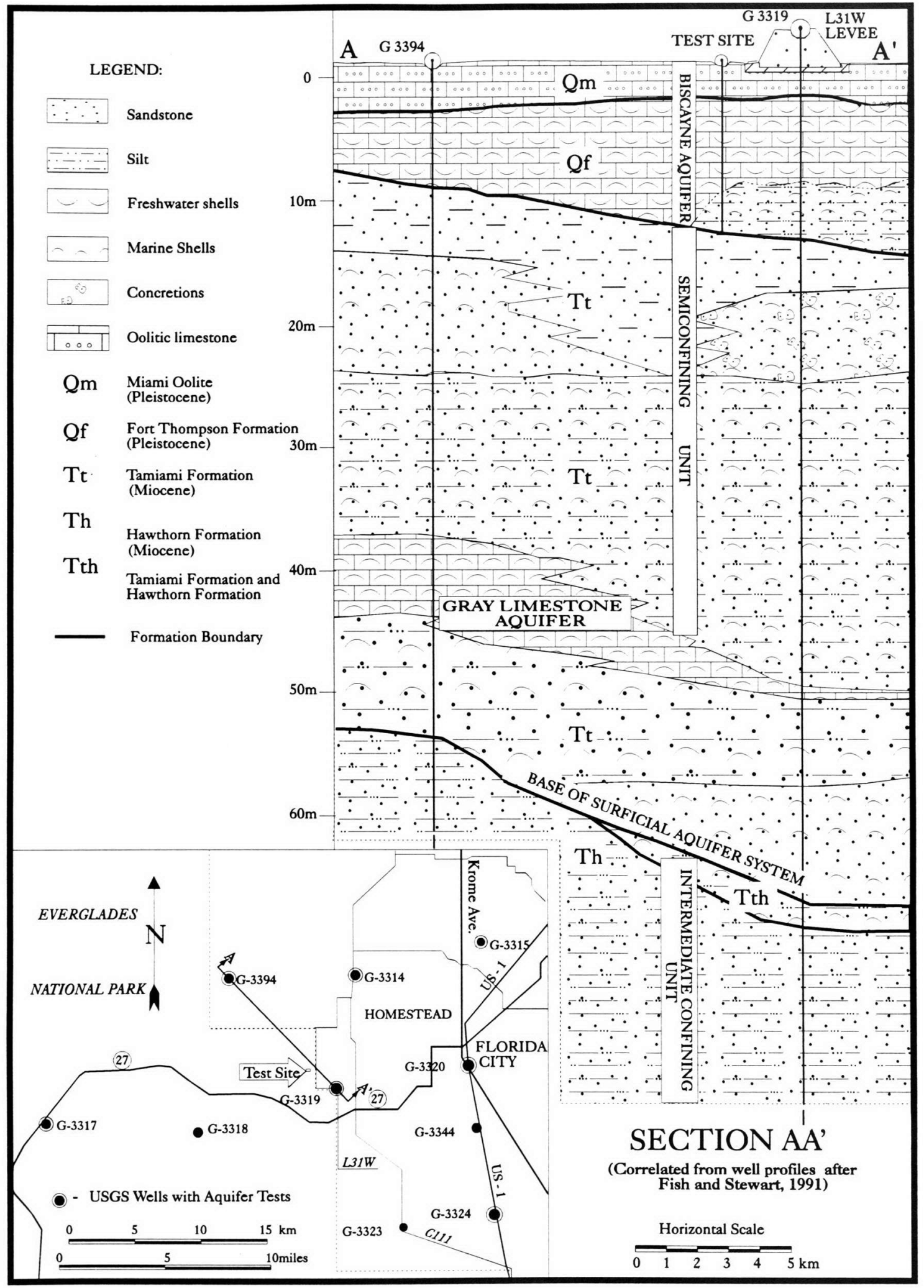

Figure 2. Hydrogeologic profile in the vicinity of the study site. 
change in the hydrologic system greatly affected fire regimes, vegetation patterns, salinization, and invasion of exotic species (Myers and Ewel, 1990; Gunderson and Snyder, 1994; White, 1994; Mazzotti and Brandt, 1994; Davis, 1994). Knowledge of the properties which govern subsurface water flow and solute transport in the Biscayne Aquifer (i.e., dispersivity and hydraulic conductivity), is crucial to understanding the behavior and eventual ecological impact of pollutants in the groundwater.

In 1987 , tracer studies were conducted to quantify groundwater flow velocities and directions in northern Taylor Slough and determine the hydraulic conductivity and dispersivity of the Biscayne Aquifer in that location (Fennema, 1988). The study site (Latitude 26²6'16.192'' and Longitude $80^{\circ} 35^{\prime} 35.682^{\prime \prime}$ ) was at the northeastern part of Everglades National Park and west of L-31W canal and levee (Figure 3). The results were inconclusive, but suggested the possibility of complex subsurface pathways, possibly due to the occurrence of solution channels that allow the groundwater to move faster than it does in the surrounding rock; further tracer tests were recommended, to enhance knowledge of the aquifer parameters.

Prior to this work, three options were considered for determination of dispersivity: (1) natural gradient tracer tests, (2) forced gradient radial flow tracer tests involving pumping, and (3) geostatistical methods. The wide variations in flow azimuths with changes in the water levels in the nearby L31W Canal and S332 pump station (which are respectively 300 meters east and 1.7 kilometers south of the study site) seriously limit the ability to 


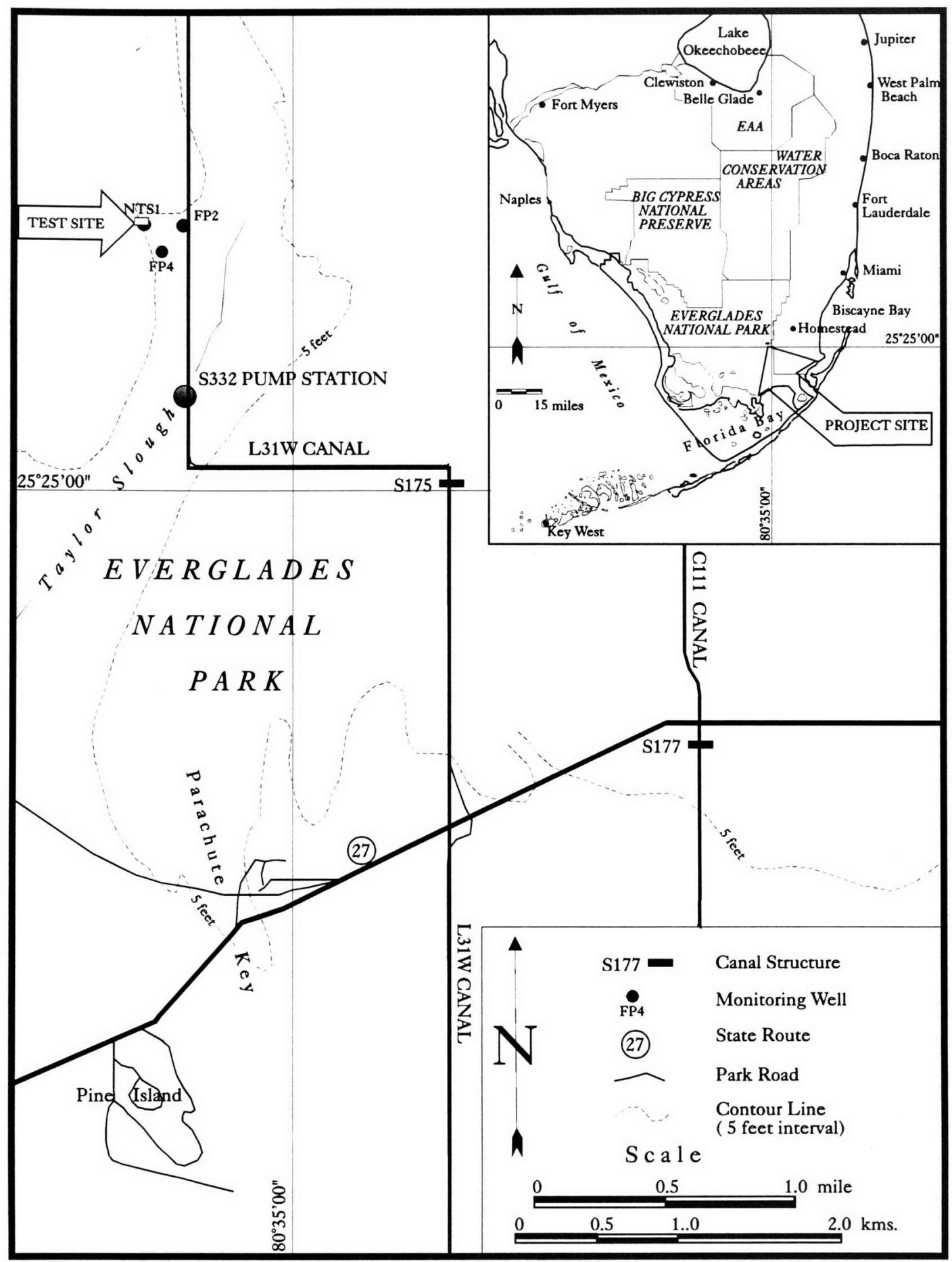

Figure 3. Location of the research site in the northern part of Taylor Slough, Everglades National Park. 
perform a natural gradient test which requires a steady uniform flow. In addition, the need for a large capacity pump to create steady radial flow imposes a problem (i.e., equipment mobilization and power source) in conducting radial flow tests. Therefore, in this work, dispersivity was estimated using the theoretical geostatistical approach developed by Gelhar and Axness (1983) which is based on the spatial distribution of hydraulic conductivity values. Previous work (Sudicky, 1986; Rehfeldt et al., 1992; Hinsby et al., 1992; Hess et al., 1992) has shown reasonable conformity between two independent methods (i.e., tracer tests and geostatistics), pointing to the potential of statistical methods for estimating dispersivity from hydraulic conductivity values.

Several methods have been developed and used for measurement of vertical profiles of hydraulic conductivity (Sudicky, 1986; Hufschmied, 1986; Hinsby et al, 1992; Molz et al, 1989; Rehfeldt et al, 1989a; Hess et al, 1992; Rehfeldt et al, 1992; Molz and Young, 1993). Among these, the borehole flowmeter is the most direct method for "in situ" measurement of hydraulic conductivity. This method may be viewed as a small-scale pumping test in which groundwater inflow to the pumping well is measured over the full depth of the well (instead of only at the top), to provide vertical resolution (instead of only a depth-averaged transmissivity). In groundwater applications several types of flowmeters, such as spinner, heat-pulse, and electromagnetic, are in use. The electromagnetic borehole flowmeter, developed by the Tennessee Valley Authority and marketed by Tisco, Inc., was utilized in this study to measure the hydraulic conductivity. A stochastic theory of solute transport was then used to estimate dispersivity from the hydraulic 
The work reported here represents, to our knowledge, the first attempt to determine the dispersivity of a rock aquifer through geostatistical analysis of borehole hydraulic conductivity measurements (all previous efforts have all been undertaken in unconsolidated sediments). The approach is shown in Figure 4.

The work involved coring and drilling of 18 boreholes along an eastwest transect in the Biscayne Aquifer in Everglades National Park. Geologic logs and porosity measurements were performed on the cores. Ambient and induced flow rates were then measured at regular intervals in the boreholes, and the layer hydraulic conductivities calculated from these values. A geostatistical analysis of the spatial distribution of the natural logarithim of hydraulic conductivity $(\operatorname{lnK})$ values was then performed using semivariograms (graphical tools for representing trends in spatial data; see section 2.2). An exponential model was fit to the semi-variograms, giving estimates of the variance and the correlation length of the spatial distribution of $\ln K$ values. The variance and correlation length were then used in computing the dispersivity of the aquifer. The results of this study are hydraulic conductivity and dispersivity values for the Biscayne Aquifer, which are essential aquifer parameters used in groundwater and solute transport modeling. 


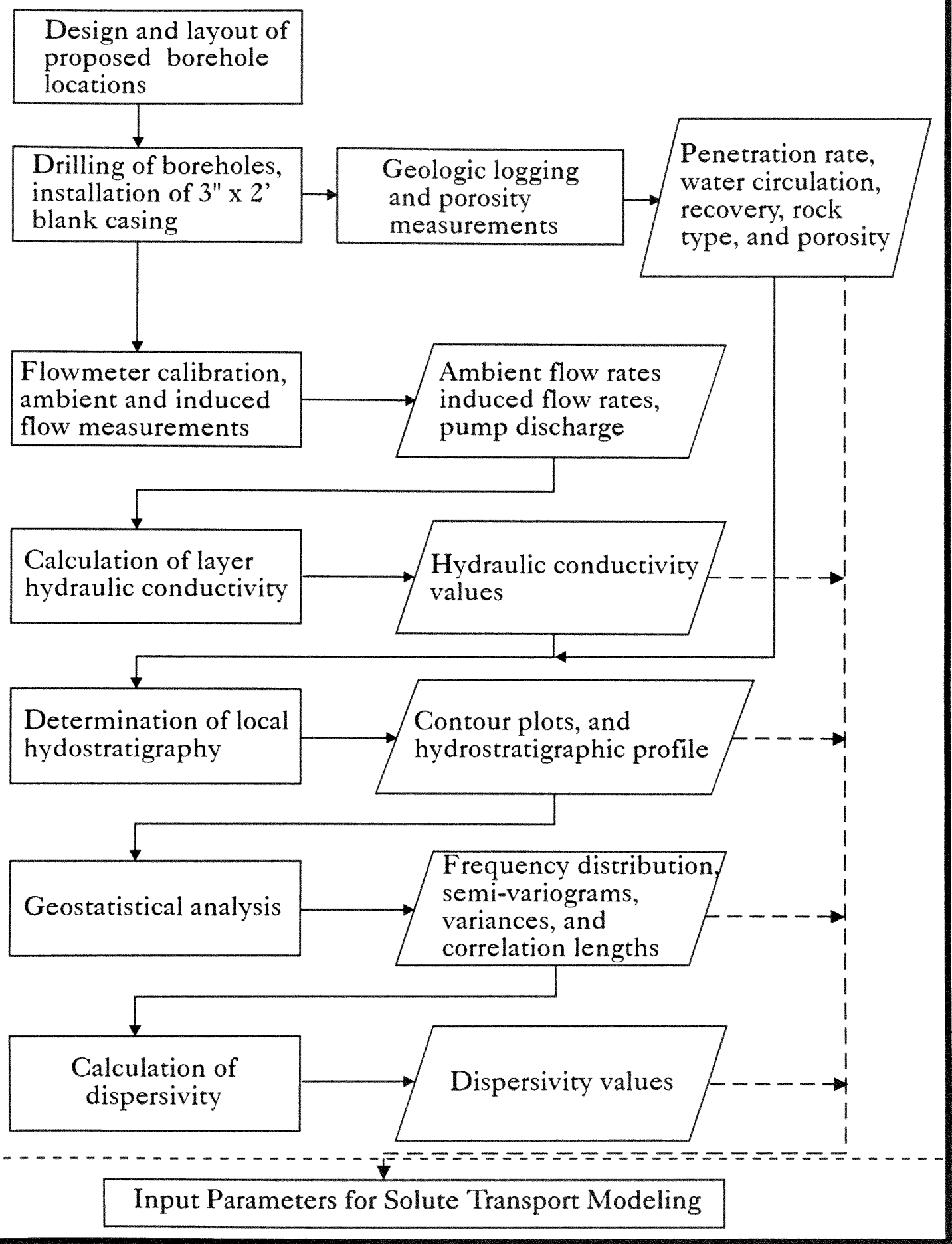

Figure 4. Flow chart summarizing the steps in data acquisition and analysis in this study. 


\section{CHAPTER 2}

\section{BACKGROUND}

\subsection{Advection-Dispersion}

Advection and dispersion are the two principal processes that govern the transport of solutes in groundwater. The three-dimensional equation of mass transport for a conservative solute in a saturated porous medium (Freeze and Cherry, 1979) is:

$$
\frac{\partial}{\partial i}\left(D_{i} \frac{\partial C}{\partial i}\right)-\frac{\partial}{\partial i}\left(v_{i} C\right)=\frac{\partial C}{\partial t}
$$

where,

$$
\begin{aligned}
& I=\text { coordinate axis, }(x, y, z) \text { or }(1,2,3) \\
& D=\text { hydrodynamic dispersion coefficient } \\
& C=\text { concentration of solute } \\
& t=\text { time } \\
& v=\text { average linear velocity }
\end{aligned}
$$

The first and second terms on the left-hand side of equation 1 denote dispersion and advection, respectively. Advection is the process by which solutes are transported by the bulk movement of water at the average velocity of the flow system, while dispersion is the solute spreading that acts to dilute concentrations as solutes are carried along by groundwater advection. Dispersion is difficult to define sharply, as it involves a combination of different processes that operate at different spatial scales. Most authors define dispersion by reference to an example. For example, Bear (1972 p. 579-580) 
offers the following description/definition:

Consider saturated flow through a porous medium, and let a portion of the flow domain contain a certain mass of solute. This solute will be referred as a tracer. The tracer which is a labeled portion of the same liquid, may be identified by its density, color, electrical conductivity, etc. Experience shows that as flow takes place the tracer gradually spreads and occupies an everincreasing portion of the flow domain, beyond the region it is expected to occupy according to the average flow alone. This phenomenon is called hydrodynamic dispersion (dispersion, miscible displacement) in a porous medium. It is a nonsteady, irreversible process (in the sense that the initial tracer distribution cannot be obtained by reversing the flow) in which the tracer mass mixes with the nonlabeled portion of the liquid.

Dispersion in flowing groundwater is a combination of molecular diffusion and mechanical dispersion (mixing), and is governed by a "hydrodynamic dispersion coefficient" expressed as:

$$
D=\alpha v+D *
$$

where,

$$
\begin{aligned}
& \mathrm{D}=\text { hydrodynamic dispersion coefficient, } \mathrm{L}^{2} / \mathrm{t} \\
& \alpha \mathrm{v}=\text { mechanical dispersion coefficient, } \mathrm{L}^{2} / \mathrm{t} \\
& \alpha=\text { dispersivity (characteristic property of the porous medium), } \mathrm{L} \\
& \mathrm{v}=\text { average linear groundwater velocity, } \mathrm{L} / \mathrm{t} \\
& \mathrm{D}^{*}=\text { coefficient of molecular diffusion in the porous medium, } \mathrm{L}^{2} / \mathrm{t} . \\
& \mathrm{L}=\text { length }
\end{aligned}
$$

In flowing groundwater, molecular diffusion is often insignificant in comparison with mechanical dispersion. On millimeter to centimeter scales (pore scale) mechanical dispersion is due to variations in fluid velocity and 
tortuous flow paths in the voids of the porous medium. At the field scale, mechanical dispersion is due to spatial variations in velocity that are linked to the large-scale spatial variability in hydraulic conductivity of the porous medium (Bear, 1972; Gelhar, 1993). Field observations indicate that dispersion coefficients required to describe large-scale transport of dissolved or suspended materials are much different from those observed in small-scale laboratory measurements (Gelhar, 1993). It is generally accepted that in field-scale transport processes spatial variations in hydraulic conductivity play a critical role in dispersion (Davis et al., 1985; Domenico and Schwartz, 1990; Freeze and Cherry, 1979; Gelhar, 1993; Fetter, 1994). Gelhar et al. (1992) pointed out that field data may suggest a systematic increase of the longitudinal dispersivity with observation scale (Figure 5) but the trend is much less clear when the reliability of the data is considered. Also, for horizontal groundwater flow roughly parallel to local stratigraphy, transverse (normal to groundwater flow direction) horizontal dispersivities are roughly one order of magnitude less than longitudinal (parallel to groundwater flow) values, and transverse vertical values are smaller by another order of magnitude.

\subsection{Determination of Dispersivity}

Dispersivity is a characteristic property of a medium, has units of length, and quantifies mechanical dispersion in the medium. Stochastic analysis of dispersion focuses on the spatial distribution of hydraulic conductivity in a porous medium. Gelhar and Axness (1983) provide the theoretical equations for calculating macrodispersivity from hydraulic conductivity data. 


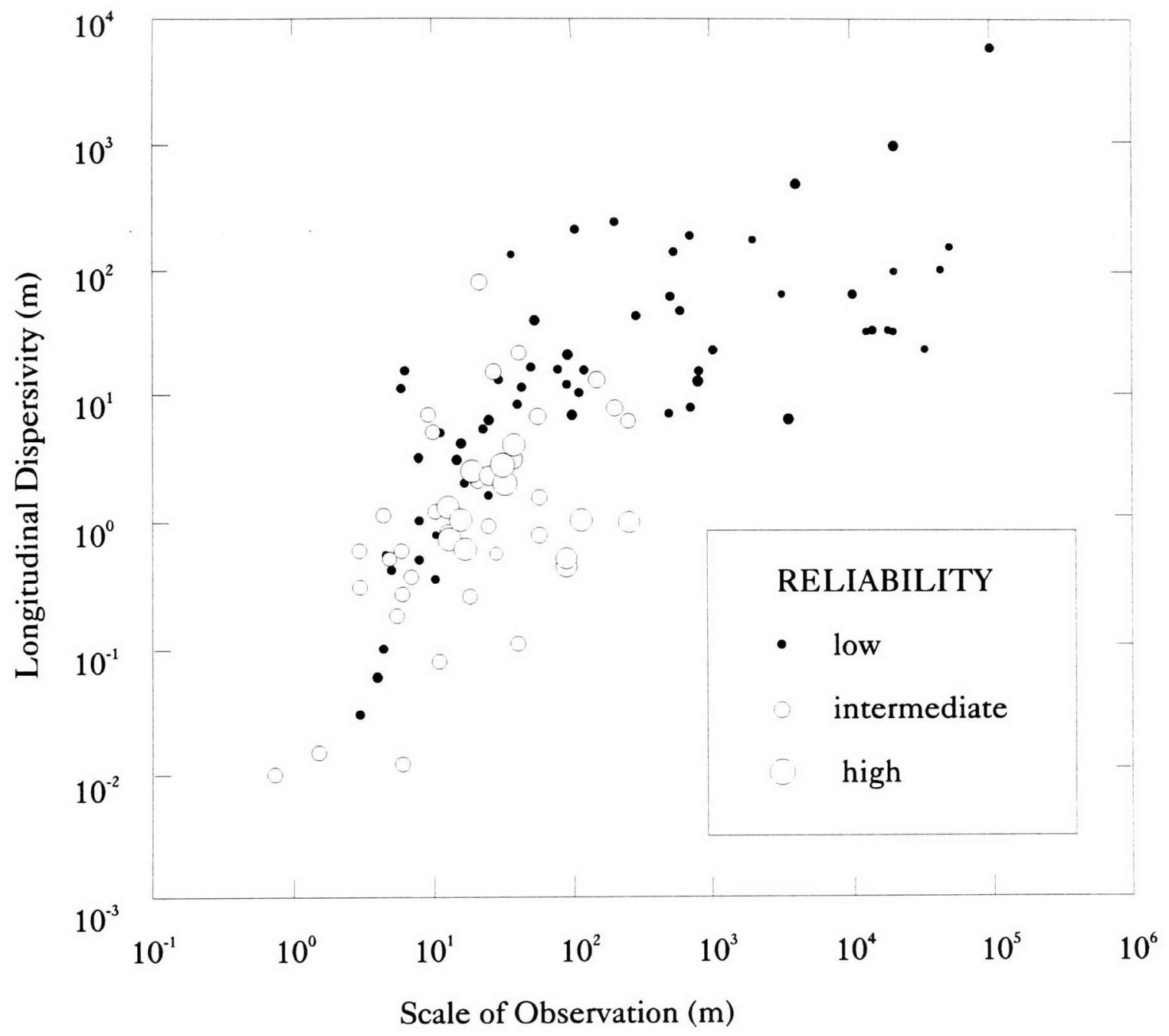

Figure 5. Field data on longitudinal dispersivity, classified according to reliability (from Gelhar et al., 1992). 
Macrodispersivity is the property that controls solute dispersion at the field scale, taking into account the full heterogeneity of the porous medium at that scale (e.g., occurrence of clay lenses in a sandy aquifer), while dispersivity (sometimes referred to as the "local dispersivity") accounts for mechanical dispersion at small (e.g., laboratory column) scales. Longitudinal macrodispersivities are generally much larger ( 2 or more orders of magnitude) than longitudinal dispersivities, indicating the importance of field scale geological heterogeneity in controlling solute dispersion in actual field settings; dispersivities estimated from column experiments would drastically underestimate solute dispersion in real aquifers.

Geostatistical studies of aquifers generally treat the natural logarithim of hydraulic conductivity $(\operatorname{lnK})$ as a regionalized variable. A regionalized variable differs from an ordinary scalar random variable in that each value in the distribution is associated with a particular location in space. Also, values in different locations generally display non-zero correlation, as opposed to the uncorrelated nature of successive values in an ordinary scalar random variable (Henley, 1981). As in many previous studies, the spatial structure of $\operatorname{lnK}$ was analyzed in this study with the use of a semi-variogram. The experimental semi-variogram is a graphical statistical tool for visualizing and quantifying the spatial distribution of a regionalized variable such as $\operatorname{lnK}$. The details of semi-variogram construction are explained in section 4.6.2. The experimental semi-variogram is the basic tool used in this study and is defined as:

$$
\gamma(h)=\frac{1}{2 N(h)} \sum_{j=1}^{N(h)}\left[Y\left(x_{j}\right)-Y\left(x_{j}+h\right)\right]^{2}
$$


where,

$$
\begin{aligned}
& \gamma(h)=\text { semi-variogram statistic } \\
& Y\left(x_{j}\right)=\text { regionalized variable } \ln K \text { at point } x_{j} \\
& h=\text { separation distance between two values of } Y \\
& N(h)=\text { number of pairs of regionalized variables separated by } h .
\end{aligned}
$$

In the present study, as in most geostatistical studies of groundwater dispersion, an exponential model was fitted to the experimental semivariogram to represent the trend of the spatial structure. The model is defined by:

$$
\gamma(h)=\sigma_{Y}^{2}\left(1-e^{-h / \lambda}\right)
$$

where,

$$
\begin{aligned}
& \sigma_{\mathrm{Y}}{ }^{2}=\text { variance of } \ln \mathrm{K} \text { in the search direction } \\
& \lambda=\text { correlation length, or correlation scale }=\text { the separation distance } \\
& \quad \text { at which } \gamma \text { takes the value of } \sigma_{\mathrm{Y}}{ }^{2}\left(1-e^{-1}\right) \\
& \mathrm{Y}=\operatorname{lnK} \text { (natural log of hydraulic conductivity). }
\end{aligned}
$$

The statistical information gathered from the semi-variogram analysis was then utilized in the estimation of the macrodispersivity. For example, Gelhar and Axness (1983) provide the equation for determining the longitudinal macrodispersivity in a statistically isotropic medium having equal correlation lengths in three mutually orthogonal directions:

$$
A_{L}=\frac{\sigma_{Y}^{2} \lambda_{L}}{\gamma^{2}}
$$


where,

$$
\begin{aligned}
& \mathrm{A}_{\mathrm{L}}=\text { longitudinal macrodispersivity } \\
& \sigma_{\mathrm{Y}}^{2}=\text { variance of the } \mathrm{Y} \text { values } \\
& \lambda_{\mathrm{L}}=\text { correlation length in the mean direction of flow } \\
& \gamma=\text { is the flow factor }=\mathrm{q} / \mathrm{J}_{\mathrm{L}} \mathrm{K}_{\text {geom }} \text {, ratio of the effective conductivity } \\
& \quad \text { to the geometric mean conductivity, } \mathrm{K}_{\mathrm{geom}} \\
& \mathrm{q}=\text { specific discharge, } \mathrm{L} / \mathrm{T} \\
& \mathrm{J}_{\mathrm{L}}=\text { hydraulic gradient } \\
& \mathrm{K}_{\text {geom }}=\text { geometric mean hydraulic conductivity, } \mathrm{L} / \mathrm{T} .
\end{aligned}
$$

Based on hydraulic conductivity data collected by Sudicky (1986) at the Borden tracer test site in Ontario (a contaminated, unconfined glacial till and outwash aquifer), where $\sigma_{Y}^{2}=0.29$, and $\lambda_{L}=2.8 \mathrm{~m}$, the estimated longitudinal dispersivity is $0.6 \mathrm{~m}$. This is close to the estimated value of 0.65 , based on spatial moment analysis of tracer test data from the Borden test site by Freyberg (1986), where $\sigma_{Y}^{2}=0.24$ and $\lambda_{L}=2.7 \mathrm{~m}$. The reasonable conformity between these two independent methods points to the potential of statistical methods in estimating dispersivity values. The advantage of the geostatistical approach is that it can be applied to large-scale systems without using tracers. The drawback is it requires a large number of hydraulic conductivity values to accurately define the spatial distribution of $\mathrm{Y}$ (Domenico and Schwartz, 1990).

\subsection{Determination of Hydraulic Conductivity}

Hydraulic conductivity is the specific discharge per unit hydraulic gradient $(\mathrm{L} / \mathrm{t})$, and expresses the ease of fluid transport through a porous 
medium. This property is a characteristic of both the medium and the fluid (Bear, 1979, Freeze and Cherry, 1979). Knowledge of the spatial distribution of hydraulic conductivity is essential in determining macrodispersivity by the geostatistical approach explained above. Various methods have been used in measuring vertical profiles of hydraulic conductivity. Permeameter tests on core sections (e.g., Sudicky, 1986; Hess et al., 1992), slug tests (e.g., Bouwer and Rice, 1976; Van der Kamp, 1976; Springer and Gelhar, 1991; Hinsby, et al., 1992), and borehole flowmeter measurements (e.g., Hufschmied, 1986; Rehfeldt et al., 1989a; Hess et al., 1992; Molz and Young, 1993) are some of these methods. Field studies by Molz et al. (1989) showed that the borehole flowmeter is better suited for detecting layers of high hydraulic conductivity than mini-slug tests. It is used in what may be thought of as a small-scale pumping test wherein the aquifer is stressed beyond the disturbed zone of the well. In groundwater applications, there are several types of flowmeters used such as spinner, heat-pulse, and electromagnetic flowmeters. An electromagnetic flowmeter was used in this study.

Molz and Young (1993) and Rehfeldt et al. (1989a) provide details on the collection and analysis of flowmeter logs. Also, Molz and Young (1993) describe the principle behind the electromagnetic flowmeter. The flowmeter consists of a down-the-hole probe that measures vertical water velocity, and is connected by a cable to an electronic unit at the ground surface which (upon calibration) displays volumetric flow readings. The probe has a 1-inch diameter hole running through it from top to bottom and an air-inflatable packer at its perimeter. The packer ensures all vertical flow in the borehole 
will pass through the 1-inch hole in the probe. The determination of hydraulic conductivity around the borehole requires measurement of ambient and induced flow profiles. The ambient flow profile involves measurement of the vertical water flow at different depths in the borehole without pumping, while the induced flow profile involves the same type of measurements while groundwater is pumped from the top of the hole, just below the water table. Figure 6 shows a schematic diagram of the flowmeter probe in borehole $2 \mathrm{~W}$, and the correlation between change in flow rate and hydraulic conductivity. The value of the induced flow, when corrected for ambient flow, approaches the value of the pump discharge at the top of the borehole.

Molz and Young (1993) provide the equation for the determination of the hydraulic conductivity of a horizontal layer between two adjacent flow measurements:

$$
K_{j}=\frac{K_{a v g} b \Delta\left(Q_{i}-Q_{a}\right)}{Q_{p} \Delta z_{j}}
$$

where,

$\mathrm{K}_{\mathrm{j}}=$ hydraulic conductivity of layer $\mathrm{j}$ defined by the interval between flowmeter measurements and not by geologic description

$\mathrm{K}_{\mathrm{avg}}=$ average aquifer hydraulic conductivity

$\mathrm{b}=$ aquifer thickness

$\Delta \mathrm{z}_{\mathrm{j}}=$ thickness of layer $\mathrm{j}$

$\mathrm{Q}_{\mathrm{p}}=$ rate at which groundwater is pumped from the borehole

$\mathrm{Q}_{\mathrm{a}}=$ ambient flow rate in the borehole at a given depth

$\mathrm{Q}_{\mathrm{i}}=$ induced flow rate in the borehole at a given depth 


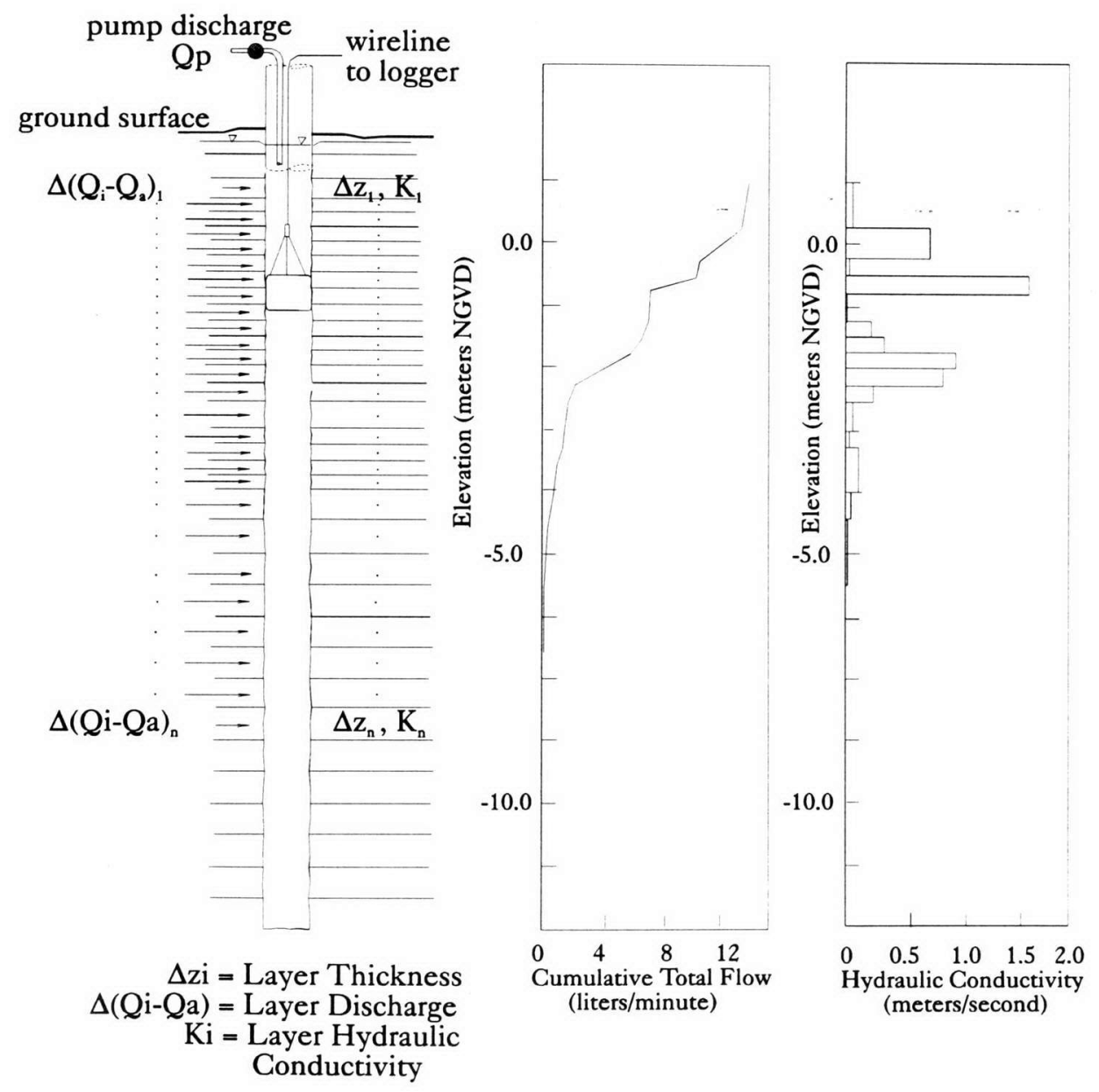

Figure 6. Schematic diagram of borehole flowmeter equipment, and relation between borehole inflow and hydraulic conductivity at borehole $2 \mathrm{~W}$, Everglades National Park. 
$\Delta\left(\mathrm{Q}_{\mathrm{i}}-\mathrm{Q}_{\mathrm{a}}\right)=$ groundwater inflow to the borehole from layer $\mathrm{j}$, computed as the difference between $Q_{i}-Q_{a}$ at the top of layer $j$ and $\mathrm{Q}_{\mathrm{i}}-\mathrm{Q}_{\mathrm{a}}$ at the bottom of layer $\mathrm{j}$.

A value of hydraulic conductivity was calculated for every depth interval between two adjacent borehole flow measurements. In this study, $\mathrm{K}_{\text {avg }}(0.18$ meter per second) was estimated using published pump test data from seven wells within a radius of 20 kilometers from the test site (Fish and Stewart, 1991). Appendix III shows the details on the determination of $K_{\text {avg }}$ for the study site. 


\section{CHAPTER 3 \\ STUDY SITE}

\subsection{Regional Setting}

The Everglades National Park (ENP) encompasses the southernmost part of the Kissimmee-Okeechobee-Everglades watershed that stretches from the Kissimmee River to Florida Bay (Light and Dineen, 1994; Whalen et al., 1992). The Everglades is a vast, shallow low relief sawgrass marsh, with elevations generally lower than 6 meters National Geodetic Vertical Datum (NGVD) and a southerly gradient of $2.8 \mathrm{~cm} / \mathrm{km}$ (Parker et al., 1955). Over a large part of the Everglades the water table rises above the ground surface. The rocks and sediments from the ground surface down to the intermediate confining unit form the surficial aquifer system (Fish and Stewart, 1991; Whalen et al, 1992), the top of which is the highly permeable, unconfined Biscayne Aquifer. Recharge is through infiltration of rainfall and seepage from canals, while the discharge is into topographically low areas, canals, and the ocean (Wedderburn et al., 1981, Whalen et al., 1992).

The ENP comprises only 20 percent of the original Everglades. Dredging of canals and construction of levees have drained close to 50 percent of the original Everglades for agricultural and urban development (Davis and Ogden, 1994). The park is bounded to the north by the Big Cypress National Preserve and the Water Conservation Areas, and to the east by the L-31W canal and levee (Figure 3). The Water Conservation Areas are managed water reservoirs designed to prevent flooding in urban and agricultural areas, recharge the regional groundwater and prevent saltwater intrusion, store and convey water supply for urban and agricultural use, and provide water for 
natural system requirements in ENP, among other objectives (Light and Dineen, 1994).

The L-31W canal and levee on the eastern boundary of ENP were designed to replenish fresh water supply in the Taylor Slough and protect agricultural land to the east of the park from flooding (Army Corps of Engineers, 1967; Wedderburn et al., 1981). Changes in L-31W canal water levels significantly affect the hydrologic system (e.g., groundwater in Taylor Slough) in ENP (Light and Dineen, 1994).

\subsection{Site Characteristics}

The experimental site is located on the northwestern side of Taylor Slough within ENP. It is 300 meters west of the L-31W Canal and is about 1.7 kilometers north of the S-332 pump station. Access to the project area is through 5.96 kilometers of levee road from the junction of State Route 27 (Figure 3).

The elevation in the test site varies from 0.432 meter to 1.584 meters NGVD, and averages 1.46 meters NGVD (Figure 7). This topographic map was based on our 5 meter x 5 meter survey using a Wild NAK 2 leveling instrument. The reference survey point was installed by ENP personnel.

The area is generally covered by sawgrass. Soil cover varies from 1 centimeter to more than 2 meters thick (Figure 8 ) as determined by driving a steel rod into the ground and measuring the depth of refusal. Soil is thicker in areas where there are solution holes, although there are some solution holes 


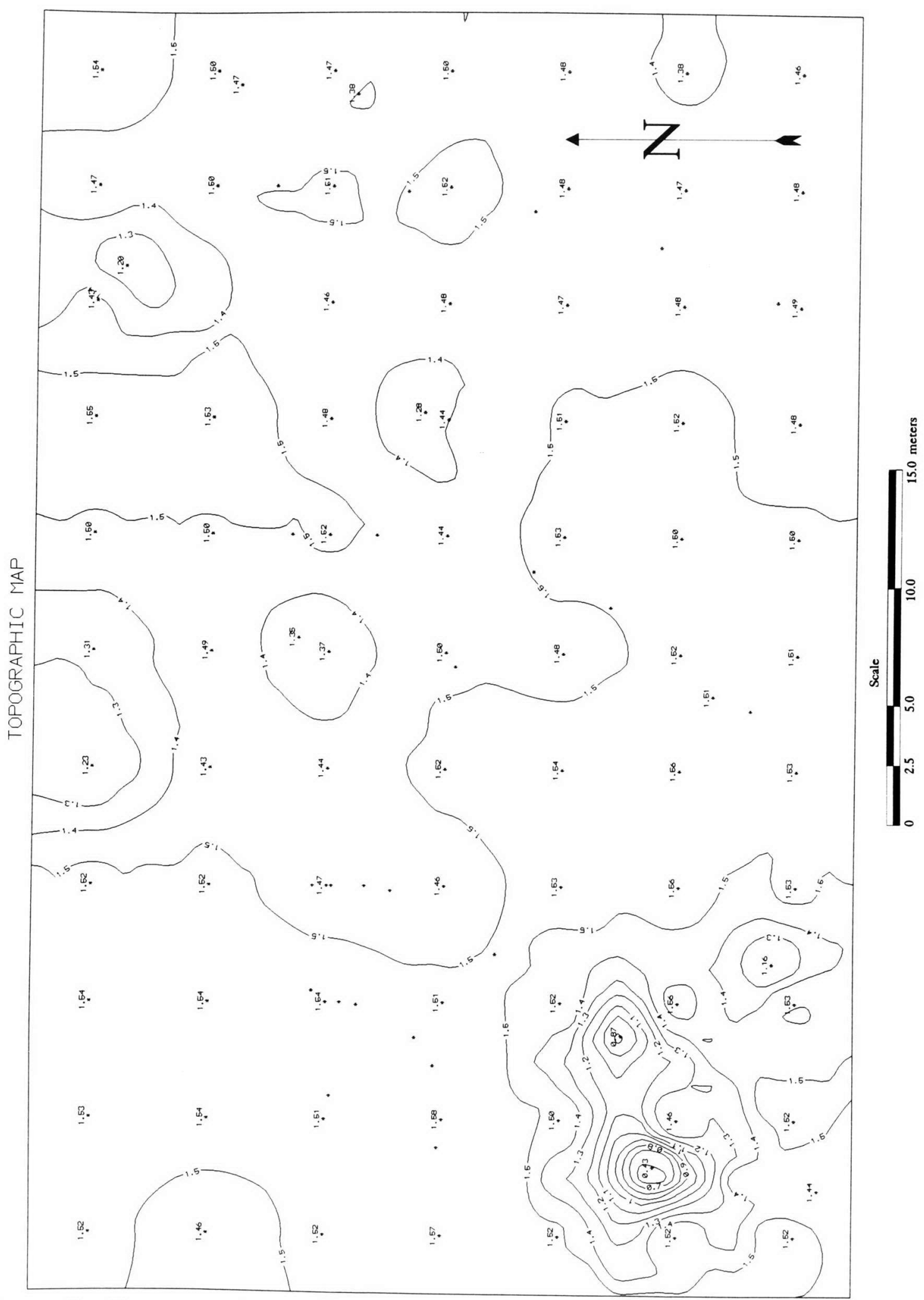

Figure 7. Topographic map of test site (ground surface elevations in meters NGVD) from our survey using Wild NAK 2 leveling instrument. 


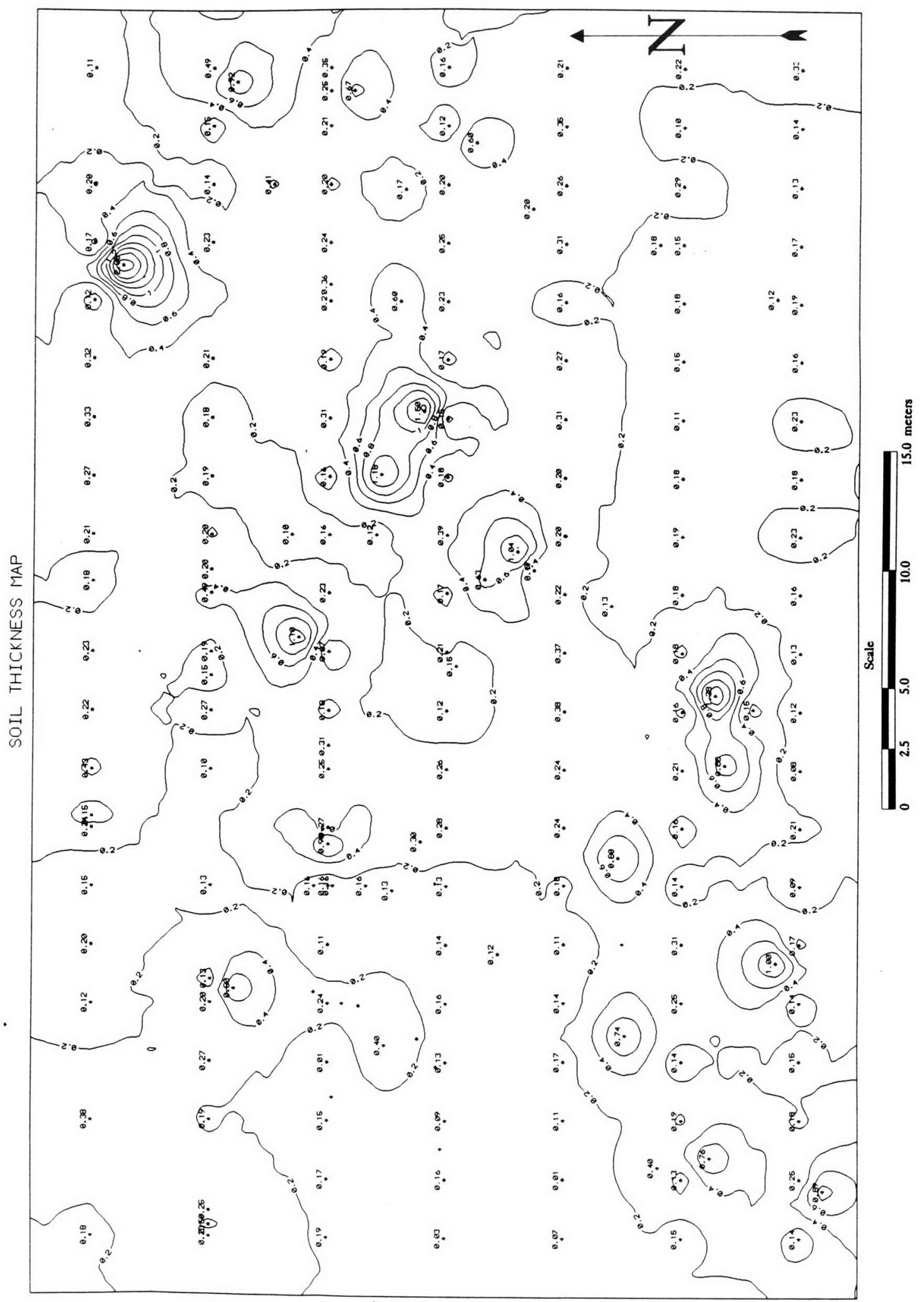

Figure 8. Soil thickness map (values in meters). 
which are not totally filled with soil. The average soil thickness in the test site is 28 centimeters.

The bedrock elevation (Figure 9) varies from -0.800 meter NGVD to 1.547 meters NGVD. The variation in bedrock elevation is attributed to the occurrence of secondary solution holes and small collapse features. Groundwater flow in the upper part of Biscayne Aquifer could be affected by the spatial distribution of soil-filled solution holes which serve as barriers to flow, considering that the muck soil (dark organic-rich soil) has a low hydraulic conductivity of less than 10 feet/day ( 0.000035 meter/second), compared to the aquifer rock of greater that $1000 \mathrm{ft} /$ day $(0.0035$ meter/second) based on the profiles presented by Fish and Stewart (1991).

The muck soil plays a significant role in the vertical flow of groundwater as observed in most of the wells during wet seasons when surface water ponds over the ground surface. The groundwater table rises above the land surface but is always lower than the surface water. However, in some wells (in the Frogpond area) that bottom above the hard dense limestone layer (later discussed in detail), the groundwater table is higher than the surface water indicating that the muck soil supports vertical hydraulic gradient (observed for a short period during the drilling of the piezometer wells).

The Biscayne Aquifer in the test site is about 12 meters thick, based on the interpretation of well profiles from Fish and Stewart (1991). It is composed of the Miami Limestone and the Fort Thompson Formation, which 


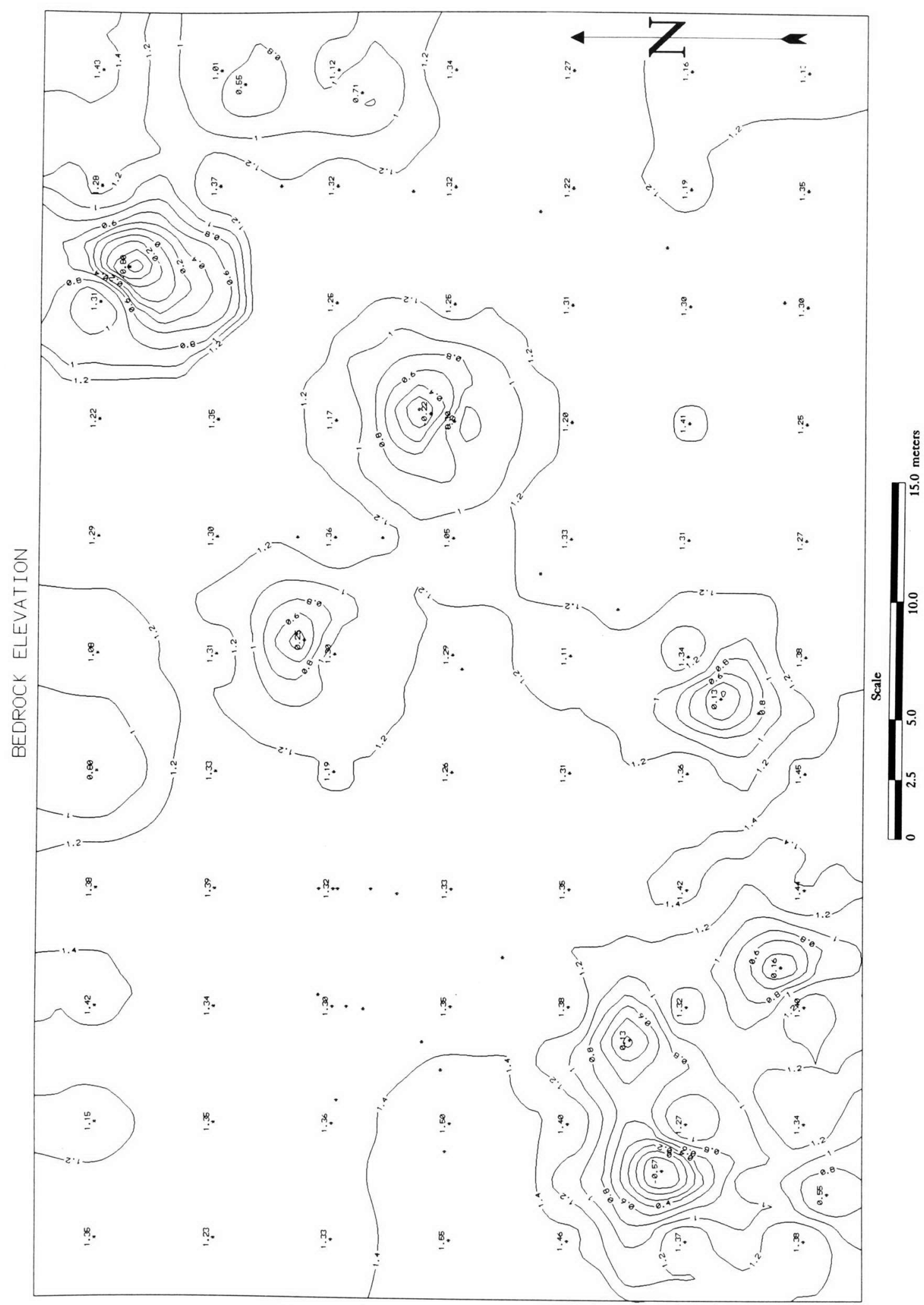

Figure 9. Bedrock elevation (values are in meters NGVD). 
are mainly oolitic and bryozoan limestone, and fossiliferous (i.e., freshwater and marine shells) limestone, respectively. Previous hydrogeologic profiles show that the hydraulic conductivity in the Biscayne Aquifer is greater than or equal to 1000 feet per day ( 0.00353 meter/second), which is at least one order of magnitude higher than the underlying Tamiami Formation (Fish and Stewart, 1991). 


\section{CHAPTER 4}

\section{FIELD AND LABORATORY METHODS AND RESULTS}

\subsection{Well Location and Drilling}

Not all wells at the study site were used for borehole flowmeter work. In 1987, twelve wells were installed by Everglades National Park (ENP) personnel for use in tracer tests (Fennema, 1988). The wells included an injection well in which a chemical tracer would be injected, and nearby observation wells from which samples would be collected for analysis of tracer concentration. Eleven of these wells were distributed along two arcs, one arc 5 meters and the other 10 meters from injection well IW-00. Six wells were drilled along the 5-meter arc and the rest were along the 10-meter arc (Figure 10). These wells were laid out between azimuth of 82 degrees to 195 degrees from IW-00 (where 0 degrees is due north).

Eleven additional shallow wells for use in tracer tests were added to the site in May 1993 (Figure 10). Ten were laid out in a sector between azimuth 87 degrees and 119 degrees from the old injection well IW-00 and another well was at 135 degrees to cover the possibility of groundwater flow in a southeasterly direction. These observation wells were installed along two arcs, one 25 meters and the other 40 meters from injection well IW-00 to ensure that the tracer cloud will not be missed during the sampling and to assess possible changes of longitudinal macrodispersivity as the scale of observation increases. Along the arcs, the wells were spaced at intervals of 8 degrees. 


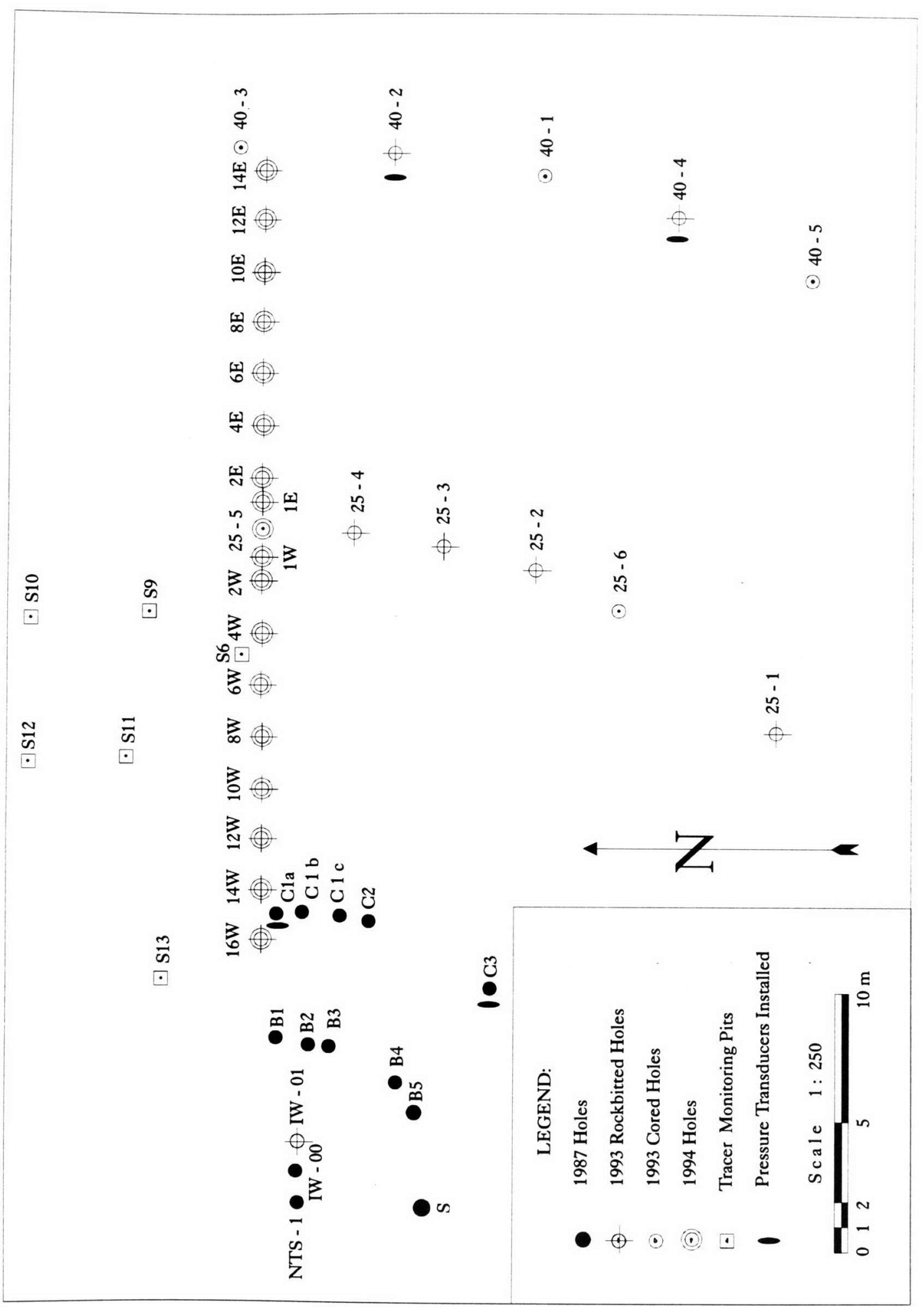

Figure 10. Well location map at the test site. All wells with the exception of the 1987 holes were drilled during this study. 
Six holes were drilled along the 25 -meter arc while five others were along the 40-meter arc. Most of these holes were drilled to a depth of -1.5 meters NGVD. Of the eleven holes drilled, five were cored to determine the geology and physical characteristics of the underlying rocks, and to correlate them later with tracer test results. During the drilling process, it was observed that the penetration rate abruptly increases within a depth of 2.0 to 2.4 meters below ground surface (about -0.5 to -0.9 meter NGVD), possibly indicating a zone of highly porous or soft limestone. However, no substantial decrease in return water was noted with the exception of $25-1$, where core drilling indicates low recovery and crumbling, highly porous limestone.

A new injection well for tracer tests, IW-01, was drilled 1 meter east of the old IW-00 in 1993. Flushing cuttings from IW-01 was difficult, but in this case the depth at which loss of return water occurred was recorded at -2.0 meters NGVD. This was the first time that the loss of return water was recorded since the previous shallow holes were only drilled to a depth of -1.5 meters NGVD. The loss of return water at this depth most likely indicates the occurrence of a layer with higher porosity and permeability. Although borehole IW-01 was drilled to a depth of -6.6 meters NGVD, the hole was only open down to -4.29 meters NGVD due to the accumulation of cuttings, which were difficult to flush out of the hole using a 10 gpm pump.

A preliminary tracer test, performed in December 1993, and groundwater flow direction monitoring (Figure 11) showed that the groundwater flow direction is unsteady (Figure 12), presenting a severe limitation on the use of natural gradient tests for determining dispersivity 


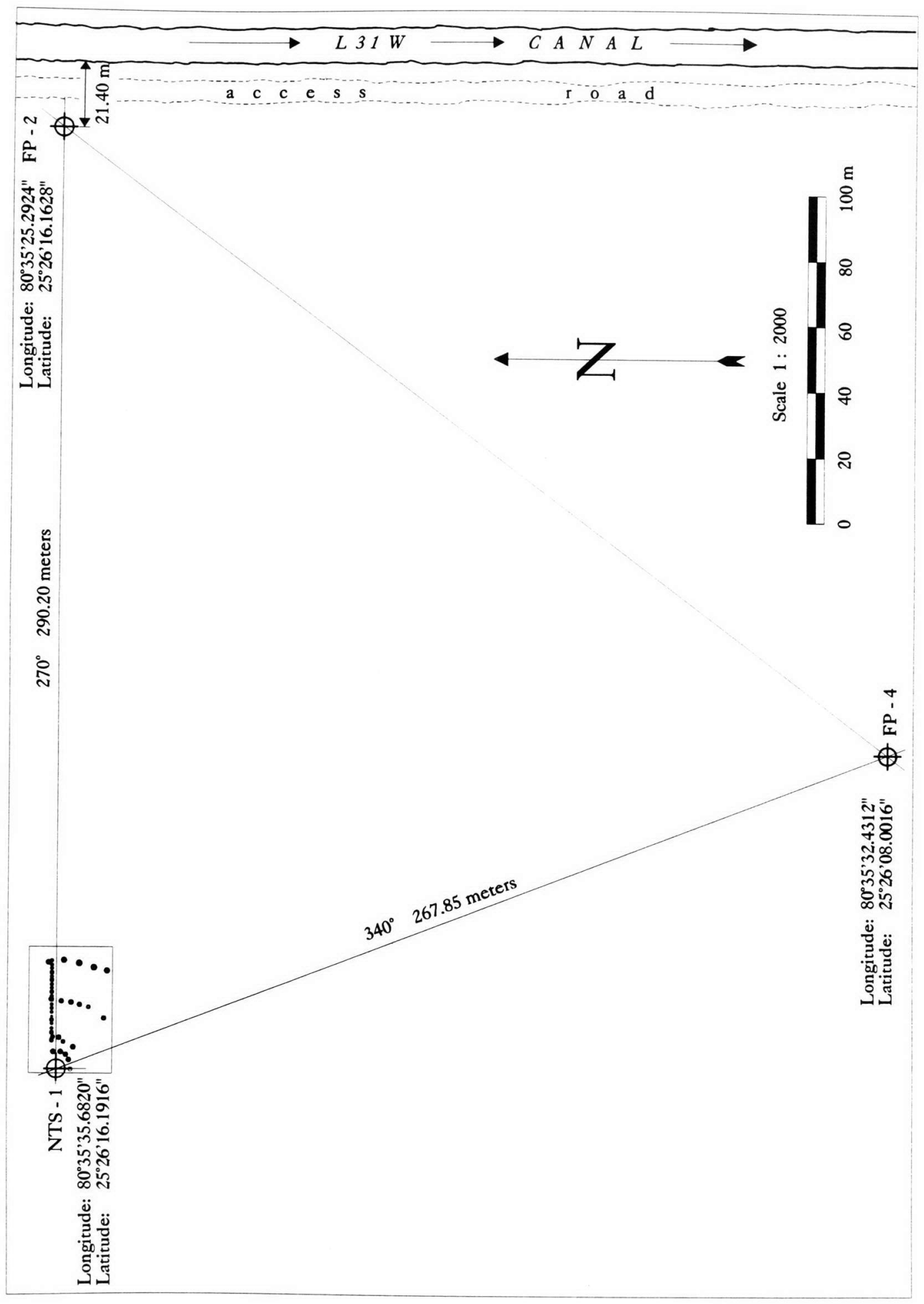

Figure 11. Location of three wells for monitoring groundwater flow direction at the test site. 


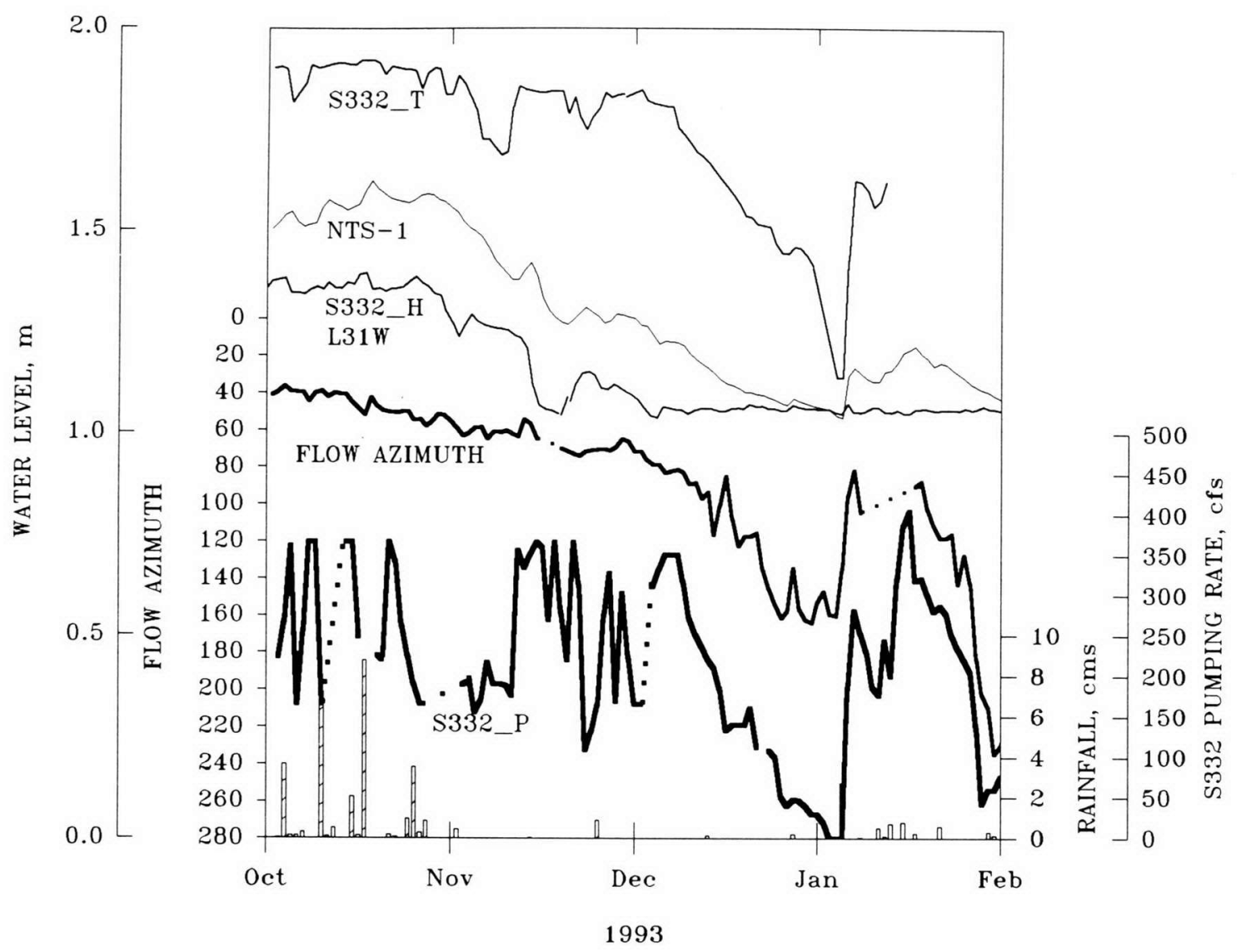

Figure 12. Relationship between rainfall (vertical bars), pumping rate at pump station S332 (S332_P), water levels at NTS-1 and the head (inlet) and tail (outlet) of S332 (S332_H and S332_T), and the regional groundwater flow azimuth. Pumping rate at S332 directly affects groundwater heads and the groundwater flow azimuth. 
(analytical methods for interpreting data from such tests require steady uniform groundwater flow). Wide variations in groundwater flow direction can spread the tracer laterally, resulting in estimation of large anomalously dispersivity values. Instead of determining dispersivity by tracer test methods, a geostatistical approach based on the spatial distribution of hydraulic conductivity was adopted. This method calls for drilling of multiple fully penetrating wells.

From May to July 1994, 18 fully penetrating wells were drilled along an east-west transect (i.e., perpendicular to $\mathrm{L}-31 \mathrm{~W}$ canal) covering a length of 30 meters (Figure 10). The spacing between adjacent wells was 2 meters, except in the middle of the transect where some were spaced 1 meter apart. The 18 fully penetrating wells were drilled with a $76 \mathrm{~mm}$ ( 3 inch)-diameter 4 wing drag bit to allow unobstructed lowering and raising of the flowmeter probe with packer.

Well 25-5, at the center of the transect, was cored farther down to a depth of 14.03 meters below ground surface. The rest were rockbitted (drilled without coring) to an average depth of about 12 meters below ground surface, where the top of a second hard layer was encountered. Figure 13 shows the profile of the 18 fully penetrating wells and the depth of different hard layers. Since all of the wells were rockbitted aside from 25-5, the depths of the hard layers around each well were determined from the decrease in drilling penetration rate. 


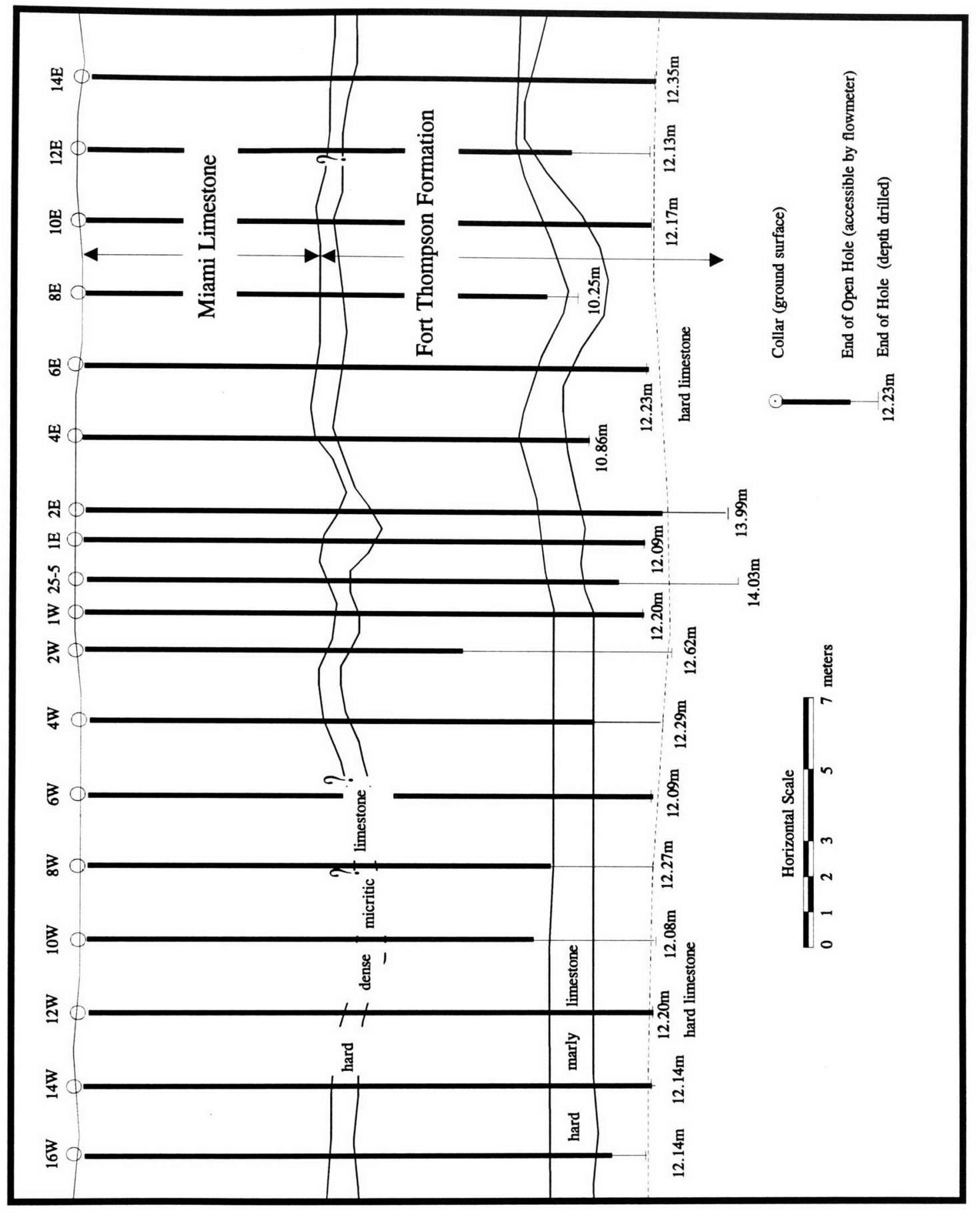

Figure 13. West-east vertical section along 18 fully penetrating wells showing the hard layers encountered during drilling. 
All of the wells were drilled with a Mobile Minuteman drill rig. The drill rig was mounted to a foot-high platform to elevate it and give enough room to connect and break drill rods. Water was supplied through a 1-1/4 inch hose connected to a pump with a capacity of at least a $10 \mathrm{gpm}$.

Coring was done with a $60 \mathrm{~mm}$ outside diameter diamond drill bit (BW) attached to a 3-foot corebarrel with an AW pin. The total length of the corebarrel with an attached bit was 55 inches. The corebarrel was pulled out after every full 3-foot run or when the core blocked the bit from further advance. Prior to lifting of the drillhead for subsequent pulling out of the corebarrel, the depth of the run was measured and recorded. This was done by determining the total length of drill rods below the ground surface. A piece of wooden block was marked with the hole identification and depth of run, and was placed at the bottom of the recovered core in a wooden core box.

The core was recovered by taking out the bit and the core catcher. The bit was lightly tapped with a hammer and uncoupled slowly so as not to dent the corebit. The core was then laid in a core box. Tapping the corebarrel with a rubber mallet facilitated the removal of the cores from the corebarrel. After the core was removed from the corebarrel, the threads were cleaned and the core catcher and diamond drill bit were re-attached. As drilling progressed, additional 3 feet long AW rods were coupled.

At depths greater than 3.5 meters below the ground surface $(-2.0$ meters NGVD), where there was no return water, cuttings were flushed out 
of the hole by pumping directly from the hole with a Monarch trash pump. Two-inch diameter PVC pipes were attached to the suction hose and lowered into the borehole to pump the cuttings out.

Information on percentage of return water, penetration rate, intervals of caving rock and other pertinent data were noted during drilling. Cores were kept clean, and the coreboxes were kept far from the drill rig to avoid tipping the coreboxes and misplacing cores.

A 3-inch PVC pipe was installed in each of the 18 fully penetrating wells. Each pipe was concreted into the bedrock with about $30 \mathrm{~cm}$ sticking up above the ground surface. A tight seal between the pipe and the bedrock may not have been attained for all wells in spite of concreting because of the occurrence of surface water during the entire installation period. The top of the casing was surveyed with a Wild NAK 2 leveling instrument for its elevation.

\subsection{Corelogging}

The cores were logged according to rock type, porosity, core recovery, and solidity (intact core). The depth and size of the core were also noted. Driller's logs were also incorporated into the corelogs. Appendix I contains detailed log for borehole 25-5. The color of the rock was identified based on the Geological Society of America Rock-Color Chart.

Figure 14 shows hydrogeologic profiles of borehole $25-5$ which we cored to a depth of 14.03 meters below ground surface. The cores show that 
CORE BORING 25-5

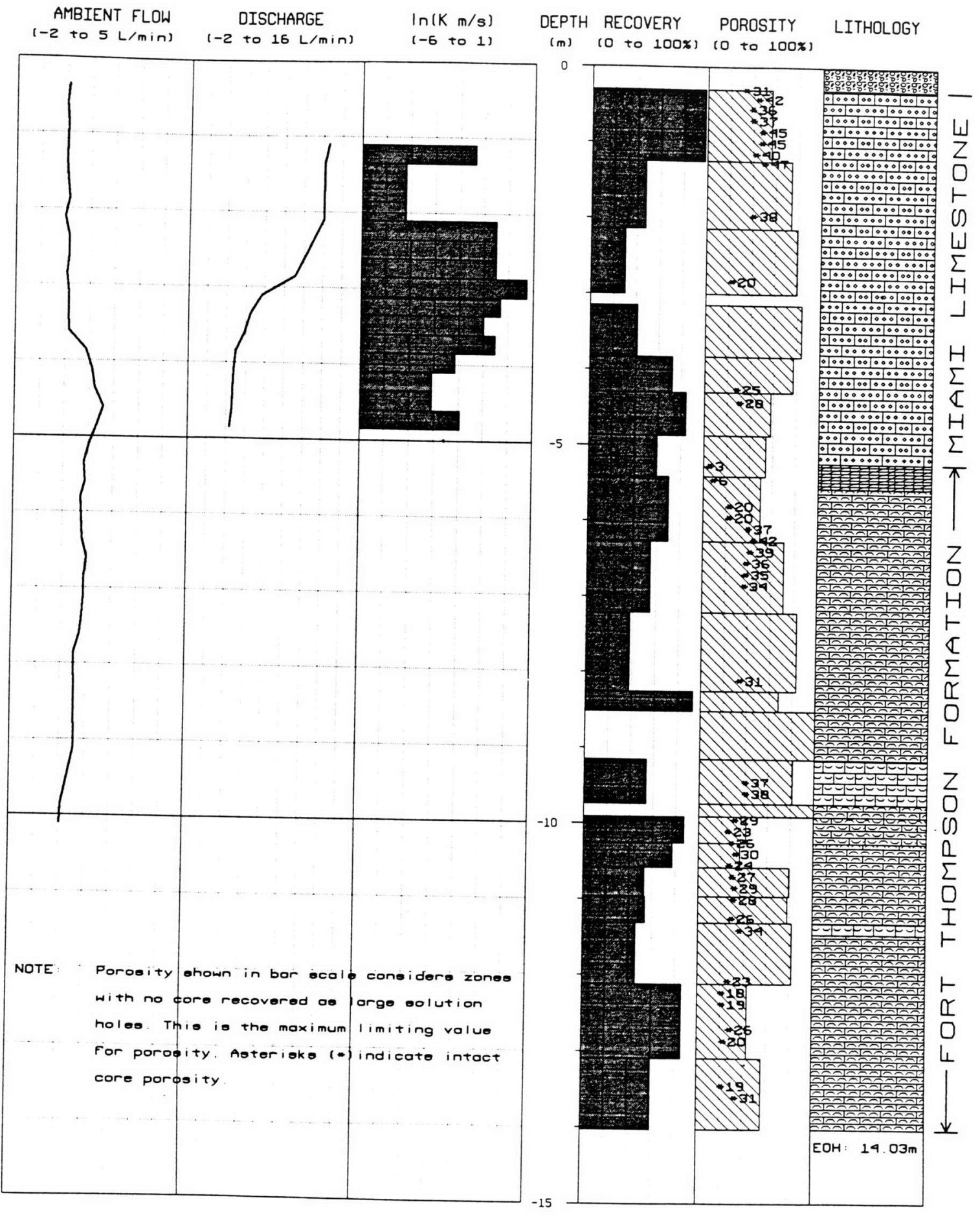

Figure 14. Core recovery, porosity, groundwater discharge, $\operatorname{lnK}$, and lithology in borehole 25-5. 
the Biscayne Aquifer can be divided into two aquifers, the Upper Biscayne Aquifer and the Lower Biscayne Aquifer, separated by a hard, dense limestone layer about 33 centimeters thick, from about -3.78 to -4.11 meters NGVD. Results in Figure 14 are described in greater detail later in this report.

The Upper Biscayne Aquifer is characterized by highly porous and permeable pelletal limestone, bryozoan limestone, and coquinal (i.e., marine shells) limestone of the Miami Formation (Figure 15a, 15b, and 15c). The pores are essentially secondary, marked by moldic porosity and solution holes. The total porosity of the intact core varies from 20 to 47 percent as determined by the imbibition method (Ramos, 1986).

The interface between the Upper and Lower Biscayne Aquifer is a hard, dense micritic limestone with some cemented breccia, and vertical borings indicative of discontinuity surfaces associated with subaerial exposure (Perkins, 1977). This hard, dense micritic limestone is considered the contact between the overlying Miami Limestone and the Fort Thompson Formation in this study site. The total porosity of the intact core from this layer varies from 3 to 6 percent and is characterized by vertical burrows. In some wells, the cores show vertical solution channels filled with sand. The usual decrease in drilling penetration rate associated with this layer was not encountered in three boreholes (10W, $6 \mathrm{~W}$ and 12E), suggesting this hard layer may contain significant solution holes or other discontinuities that reduce its competence in some spots. 


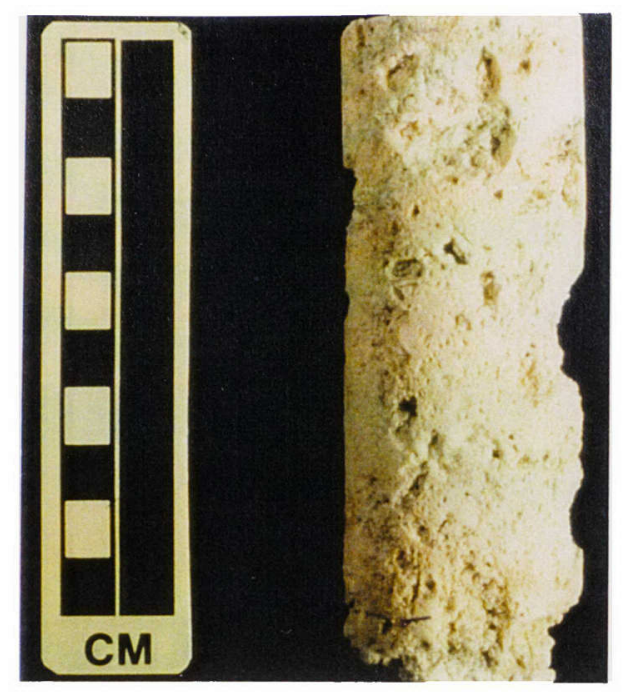

a

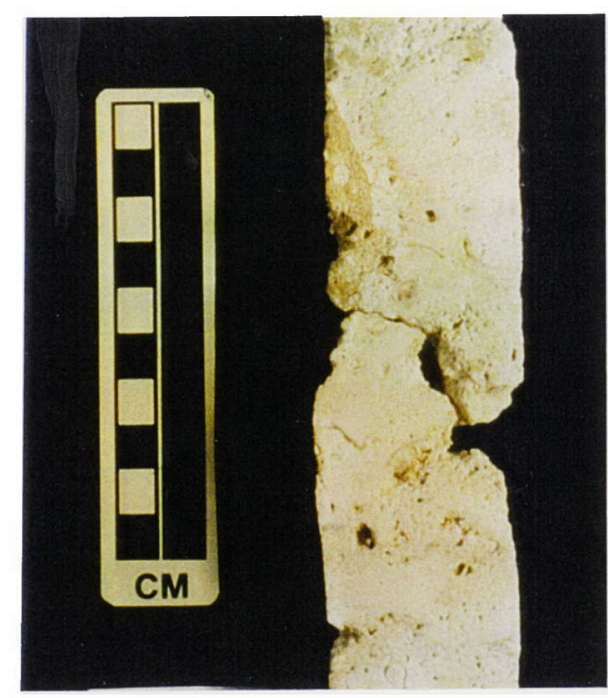

C

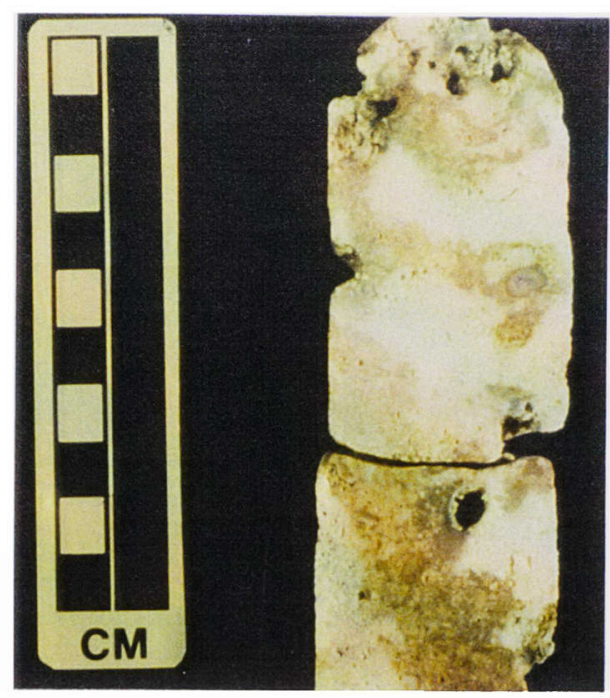

b

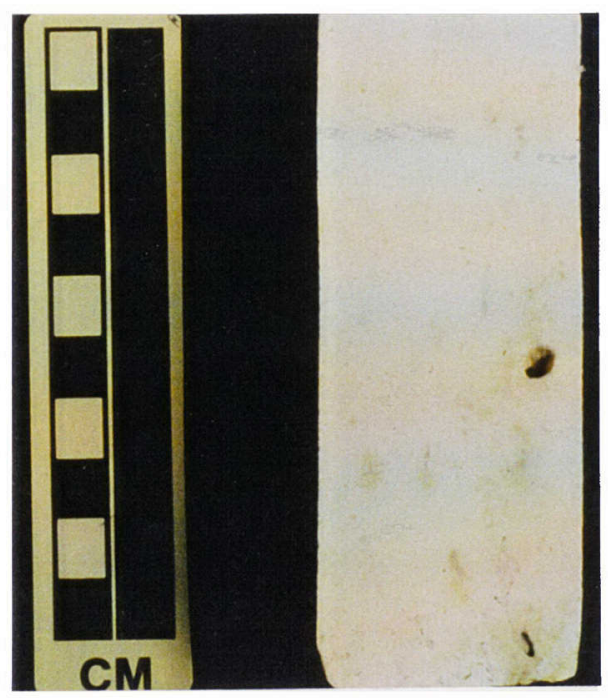

d

Figure 15. Core samples from borehole 25-5: a) pelletal limestone at $0.72 \mathrm{~m}$ from the ground surface with interparticle, intraparticle, moldic and vuggy porosity, b) iron-stained pelletal limestone at $2.97 \mathrm{~m}$ depth with sparry calcite encrusting and filling some vugs, c) coquinal limestone at $4.56 \mathrm{~m}$ depth with secondary moldic and vuggy porosity, and d) hard, dense micritic limestone at $5.30 \mathrm{~m}$ depth with small traces of root structures. 
Perkins (1977) considers this hard, dense micritic limestone as a diagenetic alteration of a mudstone. Figure $15 \mathrm{~d}$ is a photograph of a sample from borehole 25-5 at a depth of 5.3 meters below ground surface. It shows little trace of the original texture indicating replacement is extensive. Vestiges of some root structures have been observed and are dominantly vertical. These observations further substantiate that this layer is a discontinuity surface associated with subaerial exposure.

The Lower Biscayne Aquifer is within the Fort Thompson Formation and underlies the hard dense limestone. The formation is characterized by coquinal limestone with some pelletal limestone layers (please refer to Appendix 1 for details of borehole 25-5 corelogs). The tops of fresh water limestone layers were encountered at -7.7 and -9.86 meters NGVD. The thicknesses of these freshwater limestone layers were 1.106 meters and 0.15 meter respectively. Intact core total porosity within the Fort Thompson Formation varies from 10 to 42 percent. In certain areas where there was no core recovered (e.g., elevations -7.07 and -8.86 meters NGVD), the total porosity is expected to be higher. Figure 16 shows photographs of cores from the Fort Thompson Formation.

\subsection{Core Recovery}

Percentage core recovery is the length of core recovered in drill run divided by the depth interval of aquifer penetrated during the run:

$$
\% \text { CoreRecovery }=100\left(L_{c} / L_{r}\right)
$$




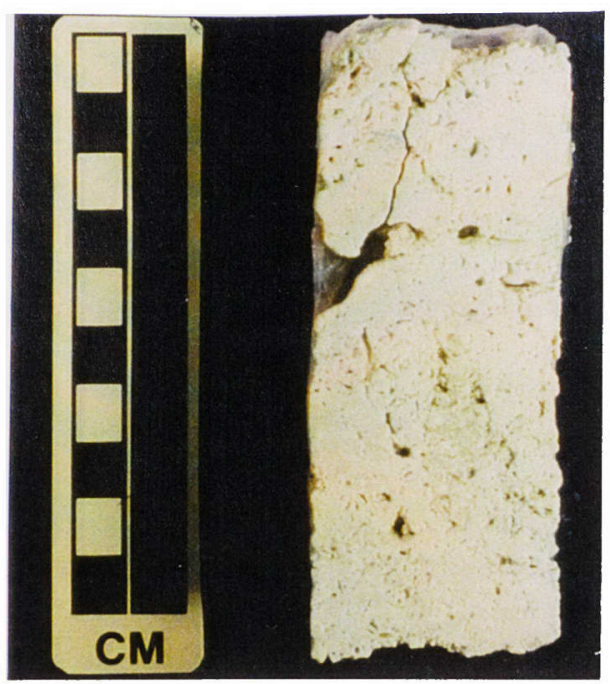

a

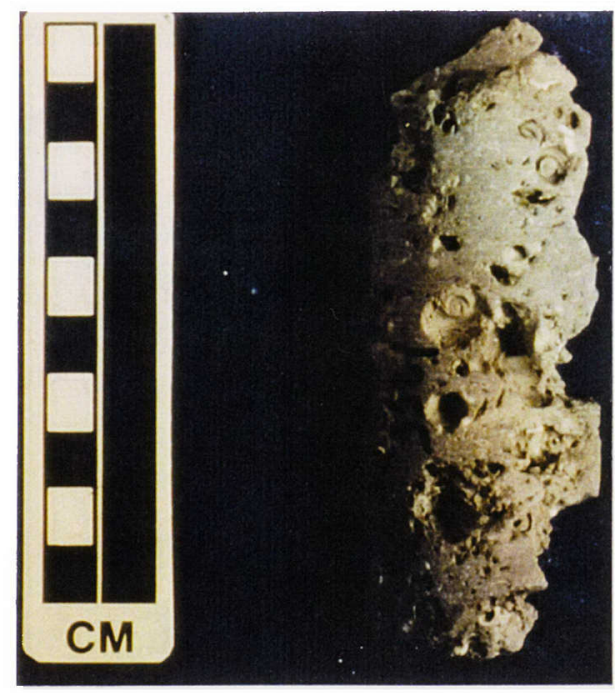

C

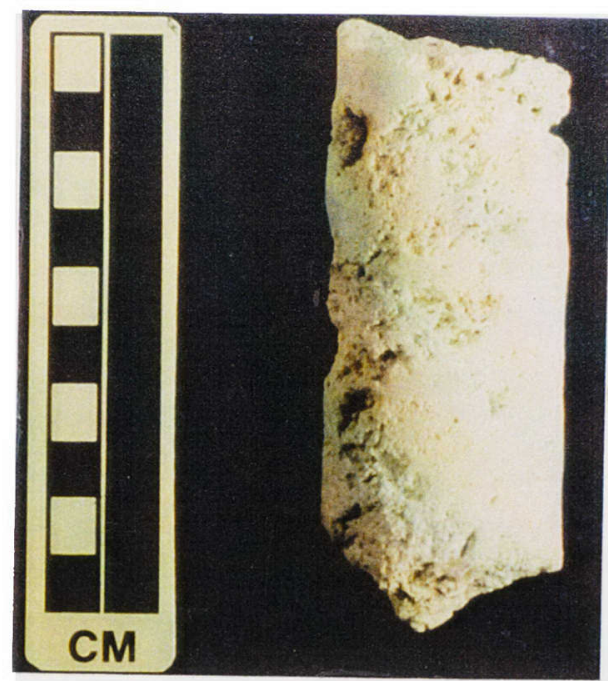

b

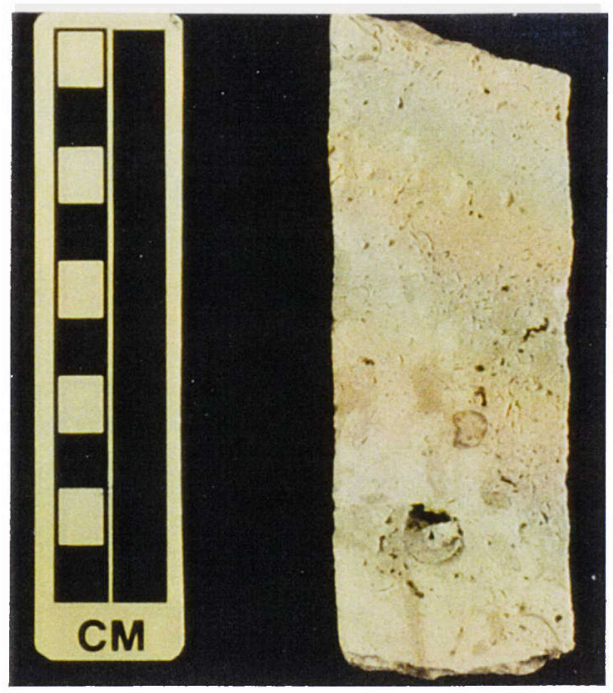

d

Figure 16. Core samples within the Fort Thompson Formation from borehole 25-5: a) coquinal limestone at $6.42 \mathrm{~m}$ depth with vuggy pores and abundant moldic pores after marine shell fragments, b) pelletal limestone at $8.2 \mathrm{~m}$ depth with some marine shell fragments and showing moldic and vuggy pores, c) freshwater limestone at $9.55 \mathrm{~m}$ depth with moldic pores after gastropods, and d) marly limestone at $10.08 \mathrm{~m}$ depth with freshwater limestone filling original solution cavities. 
where,

$$
\begin{aligned}
& L_{c}=\text { length of recovered core } \\
& L_{r}=\text { length of run. }
\end{aligned}
$$

Information on core recovery is useful in assessing the porosity and competence of a rock, especially when there are large solution holes.

\subsection{Porosity}

Five types of fabric-selective porosity (Choquette and Pray, 1970) observed in the cores from the study site: (1) interparticle porosity, pore spaces between grains, (2) intraparticle porosity, pore spaces within a grain,

(3) intercrystal porosity, spaces between calcite crystals, (4) moldic porosity, solution molds after fossils, and (5) fenestral porosity, irregular, elongated openings parallel to bedding. The first three types of porosity are mostly primary while the latter two are secondary. Figure 17 shows examples of the different types of porosity observed in core samples that contribute to the total porosity.

Total porosity is defined as the part of a rock that is void space (Domenico and Schwartz, 1990):

$$
n=100\left(V_{v} / V_{T}\right)
$$

where,

$$
\begin{aligned}
& \mathrm{n}=\text { total porosity, expressed here as a percentage } \\
& \mathrm{V}_{\mathrm{v}}=\text { volume of void space }\left(\mathrm{L}^{3}\right) \\
& \mathrm{V}_{\mathrm{T}}=\text { total volume of sample of porous medium }\left(\mathrm{L}^{3}\right) .
\end{aligned}
$$




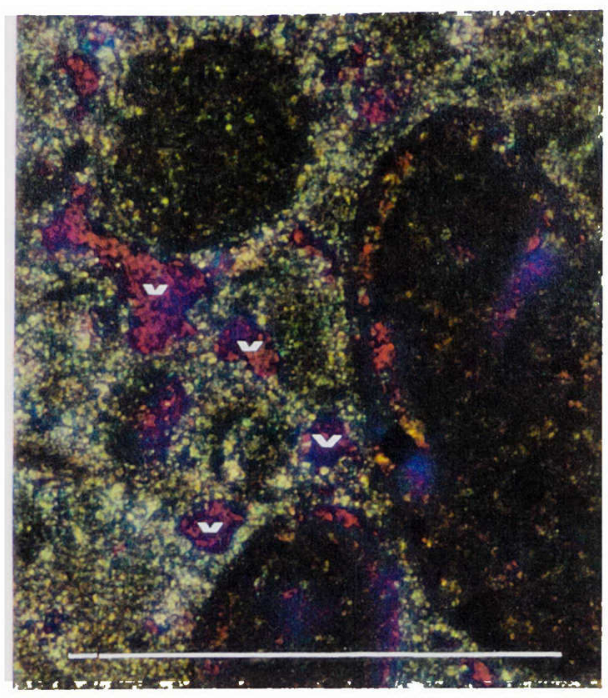

a

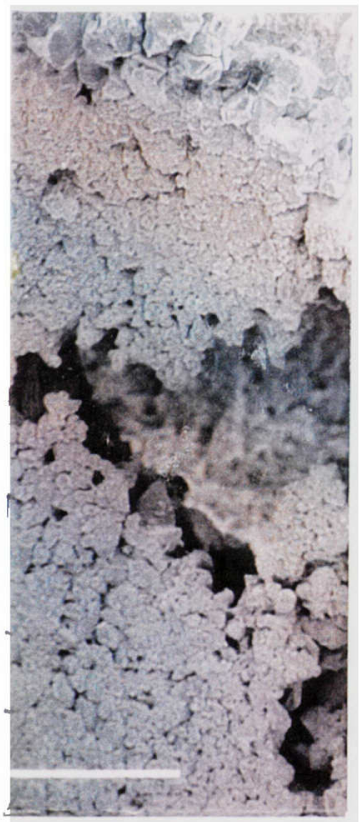

C

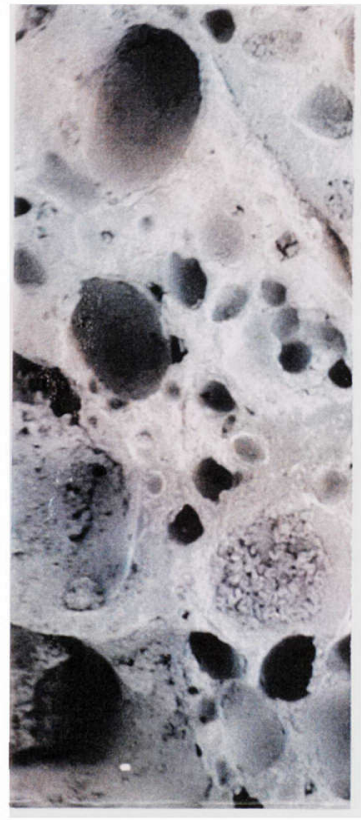

d

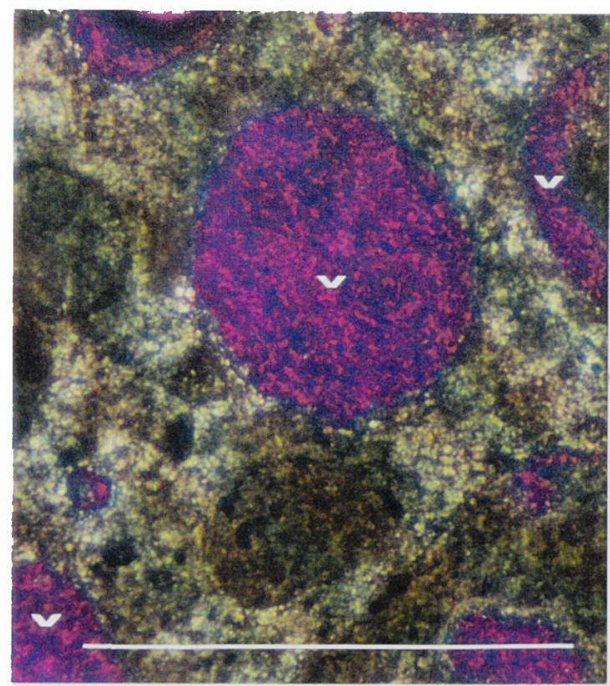

b

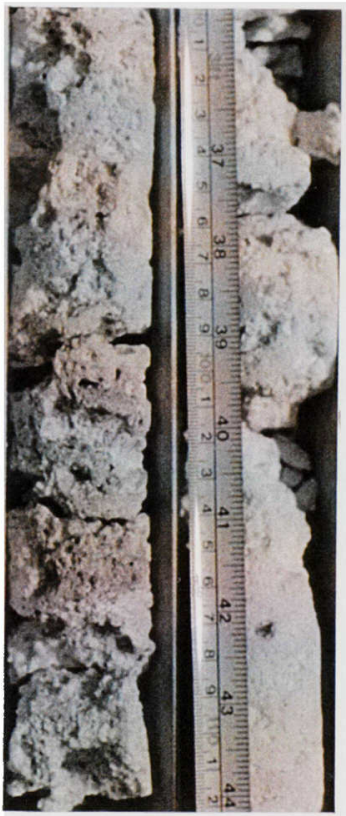

e

Figure 17. Fabric-selective types of porosity in the study site: a) interparticle porosity (v) in a pelletal limestone sample at $0.54 \mathrm{~m}$ depth, b) intraparticle to moldic porosity (v) in a pelletal limestone at $2.10 \mathrm{~m}$ depth, c) intercrystal porosity at $0.66 \mathrm{~m}$ depth, d) moldic porosity after fecal pellets and marine shell fragments, and e) fenestral porosity observe from borehole 40-5 with megapores of 3 centimeters. The bar scale shown in a, b, c, and d is 50 microns. 
Total porosity includes both interconnected and locked (dead-end) pores, while effective porosity includes only interconnected pore space; effective porosity is always less than or equal to the total porosity. Two methods were used in determining the total porosity of intact cores: the imbibition (Ramos, 1986) or water-displacement (Freeze and Cherry, 1979) method, and the gravimetric method (Rowell, 1994; Freeze and Cherry, 1979; Vomocil, 1965).

In the imbibition method, the intact core (sample), wrapped in a plastic tape with one end open was immersed in water under vacuum until air bubbles did not appear, to ensure that water had filled as much of the pore space as possible. The sample was then quickly placed in a beaker and weighed saturated. The dry weight of the sample was measured after oven drying to constant weight at $110^{\circ} \mathrm{C}$. The volume of the intact core was determined by measuring its diameter and length. This was checked by a water displacement method wherein the sample was wrapped in polyethylene, sealed with tape, and dropped into a graduated cylinder partially filled with water. The increase in water level in the graduated cylinder indicated the volume of the sample. The porosity was calculated by:

$$
n=\frac{100\left(M_{s}-M_{d}\right)}{\rho_{w} V_{T}}
$$

where,

$$
\begin{aligned}
& M_{s}=\text { saturated rock mass, grams } \\
& M_{d}=\text { dry rock mass, grams } \\
& \rho_{w}=\text { density of water. }
\end{aligned}
$$


In the gravimetric method, the porosity was calculated by (Freeze and Cherry, 1979):

$$
n=100\left(1-\rho_{b} / \rho_{s}\right)
$$

where,

$$
\begin{aligned}
& \rho_{b}=\text { bulk density of the core sample, grams } / \mathrm{cm}^{3} \text {, equal to } M_{d} / V_{T} \\
& \rho_{s}=\text { density of the solids, grams } / \mathrm{cm}^{3}\left(2.71 \mathrm{grams} / \mathrm{cm}^{3}\right. \text { for calcite, } \\
& \text { the major component of limestone }) .
\end{aligned}
$$

Figure 18 shows the relation between gravimetric and imbibition porosity of 43 intact core samples from borehole 25-5. Results suggest that some pores were not fully saturated during the imbibition process, resulting in consistently lower porosity values for the imbibition method.

The porosity from measured intact core samples was the minimum possible porosity value. Considering zones where no core was recovered as large solution holes led to a maximum limiting value for porosity (the total mass of recovered core was divided by the total volume of a core run, not just the volume of core recovered). Figure 14 shows the porosity profile of borehole 25-5 based on both types of calculations (values in asterisks are minimum porosity based on intact core, values represented by bar scale are maximum porosity based on core recovery). The gravimetric method was used for determination of the maximum porosity profile, and the calculation of the total volume of aquifer cored was based on the length of drill run and core diameter:

$$
n=100\left(1-M_{c r} / V_{T} \rho_{s}\right)
$$




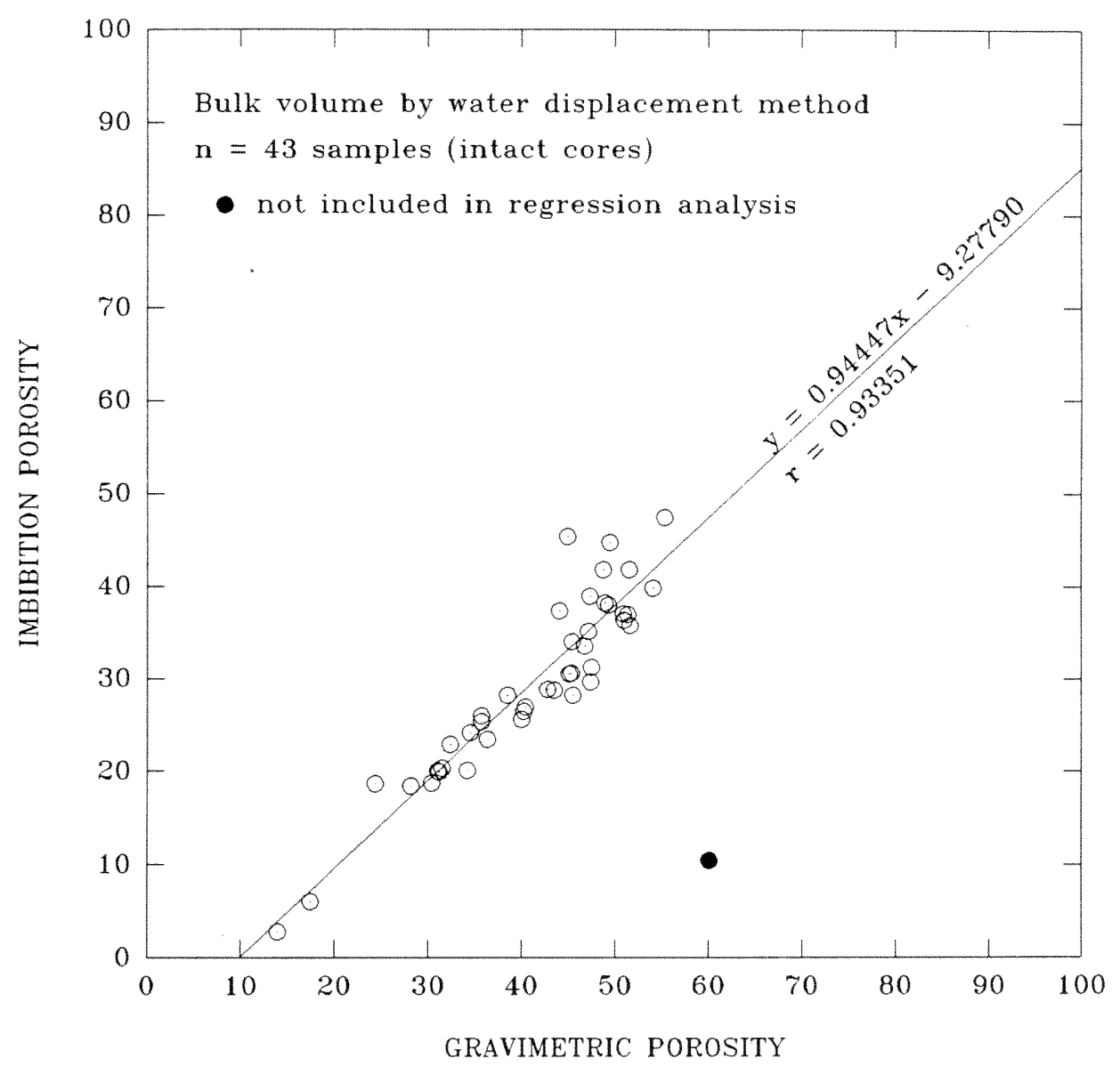

Figure 18. Gravimetric porosity in relation to imbibition porosity for intact rock cores from borehole 25-5, Biscayne Aquifer. 
where,

$$
\begin{aligned}
& M_{c r}=\text { mass of core recovered from drill run, } g \\
& V_{T}=\text { volume of drill run, } L_{r} \pi d^{2} / 4 \\
& d=\text { core diameter, cm. }
\end{aligned}
$$

Figure 19 shows the relationship between porosity and hydraulic conductivity in the Upper Biscayne Aquifer at borehole 25-5. There does not appear to be any significant relationship between hydraulic conductivity and porosity.

\subsection{Flowmeter Setup and Calibration}

As mentioned in section 2.3, an electromagnetic borehole flowmeter was used to determine the vertical profile of hydraulic conductivity around each borehole. The flowmeter (purchased from Tisco, Inc. of Roswell, Georgia) consists of the down-the-hole probe connected with a cable to a surface electronic unit. The flowmeter probe is a two-inch (outer diameter) steel cylinder with electromagnet and two electrodes set with epoxy inside it. The inner diameter of the probe, where water passes through, is one inch. The flowmeter operates according to Faraday's Law of induction, wherein the voltage induced across a conductor (in this case, water) moving at right angles through a magnetic field is directly proportional to the velocity of the conductor (Molz and Young, 1993). The probe used in the study had an airinflatable packer around its outside; the packer ensures that all vertical water flow passes through the one-inch hole during measurements. The flowmeter was rated to be capable of measuring vertical upward and downward water flow of 10 milliliters/minute to 40 liters/minute. 


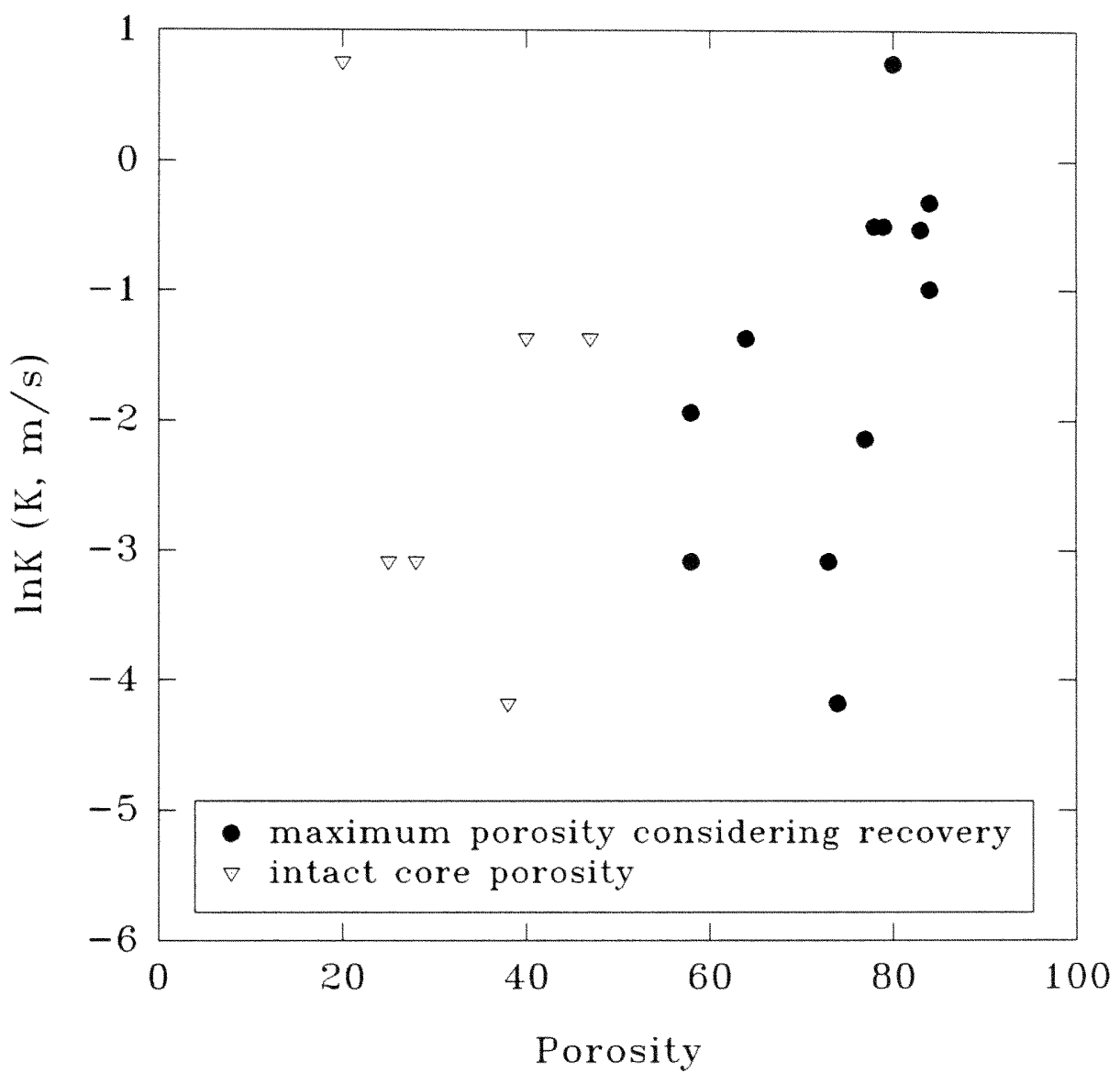

Figure 19. Scatterdiagram showing the relationship between $\operatorname{lnK}$ and porosity in the Upper Biscayne Aquifer at borehole 25-5. 
In the field, the power needed to run the flowmeter was supplied by a 120 volt generator that was properly grounded. Before the cables were connected or disconnected to the generator and the probe, the flowmeter surface electronic unit was turned off. A compressed air tank, connected to the packer assembly by 100 feet of $1 / 4$ inch Nalgene tubing, was used to inflate the packer to a maximum differential pressure of 15 psi. The pressure was controlled by a regulator attached to the compressed air tank.

The digital display on the surface electronics unit showed readings directly in volumetric flow rates. The unit was switched on and allowed to warm up for thirty minutes to stabilize equipment temperature before taking readings. A negative reading indicated downward groundwater flow in the borehole, while a positive reading indicated upward flow.

The borehole flowmeter was calibrated in a laboratory apparatus consisting of a vertical 3-inch PVC pipe with water inflow and outflow pipes. The probe, with the packer inflated, was set in between the inflow and outflow pipes (Figure 20). Water was pumped into the inflow pipe which was connected to a pump with maximum capacity of 15 liters/minute.

A control valve adjusted the flow rate. The discharge rate was measured at the outflow pipe with a graduated bucket and a timer. The digital display of the electronic unit was set to match the actual flow rate by adjusting the "meter factor" (a dial on the instrument). Flowmeter readings were taken at different flow rates and plotted on a scatter diagram for regression analysis to give a calibration curve. Appendix II gives the methodology used in 


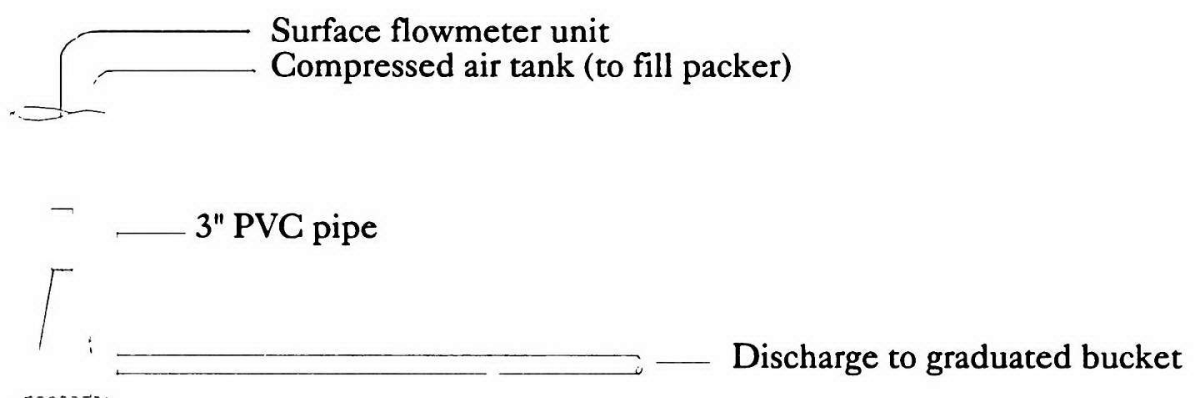

Flowmeter probe

with inflated packer

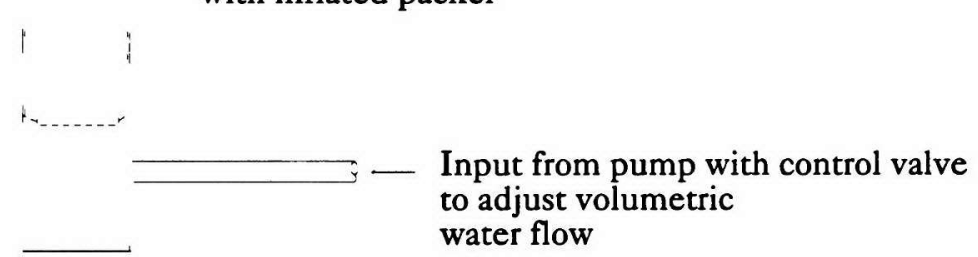

Figure 20. Schematic diagram of the flowmeter calibration set-up. 
flowmeter calibration, along with plots of the calibration. In the field, calibration was done both before and after measurements at most boreholes. Student's $t$ test (Zar, 1984) on the two regressions at a given borehole (one based on calibration results before borehole measurements, the other after) showed that they were not significantly different and that a common regression line could be created for calibration results (Figure 21). A comparison between calibration lines from different borehole flow measurement survey dates indicates that the slope of the calibration line increases with time which denotes an instrument drift (Figure 22). To eliminate the effect of instrument drift on the ambient and induced flow rates, flowmeter calibration were performed before and after borehole measurements.

\subsubsection{Ambient flow measurements}

The main purpose of taking ambient borehole flow measurements was to subtract them from induced flow measurements and thereby calculate hydraulic conductivity with Equation 6. Ambient flow data also revealed vertical hydraulic gradients and showed how different geologic layers behaved (e.g., either as an aquitard or confined aquifer).

Measurements for ambient flow were taken before any pumping was done in the test site. The probe was lowered to about 0.5 meter above the bottom of the borehole, the packer inflated, a flow measurement made, the packer deflated, and the probe moved up 0.5 meter to the next measurement depth. This sequence was repeated to measure a complete ambient flow profile in each borehole. At each level, readings were taken 10 minutes after 


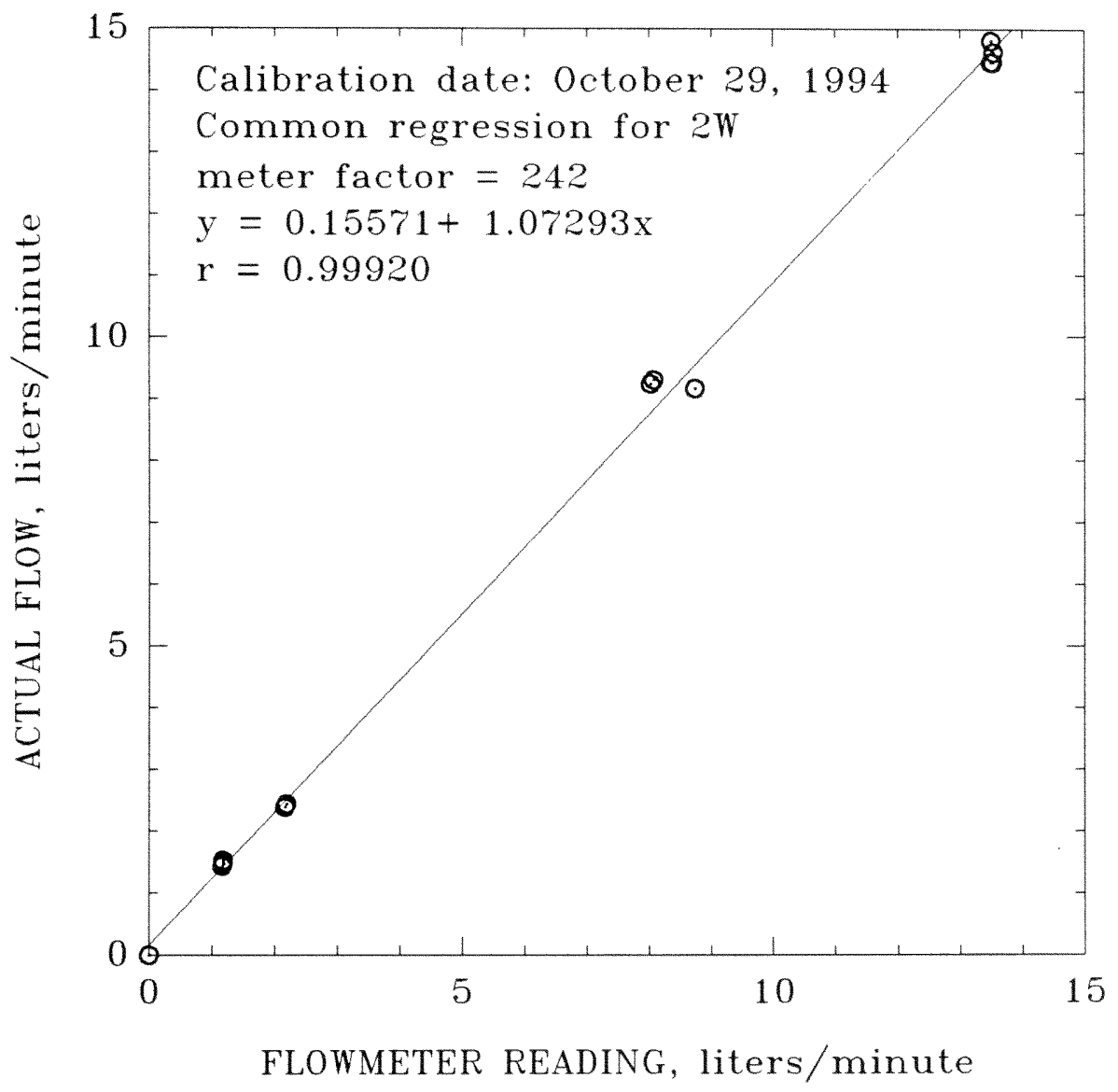

Figure 21. Example of a calibration line for correcting flowmeter readings. Other such lines are shown in Appendix II. 


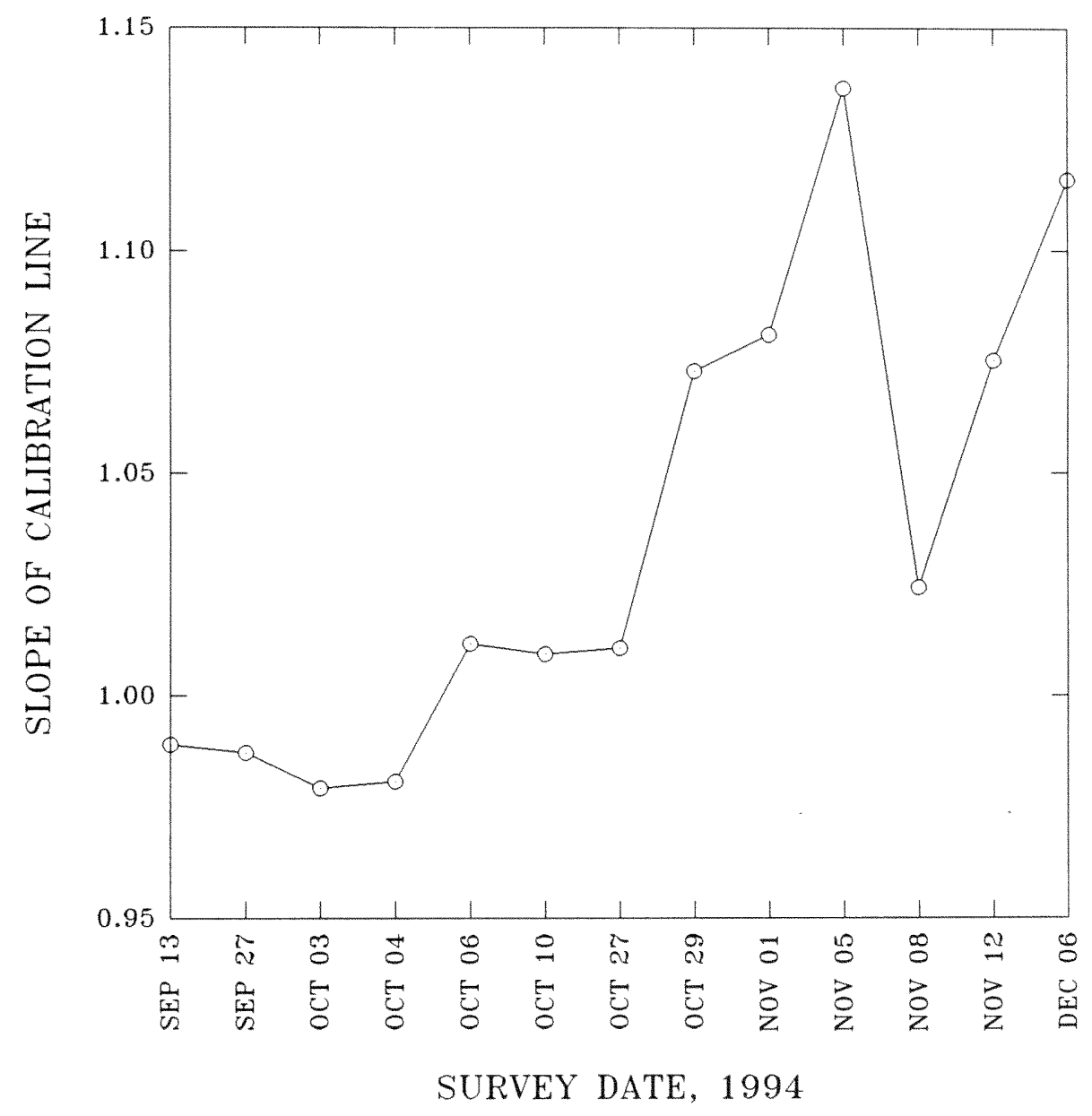

Figure 22. Temporal variation in the slope of the calibration line indicating instrument drift. 
the probe was set and the packer inflated or when the display has stabilized to a maximum of about $\pm 0.02 \mathrm{l} / \mathrm{min}$. As soon as the display stabilized, readings were taken at 5 second intervals for a duration of 2 minutes and were averaged. Figure 23a shows the ambient flow profile for borehole $2 \mathrm{~W}$.

A comparison between the ambient flow profiles from each borehole and the geology indicate that a shallow hard, dense micritic limestone layer at -4.0 meters NGVD acts as an aquitard and supports a vertical gradient (Figure 24). In addition, another hard limestone layer at about -8 to -9 meters NGVD acts in a similar manner. In boreholes 25-5, 4E, 6E, 8E, 10E, 12E, and $14 \mathrm{E}$, upward water flow (indicated by a curve bowing to the right) past the shallow hard layer was measured. This upward flow abruptly decreases above the shallow hard layer indicating that the hydraulic head is lower above the layer than below the layer.

In an opposite manner, boreholes $4 \mathrm{~W}, 2 \mathrm{~W}, 1 \mathrm{~W}, 1 \mathrm{E}$, and $2 \mathrm{E}$ show downward flow (indicated by a curve which bows to the left) around the shallow hard layer. This would mean a higher hydraulic head above the layer.

\subsubsection{Induced flow measurements}

The induced flow was measured after the ambient flow survey. In the induced flow measurements, a $3 / 4$ inch diameter PVC pipe connected to a 15 $1 /$ min pump was lowered down the hole with its intake about $30 \mathrm{~cm}$ below the water table. Water pumped from the borehole was discharged onto the ground surface about 30 meters from the borehole using a $3 / 4$ inch garden hose 
BOREHOLE 2W

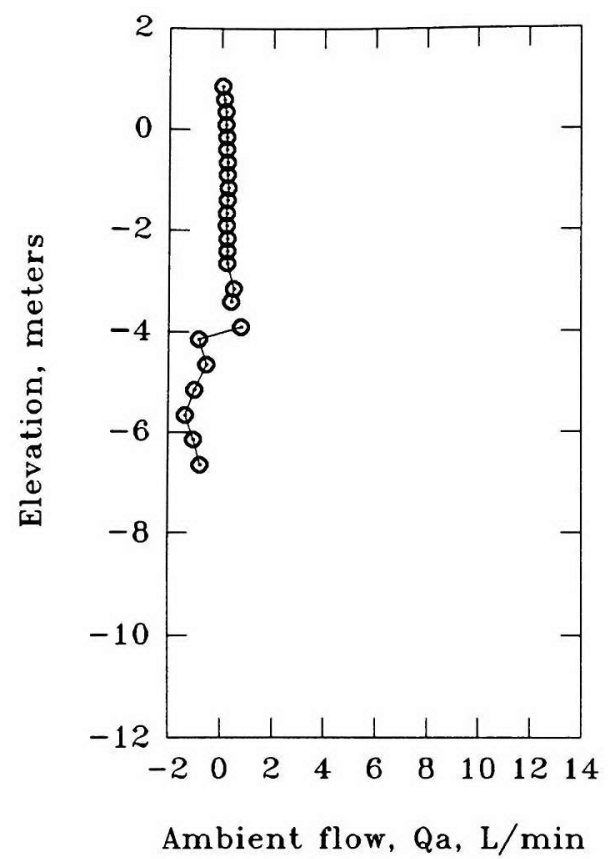

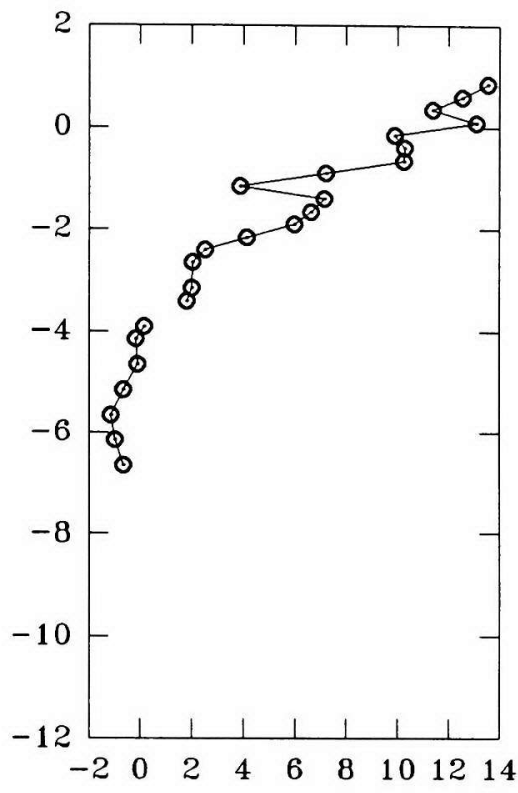

Induced flow, Qi, L/min

a

$\mathrm{b}$

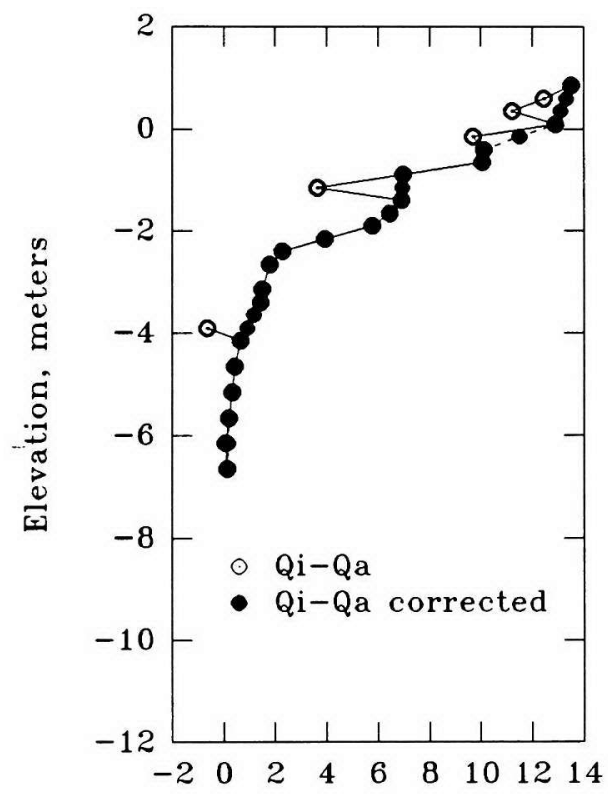

Discharge, $\mathrm{L} / \mathrm{min}$

C

Figure 23. Ambient, induced and discharge flow rate profiles of borehole $2 \mathrm{~W}$. 


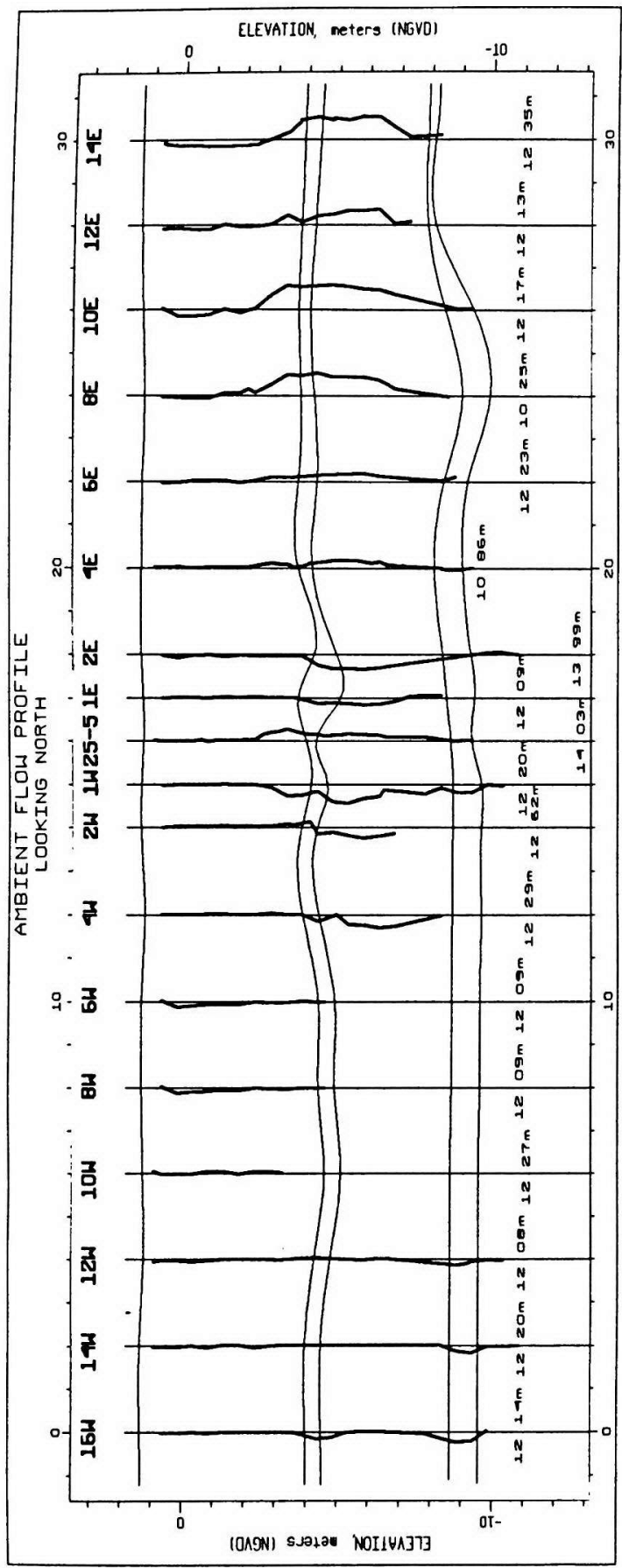

Figure 24. Cross section showing the ambient flow profile from 18 fully penetrating wells and the two hard layers encountered during drilling. The profiles that bow to the right indicate upward water flow, while those that bow to the left indicate downward water flow. A maximum ambient flow of 3.08 liters/minute was measured at borehole 10E. 
connected to the pump outlet; this prevented any significant recharge in the vicinity of the borehole.

Induced flow measurements were done thirty minutes after pumping had started to allow attainment of pseudo-steady state behavior, a condition reached when $r_{w}{ }^{2} S / 4 T t<0.01$, where $r_{w}$ is the borehole radius, $t$ is time, and $\mathrm{S}$ and $\mathrm{T}$ are the aquifer storativity and transmissivity, respectively (Molz and Young, 1993). Appendix VII shows the calculations used in determining when pseudo-steady state conditions occurred. Measurements were done at the same 0.5 meter depth interval as the ambient flow measurements. In zones where the induced flow decreased upward (e.g., the open circles shown in Figure 23.c., which represent local anomalous dips in $\mathrm{Q}_{\mathrm{i}}-\mathrm{Q}_{\mathrm{a}}$ ), measurements were done at closer intervals (i.e., 0.25 and 0.125 meter) in an attempt to narrow down these problematic zones (the nature of the problem with these zones is discussed in detail in the next section).

\subsubsection{Discharge Rate}

The induced flow profile minus the ambient flow profile shows the vertical distribution of where water entered the borehole in response to pumping. This difference (induced minus ambient) is sometimes referred to as "discharge" (Molz and Young, 1993). In principle, discharge should increase monotonically from zero at the bottom of a borehole to the pump rate $\left(Q_{p}\right)$ just below the pump intake. However, all profiles showed some intervals where discharge decreased upward as exemplified by few open circles visible in Figure 23.c. The most likely cause for this was that the packer did not seal 
tightly on the walls of the borehole resulting in some vertical water flow passing around rather than through the flowmeter probe.

A decreasing-upward discharge rate was also observed in some depth intervals at the Macrodispersion Experiment (MADE) site, located on the Columbus Air Force Base in Mississippi. Rehfeldt et al. (1989a) stated that the most likely cause of these "dips" were voids around the screen caused by incomplete collapse of the unconsolidated aquifer material back around the screen, when the augers used for screen installation were removed. Instead of all water passing through the casing, some was passing through these voids that served as channelways for water flowing upwards.

In our case, the "voids" were open spaces between the packer and the wall of the borehole. The cause for the incomplete seal between the wall and the packer in some places was the presence of crumbling, porous zones that resulted in irregular borehole surfaces. This phenomenon was observed in our wells at certain levels and was correlatable from one well to another (Figure 25). A borehole video camera proved the occurrence of highly porous zones in these areas of poor packer performance.

\subsubsection{Layer Hydraulic Conductivity Calculation}

The hydraulic conductivity of each layer was calculated from the discharge rate profile using Equation 6. The details of these calculations are shown in Appendix IV. 


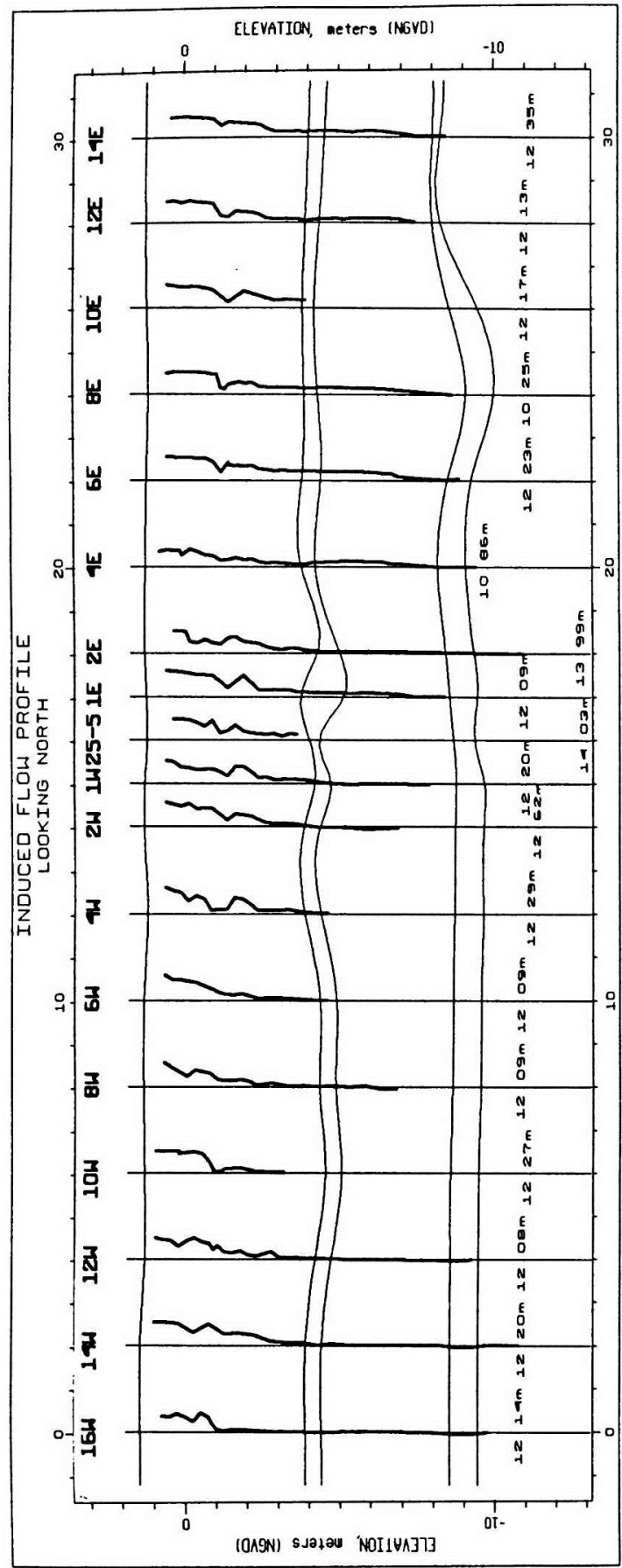

Figure 25. Cross section showing the induced flow profile from 18 fully penetrating wells. The "dips" in the induced flow profiles are caused by an incomplete seal between the wall of the borehole and the packer. These dips are correlatable from one borehole to another indicating the lateral persistence of a crumbly, highly porous zone. 
While the borehole flow measurements in zones of decreasing-upward flow were somewhat suspect due to incomplete packing, these data may still offer a rough, semi-quantitative indication of the distribution of groundwater inflow to the borehole over some of the affected intervals. This was recognized by Rehfeldt et al. (1989a), who linearized the discharge profiles across zones of decreasing-upward discharge (i.e., they drew straight line profiles across such zones, between the more reliable points with good packer seal just above and below each such zone) and then calculated the hydraulic conductivity of each zone of decreasing upward flow based on the total groundwater inflow over the entire zone (an inflow based on the more reliable points above and below the zone). Rehfeldt et al. (1989a, b) then assigned this overall hydraulic conductivity value to each interval between flow measurements in the zone of decreasing-upward flow. This approach of Rehfeldt et al. (1989a, b) is referred to as the "multiple-interval" approach since a single $\mathrm{K}$ value calculated for the zone of decreasing-upward flow was then assigned to all the intervals in that zone (all the intervals between adjacent borehole flow measurements without tight packing). This introduces multiple (one for each interval) identical $\mathrm{K}$ values into the sample of measured $\mathrm{K}$ values, and may be reasonable for zones of decreasing upward flow with discharge (induced minus ambient flow) profiles of relatively constant slope.

A more conservative means of handling a zone of poor packer seal is to calculate one $\mathrm{K}$ value for the entire zone (as above) and treat it as only one value in statistical analyses (instead of having multiple intervals of identical values). This approach is referred to as the "single-interval" approach. While the smaller number of hydraulic conductivity values could potentially 
make spatial analysis with semi-variograms less clear with the single-interval approach, this approach seems more sound than the multiple-interval approach of Rehfeldt et al. (1989a, b). For purposes of comparison, data analysis was carried through with both approaches. The two were found to give very similar semi-variograms in the horizontal direction, though semi-variograms in the vertical showed very different correlation lengths (see Section 4.6.2). The multiple-interval approach was used in the gridding and contouring of the hydraulic conductivity. Figure 26 shows the distribution of hydraulic conductivity using the multiple interval approach.

\subsection{Geostatistics}

Geostatistics differs from conventional statistics in that it focuses on the spatial distribution of regionalized variables (Journel and Huijbregts, 1978; Royle, 1980). In our case the regionalized variable was the natural log of hydraulic conductivity (see section 2.2.); its spatial distribution (Figure 27) was analyzed using semi-variograms, and statistics derived from the semivariograms were then used in a stochastic model to estimate macrodispersivity.

\subsubsection{Frequency Distribution}

It is standard geostatistical practice to transform the variable of interest to a normal distribution because most statistical tests are tied to the normal distribution (Sandefur and Grant, 1980). Studies by Bjerg et al. (1992), Hess et al. (1992), Rehfeldt et al. (1992), and Sudicky (1986), show that the natural-log of hydraulic conductivity $(\mathrm{Y}=\ln \mathrm{K})$ exhibits a normal distribution. 
$(O \wedge O N)$ NOI $\perp \forall \wedge \exists 7 \exists$

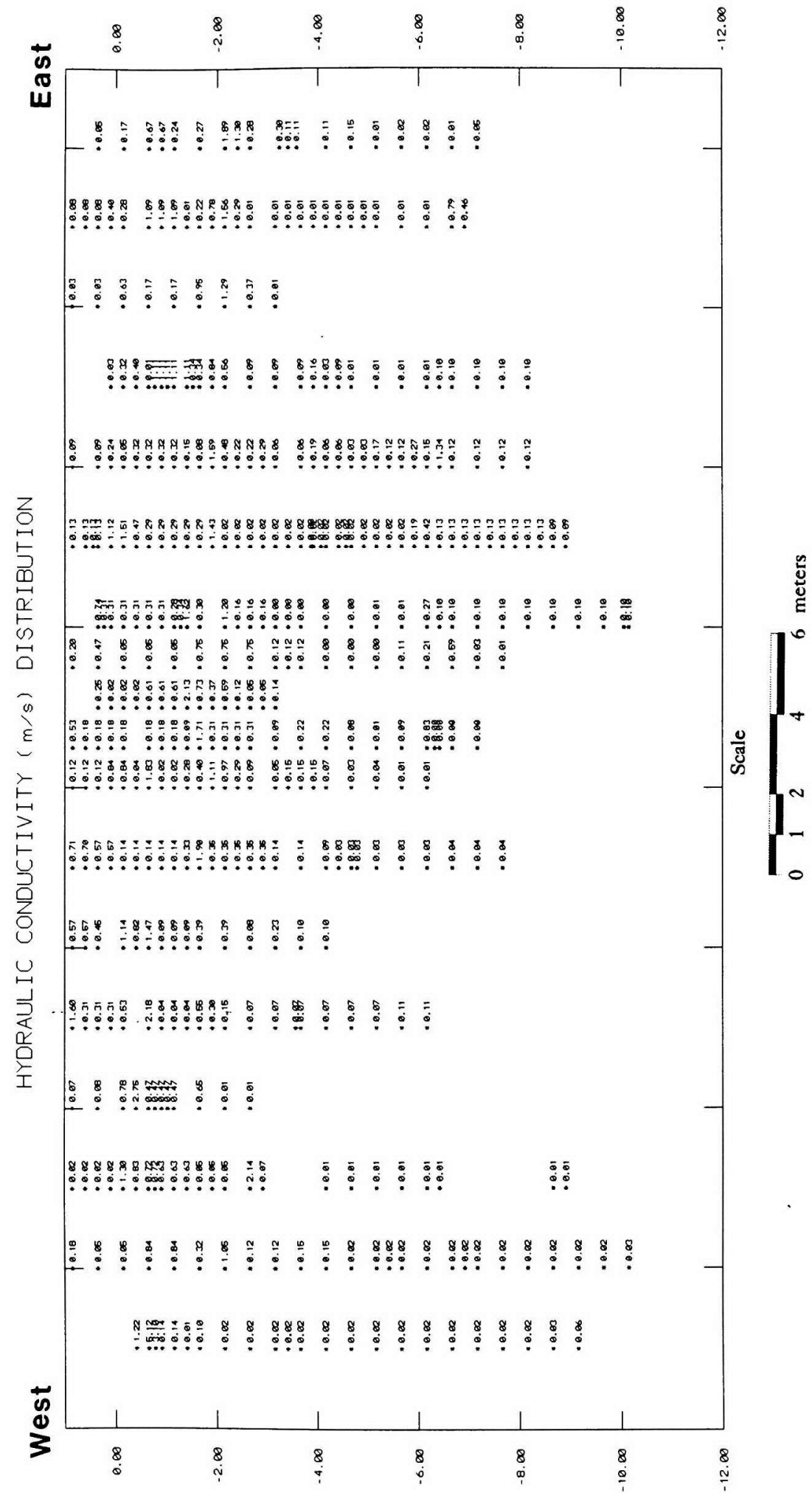

Figure 26. Hydraulic conductivity distribution along the study transect. 


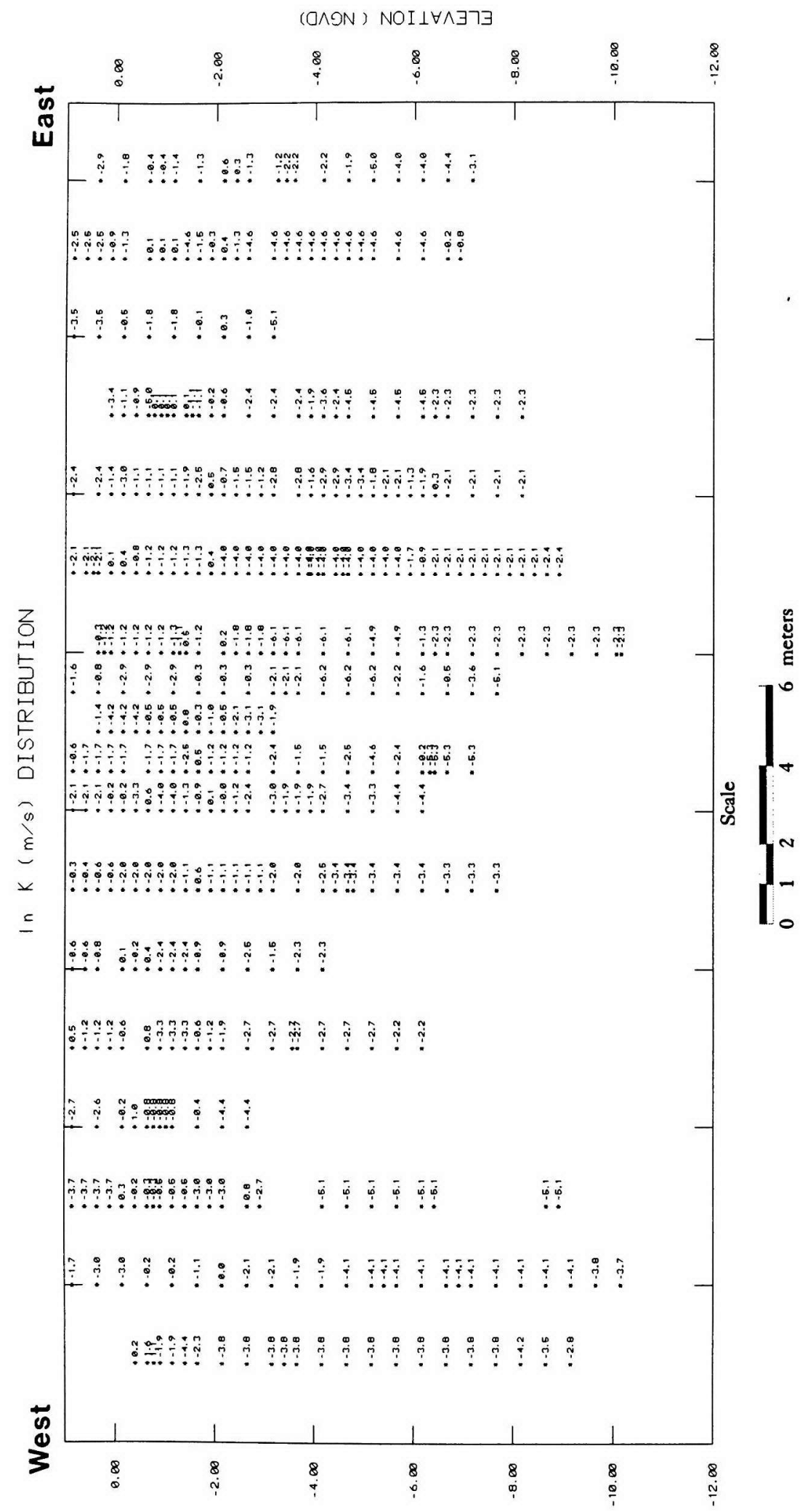

Figure 27. Distribution of natural-log of hydraulic conductivity, $\operatorname{lnK}(\mathrm{K}$ in $\mathrm{m} / \mathrm{s}$, along the study transect. 
In this study, the hydraulic conductivity values were transformed to natural-log values (Figure 27). The frequency distribution of the natural log of hydraulic conductivity (Figure 28 ) from both the multiple-interval ( $425 \mathrm{~K}$ values) and single-interval approach ( $207 \mathrm{~K}$ values) is approximately normal. While the shape of the distribution is solely dependent on our borehole flowmeter results, the value of the mean is also dependent on the $\mathrm{K}_{\text {avg }}$ value used in Equation 6, a value derived from earlier results published by Fish and Stewart (1991).

The spacing between borehole flow measurements was not constant; some zones were avoided altogether because the probe could easily be moved in the borehole with the packer inflated, indicating a very wide hole and no possibility of sealing with the packer. These zones show up in the profiles (Appendix VII) as places with relatively wide spacing between adjacent flow measurements. Because the measurement interval was not constant, some of the hydraulic conductivity values apply to longer intervals than others. In principle this could influence the shape of the distribution in Figure 28a if there is a relationship between hydraulic conductivity and poor packing (e.g., if zones with poor packing exhibit enhanced secondary solution, and were therefore more permeable, and thus fewer high conductivity points went into the distribution because fewer measurements could be made in high conductivity zones).

In an effort to address this question, the frequency of each hydraulic conductivity value was normalized to the size of the interval to which it 


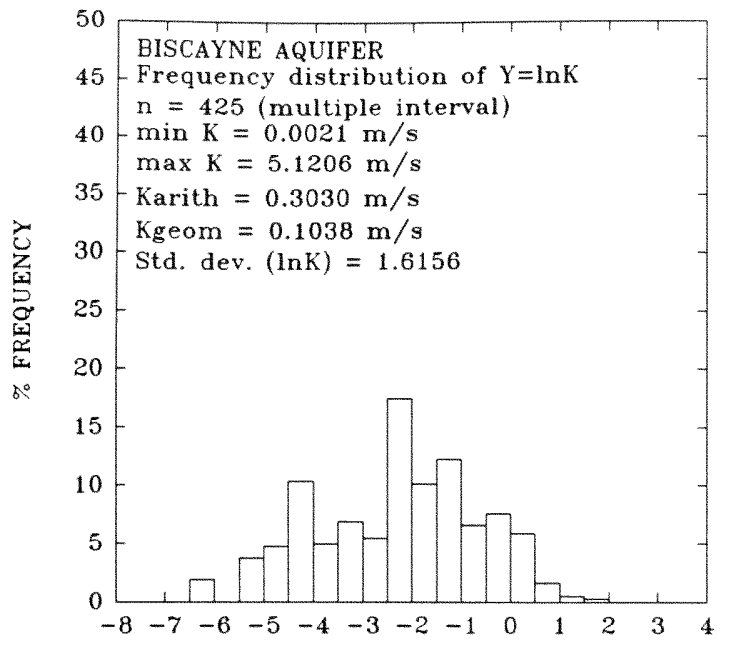

In $K$ ( $K$ in meters/second)

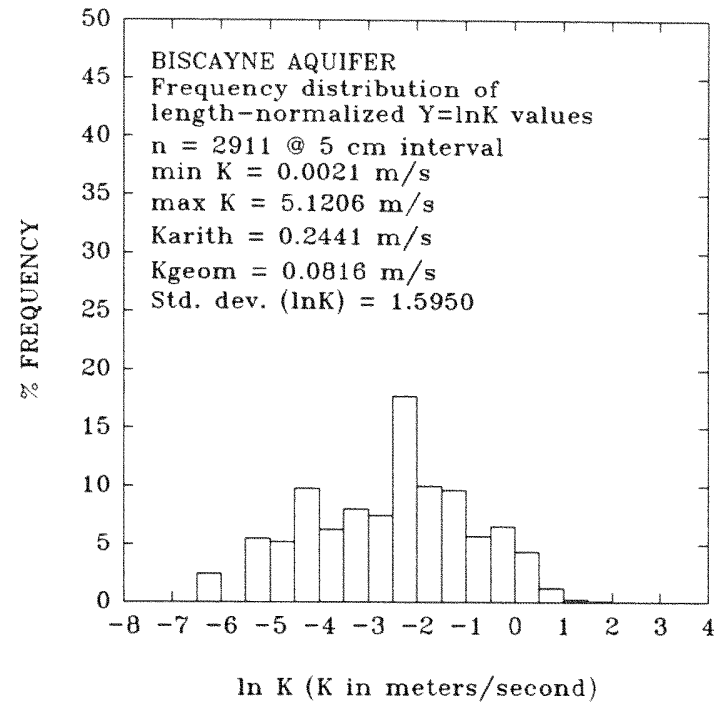

b

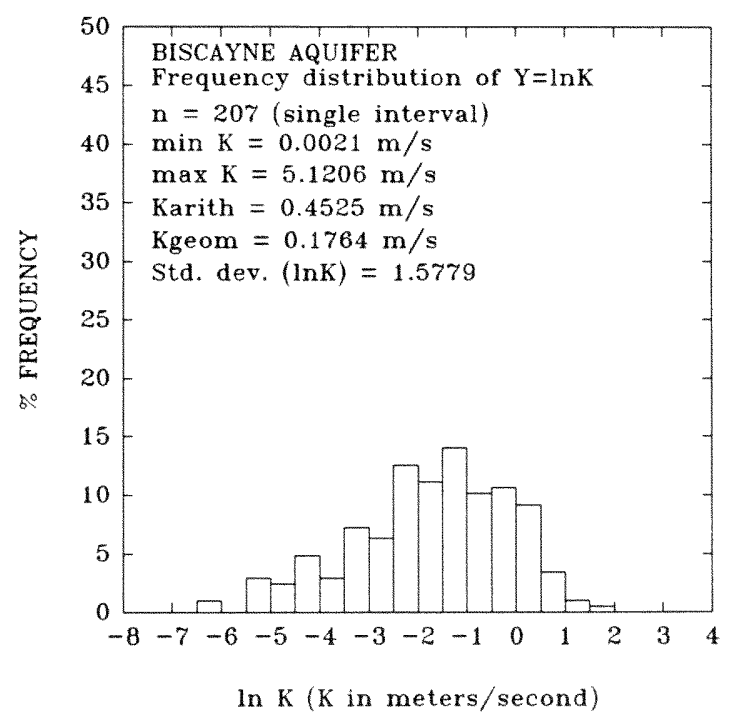

c

Figure 28. Comparison of the frequency distribution of hydraulic conductivity values within the full Biscayne Aquifer between (a) the multiple-interval approach, (b) the length-normalized $\ln \mathrm{K}$ values, and (c) the single-interval appraoch. 
applied. Since the minimum interval between flow measurements was 0.05 $\mathrm{m}$, a hydraulic conductivity value representing a 0.50 meter interval was assigned a frequency of 10 , while a value representing a 0.25 meter interval was assigned a frequency of 5 , etc. Comparison of the result of this approach is shown in Figure 28b. The length normalization shows no significant effect on the mean or standard deviation of $\mathrm{Y}$, indicating that the statistics are not affected by the uneven measurement interval.

The arithmetic mean of our $\mathrm{K}$ values $(0.24-0.45 \mathrm{~m} / \mathrm{s}$, Figure 28$)$ was not equal to the $\mathrm{K}_{\mathrm{avg}}$ value $(0.18 \mathrm{~m} / \mathrm{s})$ used in calculating our values with Eqn. 6. This is due to the lack of flowmeter measurements at greater depths where the boreholes were, in some cases, very wide and hydraulic conductivity was lower.

Figure 29 shows the comparison between frequency distributions of the natural logarithm of hydraulic conductivity values in the Upper and Lower Biscayne Aquifer based on the multiple- and single-interval approaches. While the Upper and Lower Biscayne have different mean conductivities, the means are close enough and the variances in them large enough that all the values together form a unimodal (not bimodal) normally-distributed sample of $\mathrm{Y}$ (Figure 28).

Two-sample $t$ test (Zar, 1984; Mendenhall and Ott, 1980) on the difference between the mean and variances of $\operatorname{lnK}$ values in the Upper and Lower Biscayne Aquifers (at 95 percent degree of confidence) indicate that 


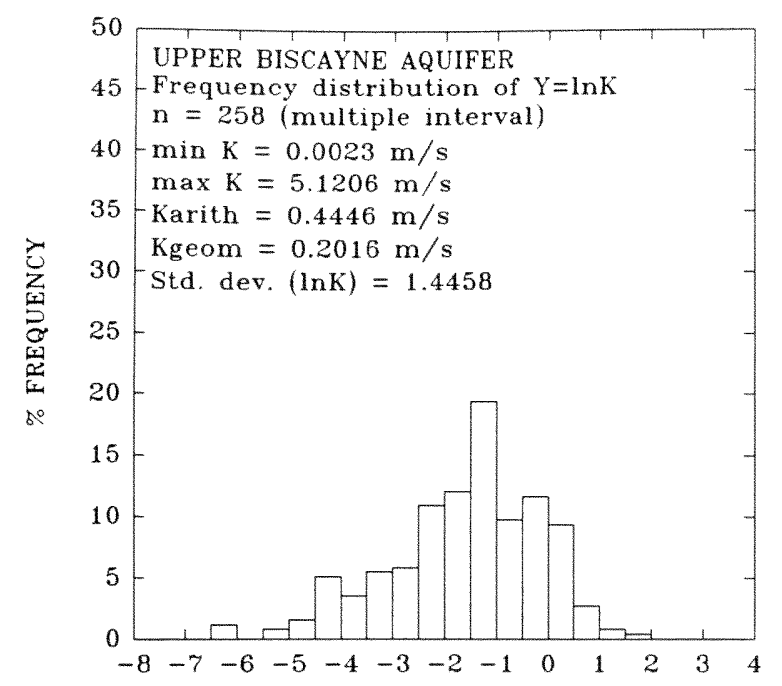

In $\mathrm{K}$ ( $\mathrm{K}$ in meters/second)

a

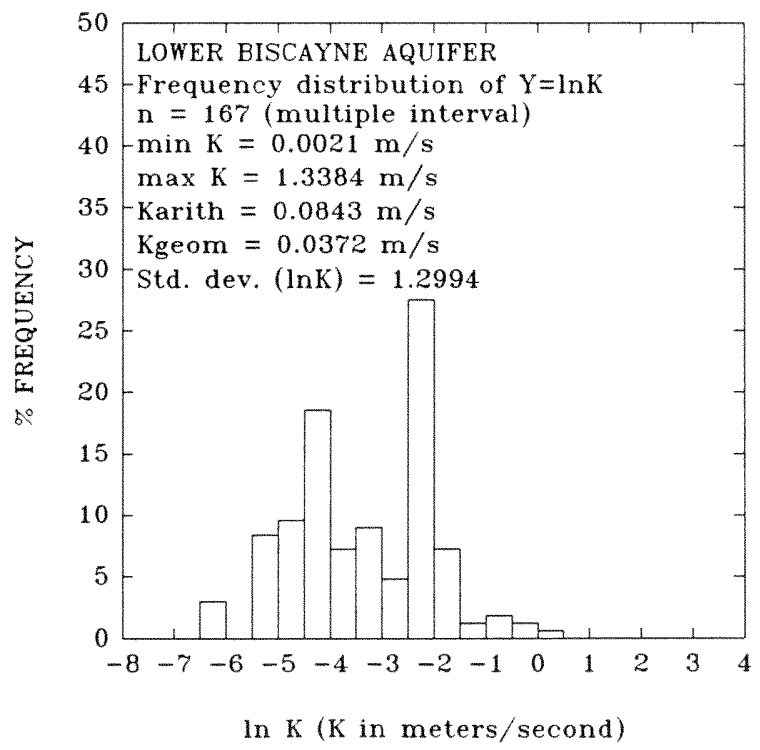

C

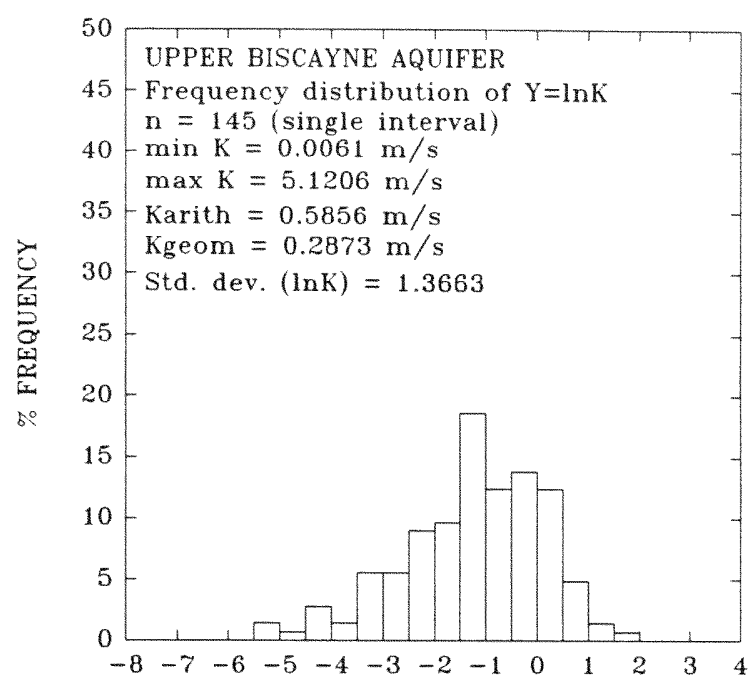

In $\mathrm{K}$ ( $\mathrm{K}$ in meters/second)

b

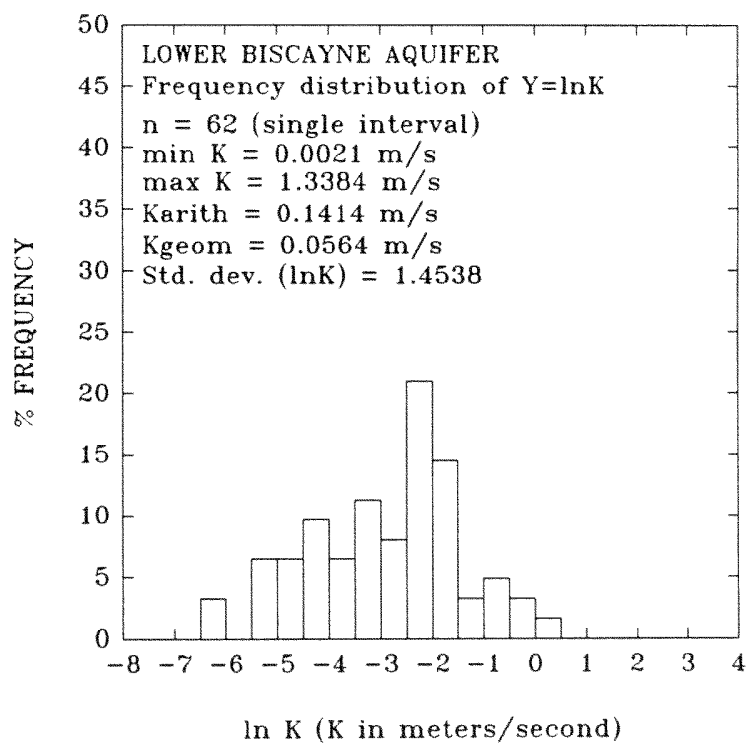

d

Figure 29. Comparison of frequency distributions of hydraulic conductivity values between the Upper and Lower Biscayne Aquifer using the multiple- and single-interval approaches. 
the two aquifers have different means and variances.

\subsubsection{Semi-variogram}

As noted earlier, it has been established experimentally that the logarithm of hydraulic conductivity in a given formation $(\mathrm{Y}=\operatorname{lnK})$ is generally normally distributed (that is, hydraulic conductivity is lognormally distributed). With the further assumption of stationarity (independence of a variable from the location $x$ ) of second order (defined below), the spatial distribution of $\operatorname{lnK}$ is amenable to description with parametric geostatistical methods developed by Matheron (1963) and others. The purpose of this description in our case is to demonstrate the length scales over which one can expect some correlation between measured $\mathrm{K}$ values in our study section of the Biscayne Aquifer, and to estimate macrodispersivity from the parameters of the $\operatorname{lnK}$ distribution, using the theory of Gelhar and Axness (1983).

Implicit in this treatment is that $\mathrm{Y}$, the natural logarithm of hydraulic conductivity, is a regionalized random variable exhibiting second order stationarity. A regionalized variable differs from an ordinary scalar random variable in that each realization (each measurement) is associated with a particular spatial location, and in general two realizations have a non-zero correlation, unlike the ordinary scalar random variable in which any two realizations are independent (Henley, 1981). In general (and in our case), the similarity between two $\mathrm{Y}$ values depends on the distance between the points of measurement of the two values (the difference in $\mathrm{Y}$ increasing as the distance between the measurement points increases). A regionalized variable 
is said to exhibit first order stationarity if its expected value is the same over the entire spatial domain of interest:

$$
E[Y(x)]=m
$$

where $m$ is the mean value of $Y$, and the left-hand side of the equation is the expected value of $\mathrm{Y}, \mathrm{Y}$ being a function of position, $\mathrm{x}$. This can also be stated:

$$
E[Y(x)-Y(x+h)]=0
$$

In other words, the expected value of the difference between two $\mathrm{Y}$ measurements made a distance $\mathrm{h}$ apart is zero. The covariance $\mathrm{C}$ of the two $\mathrm{Y}$ values may be defined as the expected value of the product of their deviations from the mean:

$$
E[\{Y(x)-m\}\{Y(x+h)-m\}]=C(h)
$$

If $\mathrm{C}(\mathrm{h})$ thus defined is independent of $\mathrm{x}$ (the same spatial covariance holds everywhere in the domain), then second order stationarity holds (and if this is the case, first order stationarity must also apply) (Henley, 1981). If second order stationarity holds, the covariance of $\mathrm{Y}$ will approach its variance as $\mathrm{h}$ approaches zero:

$$
C(0)=E[\{Y(x)-m\}\{Y(x)-m\}]=\operatorname{var}(x)=\sigma_{Y}^{2}
$$

In practice full second order stationarity is rarely justified, and a somewhat weaker assumption may be adopted (involving an approach to 
calculation of covariance which does not require the unknown mean, m). This is the so-called "intrinsic hypothesis":

$$
\begin{gathered}
E[Y(x)-Y(x+h)]=0 \\
E\left[\{Y(x)-Y(x+h)\}^{2}\right]=\operatorname{var}[Y(x)-Y(x+h)]=2 \gamma(h)
\end{gathered}
$$

where $\gamma(\mathrm{h})$ is the semi-variogram, one-half the spatial variance $(2 \gamma(\mathrm{h})$ is the variogram). Note that although the expected value of $Y(x)-Y(x+h)$ may be zero, the expected value of its square is not necessarily zero. The value of $\gamma$ is taken to be dependent on separation, $\mathrm{h}$ (and possibly on direction in the spatial domain, as discussed below), but not on location, $x$. In theory the value of $\gamma(0), \gamma$ at a separation of zero, should be zero (two measurements made in exactly the same location should be identical). In practice, measurement error and very small scale spatial heterogeneity (below the scale of measurements) may lead to a non-zero value for $\gamma(0)$. In mining geostatistics a non-zero $\gamma(0)$ is referred to as the " nugget effect" (based on the potentially large difference in ore grade of two samples taken right next to each other, if one of the two contains a large nugget of the ore mineral). In general $\gamma(\mathrm{h})$ tends to increase with $\mathrm{h}$. The semi variogram and covariance are related by:

$$
\gamma(h)=C(0)-C(h)
$$

where $C(0)$ is simply the variance of $Y, \sigma_{Y}{ }^{2}$. A scatter plot of $\gamma(h)$ vs. h can be constructed from a series of measurements of a regionalized variable; both 
the values of the variable and the locations of the measurements are required. Such a plot is referred to as a semi-variogram (the word semi-variogram applies both to the statistic $\gamma(\mathrm{h})$ and to plots of $\gamma(\mathrm{h})$ vs. h). Commonly the analysis of semi-variograms focuses on fitting a simple function to the scatterplot of $\gamma(\mathrm{h})$ vs. $\mathrm{h}$, and deriving values for 2 or 3 parameters of the simple function. The function most widely used in analysis of hydraulic conductivity is an exponential function:

$$
\gamma(h)=B+\sigma_{Y}^{2}\left[1-e^{-h / \lambda}\right]
$$

where $\lambda$ is the correlation length of $\mathrm{Y}$, and $\mathrm{B}$ is a constant representing the nugget effect ( $B=0$ if there is no nugget effect). Analysis of our $\mathrm{Y}$ data from the Biscayne Aquifer involved fitting exponential semi-variogram models to the data and estimating values of $\mathrm{B}, \sigma_{\mathrm{Y}}{ }^{2}$, and $\lambda$.

Construction of a semi-variogram requires selection of a separation distance $\mathrm{H}$, and computation of $\gamma$ using pairs of data points at each integer multiple of $\mathrm{H}$. Thus one locates the measurements taken distance $\mathrm{H}$ apart and calculates $\gamma(\mathrm{H})$ for each pair, then locates the measurements taken distance $2 \mathrm{H}$ apart and calculates $\gamma(2 \mathrm{H})$ for each pair, etc. A scatter plot of $\gamma \mathrm{vs.} h$ is prepared (the semi-variogram), with points located at $h=H, h=2 \mathrm{H}, h=3 \mathrm{H}$, etc. The $\gamma$ value plotted at each $h$ is the average of the $\gamma$ values over all the pairs at that $h$. Construction is relatively simple when measurements are taken on a grid with constant spacing $\mathrm{H}$. If measurements are not evenly spaced (as in this study), they must be grouped into intervals, in the manner required for construction of a histogram. In this case $\gamma$ is calculated for each 
pair of $\mathrm{Y}$ values separated in space by $\mathrm{H}$ or more but less than $2 \mathrm{H}$, the average $\gamma$ is computed for these pairs, and this average $\gamma$ is plotted on the semi-variogram at an $\mathrm{h}$ value equal to the average separation distance for pairs in this class interval ( $\mathrm{H} \preceq \mathrm{h} \prec 2 \mathrm{H}$ ). $\mathrm{H}$ is usually chosen to be approximately the average distance between adjacent measurement points, with some flexibility allowed if a slightly different $\mathrm{H}$ would produce a semi-variogram that is better fit by the model in use (in our case, the exponential model).

Both global and directional semi-variograms may be constructed. A global semi-variogram includes all possible measurement pairs at a given separation, while a directional semi-variogram includes only those pairs separated along a line parallel to the direction of interest. In practice, this requirement for selection of pairs in directional variograms is often relaxed a bit, and pairs are allowed if they fall along a line within a specified angular search window ( $\pm \mathrm{p}$ degrees from the direction of interest, where $\mathrm{p}$ is usually less than 10). This allows one to increase the number of pairs used in constructing the semi-variogram and hence improve its definition and accuracy. For example, if one is constructing a horizontal variogram one may specify that two measurement points need not lie along a perfectly horizontal line to be considered, but rather may lie along a line within, say, \pm 5 degrees of horizontal. As with the choice of class interval for unevenly spaced measurements, the choice of angular search window is somewhat subjective, being driven in part by the goal of obtaining a smooth trend wellfit to a simple function (e.g., exponential) on the resulting semi-variogram (Isaaks and Srivastava, 1989). In our study, the parameters of directional semi-variograms were used to compute macrodispersivity. Table 1 shows the 
search parameters (class interval and search window) used in calculating semivariograms from the hydraulic conductivity values obtained from the two

\begin{tabular}{|c|c|c|c|c||}
\hline Approach & $\begin{array}{c}\text { Semi- } \\
\text { Variogram }\end{array}$ & $\begin{array}{c}\text { Average } \\
\text { Sampling } \\
\text { Distance }\end{array}$ & $\begin{array}{c}\text { Class } \\
\text { Interval }\end{array}$ & $\begin{array}{c}\text { Search } \\
\text { Window }\end{array}$ \\
\hline MI & global & $1.1 \mathrm{~m}$ & $1.0 \mathrm{~m}$ & - \\
\hline MI & horizontal & $2.0 \mathrm{~m}$ & $2.0 \mathrm{~m}$ & $\pm 5^{\circ}$ \\
\hline MI & vertical & $0.3 \mathrm{~m}$ & $0.5 \mathrm{~m}$ & $0^{\circ}$ \\
\hline SI & global & $1.3 \mathrm{~m}$ & $1.0 \mathrm{~m}$ & - \\
\hline SI & horizontal & $2.0 \mathrm{~m}$ & $2.0 \mathrm{~m}$ & $\pm 5^{\circ}$ \\
\hline SI & vertical & $0.7 \mathrm{~m}$ & $0.7 \mathrm{~m}$ & $0^{\circ}$ \\
\hline
\end{tabular}

Table 1. Parameters used in this study for the calculation of semivariograms. "Approach" is either multiple-interval (MI; 425 values) or single-interval (SI; 207 values) as discussed in section 4.5.4. "Average sampling distance" is the average distance between field measurements of $\mathrm{K}$.

approaches mentioned earlier (i.e., multiple-interval and single-interval approaches). Since each hydraulic conductivity value had to be assigned to a point location, when in reality it applied to an interval, each value was assigned to the midpoint of the interval to which it applied.

A program called VGRAM3 (from Kathryn M. Hess at the US Geological Survey in Marlboro, Massachusetts) was used for computation of semi-variograms. The first class size or interval was 2 meters for the horizontal semi-variogram. Any two data points separated by less than 2 meters were included as a pair in the computation of $\gamma(\mathrm{h})$ for the first lag interval. Also, data pairs within \pm 5 degrees search window were included. 
Figure 30 shows an illustration of the tolerances applied in this study for the calculation of $\gamma(\mathrm{h})$ in the horizontal direction.

Global, horizontal and vertical semi-variograms were prepared for the full Biscayne Aquifer, and the Upper and Lower Biscayne Aquifers. An exponential model was fit to the experimental semi-variograms (Figures 31, 32, 33, and 34) using Sigma Plot version 5.0. The variances $\sigma_{\mathrm{Y}}{ }^{2}$ and correlation lengths $\lambda$ determined from the model fits were used in computing macrodispersivity. A summary of the semi-variogram parameters for the Biscayne Aquifer is presented in Table 2.

A conservative approach to data interpretation suggests a greater focus on the single interval approach, since the semi-variograms based on this approach utilized only the highest quality flow meter measurements. While the multiple interval approach seems to give a smoother fit to an exponential function in some cases, this should not be construed to indicate that it provides more reasonable or reliable estimates of aquifer parameters than the single interval approach. For example, the multiple interval approach yielded values of $1.69 \mathrm{~m}$ and $1.45 \mathrm{~m}$ for $\lambda_{\mathrm{v}}$ and $\lambda_{\mathrm{h}}$, respectively, for the full aquifer (without nugget effect). These values do not seem to be in realistic proportion to one another, as studies of other stratified sedimentary media (Gelhar, 1993; Sudicky, 1986; Hess et al, 1992; Rehfeldt et al, 1992) show that $\lambda_{\mathrm{h}}$ is usually a few times larger than $\lambda_{v}$ (not surprisingly, given that $\lambda_{v}$ is normal to bedding, and properties of the medium should vary most rapidly normal to rather than along bedding). In addition, the value of $\lambda_{\mathrm{v}}(1.45 \mathrm{~m})$ seems large, 


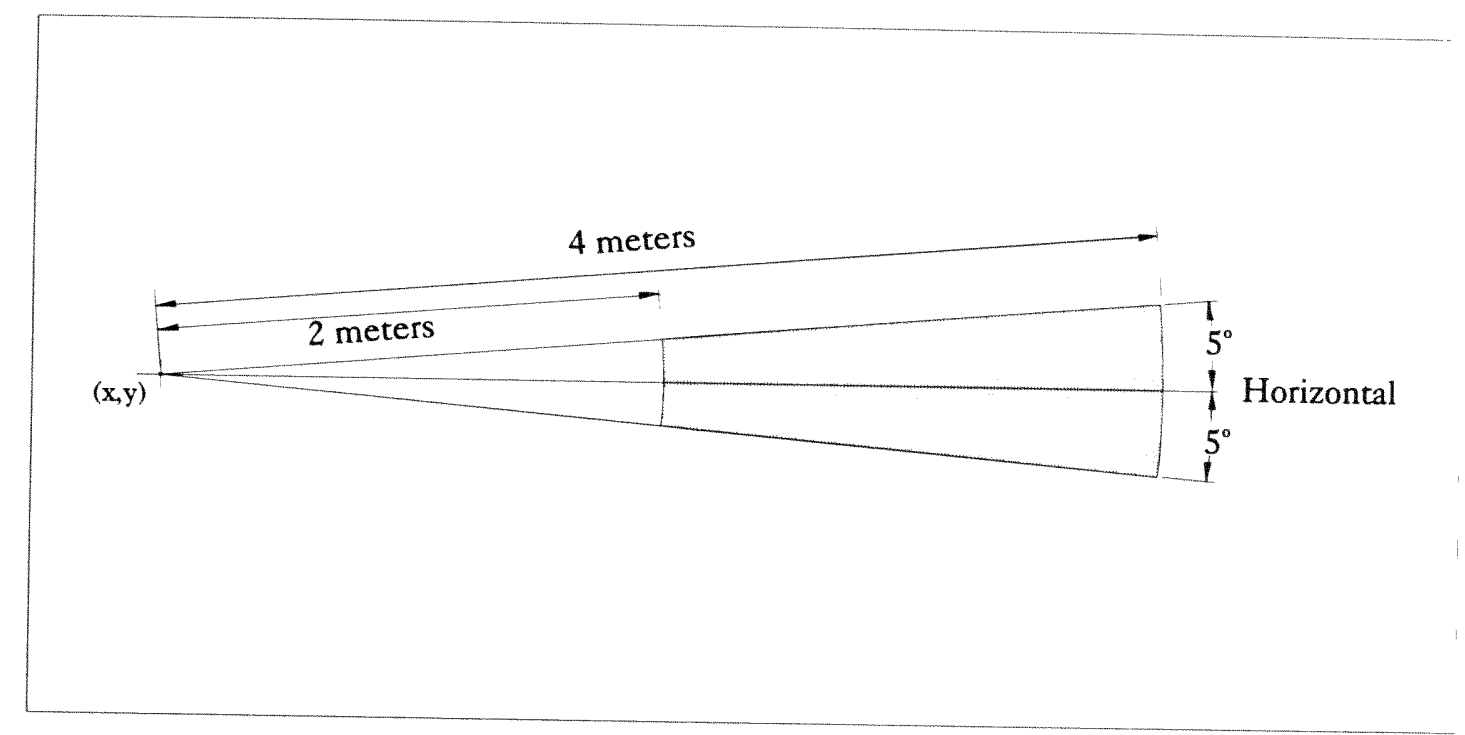

Figure 30. An illustration of the search parameters used in selecting data pairs for the second class interval of horizontal semi-variograms (h greater than or equal to 2 meters but less than 4 meters). All samples within the shaded area were paired with the sample at $(\mathrm{x}, \mathrm{y})$. 


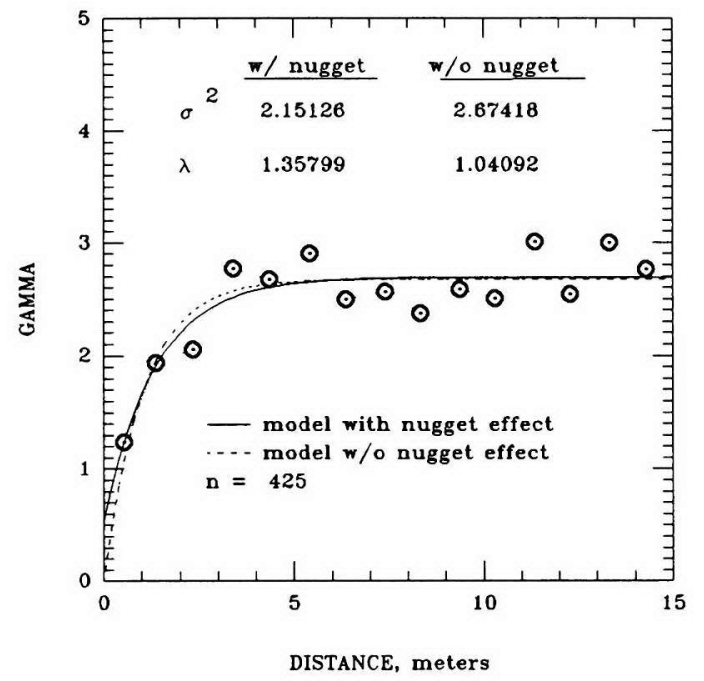

Global variogram of $\ln (\mathrm{K})$ values of the entire Biscayne Aquifer at 1.0 meter class interval.

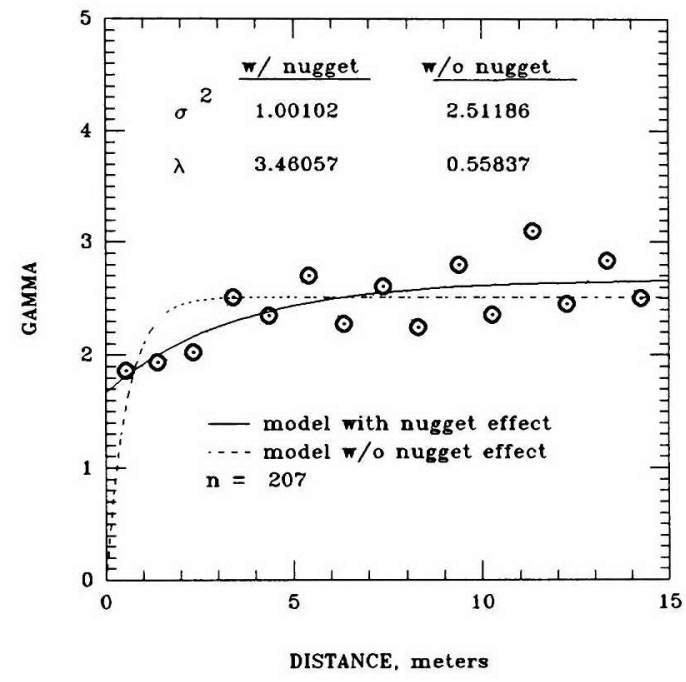

Global variogram of $\ln (K)$ values of the entire Biscayne Aquifer at 1.0 meter class interval.

Figure 31. Global semi-variograms of the full Biscayne Aquifer fitted with an exponential model. Full-aquifer semi-variogram with $425 \mathrm{lnK}$ values is based on the "multiple-interval" approach to zones with incomplete packer seal, that with $207 \mathrm{lnK}$ values is based on the singleinterval approach (see section 4.5.4 for explanation of these terms). 


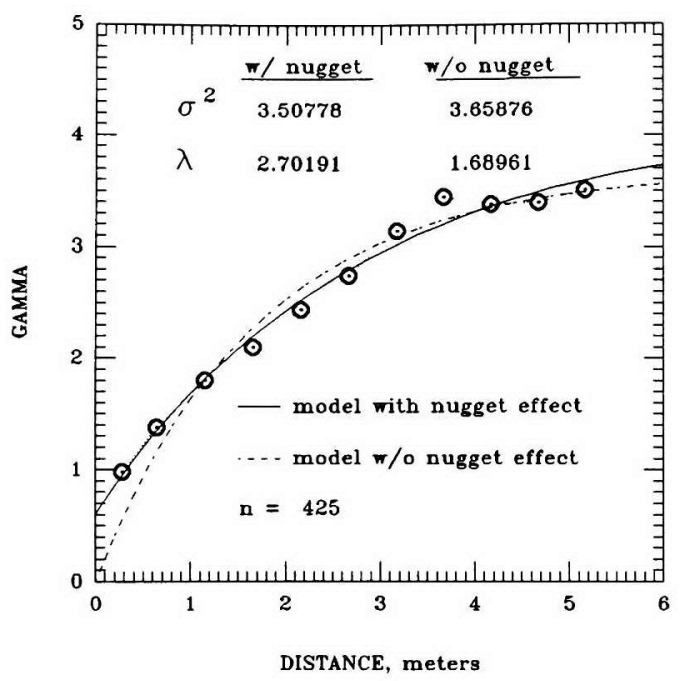

Vertical variogram of $\ln (K)$ values of the entire Biscayne Aquifer at 0.5 meter class interval and 0 degree search window.

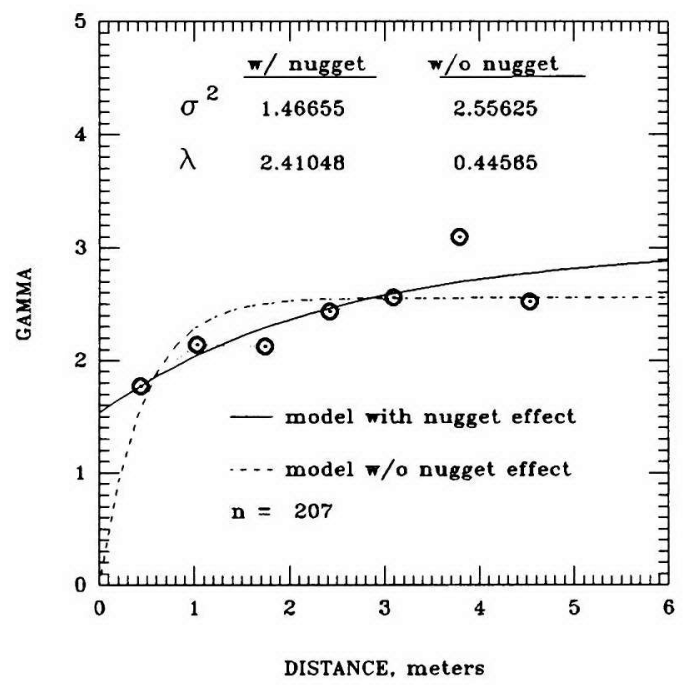

Vertical variogram of $\ln (K)$ values of the entire Biscayne Aquifer at 0.7 meter class interval and 0 degree search window.

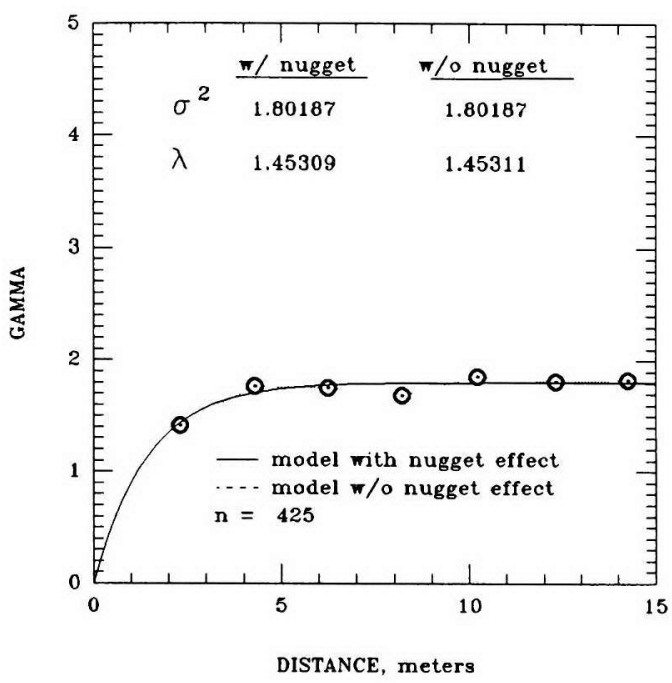

Horizontal variogram of $\ln (K)$ values of the entire Biscayne Aquifer at 2.0 meter class interval and 5 degree search window.

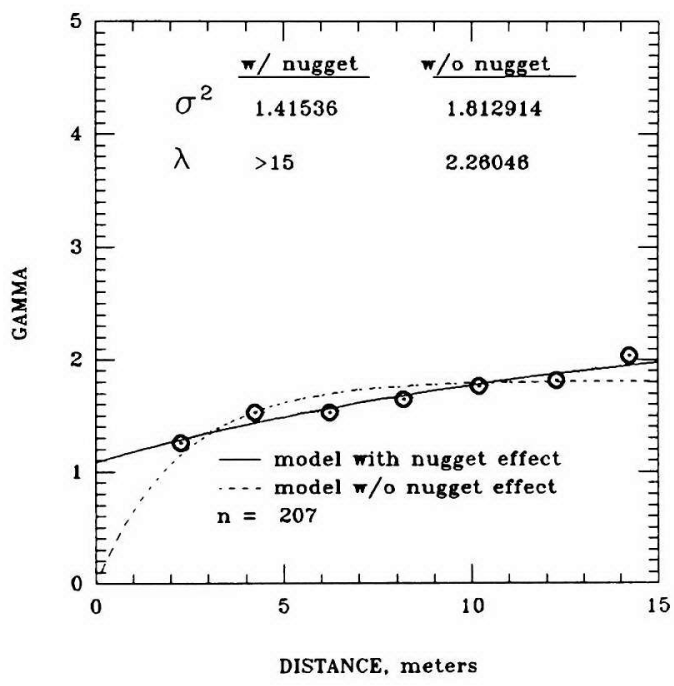

Horizontal variogram of $\ln (K)$ values of the entire Biscayne Aquifer at 2.0 meter class interval and 5 degree search window.

Figure 32. Vertical and horizontal experimental semi-variograms of the full Biscayne Aquifer based on the multiple- and single-interval approaches, and fitted with an exponential model. 


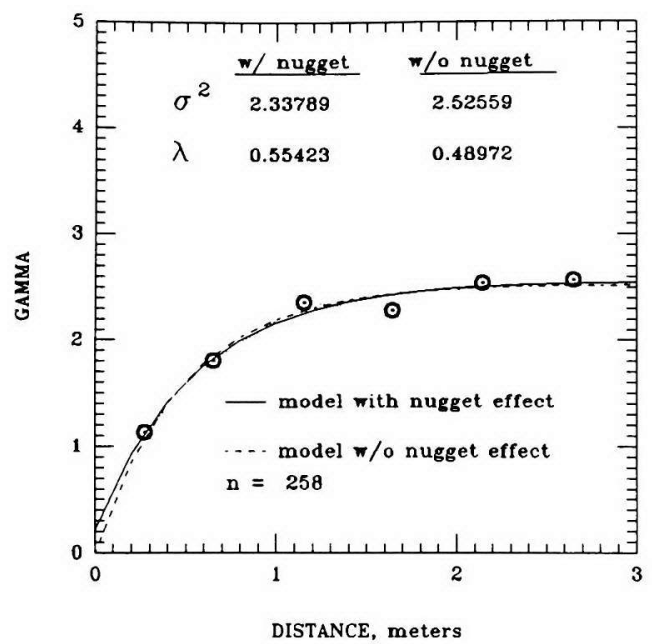

Vertical variogram of $\ln (K)$ values of the Upper Biscayne Aquifer at 0.5 meter class interval and 0 degree search window.

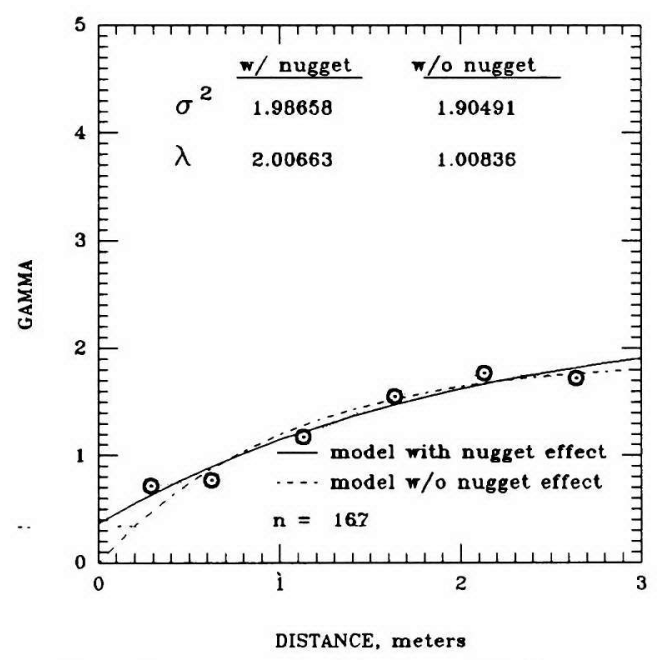

Vertical variogram of $\ln (K)$ values of the Lower Biscayne Aquifer at 0.5 meter class interval and 0 degree search window.

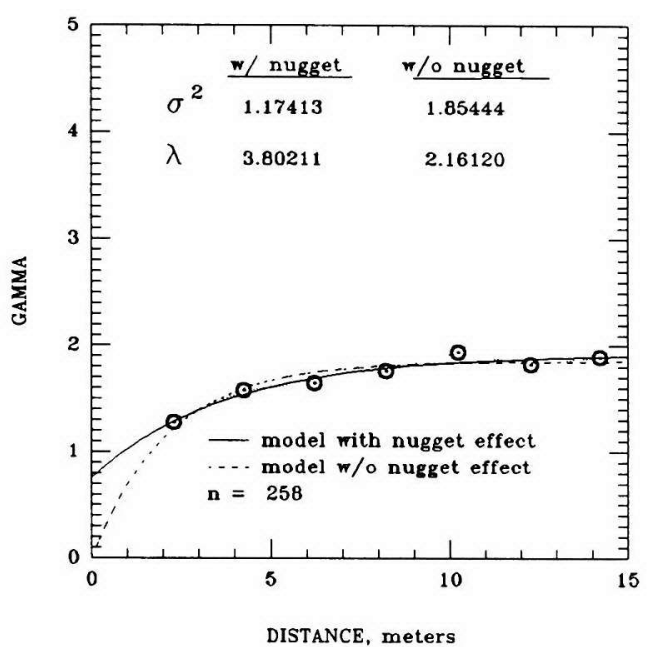

Horizontal variogram of $\ln (\mathrm{K})$ values of the Upper Biscayne Aquifer at 2.0 meter class interval and 5 degree search window.

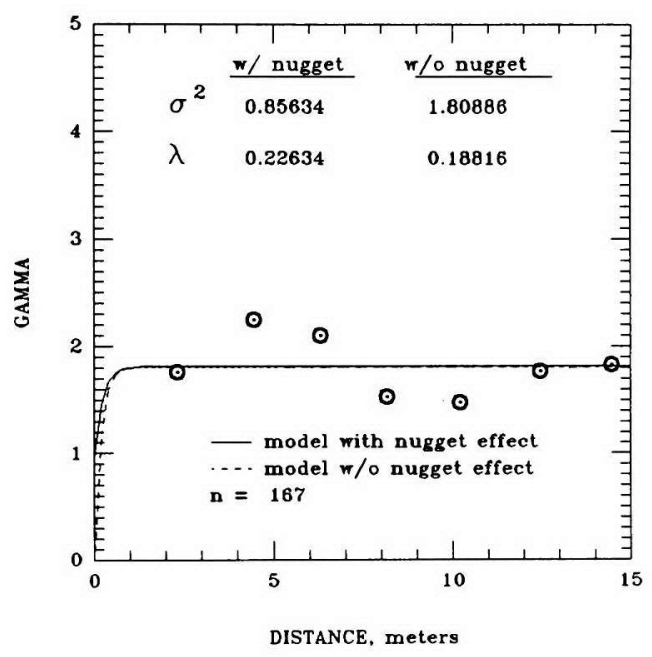

Horizontal variogram of $\ln (K)$ values of the Lower Biscayne Aquifer at 2.0 meter class interval and 5 degree search window 


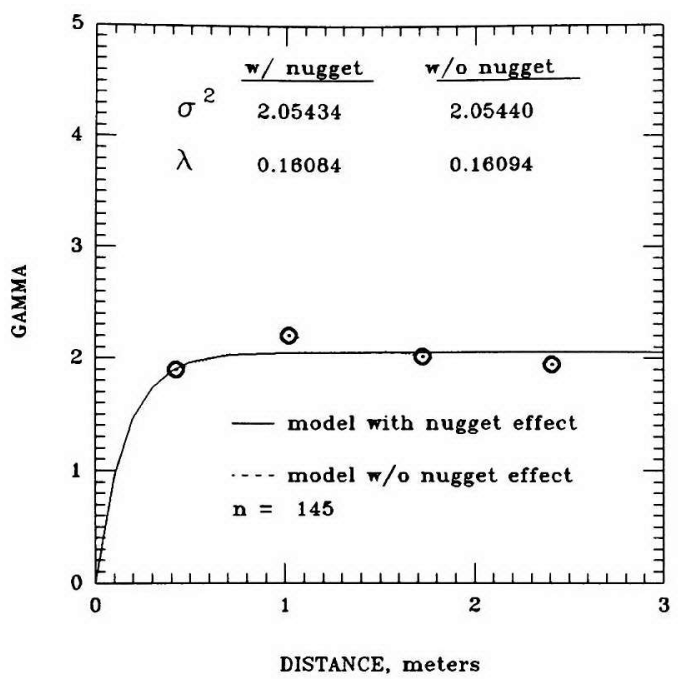

Vertical variogram of $\ln (K)$ values of the Upper Biscayne Aquifer at 0.7 meter class interval and 0 degree search window.

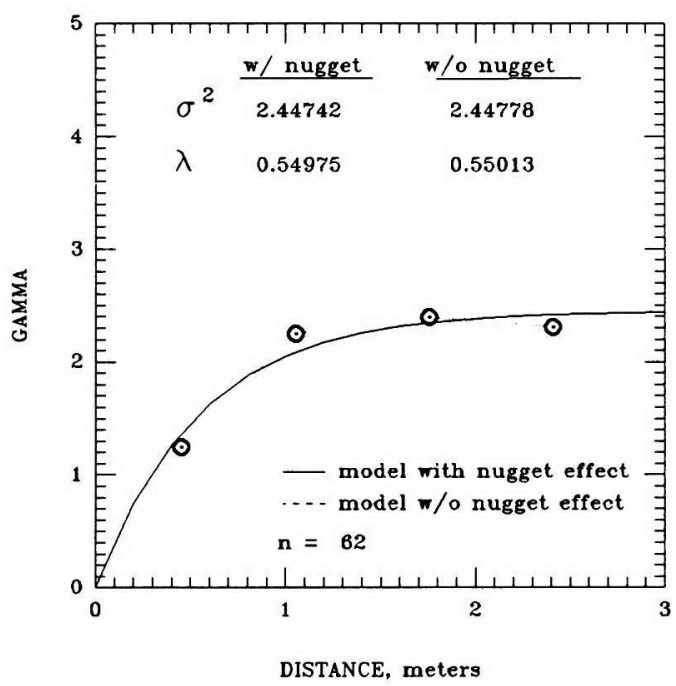

Vertical variogram of $\ln (K)$ values of the Lower Biscayne Aquifer at 0.7 meter class interval and 0 degree search window.

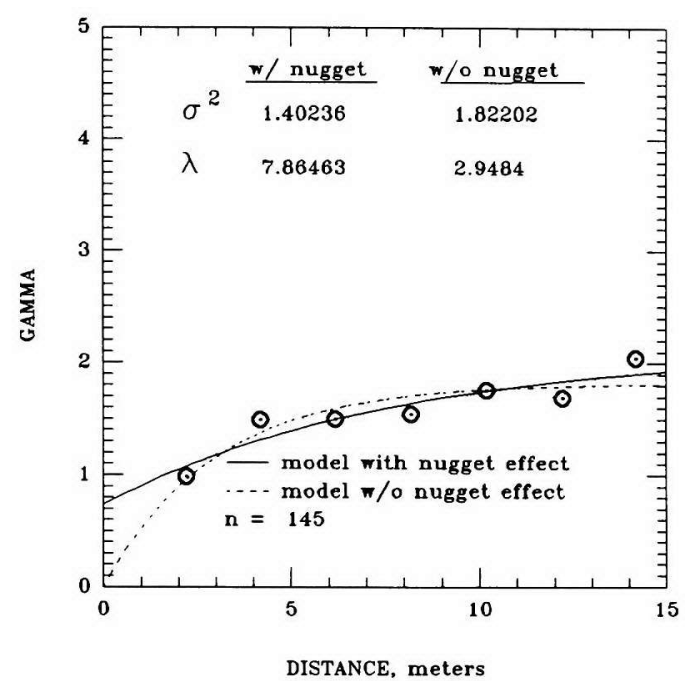

Horizontal variogram of $\ln (K)$ values of the Upper Biscayne Aquifer at 2.0 meter class interval and 5 degree search window.

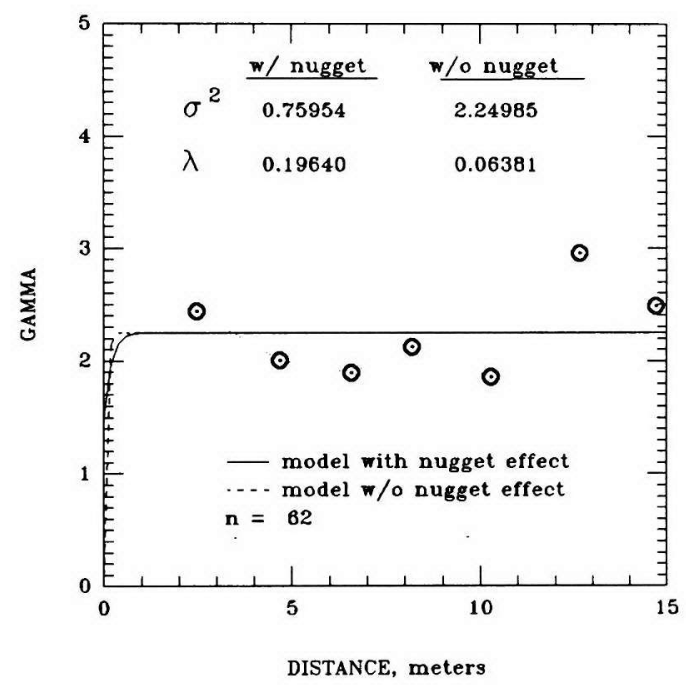

Horizontal variogram of $\ln (K)$ values of the Lower Biscayne Aquifer at 2.0 meter class interval and 5 degree search window. 


\begin{tabular}{|c|c|c|c|c|c|c|c|}
\hline & $\mathrm{N}$ & $\sigma_{g}^{2}$ & $\lambda_{\mathrm{g}}, \mathrm{m}$ & $\sigma_{v}^{2}$ & $\lambda_{x}, \mathrm{~m}$ & $o_{h}^{2}$ & $\lambda_{\mathrm{h}}, \mathrm{m}$ \\
\hline \multicolumn{8}{|l|}{ Full Biscavne Aquifer } \\
\hline \multicolumn{8}{|l|}{ multiple interval } \\
\hline with nugget & 425 & 2.15 & 1.36 & 3.51 & 2.70 & 1.80 & 1.45 \\
\hline without nugget & 425 & 2.67 & 1.04 & 3.66 & 1.69 & 1.80 & 1.45 \\
\hline \multicolumn{8}{|l|}{ single interval } \\
\hline with nugget & 207 & 1.00 & 3.46 & 1.47 & 2.41 & 1.42 & $>15.0$ \\
\hline without nugget & 207 & 2.51 & 0.56 & 2.56 & 0.45 & 1.81 & 2.26 \\
\hline \multicolumn{8}{|l|}{ Upper Biscayne Aquifer } \\
\hline \multicolumn{8}{|l|}{ multiple interval } \\
\hline with nugget & 258 & $1.93^{*}$ & $0.30^{*}$ & 2.34 & 0.55 & 1.17 & 3.80 \\
\hline without nugget & 258 & $1.91 *$ & $5.5 \times 10^{-3 *}$ & 2.53 & 0.49 & 1.85 & 2.16 \\
\hline \multicolumn{8}{|l|}{ single interval } \\
\hline with nugget & 145 & $1.0 \times 10^{-5 *}$ & $5.6 \times 10^{-3 *}$ & 2.05 & 0.16 & 1.40 & 7.86 \\
\hline without nugget & 145 & $1.74 *$ & $3.7 \times 10^{-9 *}$ & 2.05 & 0.16 & 1.82 & 2.95 \\
\hline \multicolumn{8}{|l|}{ Lower Biscayne Aquifer } \\
\hline \multicolumn{8}{|l|}{ multiple interval } \\
\hline with nugget & 167 & $1.91^{*}$ & $0.89^{*}$ & 1.99 & 2.01 & 0.86 & 0.23 \\
\hline without nugget & 167 & $1.91 *$ & $0.89^{*}$ & 1.90 & 1.01 & 1.81 & 0.19 \\
\hline \multicolumn{8}{|l|}{ single interval } \\
\hline with nugget & 62 & $2.21^{*}$ & $0.42 *$ & 2.45 & 0.55 & 0.76 & 0.20 \\
\hline without nugget & 62 & $2.21^{*}$ & $0.42 *$ & 2.45 & 0.55 & 2.25 & 0.06 \\
\hline
\end{tabular}

Table 2. Estimates of the semi-variogram parameters from borehole flowmeter measurements. Subscripts "g", "v" and "h" refer to results from global, vertical and horizontal semi-variograms, respectively. Results in boxes marked with * are based on semi-variograms computed but not plotted in this thesis. 
relative to other $\lambda_{v}$ values in the references above. In contrast, the single interval approach gave values of $2.26 \mathrm{~m}$ and $0.45 \mathrm{~m}$ for $\lambda_{\mathrm{h}}$ and $\lambda_{\mathrm{v}}$, respectively (without nugget), values of reasonable magnitude in realistic proportion to each other. While values based on both the multiple and single interval approaches are presented and, to some extent, used, we have greater confidence in the latter.

Traditionally, exponential model fits are done using models both with and without nuggets (e.g., Hess et al, 1992). Naturally, the models with a nugget effect fit the experimental data better, because they have one additional parameter that can be varied to bring the function closer to the data. In the absence of a compelling physical reason to consider a nugget effect and add an additional parameter to the analysis (better fit to the data not being a compelling reason in itself), the fits without the nugget effect are given greater emphasis here. Parameters derived from these fits were used in estimation of macrodispersivity, as indicated by Gelhar and Axness (1983).

Separate semi-variograms were constructed for the upper and lower aquifers, though the small number of points available for each half of the full aquifer (145 $\operatorname{lnK}$ values for the upper, 62 for the lower, with the single interval approach) means that parameters from these semi-variograms are more uncertain. The single interval, no-nugget correlation lengths bear this out for the lower aquifer $\left(0.55 \mathrm{~m}\right.$ for $\lambda_{v}$, which appears reasonable, but only $0.06 \mathrm{~m}$ for $\lambda_{\mathrm{h}}$ ). Analogous results for the upper aquifer are perhaps more realistic $\left(\lambda_{\mathrm{v}}=0.16 \mathrm{~m}, \lambda_{\mathrm{h}}=2.95 \mathrm{~m}\right)$. 
There were six model fits without nuggets on the full aquifer semi-variograms: single and multiple interval plots, for the global, vertical, and horizontal semi-variograms. Of these six, three gave estimates of variance $\left(\sigma_{\mathrm{Y}}{ }^{2}\right)$ that were very close to the values obtained by direct calculation independent of the semi-variograms (2.61 and 2.49, shown on the histograms in Figure 28): the two global semi-variograms (2.67 and 2.51), and the vertical semi-variogram based on the single interval approach (2.56). The vertical semi-variogram based on the multiple interval approach gave a variance of 3.66, significantly higher (following a procedure outlined in Hess et al. (1992), we found $95 \%$ confidence limits on the variance values to be about 0.5). Both horizontal full aquifer semi-variograms gave smaller variance values $(1.80$ and $1.81 \mathrm{~m})$, a possible indication of the "zonal anisotropy" discussed by Journel and Huijbregts (1978) for ore bodies. While well-know from the literature on mining geology, discussion of zonal anisotropy (different variance values in different directions) is absent from the relatively young literature on groundwater applications of geostatistics.

Most variance estimates for the separate upper and lower aquifers were smaller than for the full aquifer, consistent with the fact that there is a small difference in mean $\operatorname{lnK}$ value between upper and lower aquifers (hence, the full aquifer samples a wider spread of $\operatorname{lnK}$ values than either upper or lower alone). 


\section{CHAPTER 5 \\ DISCUSSION}

\subsection{Hydraulic Conductivity Distribution}

Profiles of the hydraulic conductivity were created using SURFER by Golden Software, Inc. of Golden, Colorado. For purposes of contouring, each hydraulic conductivity value was assigned to the midpoint of its measurement interval. Gridding was done by the inverse distance squared method using 0.2 meter by 0.2 meter grid. The search parameters were: quadrant search, search radius of 4 meters, and only 1 nearest sample per quadrant considered (Golden Software, 1993). The quadrant search is normally used when data points are at closely spaced intervals along widely separated traverses (Golden Software, 1993), in this case roughly 0.50 meter measurement intervals along boreholes spaced about 2 meters apart.

The respective contoured sections (Figure 35 and 36) of hydraulic conductivity and $\operatorname{lnK}$ values (Figure 26 and 27 ) show that the limestone above elevation -3.0 meters NGVD has the highest hydraulic conductivity (up to 4.6 meters/second), well above the geometric mean (about 0.10 meter/second) of the entire Biscayne Aquifer at the test site. Another localized zone of high hydraulic conductivity was observed below elevation -6.0 meters NGVD. Hydraulic conductivity here is not as high as in the upper layers (the maximum hydraulic conductivity determined within this zone was 0.75 meter/second). 


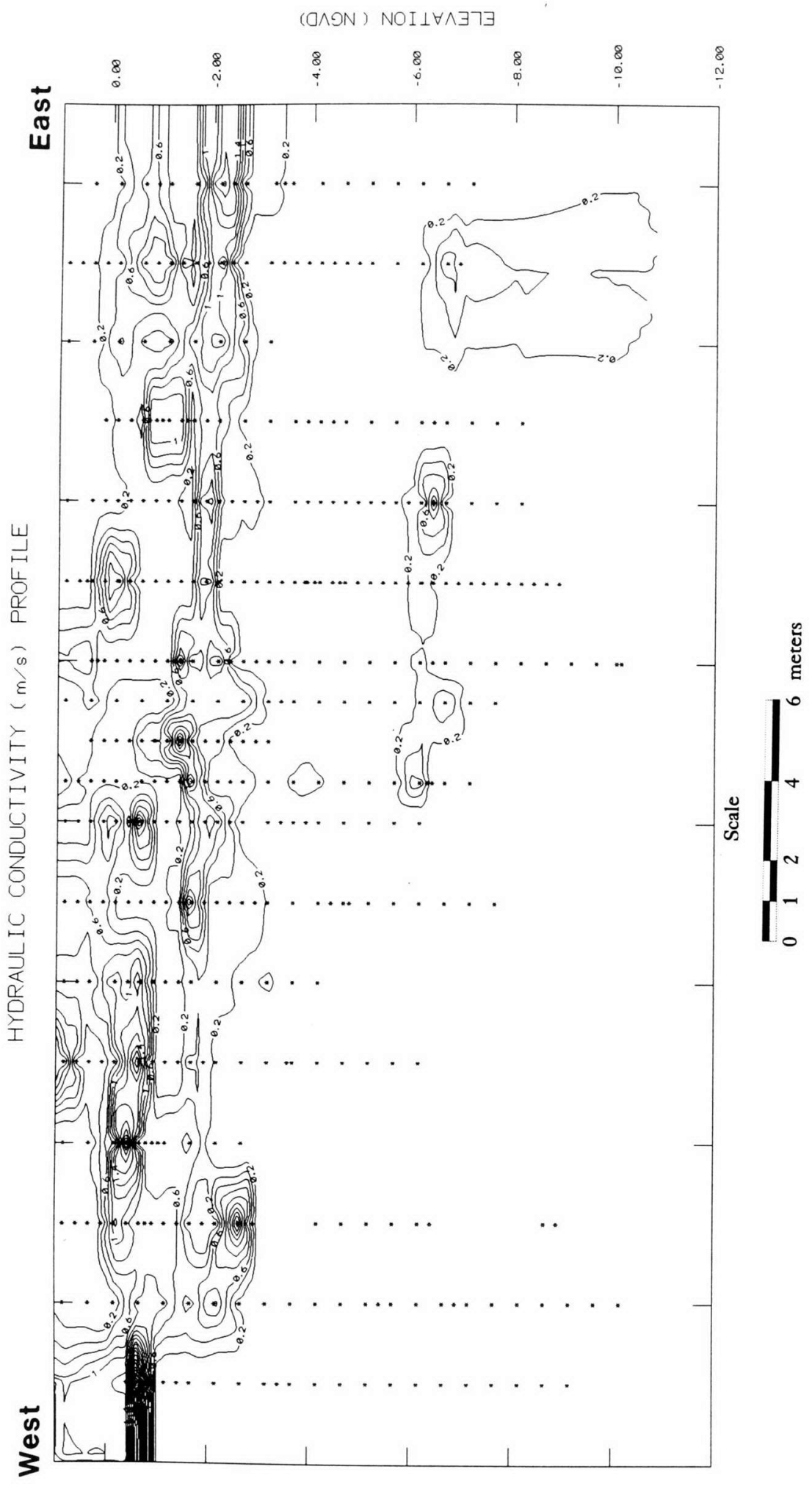

Figure 35. Hydraulic conductivity along the study transect. The contour interval is $0.2 \mathrm{~m} / \mathrm{s}$ with a minimum contour line of $0.2 \mathrm{~m} / \mathrm{s}$ which is above the geometric mean of $0.10 \mathrm{~m} / \mathrm{s}$. 


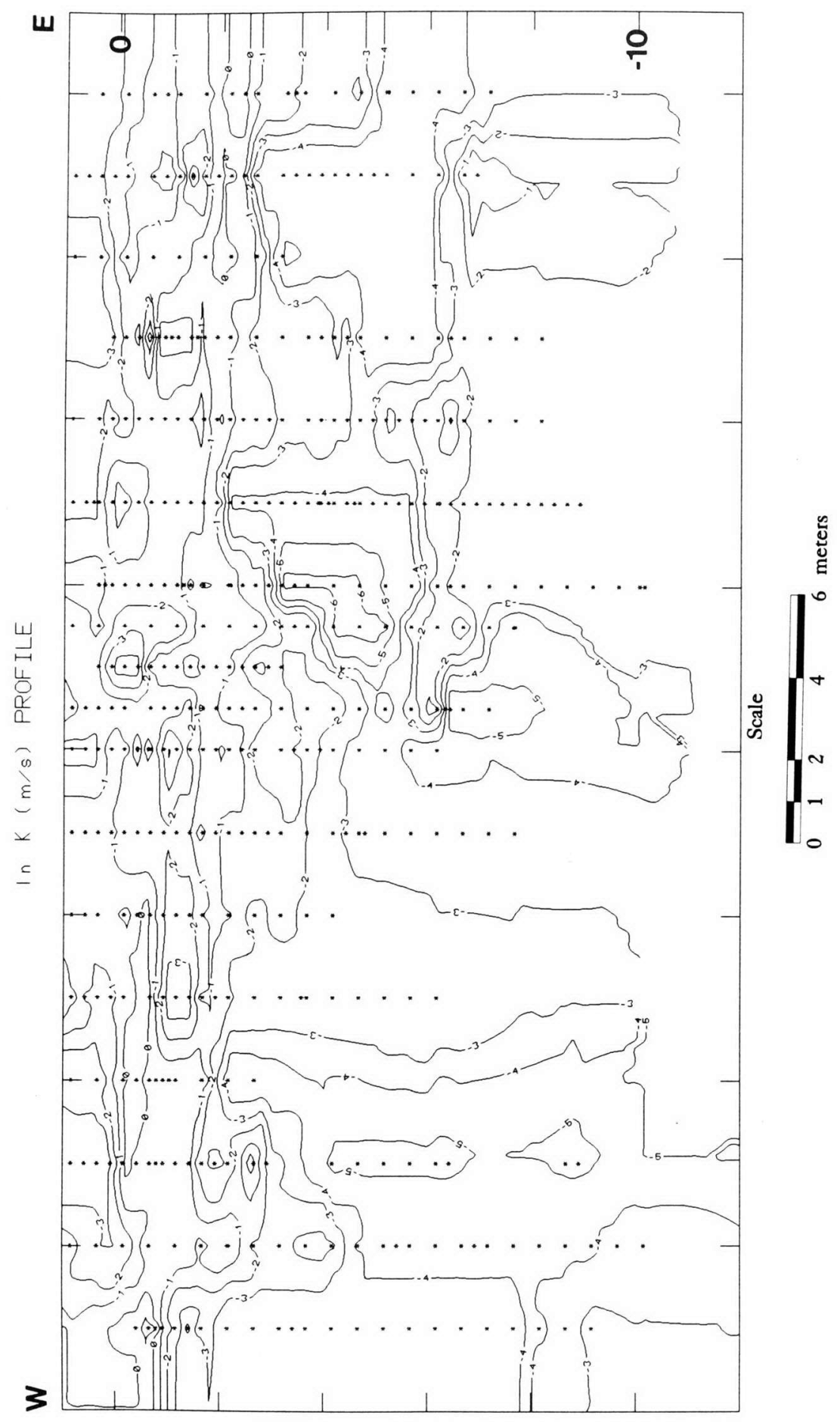

Figure 36. Contours of the natural-log of hydraulic conductivity, $\operatorname{lnK}(\mathrm{K}$ in $\mathrm{m} / \mathrm{s})$, along the study transect $(\mathrm{m} / \mathrm{s})$. Contours are at natural $\log$ intervals of 1.0 , with the minimum contour at -6.0 . 
The two regions of high hydraulic conductivity are separated by a thin extensive, horizontal zone of relatively low hydraulic conductivity, the shallow hard layer referred to earlier. Its elevation is about -4 meters NGVD. The true hydraulic conductivity value of the shallow hard layer may not be reflected in the borehole profiles because its 0.33 meter thickness is smaller than the 0.50 meter measurement interval. The hydraulic conductivity values measured in the vicinity of the shallow hard layer are probably higher than the hydraulic conductivity of this layer alone. Contouring may also cause a smoothing effect across the shallow hard layer resulting in apparently higher hydraulic conductivity values in contoured plots.

A distinct zone of relatively low hydraulic conductivity $(0.01$ meter/second to 0.04 meter/second) was also observed on the lower western section of the transect. The highest hydraulic conductivity determined in this section was only 0.10 meter/second.

\subsection{Hydrostratigraphy}

Figure 37 is a delineation of the different hydrostratigraphic layers at the study site based on geology, ambient flow, and hydraulic conductivity profiles. As mentioned in section 3, core drilling of 25-5 revealed a 33centimeter thick, hard, dense limestone layer within the Fort Thompson Formation. This shallow hard layer is the interface between the Upper and Lower Biscayne Aquifers. Ambient flow measurements in seven adjacent wells (boreholes 25-5, 4E, 6E, 8E, 10E, 12E, and 14E) in September 1994 indicated an upward water flow around the shallow hard layer, from the Lower Biscayne to the Upper Biscayne, demonstrating that this layer acted as 


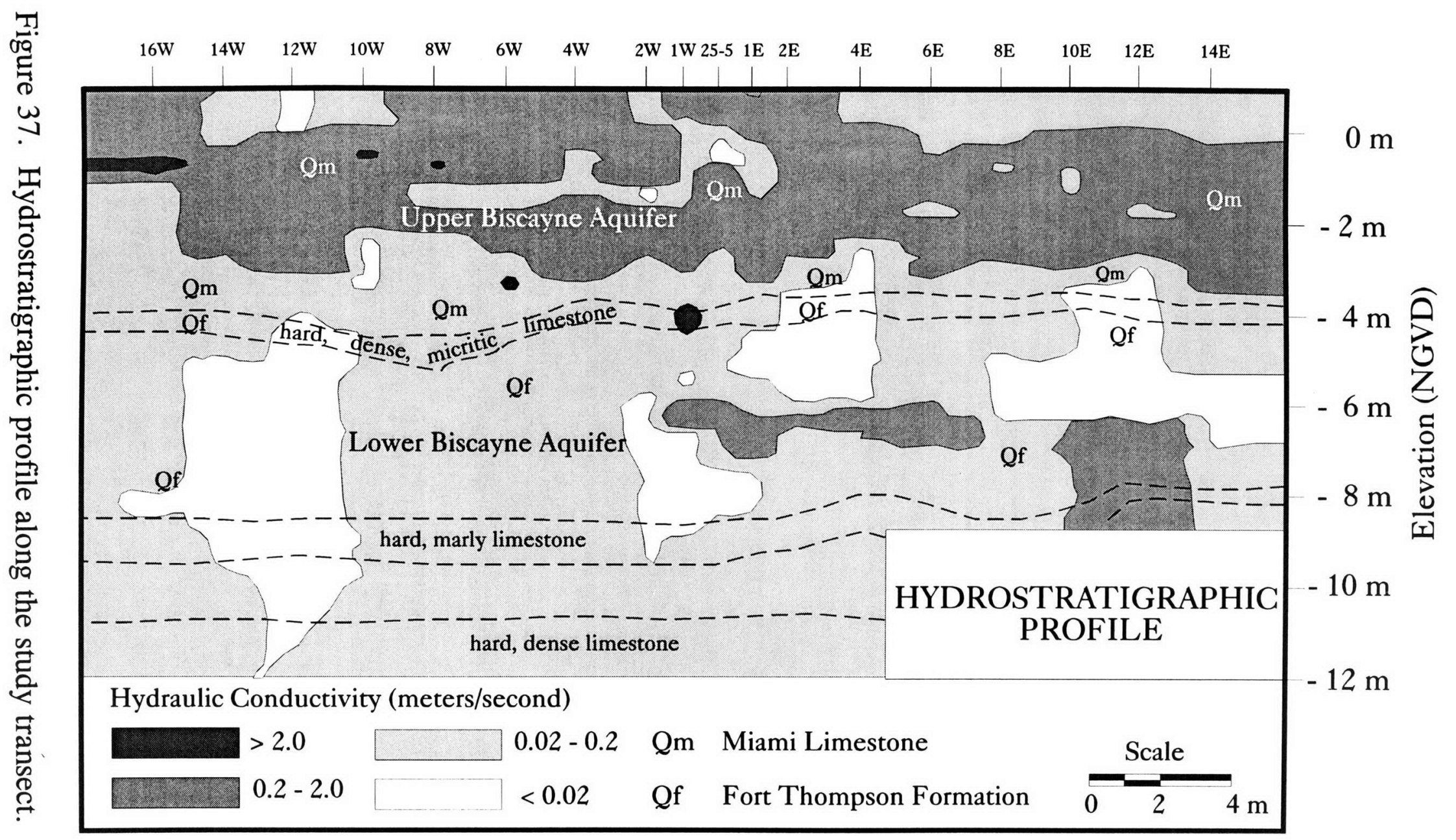


an aquitard, maintaining a difference in hydraulic head between the more permeable zones above and below.

Ambient borehole flow measurements in boreholes $2 \mathrm{E}, 1 \mathrm{E}, 1 \mathrm{~W}, 2 \mathrm{~W}$, $4 \mathrm{~W}$, and $16 \mathrm{~W}$ show water flowing downward from the Upper to Lower Biscayne Aquifer, again demonstrating that the shallow hard layer supports vertical hydraulic head gradient thus acting as an aquitard. This difference in ambient flow direction between these six boreholes (flow downward past the shallow hard layer) and those mentioned in the previous paragraph (flow upward past the shallow hard layer) was one of the most intriguing aspects of the data. At first it was thought that the different flow directions were due to different boundary conditions on the aquifer on the different days of flowmeter measurements (e.g., head changes associated with rainfall, evapotranspiration, and changes in canal stage during the period of flowmeter measurements). However, local canal stage and groundwater elevations were relatively steady during the measurement period, and groundwater flow direction in the area was very steady along the transect from west to east (Figure 38). In addition, repeat measurements in early December at boreholes $14 \mathrm{~W}, 4 \mathrm{~W}$, and $14 \mathrm{E}$ demonstrated that each borehole had essentially the same ambient flow profile as it did earlier in the fall, and perhaps more significantly all three types of profiles (no flow past the shallow hard layer, as in $14 \mathrm{~W}$, flow downward past it as in $4 \mathrm{~W}$, and flow upward past it as in 14E) could exist on the same day (Figure 39).

A tentative explanation of this phenomenon (different ambient flow profiles) can be made with reference to the spatial distribution of hydraulic 

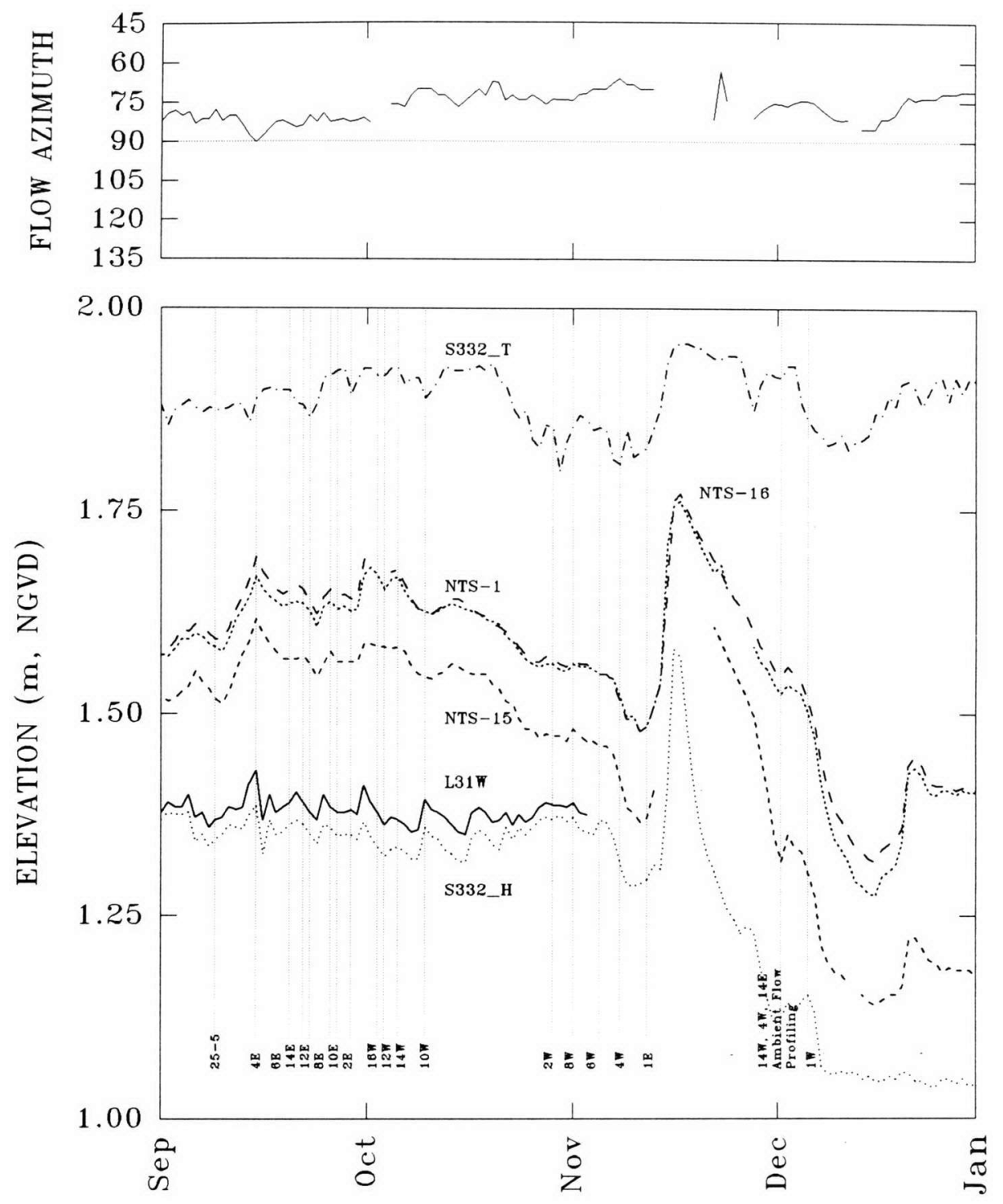

1994

Figure 38. Water levels at NTS-1, NTS-15, and NTS-16 boreholes, L-31W canal, head (inlet) and tail (outlet) of S332 (S332_H and S332_T), and groundwater flow directions during borehole flowmeter measurements. 

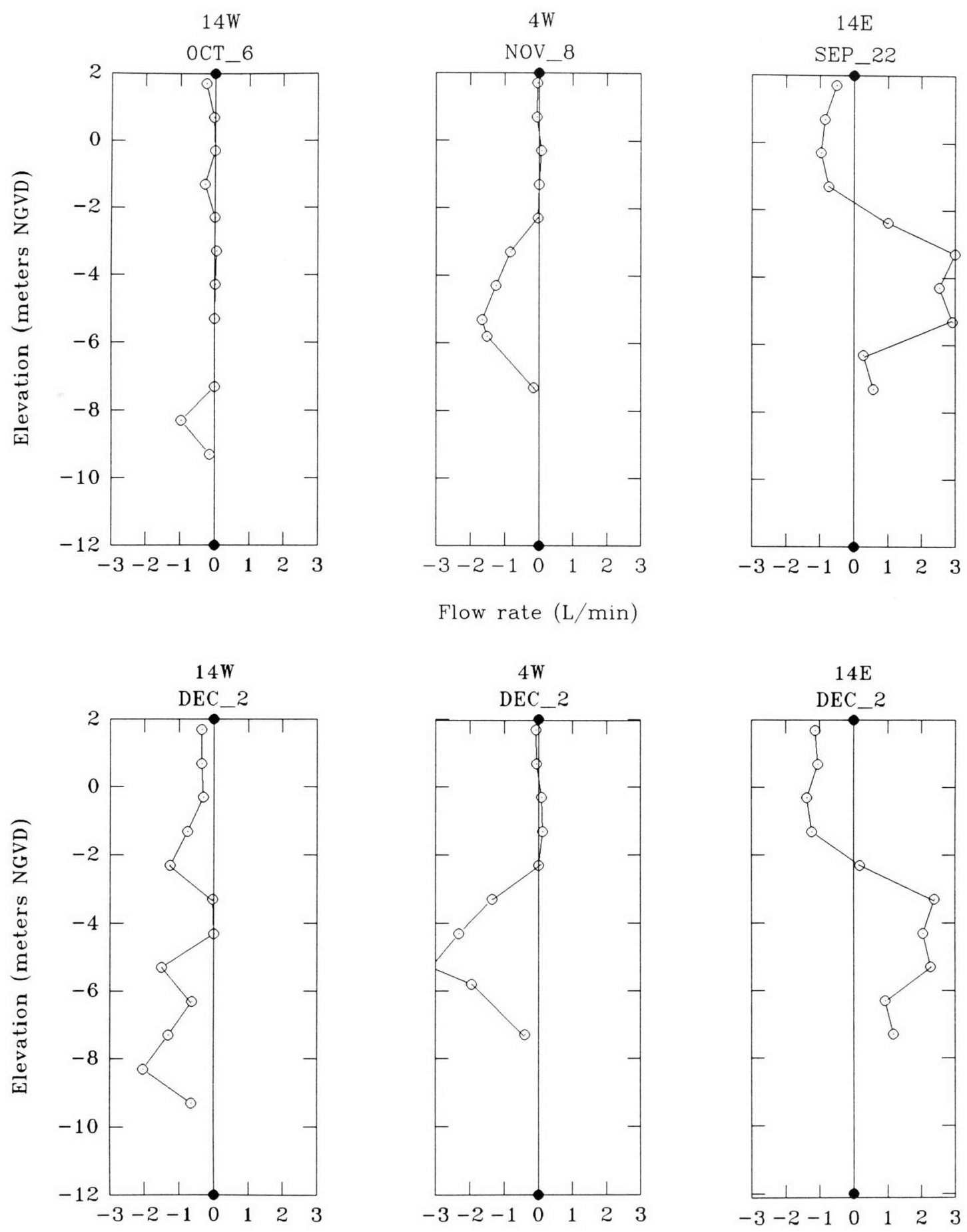

Flow rate $(\mathrm{L} / \mathrm{min})$

Figure 39. Temporal variations in ambient flow profiles in boreholes $14 \mathrm{~W}$, $4 \mathrm{~W}$, and $14 \mathrm{E}$. 
conductivity in the area, the groundwater flow direction, and the characteristics of the shallow hard layer. Based on field observations of drill penetration rate, the shallow hard layer was poorly developed on the west end of the transect. A less competent or completely absent shallow hard layer would diminish the likelihood of a head difference between the upper and lower portions of the aquifer, consistent with the general lack of vertical ambient flow in this area. Further to the east, in the center of the transect, the direction of ambient flow indicated a higher head in the upper aquifer, implying slightly less head loss in the upper aquifer compared to the lower, as groundwater flows from the west end of the transect to the center (remember, groundwater flow in the area was to the east). At the east end of the transect, flowmeter data indicate the head was slightly higher in the lower aquifer, implying greater head loss in the upper aquifer compared to the lower, as groundwater flowed from the center of the transect to the east end. These observations would be consistent with an upper aquifer that has higher $\mathrm{K}$ on the west side of the transect, and a lower aquifer that has higher $\mathrm{K}$ on the east side; in fact, this is exactly what Figures 35, 36, and 37 show.

Of course, $\mathrm{K}$ is not the only factor controlling head loss along the direction of groundwater flow; specific discharge (Darcy velocity) is also important. The specific discharge of groundwater flow in the area is not well known, but in a flat-lying system with little vertical gradient it is reasonable to suppose that the ratio of specific discharge to hydraulic conductivity remains approximately the same throughout the aquifer, so that the head remains approximately the same between the upper and lower aquifers. This would fit with the flowmeter data into a picture of an aquifer divided over 
most but not all of its extent by a reasonably continuous aquitard, the shallow hard layer. The occasional breaches in the shallow hard layer would be places where heads in the upper and lower aquifers could equilibrate, with the potential for disequilibrium increasing downgradient from the breaches, as the shallow hard layer prevents water exchange and the head distribution above and below the layer becomes more and more influenced by the local hydraulic conductivity of the rock, until another breach is encountered and upper and lower aquifers equilibrate again. In this view of the aquifer, head in the upper and lower parts may diverge by an amount controlled by the local heterogeneity in the hydraulic conductivity and the proximity of breaches in the hard layer. The nearly but not fully continuous nature of the shallow hard layer was confirmed in drilling in the Frog Pond area between the L31-W and C-111 canals, where the layer was found in five of six $15 \mathrm{~m}$ boreholes.

A deeper low-K layer at -10 meters NGVD also functions as an aquitard. There was vertical flow upward past this layer in boreholes $16 \mathrm{~W}$, 14W, and 12W on October 3, 6, and 4, respectively, 1994.

\subsection{Macrodispersivity values}

Longitudinal and transverse macrodispersivity values $\left(A_{L}\right.$ and $\left.A_{T}\right)$ were calculated with the stochastic theory of Gelhar and Axness (1983), using results from our semi-variograms (Table 2). Details of the approach are presented in Appendix IX, and results are given in Table 3. The values of $A_{T}$ are comparable to the magnitude of local-scale transverse dispersivities (on the order of 1 millimeter), consistent with the finding that local dispersivities control dispersion normal to groundwater flow in isotropic media, or in 


\begin{tabular}{|c|c|c|}
\hline & $\mathrm{A}_{\mathrm{L}}$, meters & $\mathrm{A}_{\mathrm{T}}$, meters \\
\hline \multicolumn{3}{|l|}{ Full Biscayne Aquifer } \\
\hline \multicolumn{3}{|l|}{ multiple interval approach } \\
\hline with nugget & 1.86 & 0.00120 \\
\hline without nugget & 1.85 & 0.00119 \\
\hline \multicolumn{3}{|l|}{ single interval approach } \\
\hline with nugget & 6.90 & 0.000430 \\
\hline without nugget & 0.934 & 0.000397 \\
\hline \multicolumn{3}{|l|}{ Upper Biscayne Aquifer } \\
\hline \multicolumn{3}{|l|}{ multiple interval approach } \\
\hline with nugget & 1.615 & 0.000397 \\
\hline without nugget & 0.973 & 0.000420 \\
\hline \multicolumn{3}{|l|}{ single interval approach } \\
\hline with nugget & 2.572 & 0.000305 \\
\hline without nugget & 0.971 & 0.000346 \\
\hline \multicolumn{3}{|l|}{ Lower Biscayne Aquifer } \\
\hline \multicolumn{3}{|l|}{ multiple interval approach } \\
\hline with nugget & 0.214 & 0.00151 \\
\hline without nugget & 0.202 & 0.00173 \\
\hline \multicolumn{3}{|l|}{ single interval approach } \\
\hline with nugget & 0.200 & 0.00162 \\
\hline without nugget & 0.072 & 0.00194 \\
\hline
\end{tabular}

Table 3. Longitudinal $\left(\mathrm{A}_{\mathrm{L}}\right)$ and transverse $\left(\mathrm{A}_{\mathrm{T}}\right)$ macrodispersivity values estimated from $\operatorname{lnK}$ semi-variograms using the stochastic theory of Gelhar and Axness (1983). Details presented in Appendix IX. 
anisotropic media when flow is parallel or normal to bedding (Gelhar and Axness, 1983).

Our estimates of $A_{L}$ are similar to those found through stochastic analysis of the spatial distribution of hydraulic conductivity in other aquifers (Sudicky, 1986, 0.6 m; Hess et al., 1992, 0.35-0.78 m; Rehfeldt et al., 1992 , 1.5-1.8 m), demonstrating that the longitudinal macrodispersivity controlling dispersion in the marine carbonates of the Biscayne Aquifer is not significantly different from the dispersivities that apply in unconsolidated sand and gravel aquifers (Table 4). Our best estimate of $A_{L}$ for the full Biscayne Aquifer is probably that based on the single interval semi-variograms without nugget $\left(A_{L}=0.93 \mathrm{~m}\right)$. These semi-variograms produced realistic values of $\lambda_{v}$ and $\lambda_{h}\left(0.45\right.$ and $2.26 \mathrm{~m}$, respectively), and the ratio of $\lambda_{v}$ and $\lambda_{h}$; also, the vertical semi-variograms gave an accurate estimate of the variance $\sigma_{\mathrm{Y}}{ }^{2}$

\begin{tabular}{|c|c|c|c|c|}
\hline Site & Biscayne & Columbus & Borden & Cape Cod \\
\hline Medium & Limestone & \multicolumn{3}{|c|}{ Unconsolidated Clastic Sediments } \\
\hline$\sigma_{\mathrm{Y}}{ }^{2}(\mathrm{~m})$ & 2.3 & 2.7 & 0.29 & 0.24 \\
\hline$\lambda_{\mathrm{h}}(\mathrm{m})$ & 2.3 & 4.8 & 2.8 & 3.5 \\
\hline$\lambda_{\mathrm{v}}(\mathrm{m})$ & 0.45 & 0.8 & 0.12 & 0.19 \\
\hline $\mathrm{A}_{\mathrm{L}}(\mathrm{m})$ & 0.93 & 1.6 & 0.61 & 0.67 \\
\hline $\mathrm{A}_{\mathrm{T}}(\mathrm{m})$ & $4.0 \times 10^{-4} *$ & few $10^{-3}$ & N.A. & $10^{-6}-10^{-5 *}$ \\
\hline
\end{tabular}

Table 4. Comparison of InK statistics and calculated macrodispersivities for four aquifers (boxes marked with ${ }^{*}$ are transverse vertical or horizontal, and " are transverse horizontal). The variance $\left(\sigma_{\mathrm{Y}}{ }^{2}\right)$ for the Biscayne Aquifer is the average from the vertical and horizontal semivariograms, and the sample variance. 
(based on agreement with the variance indicated by the standard deviation values in Figures 28a, 28b and 28c). In comparison, the multiple interval approach overpredicted the variance, led to a rather large $\lambda_{\mathrm{v}}(1.69 \mathrm{~m})$, and gave $\lambda_{h}<\lambda_{v}$, unrealistic results (especially the latter) for flat-lying sedimentary rocks of the Biscayne Aquifer.

The macrodispersivity calculated from a semi-variogram with a nugget effect is higher than that from the corresponding semi-variogram without a nugget effect (see second column, Table 3). This was also noted in the calculated macrodispersivities at Cape Cod, Massachusetts (Hess et al., 1992).

The best estimate of longitudinal macrodispersivity for the Lower Biscayne Aquifer $\left(A_{L}=0.20 \mathrm{~m}\right)$ is much lower than that of the Upper Biscayne Aquifer $(0.97 \mathrm{~m})$, indicating that dispersion will be different between the layers above and below the shallow hard layer that acts as an aquitard at the study site. As it is at least a partial barrier to groundwater flow, the shallow hard layer will likely inhibit the vertical migration of solutes in some areas of the Biscayne Aquifer. The importance and scale of this effect will depend on the lateral extent of the shallow hard layer, something poorly known at this time (though it has been observed in several boreholes in the vicinity of L-31W).

The stochastic analysis of Gelhar and Axness (1983) also leads to an analytical expression for the anisotropy ratio, $\mathrm{K}_{\mathrm{h}} / \mathrm{K}_{\mathrm{v}}$ (the ratio of horizontal to vertical hydraulic conductivity): 


$$
K_{h} / K_{v}=\exp \left[\sigma_{Y}^{2}\left(g_{33}-g_{11}\right)\right]
$$

where $g_{33}$ and $g_{11}$ are functions of $\lambda_{h} / \lambda_{v}$ defined in Appendix IX. Using results from the full Biscayne Aquifer semi-variograms based on the singleinterval and multiple-interval without a nugget, the anisotropy ratio for the Biscayne Aquifer at the study site is estimated to be about 4 . 


\section{CHAPTER 6 \\ SUMMARY AND CONCLUSIONS}

Borehole flowmeter measurements were used to determine the spatial distribution of hydraulic conductivity and to estimate dispersivity in the Biscayne Aquifer. Measurements were made in 18 boreholes each about 12 meters deep along an east-west transect in the northwestern part of Taylor Slough, Everglades National Park.

Core boring in some of the boreholes revealed the presence of a hard, $\sim 33 \mathrm{~cm}$ thick dense micritic limestone with very low porosity at about $-4 \mathrm{~m}$ NGVD. Measurements of ambient groundwater flow in several of the boreholes revealed the presence of vertical flow (upward or downward, depending on the borehole) around this "shallow hard layer", demonstrating that, at least locally, the layer acts as an aquitard, supporting vertical head gradients and restricting the vertical movement of water. A second low- $\mathrm{K}$ layer at about $-10 \mathrm{~m}$ NGVD was found to act in a similar fashion at the western end of the transect. The presence of these and other relatively thin, low-K beds could be a key consideration in modeling the movement of water and solutes in the Biscayne Aquifer. These beds could significantly retard the vertical movement of water and solutes. Such beds would most likely not be detected by standard pump or slug tests, as their contribution to transmissivity would be trivial (their main effect is on vertical, not horizontal, flow). In addition, they may not show up in driller's logs from drilling operations using large rigs, as they are relatively thin and would slow the penetration rate of a large rig only briefly (in comparison to their large effect on penetration rate with the small drill rig used in this study). Careful continuous coring and 
borehole flowmeter measurements are the best means of identifying thin low$\mathrm{K}$ beds. The ambient borehole flowmeter data and drill logs from both sides of the L-31W canal suggest that permeable rocks above and below the shallow hard layer are largely but not completely separated by the layer, and that small areas were the layer is missing or poorly developed provide local spots for equilibration of head between the upper and lower aquifers.

The geometric mean conductivities of the full, Upper, and Lower Biscayne Aquifers (Upper and Lower are separated by the shallow hard layer) are $0.18,0.29$, and $0.056 \mathrm{~m} / \mathrm{s}$, respectively based on the single-interval approach. These values are dependent on the average hydraulic conductivity value for the full aquifer in the study area $(0.18 \mathrm{~m} / \mathrm{s})$, estimated from data in Fish and Stewart (1991). Not surprisingly, since the full aquifer is a combination of two zones representing different populations, the variance of the natural log of hydraulic conductivity is larger (2.5) than for the Upper and Lower aquifers separately (about 1.9 and 2.1, respectively). Vertical and horizontal correlation lengths $\left(\lambda_{v}\right.$ and $\left.\lambda_{h}\right)$ for the natural log of hydraulic conductivity $(\mathrm{Y})$ were determined by fitting exponential autocovariance models to experimental semi-variograms of the $\mathrm{Y}$ data. The best estimates of vertical and horizontal correlation lengths for the full Biscayne Aquifer are 0.45 and $2.26 \mathrm{~m}$, respectively, values that seem reasonable in comparison to those found for other heterogeneous sedimentary formations and that are in realistic proportion to each other $\left(\lambda_{\mathrm{h}} / \lambda_{\mathrm{v}}=5.0\right)$. The vertical and horizontal semi-variograms produced somewhat different variance estimates. Further measurements would be useful in confirming whether or not this is a true indication of the phenomenon of zonal anisotropy, previously described in the 
geostatistical literature on ore grades but not aquifer hydraulic properties. This could be relevant to the estimation of dispersivity from spatially distributed $\mathrm{Y}$ data, as present theories for this do not explicitly consider the possibility of zonal anisotropy.

The stochastic theory of Gelhar and Axness (1983) was used with our variance and correlation length data to estimate longitudinal "macrodispersivity" ( $A_{L}$, the dispersivity applicable to field-scale solute transport problems) for the Biscayne Aquifer. This report is believed to be the first such application of the theory to carbonate rock. The best estimate of $A_{L}$ for the full Biscayne Aquifer, $0.87 \mathrm{~m}$, is similar to stochastic $A_{L}$ values derived for unconsolidated sand and gravel aquifers in Massachusetts (0.350.78 m), Mississippi (1.5-1.8 m), Denmark (0.3-0.5 m), and Ontario (0.60 $\mathrm{m})$. While these latter aquifers are very different geologically from the marine carbonates of the Biscayne, there is apparently a fundamental similarity in dispersion in spite of the large differences in lithology and sedimentary petrology. The estimate of $A_{L}$ for the Lower Biscayne Aquifer $(0.23 \mathrm{~m})$ was lower than that for the Upper Biscayne Aquifer $(1.1 \mathrm{~m})$, though there is significant uncertainty in the former value because of the small number of points used to construct the semi-variograms. Rough estimates of transverse macrodispersivity were all about a millimeter, consistent with the conclusion from previous work that local-scale dispersivities on the order of a millimeter control transverse dispersion for steady flow parallel to bedding. The stochastic theory also provides a means of estimating the anisotropy ratio for hydraulic conductivity of the aquifer from the variance and correlation 
scales. The ratio of horizontal to vertical hydraulic conductivity for the Biscayne Aquifer was found to be about 4 .

The dispersivities and hydraulic conductivity distributions reported here will prove useful in the numerical modeling of solute transport in the Biscayne Aquifer in the Taylor Slough area. High priorities for future investigations include measurements along transects with orientations other than east-west, to investigate the possibility of significant anisotropy in the horizontal plane, and further coring and borehole flow measurements to define the spatial extent of important low-K layers and facies changes that may affect dispersivity, hydraulic conductivity distribution and vertical hydraulic gradient.

The vertical hydraulic conductivity of low-K layers (which cannot be determined with the borehole flowmeter, but can be measured on core samples with a permeameter) would also be useful information for groundwater flow and transport modeling, as thin low-K layers may dominate the vertical resistance to water and solute migration. A similar study on the determination of the vertical hydraulic conductivity would also be applicable for the low-K soil layer which will be useful in modeling surface and groundwater interaction. 


\section{BIBLIOGRAPHY}

Appel, C. A. 1973. Electrical-analog model study of a hydrologic system in southeast Florida. U. S. Geological Survey Open-File Report FL$73004,51 \mathrm{pp}$.

Atkinson, T. C., D. I. Smith, J. J. Lavis, and R. J. Whitaker. 1973. Experiments in tracing underground waters in limestones. Journal of Hydrology 19: 323-349.

Bear, J. 1972. Dynamics of Fluids in Porous Media. Dover Publications, New York, 764 pp.

Bear, J. 1979. Hydraulics of Groundwater. McGraw-Hill, Inc., New York, 569 pp.

Bjerg, P. L., K. Hinsby, T. H. Christensen, and P. Gravesen. 1992. Spatial variability of hydraulic conductivity of an unconfined sandy aquifer determined by a mini-slug test. Journal of Hydrology 136: 107-121

Boggs, J. M., S. C. Young, and L. S. Beard. 1992. Field study of dispersion in a heterogeneous aquifer: 1. Overview and site description. Water Resources Research 28: 3281-3291.

Bouwer, H., and R. C. Rice. 1976. A slug test for determining hydraulic conductivity of unconfined aquifers with completely or partially penetrating wells. Water Resources Research 12: 423-428.

Bowman, R. S., and J. F. Gibbens. 1992. Difluorobenzoates as nonreactive tracers in soil and groundwater. Ground Water 30(1): 8-14.

Bredehoeft, J. D., H. Cooper, Jr., and I. S. Papadopulos. 1966. Inertial and storage effects in well-aquifer systems: An analog investigation. Water Resources Research 2: 697-707. 
Browder, J. A., P. J. Gleason, D. R. Swift. 1994. Periphyton in the Everglades: Spatial variation, environmental correlates, and ecological implication, In: Davis, S. M., and J. C. Ogden (editors), Everglades: The ecosystem and its restoration, St. Lucie Press, Delray Beach, p. 379-418.

Causaras, C. R. 1987. Geology of the surficial aquifer system, Dade County, Florida. U. S. Geological Survey Water Resources Investigations Report 86-4126, 240 pp., 3 sheets.

Choqette, P. W., and L. C. Pray, 1970. Geologic nomenclature and classification of porosity in sedimentary carbonates. American Association of Petroleum Geologists Bulletin 54: 207-250.

Clark, I. 1979. Practical Geostatistics, Elsevier Applied Science Publishers Ltd., London, 129 pp.

Davis, S. N., D. J. Campbell, H. W. Bentley, and T. J. Flynn. 1985. Groundwater tracers, Robert Kerr Environmental Research Laboratory, $200 \mathrm{pp}$.

Davis, S. M. 1994. Phosphorus inputs and vegetation sensitivity in the Everglades, In: Davis, S. M., and J. C. Ogden (editors), Everglades: The ecosystem and its restoration, St. Lucie Press, Delray Beach, p. 357-378.

Davis, S. M., and J. C. Ogden (editors). 1994. Everglades: The ecosystem and its restoration, St. Lucie Press, Delray Beach, 826 pp.

Dominico, P. A., and F. W. Schwartz. 1990. Physical and Chemical Hydrogeology, Wiley and Sons, Inc., New York, 824 pp.

Dominico, P. A., and G. A. Robbins. 1984. A dispersion scale effect in model calibrations and field tracer experiments. Journal of Hydrology 70: $123-132$.

Fennema, R. J. 1988. Groundwater tracer study in Northeast Taylor Slough. Florida International University, $23 \mathrm{pp}$. 
Fetter, C. W. 1994. Applied Hydrogeology, Macmillan College Publishing Company, New York, Inc., 691 pp.

Fish, J. E., and M. Stewart. 1991. Hydrogeology of the surficial aquifer system, Dade County, Florida. U. S. Geological Survey, Water Resources Investigation Report 90-4108, 50 pp, 11 sheets.

Freeze, A. R., and J. A. Cherry. 1979. Groundwater, Prentice-Hall, Inc., New Jersey, $604 \mathrm{pp}$.

Freyberg, D. L. 1986. A natural gradient experiment on solute transport in a sand aquifer: Spatial moments and the Advection and dispersion of nonreactive tracers. Water Resources Research 22: 2031-2046.

Gelhar, L. W., and C. L. Axness. 1983. Three-dimensional stochastic analysis of macrodispersion in aquifers. Water Resources Research 19: 61- 80 .

Gelhar, L. W., C. Welty, and K. R. Rehfeldt. 1992. A critical review of data on field-scale dispersion in aquifers. Water Resources Research 28(7): 955-1974.

Gelhar, L. W., 1993. Stochastic Subsurface Hydrology, Prentice Hall, New Jersey, $390 \mathrm{pp}$.

Genereux, D. P., and J.D.A. Guardiario. 1995. Estimating dispersivity from the spatial distribution of hydraulic conductivity in the Biscayne Aquifer of southeast Florida: Borehole flowmeter measurements and stochastic analysis. EOS, Transactions, American Geophysical Union 75(44): 261. Presented at the American Geophysical Union Fall Meeting, San Francisco, California, December 1995.

Gunderson, L. H., and J. R. Snyder. 1994. Fire patterns in the Southern Everglades, In: Davis, S. M., and J. C. Ogden (editors), Everglades: The Ecosystem and its Restoration, St. Lucie Press, Delray Beach, p. 291-306.

Golden Software, 1993. Surfer Reference Manual, Colorado. 
Halley, R. B., and C. C. Evans. 1983. The Miami Limestone: A guide to selected outcrops and their interpretation, Miami Geological Society, $67 \mathrm{pp}$.

Henley, S., 1981. Nonparametric Geostatistics, Elsevier Applied Science Publishers, London.

Hess, K. M., S. H. Wolf, M. A. Celia. 1992. Large-scale natural gradient tracer test in sand and gravel, Cape Cod, Massachusetts: 3. Hydraulic conductivity variability and calculated macrodispersivities. Water Resources Research 28(8): 2011-2027.

Hinsby, K., P. L. Bjerg, L. J. Andersen, B. Skov, and E. Clausen. 1992. A mini slug test method for determination of local hydraulic conductivity of an unconfined sandy aquifer. Journal of Hydrology 136: 87-106.

Hoffmeister, J. E., K. W. Stockman, and H. G. Multer. 1967. Miami Limestone of Florida and its recent Bahamian Counterpart. Geological Society of America Bulletin 78: 175-190.

Hufschmied, P. 1986. Estimation of three-dimensional statistically anisotropic hydraulic conductivity field by means of single well pumping tests combined with flowmeter measurements. Hydrogéologie 2: $163-174$.

Isaaks, E. H., and R. M. Srivastava. 1989. Applied Geostatistics, Oxford University Press, New York, Inc. 561 pp.

Jensen, K. H., K. Bitsch, and P. L. Bjerg. 1993. Large-scale dispersion experiments in a sandy aquifer in Denmark: Observed tracer movements and numerical analyses. Water Resources Research 29(3): 673-696.

Johnson, A. I., 1967. Specific yield - Compilation of specific yields for various materials. U.S. Geological Survey Water Supply Paper 1662D, 74 pp. 
Jones, W., 1984. Dye tracer tests in karst areas. National Speleological Society Bulletin 26: 3-9.

Journel, A. G., and Ch. J. Huijbregts. 1978. Mining Geostatistics, Academic Press, San Diego, 600 pp.

Killey, R. W. D., and G. L. Moltyaner. 1988. Twin Lake tracer tests: Setting, methodology, and hydraulic conductivity distribution. Water Resources Research 24: 1585-1612.

Leap, D. I., and P. M. Belmonte. 1992. Influence of pore pressure on apparent dispersivity of a fissured dolomitic aquifer. Ground Water 30 (1): $87-95$.

LeBlanc, D. R., S. P. Garabedian, K. M. Hess, L. W. Gelhar, R. D. Quadri, K. G. Stollenwerk, and W. W. Wood. 1991. Large-scale natural gradient tracer test in sand and gravel, Cape Cod, Massachusetts 1. Experimental design and observed tracer movement. Water Resources Research 27: 895-910.

Levy, B. S., and R. M. Chambers. 1987. Bromide as a conservative tracer for soil-water studies. Hydrological Processes 1: 385-389.

Light, S.S., and J.W. Dineen. 1994. Water control in the Everglades: A historical perspective, In: Davis, S. M., and J. C. Ogden (editors), Everglades: The ecosystem and its restoration, St. Lucie Press, Delray Beach, p. 47-84.

Matheron, G. 1963. Principles of geostatistics. Economic Geology 58: 1246-1266.

Mazzotti, F. J., and L. A. Brandt. 1994. Ecology of the American alligator in a seasonally fluctuating environment. In: Davis, S. M., and J. C. Ogden (editors), Everglades: The ecosystem and its restoration, St. Lucie Press, Delray Beach, p. 485-506.

Mendenhall, W., and L. Ott. 1980. Understanding Statistics, Duxbury Press, North Scituate, 459 pp. 
Moltyaner, G. L., and R. W. D. Killey. 1988. Twin Lake tracer tests: Longitudinal dispersion. Water Resources Research 24(10): 16131627.

Moltyaner, G. L., and R. W. D. Killey. 1988. Twin Lake tracer tests: Transverse dispersion. Water Resources Research 24(10): 1628-1637.

Molz, F. J., R. H. Morin, A. E. Hess, J. G. Melville, and O. Guven. 1989. The impeller meter for measuring aquifer permeability variations: Evaluation and comparison with other tests. Water Resources Research 5(7): $1677-1683$.

Molz, F. J., S. C. Young. 1993. Development and application of borehole flowmeters for environmental assessment. The Log Analyst, JanuaryFebruary, p. 13-23.

Myers, R. L., and J. J. Ewel. 1990. Ecosystems of Florida, University of Central Florida Press, Orlando,765 pp.

Nordlie, F. G. 1990. Rivers and Springs. In: Myers, R. L., and J. J. Ewel. 1990. Ecosystems of Florida, University of Central Florida Press, Orlando, $765 \mathrm{pp}$.

Parker, G. G., G. E. Ferguson, and S. K. Love. 1955. Water resources of Southeastern Florida. U. S. Geological Survey Water-Supply Paper $1255,965 \mathrm{pp}$.

Ramos, H. R. 1986. A mathematical model of the strength capacity and modulus of elasticity of the Miami Limestone in the Dade county area as a function of porosity and density, M.S. Thesis, Florida International University, Miami, $147 \mathrm{pp}$.

Rehfeldt, K. R., P. Hufschmied, L. W. Gelhar, M. E. Schaefer. 1989a. Measuring hydraulic conductivity with the borehole flowmeter. Electric Power Research Institute, Report EN-6511, Palo Alto, California. 
Rehfeldt, K. R., L. W. Gelhar, J. B. Southard, A. M. Dasinger. 1989 b. Estimates of macrodispersivity based on analyses of hydraulic conductivity variability at the MADE site. Electric Power Research Institute, Report EN-6405, Palo Alto, California.

Rehfeldt, K. R., J. M. Boggs, L. W. Gelhar. 1992. Field study of dispersion in a heterogeneous aquifer. 3. Geostatistical analysis of hydraulic conduc-tivity. Water Resources Research 28(12): 33093324.

Rowell, D. L. 1994. Soil Science: Methods and applications, Longman Scientific and Technical, England, $350 \mathrm{pp}$.

Royle, A.G. 1979. Why geostatistics? Engineering and Mining Journal 180(5): 92-102.

Sandefur, R. L., and D. C. Grant. 1980. Applying geostatistics to roll-front uranium in Wyoming. In: Royle, A. G. (ed.), Geostatistics. McGraw Hill, New York, pp. 127-143.

Sauty, Jean-Pierre. 1980. An analysis of hydrodispersive transfer in aquifers. Water Resources Research 16(1): 145-158.

Segol, G. and G. F. Pinder. 1976. Transient simulation of saltwater intrusion in southeastern Florida. Water Resources Research 12(1): 65-70.

Smart, P. L., and I. M. S. Laidlaw. 1977. An evaluation of some fluorescent dyes for water tracing. Water Resources Research 13(1): 15-33.

Springer, R. K., and L. W. Gelhar. 1991. Characterization of large-scale aquifer heterogeneity in glacial outwash by analysis of slug tests with oscillatory responses, Cape Cod, Massachusetts. U. S. Geological Survey Toxic Substances Hydrology Program, Water Resources Investigation Report 91-4034, p. 36-40.

SRIE Proprietary Limited. 1989. Kstat version 2.20 User Manual, Sydney, $58 \mathrm{pp}$. 
Sudicky, E. A. 1986. Natural gradient experiment on solute transport in a sand aquifer: Spatial variability of hydraulic conductivity and its role in the dispersion process. Water Resources Research 22: 2069-2082.

Turner Designs. 1983. Fluorometric facts: Flow measurements in sanitary sewers by dye dilution, $9 \mathrm{pp}$.

Turner Designs. 1990. Fluorometric facts: A practical guide to flow measurement, $25 \mathrm{pp}$.

Van Der Kamp, G. 1976. Determining aquifer transmissivity by means of well response tests: The underdamped case. Water Resources Research 12: 71-77.

Vomocil, J. A. 1965. Porosity, In: C. A. Black (editor), Methods of soil analysis, American Society of Agronomy, Madison Wisconsin, pp. 299-314.

Welty, C., and L. W. Gelhar. 1989. Evaluation of longitudinal dispersivity from tracer test data. Ralph M. Parsons Laboratory for Water Resources and Hydrodynamics, Report No. 320, 107 pp.

Whalen, P. J., VanArman, J. Mulliken, J., Swift, D., Bellmund, S., Worth, D., Fontaine, T. D., Gulick, L., Formati, S. 1992. Surface water improvement and management plan for the Everglades. South Florida Water Management District, West Palm Beach, Florida.

White, P. S. 1994. Synthesis: Vegetation pattern and process in the Everglades ecosystem, In: Davis, S. M., and J. C. Ogden (editors), Everglades: The ecosystem and its restoration, St. Lucie Press, Delray Beach, p. 445-458.

Wilson, J. F. Jr. 1968. Fluorometric procedures for dye tracing: Techniques for water resources investigations of the United States Geological Survey, Book 3: Applications of hydraulics, Chapter A12, 31 pp.

Zar, J. H. 1984. Biostatistical Analysis, Prentice-Hall, Inc., New Jersey, $718 \mathrm{pp}$. 
APPENDIX I

Borehole 25-5 Logs 


\section{CPRE BRRING 25-5}

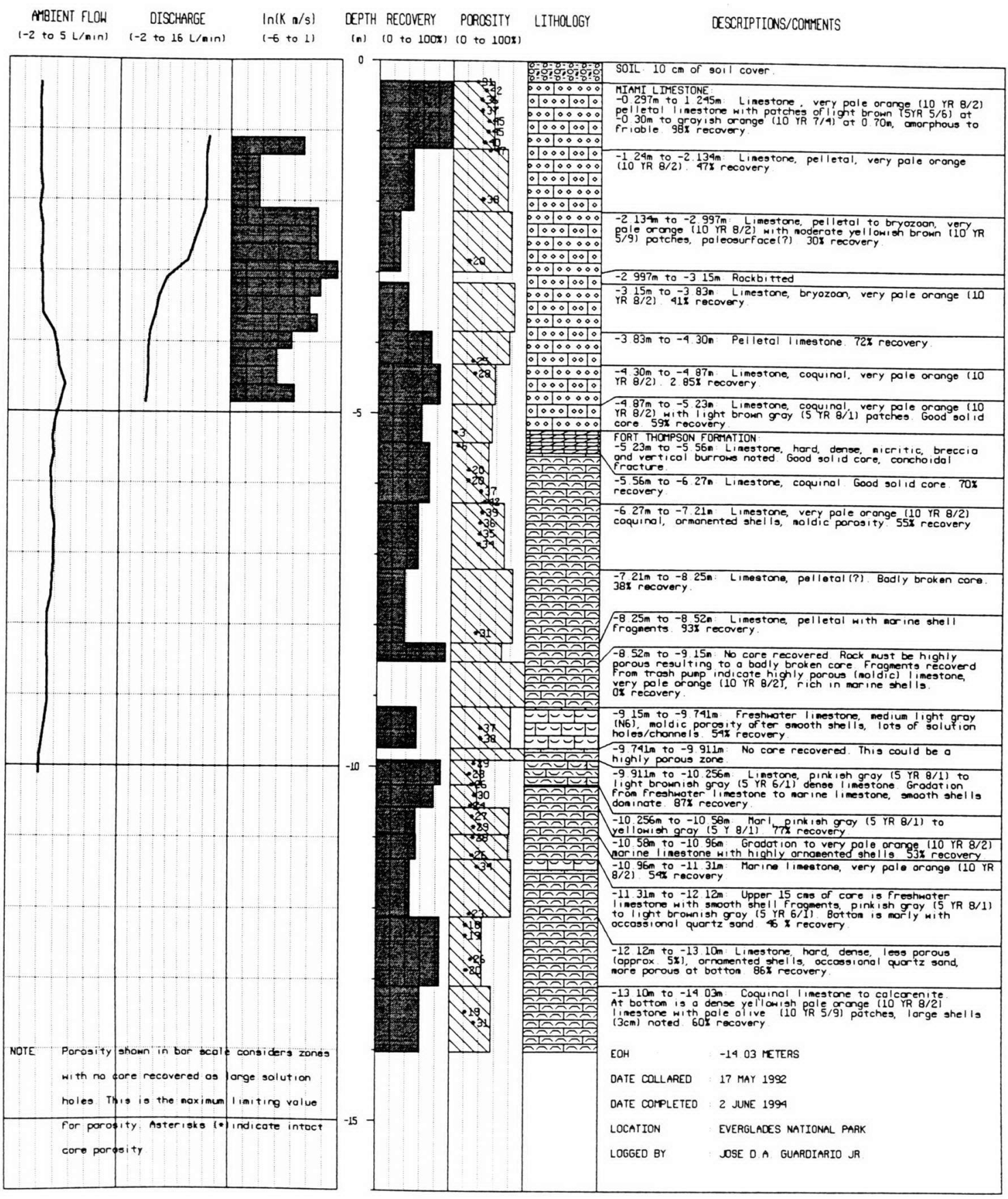




\section{APPENDIX II}

Flowmeter Calibration and Calibration Curves 
The following items are needed for borehole flowmeter measurements:

- $\quad$ Flowmeter Surface Electronic Unit

- Flowmeter Probe

- $\quad$ Flowmeter Cable with depth markings

- $\quad$ Flowmeter Packer Assembly

- $\quad$ Packer Rubber Glands

- $\quad 1 / 4$ " diameter, 30-meter Nalgene tubing with appropriate connectors

- Compressed air tank

- Pressure regulator

- Power generator (105 to $130 \mathrm{VAC}, 58$ to $62 \mathrm{Hertz}$ )

- Cable and iron spike for grounding

- $\quad 3 / 4$ " diameter, 30-meter garden hose

- Electric water pump with 40 liters/minute maximum discharge

- Control Valve

- $\quad$ Two buckets, one graduated

- Timer

- Pressure Transducer and Datalogger

- $\quad$ Measuring Tape

A. Steps in Setting-up the Flowmeter (after Tisco, Inc. Electromagnetic Borehole Flowmeter System Operation)

1. Check that the power source is 105 to $130 \mathrm{VAC}, 58$ to $62 \mathrm{Hertz}$, and properly grounded.

2. Check the packer assembly for wear and tear of the rubber gland, and change the rubber gland when needed. 
3. Connect the compressed air line to the packer assembly and to the regulator on the compressed air tank. Check connection for air leaks.

4. Adjust the "meter factor" setting on the flowmeter surface electronic unit to match the meter factor printed on the label of the probe.

5. The surface electronic unit must be off when connecting and disconnecting the probe to prevent the latter from being damaged.

6. Connect the probe to the cable, making sure that the large pin of the probe aligns with the mark on the cable connector.

7. Connect the cable to the input connector of the surface electronic unit.

8. Lower the probe into the calibration set-up (e.g., 4" diameter PVC pipe) in between the inflow and outflow pipes or into the borehole below the water level. The probe must be in the water whenever the flowmeter is on to prevent it from overheating.

9. Inflate the packer to a maximum differential pressure of $15 \mathrm{psi}$.

10. Turn on the power and allow the system to warm up for at least 30 minutes before taking any measurements.

B. Steps in calibrating the flowmeter

A laboratory apparatus built of PVC pipe was used for calibration.

1. Set a bucket (which need not be graduated) under a faucet and fill it with water. Let the faucet run to keep the bucket filled as water is pumped from it.

2. Connect a control valve between the $3 / 4$ " intake pipe and the pump to adjust the flow rate.

3. Set the 4" diameter PVC pipe upright, and attach a 3/4" garden hose between the PVC pipe and the pump. 
4. Start the pump and allow continuous flow of water through the set-up to eliminate air blocked in the hose. Stop the pump as soon as no air bubbles are observed in the PVC pipe.

5. Plug the inner hole of the probe with a stopper before lowering it into the PVC pipe to prevent any flow through the hole, then follow steps 8 to 10 of Section A.

6. After the system has warmed up, adjust the zero control so that the digital display reads zero.

7. Turn the system off, deflate the packer, remove the probe, remove the stopper, return the probe into the PVC pipe, and inflate the packer. Turn the system back on and start the pump at its maximum flow rate.

8. Allow the system to stabilize such that the digital display is within \pm 0.02 $\mathrm{L} / \mathrm{min}$.

9. Simultaneously take flowmeter readings at 5-second intervals while filling up the graduated bucket at the discharge pipe. Take note of the time to fill up the bucket for computation of the volumetric discharge rate. Make two trials.

10. Reduce the flow rate by adjusting the control valve.

11. Repeat steps 8 to 10 until there are at least three or four different flow rate measurements (i.e. $0,5,10,15 \mathrm{~L} / \mathrm{min}$ ).

12. Calculate the regression line of the relation between flowmeter readings and actual flow rate, with the latter as the dependent variable.

C. Steps in taking ambient and induced flow rates in the field An ambient flow profile must be taken first before any pumping is done in the well. Ambient flow profiles are taken without any pumping. 
1. Follow steps 1 to 10 of Section A to set-up the flowmeter at the first point of measurement.

2. Record the water level in the well.

3. As soon as the readings in the display stabilize within $\pm 0.02 \mathrm{~L} / \mathrm{min}$, start taking readings at 5 second intervals for two minutes.

4. Deflate the packer, move the probe to a new location, inflate the packer, allow the system and the aquifer to stabilize (within $+0.02 \mathrm{~L} / \mathrm{min}$ ), and begin taking readings at the new depth.

5. Repeat steps 2 to 4 until the well is completely logged.

6. When doing the induced flow, check the actual pump discharge flow rate with a graduated cylinder and a timer.

7. When logging is finished turn the system off then remove the probe from the well. The cable can now be detached from the probe and the surface electronic unit.

D. Calibration lines

For measurements made in October-December 1994, the calibration apparatus was taken to the field, and used before and after measurements in each borehole. In this way, a separate calibration line was determined and used with measurements from each borehole. For earlier borehole measurements in September 1994, calibration lines were determined through measurements with the same calibration apparatus in the lab. Table II shows each calibration line determined, and which borehole data it was applied to (the table continues on the next page). Plots of the calibration lines follow Table II. 


\begin{tabular}{|c|c|c|}
\hline Date & Calibration Line & Borehole(s) \\
\hline 4 Sept 1994 & $y=0.0459+0.9952 x$ & $25-5$ \\
\hline 13 Sept 1994 & $y=0.0705+0.9889 x$ & $4 \mathrm{E}, 6 \mathrm{E}, 8 \mathrm{E}, 12 \mathrm{E}, 14 \mathrm{E}$ \\
\hline 27 Sept 1994 & $y=0.9817 x$ & $2 \mathrm{E}, 10 \mathrm{E}$ \\
\hline 3 Oct 1994 & $y=0.9792 x$ & $16 \mathrm{~W}$ \\
\hline 4 Oct 1994 & $y=-0.0003+0.9807 x$ & $12 \mathrm{~W}$ \\
\hline 6 Oct 1994 & $\mathrm{y}=0.0221+1.0116 \mathrm{x}$ & $14 \mathrm{~W}$ \\
\hline 10 Oct 1994 & $y=0.2650+1.0094 x$ & $10 \mathrm{~W}$ \\
\hline 27 Oct 1994 & $y=0.1454+1.0107 x$ & not used with field data \\
\hline 29 Oct 1994 & $\mathrm{y}=0.1557+1.0729 \mathrm{x}$ & $2 \mathrm{~W}$ \\
\hline 1 Nov 1994 & $y=0.1652+1.0811 x$ & $8 W$ \\
\hline 5 Nov 1994 & $y=0.1352+1.3661 x$ & $6 \mathrm{~W}$ \\
\hline 8 Nov 1994 & $y=0.0684+1.0244 x$ & $4 \mathrm{~W}$ \\
\hline 12 Nov 1994 & $\mathrm{y}=-0.0011+1.0752 \mathrm{x}$ & $1 \mathrm{E}$ \\
\hline 6 Dec 1994 & $y=0.0047+1.1161 x$ & $1 \mathrm{~W}$ \\
\hline
\end{tabular}

Table II. Calibration lines used to transform flowmeter readings to actual flow rates. 

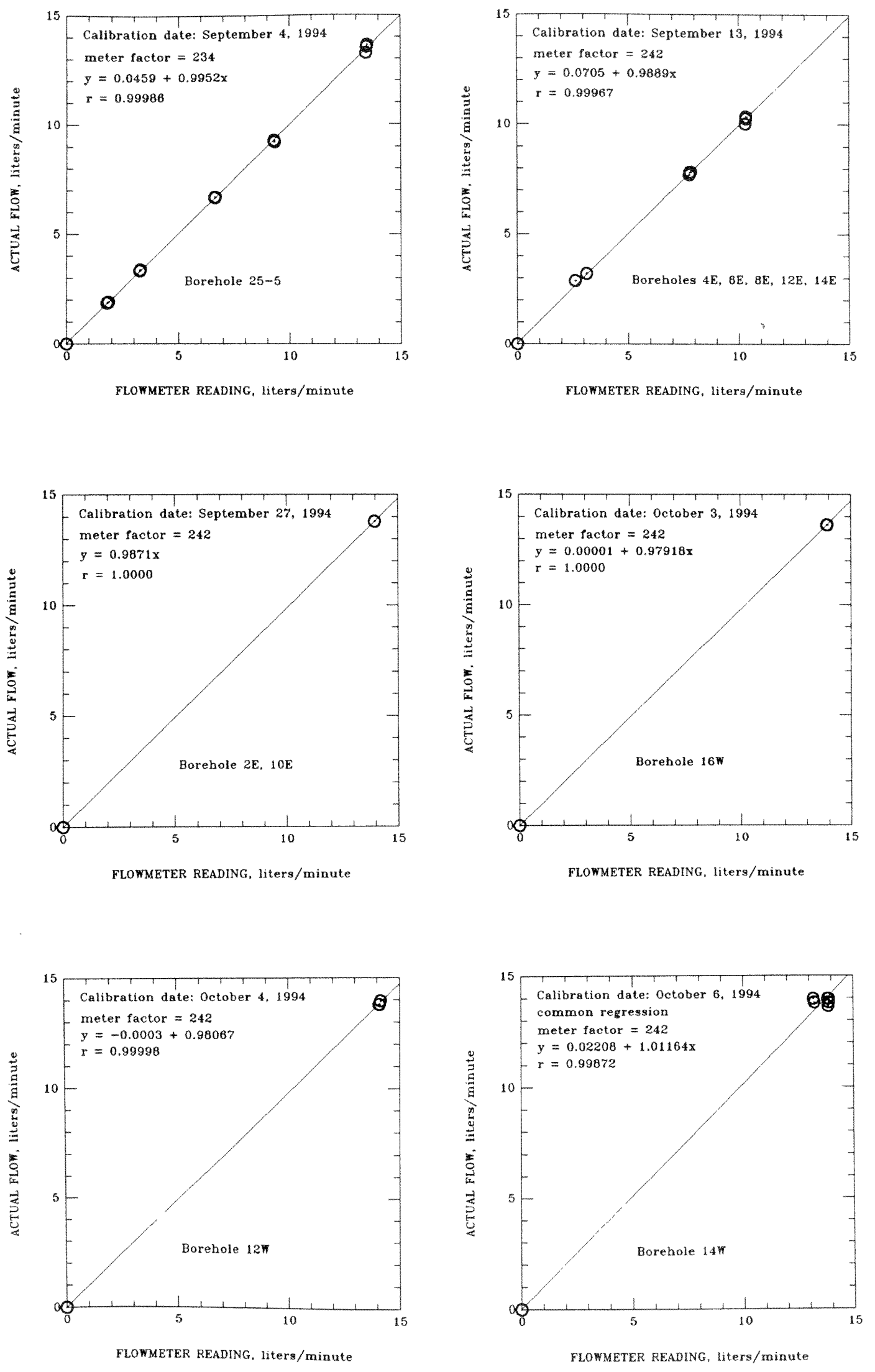

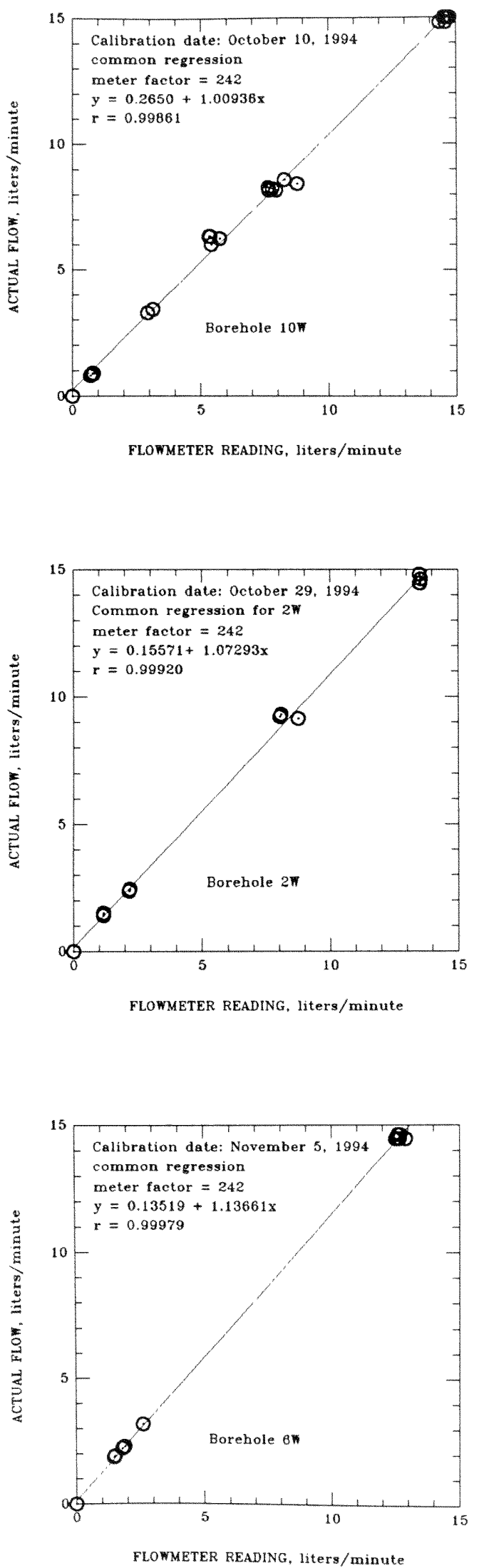
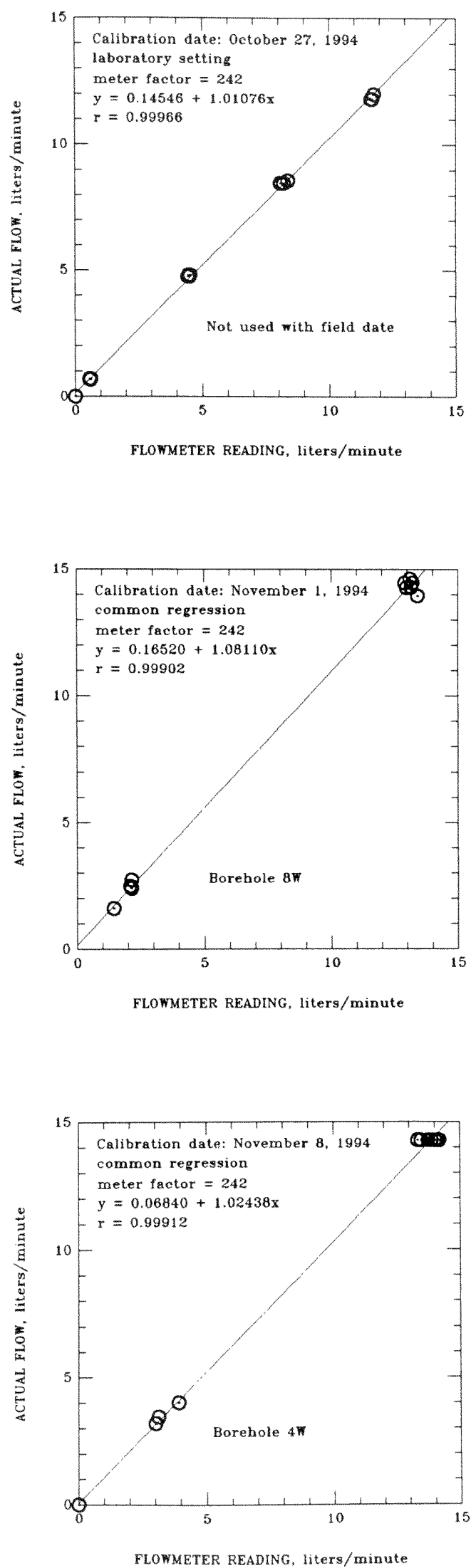

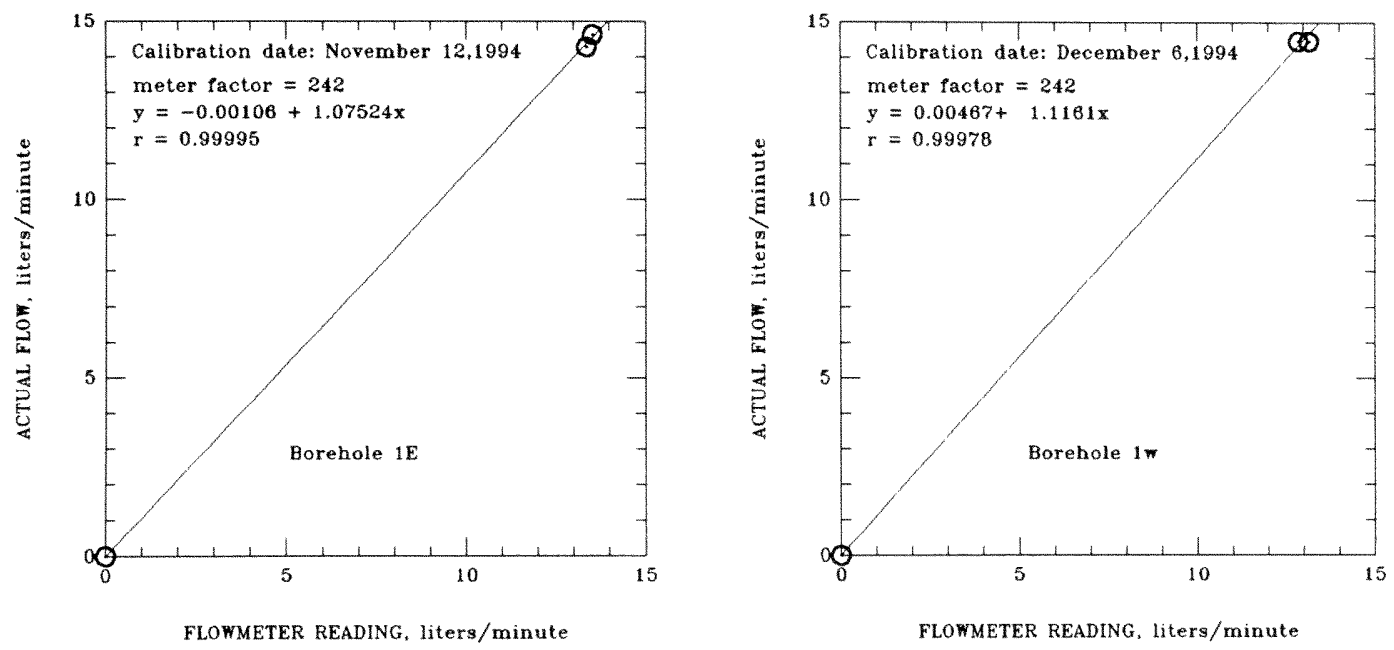


\section{APPENDIX III}

Estimation of Average Hydraulic Conductivity At The Test Site Based On Existing Aquifer Tests 
Fish and Stewart (1991) give the estimates of hydraulic conductivity based on pump tests in seven wells near the test site.

\begin{tabular}{|c|c|c|}
\hline Well & $\begin{array}{c}\text { Distance from study } \\
\text { site }(\mathrm{km})\end{array}$ & $\begin{array}{c}\text { Hydraulic conductivity } \\
\text { (feet/day) }\end{array}$ \\
\hline G-3317D & 18.87 & 36,000 \\
\hline G-3394A & 10.42 & 42,000 \\
\hline G-3314E & 7.89 & $30,000+$ \\
\hline G-3320C & 12.39 & $21,000+$ \\
\hline G-3319E & 2.25 & $55,000+$ \\
\hline G-3324E & 17.61 & 24,000 \\
\hline G-3315E & 16.06 & $27,000+$ \\
\hline
\end{tabular}

The wells were installed using an air-circulation method (no drilling mud) to minimize the clogging of pore spaces or cavities in the rock (Fish and Stewart, 1991). The step-drawdown method was used with sequential pumping and recovery cycles (i.e., 30 minutes of pumping followed by a recovery period for each cycle). The maximum pump discharge for a 6-7.5 inch diameter well was $1000 \mathrm{gpm}$. Head values in the aquifer recovered within 1 or 2 minutes of the end of pumping (Fish and Stewart, 1991).

The method used to estimate the average hydraulic conductivity of the Biscayne Aquifer at the test site was the inverse-distance-squared method (IDS): 


$$
K_{\text {avg }}=\frac{\sum_{i=1}^{n} K_{i} / d_{i}^{2}}{\sum_{i=1}^{n} 1 / d_{i}^{2}}
$$

where,

$\mathrm{K}_{\mathrm{i}}=$ hydraulic conductivity near neighboring well

$\mathrm{d}_{\mathrm{i}}=$ distance from the study site to the neighboring well

$\mathrm{n}=$ number of wells considered.

$\mathrm{K}_{\mathrm{avg}}$ was found to be $50,600 \mathrm{ft} /$ day, or 0.179 meters/second. 


\section{APPENDIX IV}

Computation of Layer Hydraulic Conductivity 
Steps in computing hydraulic conductivity from flowmeter data

The field data consist of:

- depths of the flowmeter measurements

- time intervals

- ambient flow, Qa, readings at 5 second intervals for a duration of at least 1 minute at each depth

- induced flow, Qi, readings at 5 second intervals for a duration of at least 1 minute at each depth

- $\quad$ pump discharge, Qp, measurements

- water level readings in study well (to verify steady-state behavior)

- flowmeter calibration data

All of the above data, except time interval and pressure transducer readings, were used in the calculation of hydraulic conductivity of each depth interval, as outlined below:

1. Calculate the average flowmeter reading.

2. Determine the calibration line (Appendix II) relating actual flow rate to flowmeter reading.

3. Correct the ambient and induced flow readings based on the calibration curve (Appendix II).

4. Compute Qi-Qa.

5. Correct the Qi-Qa profile by drawing a straight line across zones of decreasing-upward discharge rate, between more reliable points with good packer seal above and below.

6. Correct the average $\mathrm{Qp}$ with the uppermost negative ambient flow rate (which is an indication of surface water leaking into the borehole due to an incomplete concrete seal between the PVC pipe and the bedrock). 
7. Calculate the hydraulic conductivity of each zone using Eqn. 6. 


\section{APPENDIX V}

Ambient, Pump, and Induced Flow Rates 
Borehole 16W: Ambient, Pump, and Induced Flow Rates Elevation, $\mathrm{m}$ Qa, L/min $Q p, L / \mathrm{min} \quad Q i, L / \mathrm{min}$

\begin{tabular}{|c|c|c|c|c|}
\hline 1 & -9.653 & 0.127 & 13.790 & 0.069 \\
\hline 2 & -9.153 & -1.175 & 13.950 & -1.028 \\
\hline 3 & -8.653 & -1.293 & 13.790 & -1.048 \\
\hline 4 & -8.153 & -0.774 & 13.950 & -0.480 \\
\hline 5 & -7.653 & -0.186 & 14.120 & 0.088 \\
\hline 6 & -7.153 & -0.088 & 13.950 & 0.088 \\
\hline 7 & -6.653 & -0.010 & 13.950 & 0.118 \\
\hline 8 & -6.153 & 0.049 & 13.790 & 0.176 \\
\hline 9 & -5.653 & 0.039 & 13.950 & 0.127 \\
\hline 10 & -5.153 & 0.010 & $\ldots$ & 0.206 \\
\hline 11 & -4.653 & -0.744 & 13.950 & -0.010 \\
\hline 12 & -4.153 & -0.862 & 13.950 & -0.010 \\
\hline 13 & -3.653 & -- & -- & -- \\
\hline 14 & -3.403 & 0.000 & 13.950 & 0.196 \\
\hline 15 & -3.153 & 0.000 & 13.950 & 0.411 \\
\hline 16 & -2.653 & 0.010 & 13.950 & 0.401 \\
\hline 17 & -2.153 & 0.010 & 13.950 & 1.165 \\
\hline 18 & -1.653 & 0.000 & 13.950 & 1.488 \\
\hline 19 & -1.403 & 0.010 & 13.950 & 1.518 \\
\hline 20 & -1.153 & 0.020 & -- & 0.725 \\
\hline 21 & -0.903 & -0.083 & 13.950 & 1.890 \\
\hline 22 & -0.778 & -0.135 & 13.950 & 4.338 \\
\hline 23 & -0.653 & -0.186 & 13.950 & 8.421 \\
\hline 24 & -0.403 & -0.122 & 13.950 & 10.458 \\
\hline 25 & -0.153 & -0.059 & -- & 5.875 \\
\hline 26 & 0.097 & -0.098 & -13.950 & 8.450 \\
\hline 27 & 0.222 & -0.117 & 13.950 & 8.940 \\
\hline 28 & 0.347 & -0.137 & -- & 10.203 \\
\hline 29 & 0.597 & -0.117 & -- & 8.401 \\
\hline 30 & 0.847 & -0.098 & 13.950 & 8.764 \\
\hline
\end{tabular}


Borehole 14W: Ambient, Pump, and Induced Flow Rates Elevation, $\mathrm{m}$ Qa, L/min $Q p, L / m i n ~ Q i, L / m i n$

$\begin{array}{rrrr}-10.653 & -0.079 & 13.790 & 0.032 \\ -10.153 & -0.120 & 13.950 & 0.073 \\ -9.653 & -0.150 & 13.790 & 0.113 \\ -9.153 & -0.959 & 13.790 & -0.818 \\ -8.653 & -0.727 & 13.950 & -0.807 \\ -8.153 & 0.022 & 13.950 & 0.042 \\ -7.653 & 0.052 & 14.120 & 0.123 \\ -7.153 & -- & - & -- \\ -6.903 & 0.022 & 13.950 & 0.093 \\ -6.653 & 0.042 & 13.950 & 0.123 \\ -6.153 & 0.022 & 13.950 & 0.123 \\ -5.653 & -- & -- & - \\ -5.403 & 0.022 & 13.950 & 0.113 \\ -5.153 & 0.042 & 13.950 & 0.123 \\ -4.653 & 0.022 & 13.950 & 0.831 \\ -4.153 & 0.083 & 13.950 & 0.386 \\ -3.653 & 0.022 & 13.950 & 1.803 \\ -3.153 & 0.022 & 13.950 & 1.742 \\ -2.653 & -0.008 & 13.950 & 2.571 \\ -2.153 & -0.271 & 13.950 & 5.667 \\ -1.653 & 0.012 & 13.950 & 6.972 \\ -1.153 & 0.022 & 13.950 & 6.598 \\ -0.653 & -0.261 & 13.790 & 12.091 \\ -0.153 & 0.002 & 13.950 & 7.326 \\ 0.347 & -0.221 & 13.950 & 12.445 \\ 0.847 & -0.241 & 13.950 & 13.012 \\ 1.107 & -0.231 & 13.950 & 12.951\end{array}$


Borehole 12W: Ambient, Pump, and Induced Flow Rates

Elevation, m

$$
\begin{array}{r}
-10.153 \\
-9.653 \\
-9.153 \\
-8.903 \\
-8.653 \\
-6.403 \\
-6.153 \\
-5.653 \\
-5.153 \\
-4.653 \\
-4.153 \\
-2.903 \\
-2.653 \\
-2.153 \\
-1.903 \\
-1.653 \\
-1.403 \\
-1.153 \\
-0.903 \\
-0.778 \\
-0.653 \\
-0.403 \\
-0.153 \\
0.097 \\
0.347 \\
0.597 \\
0.847 \\
1.097
\end{array}
$$

Qp, L/min

$-0.177$

$-0.040$

$-0.304$

$-0.687$

$-0.697$

0.117

0.127

$-0.020$

$-0.000$

0.098

0.304

$-0.010$

0.029

0.010

0.014

0.019

0.010

$-0.000$

$-0.069$

$-0.103$

$-0.138$

$-0.231$

$-0.324$

$-0.250$

$-0.177$

$-0.177$

$-0.177$

$-0.314$
$-$

13.630

13.790

13.630

13.790

13.790

13.950

13.630

13.480

13.790

13.950

14.035

14.120

13.640

13.790

13.795

13.790

13.795

13.790

13.790

13.950

14.120

13.870

13.880

13.870

13.880

13.640
Qi, L/min

$$
\begin{array}{r}
- \\
-- \\
0.029 \\
-0.471 \\
-0.628 \\
0.137 \\
0.157 \\
0.068 \\
0.117 \\
0.343 \\
0.843 \\
1.059 \\
4.550 \\
1.834 \\
2.746 \\
4.854 \\
3.883 \\
4.334 \\
7.796 \\
5.629 \\
8.894 \\
10.140 \\
12.140 \\
10.454 \\
7.639 \\
10.885 \\
11.022 \\
12.346
\end{array}
$$


Borehole 10w: Ambient, Pump, and Induced Flow Rates

$\begin{array}{rrrr}\text { Elevation, } & \text { Qa, L/min } & Q p, L / m i n & Q i, L / m \\ -3.043 & 0.104 & 14.810 & 0.790 \\ -2.653 & 0.285 & 14.810 & 0.861 \\ -2.153 & 0.305 & 14.810 & 1.062 \\ -1.653 & -0.068 & 14.810 & 2.879 \\ -1.653 & -0.068 & 14.810 & 2.839 \\ -1.153 & 0.235 & -- & 2.607 \\ -1.023 & 0.255 & 14.810 & 1.002 \\ -0.903 & 0.265 & -- & 0.982 \\ -0.778 & 0.275 & 14.810 & 1.476 \\ -0.653 & 0.285 & -- & 6.351 \\ -0.653 & 0.285 & -- & 6.402 \\ -0.403 & 0.124 & 14.810 & 10.904 \\ -0.153 & -0.048 & 14.810 & 12.054 \\ 0.347 & -0.028 & -- & 11.176 \\ 0.347 & -0.028 & 14.810 & 12.337 \\ 0.847 & -0.028 & -- & 12.569 \\ 1.097 & 0.265 & & 12.670\end{array}$


Borehole 8W: Ambient, Pump, and Induced Flow Rates Elevation, $\mathrm{Qa}$, L/min QP, L/min Qi, L/min

\begin{tabular}{ll}
-8.153 & \multicolumn{1}{l}{-} \\
-7.653 & \multicolumn{1}{l}{-} \\
-7.153 & -- \\
-6.653 & -0.938 \\
-6.153 & -0.786 \\
-5.653 & 0.057 \\
-5.153 & 0.414 \\
-4.653 & 0.403 \\
-4.153 & 0.295 \\
-3.653 & -- \\
-3.553 & 0.262 \\
-3.153 & 0.187 \\
-2.653 & 0.241 \\
-2.153 & 0.598 \\
-1.903 & 0.408 \\
-1.653 & 0.219 \\
-1.403 & 0.203 \\
-1.153 & 0.187 \\
-0.903 & 0.079 \\
-0.653 & -0.029 \\
-0.153 & 0.057 \\
0.097 & 0.122 \\
0.347 & 0.187 \\
0.597 & -0.051 \\
0.847 & -0.289
\end{tabular}

-

$-$$$
14.280
$$

14.460

14.630

14.460

14.280

-

-

-

--

-

14.280

-.

-

-

14.280

$-$

14.280

--

-

14.280
-

-

-

$-1.110$

$-1.013$

0.641

0.187

0.565

0.500

-

0.695

0.879

2. 241

1. 117

3. 409

4.133

3. 819

3. 830

4.176

7.711

9.571

5.927

8. 544

11.030

13.474 
Borehole 6W: Ambient, Pump, and Induced Flow Rates Elevation, $\mathrm{Qa}$, L/min Qp, L/min Qi, L/min

\begin{tabular}{rlll}
-5.153 & -- & -- & -- \\
-4.653 & \multicolumn{1}{c}{--} & -- & -- \\
-4.403 & -0.024 & 14.460 & 0.272 \\
-4.153 & -0.035 & 14.280 & 0.226 \\
-3.653 & 0.044 & 14.460 & 0.840 \\
-3.153 & -0.126 & 14.460 & 1.431 \\
-2.653 & -0.069 & 14.460 & 1.772 \\
-2.153 & -0.024 & 14.460 & 1.408 \\
-1.653 & -0.365 & 14.460 & 4.102 \\
-1.403 & -0.359 & 14.460 & 3.363 \\
-1.153 & -0.354 & 14.460 & 3.579 \\
-0.903 & -0.371 & 14.460 & 4.557 \\
-0.653 & -0.388 & 14.460 & 7.012 \\
-0.403 & -0.467 & -- & 8.319 \\
-0.153 & -0.547 & 14.460 & 10.160 \\
0.347 & -0.695 & 14.460 & 11.524 \\
0.597 & -0.280 & -- & 11.763 \\
0.847 & 0.135 & 14.460 & 14.286
\end{tabular}


Borehole 4W: Ambient, Pump, and Induced Flow Rates

$\begin{array}{cccc}\text { Elevation, } & \text { Qa, L/min } & \text { Qp, L/min } & Q i, L / m i n \\ -8.153 & -0.096 & 14.280 & 0.191 \\ -7.653 & -- & 14.280 & -- \\ -7.153 & -- & 14.280 & -- \\ -6.653 & -1.478 & 14.280 & -0.833 \\ -6.153 & -1.632 & 14.280 & -1.038 \\ -5.653 & -1.345 & 14.280 & -0.710 \\ -5.153 & -1.212 & 14.280 & -- \\ -4.773 & 0.038 & 14.280 & 0.171 \\ -4.653 & -- & 14.280 & -- \\ -4.403 & -0.567 & -- & 0.601 \\ -4.153 & -0.782 & -- & 0.529 \\ -3.653 & 0.048 & 14.280 & 0.878 \\ -3.153 & 0.048 & 14.280 & 2.281 \\ -2.903 & 0.130 & -- & 1.964 \\ -2.653 & 0.212 & -- & 1.964 \\ -2.403 & 0.145 & -- & 2.086 \\ -2.153 & 0.079 & -- & 2.107 \\ -1.903 & 0.053 & 14.280 & 5.201 \\ -1.653 & 0.027 & -- & 8.345 \\ -1.403 & 0.089 & -- & 8.960 \\ -1.153 & 0.150 & -- & 2.404 \\ -0.903 & 0.166 & -- & 2.373 \\ -0.653 & 0.181 & -- & 8.304 \\ -0.403 & 0.099 & -- & 7.137 \\ -0.153 & 0.017 & -- & 11.961 \\ 0.097 & 0.022 & -- & 14.533 \\ 0.347 & 0.027 & -- & \\ 0.597 & 0.027 & -- & \\ 0.847 & 0.027 & 14.280 & 129 \\ & & & \end{array}$


Borehole 2W: Ambient, Pump, and Induced Flow Rates

Elevation, m

-6.653
-6.153
-5.653
-5.153
-4.653
-4.153
-3.903
-3.653
-3.403
-3.153
-2.653
-2.403
-2.153
-1.903
-1.653
-1.403
-1.153
-0.903
-0.653
-0.403
-0.153
0.097
0.347
0.597
0.847

$\begin{array}{llr}\text { Qa, L/m } & \text { QP, L/m } & \text { Qi, L/m } \\ -0.767 & 14.460 & -0.638 \\ -1.046 & -- & -0.971 \\ -1.357 & -- & -1.143 \\ -0.992 & -- & -0.660 \\ -0.542 & -- & -0.102 \\ -0.821 & -- & -0.155 \\ 0.778 & 14.460 & 0.156 \\ -- & -- & -- \\ 0.392 & 14.460 & 1.819 \\ 0.488 & -- & 2.001 \\ 0.231 & -- & 2.033 \\ 0.225 & -- & 2.516 \\ 0.220 & -- & 4.136 \\ 0.204 & -- & 5.982 \\ 0.188 & 14.460 & 6.636 \\ 0.225 & -- & 7.140 \\ 0.263 & -- & 3.890 \\ 0.242 & -- & 7.216 \\ 0.220 & 14.460 & 10.263 \\ 0.204 & -- & 10.306 \\ 0.188 & -- & 9.887 \\ 0.183 & -- & 13.095 \\ 0.177 & 14.460 & 11.379 \\ 0.107 & & 12.570 \\ 0.038 & & 13.557\end{array}$


Borehole 1W: Ambient, Pump, and Flow Rates Elevation, $\mathrm{m} Q \mathrm{Q}, \mathrm{L} / \mathrm{min} \quad Q \mathrm{p}, \mathrm{L} / \mathrm{min} \quad \mathrm{Qi}, \mathrm{L} / \mathrm{min}$

$\begin{array}{rrll}-10.153 & -0.194 & -- & -- \\ -9.653 & 0.018 & -- & -- \\ -9.153 & -1.054 & -- & -- \\ -8.653 & -1.065 & -- & -- \\ -8.153 & -0.406 & - & -- \\ -7.653 & -1.177 & 14.460 & -0.496 \\ -7.153 & -- & -- & -- \\ -6.653 & -- & -- & -- \\ -6.403 & -- & - & - \\ -6.303 & -0.708 & -- & 0.018 \\ -6.153 & -1.511 & - & 0.051 \\ -5.653 & -1.835 & - & 0.029 \\ -5.153 & -2.382 & -- & -0.485 \\ -4.653 & -2.192 & - & -0.027 \\ -4.153 & -0.898 & - & 0.620 \\ -3.653 & -1.355 & - & 2.294 \\ -3.153 & -1.467 & - & 2.495 \\ -2.653 & -0.373 & - & 2.250 \\ -2.403 & -0.189 & - & 3.533 \\ -2.153 & -0.005 & -- & 3.344 \\ -1.903 & -0.021 & -- & 6.525 \\ -1.653 & -0.038 & -- & 9.393 \\ -1.403 & 0.006 & -- & 9.583 \\ -1.153 & 0.051 & -- & 4.516 \\ -0.903 & 0.034 & -- & 8.547 \\ -0.653 & 0.018 & 14.460 & 8.009 \\ -0.153 & 0.006 & 14.460 & 7.708 \\ 0.097 & 0.006 & -- & 8.634 \\ 0.347 & 0.006 & -- & 9.080 \\ 0.597 & -0.055 & 14.460 & 11.926 \\ 0.847 & -0.116 & 14.460 & 12.752\end{array}$


Borehole 25-5: Ambient, Pump, and InducedFlow Rates Elevation, $\mathrm{Qa}$, L/min $\mathrm{Qp}, \mathrm{L} / \mathrm{min} \mathrm{Qi}, \mathrm{L} / \mathrm{min}$

\begin{tabular}{|c|c|c|c|}
\hline-9.153 & 0.106 & -- & -- \\
\hline-8.903 & 0.116 & -- & -- \\
\hline-8.653 & 0.056 & -- & -- \\
\hline-8.403 & 0.086 & -- & - \\
\hline-8.153 & -- & -- & -- \\
\hline-7.903 & -- & - - & -- \\
\hline-7.653 & 0.573 & -- & - - \\
\hline-7.403 & -- & -- & - \\
\hline-7.153 & -- & -- & -- \\
\hline-6.903 & -- & - - & -- \\
\hline-6.653 & -- & -- & -- \\
\hline-6.403 & 0.544 & -- & -. \\
\hline-6.153 & 0.762 & -- & -- \\
\hline-5.903 & 0.832 & -- & -- \\
\hline-5.653 & 0.902 & - - & -. \\
\hline-5.403 & 0.892 & -- & -- \\
\hline-5.153 & 0.991 & -- & -- \\
\hline-4.903 & 0.802 & -- & -- \\
\hline-4.653 & -- & -- & -- \\
\hline-4.353 & 0.723 & -- & -- \\
\hline-4.153 & 0.892 & -- & -- \\
\hline-3.903 & 0.842 & -- & -- \\
\hline-3.653 & 1.021 & -- & -- \\
\hline-3.403 & 1.330 & 13.160 & 3.449 \\
\hline-3.153 & 1.588 & 13.170 & 3.927 \\
\hline-2.903 & 1.230 & 12.910 & 2.345 \\
\hline-2.653 & 1.121 & 13.200 & 3.599 \\
\hline-2.403 & 0.862 & 13.480 & 3.519 \\
\hline-2.153 & 0.175 & 13.160 & 3.738 \\
\hline-1.903 & 0.155 & 13.060 & 4.285 \\
\hline-1.653 & 0.145 & 13.030 & 5.390 \\
\hline-1.403 & 0.076 & 13.230 & 8.575 \\
\hline-1.153 & 0.145 & 13.060 & 5.151 \\
\hline-0.903 & 0.145 & 13.310 & 4.076 \\
\hline-0.653 & -0.024 & 13.130 & 11.262 \\
\hline-0.403 & 0.155 & 13.210 & 7.669 \\
\hline-0.153 & 0.066 & 13.090 & 9.928 \\
\hline 0.097 & 0.036 & 13.100 & 11.391 \\
\hline 0.347 & 0.056 & 12.830 & 11.799 \\
\hline 0.597 & 0.066 & 12.690 & 11.789 \\
\hline
\end{tabular}


Borehole 1E: Ambient, Pump, and Induced Flow Rates Elevation, $\mathrm{m} Q \mathrm{Q}, \mathrm{L} / \mathrm{min} \mathrm{Qp}, \mathrm{L} / \mathrm{min} \mathrm{Qi}, \mathrm{L} / \mathrm{min}$

$\begin{array}{rrlr}-8.153 & 0.354 & -- & 0.354 \\ -7.653 & 0.332 & -- & 0.354 \\ -7.153 & 0.192 & 14.460 & 0.311 \\ -6.653 & -0.410 & -- & 1.719 \\ -6.153 & -0.797 & -- & 2.053 \\ -5.653 & -0.872 & 14.630 & 2.343 \\ -5.153 & -0.668 & -- & 2.203 \\ -4.653 & -0.603 & 14.460 & 2.590 \\ -4.153 & -0.721 & -- & 2.515 \\ -3.653 & -- & 14.290 & - \\ -3.403 & 0.074 & -- & 2.945 \\ -3.153 & 0.042 & 14.290 & 4.106 \\ -2.653 & 0.042 & -- & 4.096 \\ -2.153 & 0.106 & -- & 3.934 \\ -1.653 & 0.042 & 14.290 & 11.805 \\ -1.153 & 0.106 & -- & 4.848 \\ -0.653 & 0.010 & -- & 12.074 \\ -0.153 & 0.063 & 14.460 & 12.386 \\ 0.347 & 0.042 & -- & 13.977 \\ 0.847 & 0.010 & 14.630 & 14.630\end{array}$


Borehole 2E: Ambient, Pump, and Induced Flow Rates Elevation, $\mathrm{Q}$ a, L/min $Q p, L / \mathrm{min} \quad Q i, L / m i n$

\begin{tabular}{|c|c|c|c|}
\hline-10.653 & 0.010 & 13.640 & -0.088 \\
\hline-10.153 & -- & -- & -- \\
\hline-10.053 & 0.373 & 13.790 & 0.137 \\
\hline-9.653 & 0.304 & 13.790 & 0.029 \\
\hline-9.153 & -- & -- & -- \\
\hline-8.653 & -- & -- & - \\
\hline-8.153 & -- & -- & -- \\
\hline-7.653 & -- & -- & -- \\
\hline-7.153 & -- & - - & -- \\
\hline-6.653 & -- & -- & -- \\
\hline-6.403 & -1.531 & 13.640 & 1.031 \\
\hline-6.153 & -1.718 & 13.640 & 1.276 \\
\hline-5.653 & -1.826 & 13.640 & 1.149 \\
\hline-5.153 & -1.767 & 13.950 & 1.276 \\
\hline-4.653 & -1.806 & -- & 1.109 \\
\hline-4.153 & -1.384 & -- & 1.041 \\
\hline-3.653 & -0.187 & 13.790 & 1.738 \\
\hline-3.403 & -0.177 & 13.640 & 2.817 \\
\hline-3.153 & -0.167 & 13.790 & 2.906 \\
\hline-2.903 & -0.152 & -- & 2.327 \\
\hline-2.653 & -0.137 & -- & 2.611 \\
\hline-2.403 & -0.128 & 13.790 & 3.701 \\
\hline-2.153 & -0.118 & 13.640 & 5.625 \\
\hline-1.653 & -0.059 & 13.790 & 6.626 \\
\hline-1.403 & -0.137 & 13.640 & 9.130 \\
\hline-1.278 & -0.206 & 13.790 & 9.336 \\
\hline-1.153 & -0.275 & 13.790 & 8.600 \\
\hline-0.903 & -0.152 & -- & 5.203 \\
\hline-0.653 & -0.029 & -- & 5.969 \\
\hline-0.403 & -0.059 & -- & 7.795 \\
\hline-0.153 & -0.088 & 13.640 & 6.067 \\
\hline 0.097 & -0.245 & 13.790 & 6.509 \\
\hline 0.232 & -0.324 & -- & 12.193 \\
\hline 0.347 & -0.402 & 13.640 & 12.654 \\
\hline 0.597 & -0.226 & 13.640 & 12.458 \\
\hline 0.847 & -0.049 & & 2.474 \\
\hline
\end{tabular}


Borehole 4E: Ambient, Pump, and Induced Flow Rates Elevation, $\mathrm{m}$ Qa, L/min $Q p, L / \mathrm{min} \quad Q i, L / m i n$

$\begin{array}{lccc}-9.153 & 0.061 & 10.330 & -0.098 \\ -8.903 & -0.127 & 10.310 & -0.108 \\ -8.653 & -0.187 & 10.340 & -0.127 \\ -8.403 & -0.167 & 10.340 & -0.157 \\ -8.153 & -0.088 & 10.250 & -0.117 \\ -8.153 & 0.070 & -- & -- \\ -7.903 & 0.061 & 10.140 & -0.048 \\ -7.653 & -- & -- & -- \\ -7.403 & -- & -- & -- \\ -7.153 & -- & -- & -- \\ -6.903 & -- & -- & - \\ -6.653 & - & 10.240 & 1.742 \\ -6.403 & 0.436 & 10.260 & 1.870 \\ -6.153 & 0.822 & 10.400 & 2.770 \\ -5.903 & 0.703 & 10.170 & 2.879 \\ -5.653 & 0.881 & 10.310 & 2.770 \\ -5.653 & 1.030 & -- & -- \\ -5.403 & 1.030 & 10.400 & 3.097 \\ -5.403 & 0.802 & -- & -- \\ -5.153 & 1.020 & 10.320 & 3.176 \\ -5.153 & 0.980 & -- & -- \\ -4.903 & 0.990 & 10.210 & 3.156 \\ -4.653 & 1.000 & 10.310 & 2.790 \\ -4.553 & 0.911 & 10.410 & 2.899 \\ -4.403 & 0.822 & 10.430 & 2.899 \\ -4.153 & 0.758 & 10.250 & 2.572 \\ -4.053 & 0.694 & -- & - \\ -3.903 & 0.639 & 10.570 & 2.483 \\ -3.853 & 0.585 & -- & - \\ -3.653 & 0.278 & 10.390 & 1.267 \\ -3.403 & 0.209 & 10.260 & 1.297 \\ -3.153 & 0.486 & 10.270 & 1.870 \\ -2.903 & 0.506 & 10.100 & 2.058 \\ -2.903 & 0.565 & -- & -- \\ -2.653 & 0.694 & 10.420 & 2.632 \\ -2.403 & 0.506 & 10.060 & 2.276 \\ -2.153 & 0.377 & 10.200 & 2.869 \\ -1.903 & 0.209 & 10.140 & 4.412 \\ -1.653 & 0.189 & 10.040 & 4.135 \\ -1.403 & 0.179 & 10.190 & 5.064 \\ -1.153 & 0.209 & 10.360 & 4.046 \\ -0.903 & 0.189 & 10.170 & 3.650 \\ -0.653 & 0.169 & 10.170 & 6.093 \\ -0.403 & 0.120 & 9.830 & 6.607 \\ -0.153 & 0.070 & 10.170 & 8.367 \\ 0.097 & 0.110 & 10.080 & 9.752 \\ 0.347 & 0.229 & 10.170 & 6.597 \\ 0.447 & 0.204 & 10.260 & 9.267 \\ 0.597 & 0.179 & 10.260 & 8.971 \\ 0.847 & 0.179 & 10.260 & 9.574 \\ 1.097 & 0.140 & 10.260 & 8.278\end{array}$


Borehole 6e: Ambient, Pump, and Induced Flow Rates Elevation, $\mathrm{m}$ Qa, L/min $Q p, L / m i n \quad Q i, L / m i n$

\begin{tabular}{|c|c|c|c|}
\hline-8.603 & 0.624 & 10.530 & 0.961 \\
\hline-8.603 & 0.624 & 10.430 & 0.941 \\
\hline-8.153 & 0.169 & -- & 0.219 \\
\hline-7.653 & -- & -- & -- \\
\hline-7.153 & -- & -- & -- \\
\hline-6.653 & 0.575 & 10.710 & 2.068 \\
\hline-6.403 & 0.669 & 10.530 & 3.779 \\
\hline-6.153 & 0.763 & 10.620 & 4.056 \\
\hline-5.903 & 0.921 & 10.620 & 4.540 \\
\hline-5.653 & 1.079 & 10.430 & 4.649 \\
\hline-5.403 & 1.050 & 10.530 & 4.956 \\
\hline-5.153 & 1.020 & 10.620 & 5.134 \\
\hline-4.903 & 0.985 & -- & 4.966 \\
\hline-4.653 & 0.951 & 10.430 & 5.144 \\
\hline-4.403 & 0.886 & 10.480 & 5.045 \\
\hline-4.153 & 0.822 & 10.530 & 5.153 \\
\hline-3.903 & 0.728 & 10.530 & 5.292 \\
\hline-3.653 & 0.634 & -- & -- \\
\hline-3.153 & 0.565 & 10.530 & 5.351 \\
\hline-2.903 & 0.585 & 10.520 & 5.727 \\
\hline-2.653 & 0.605 & -- & 5.331 \\
\hline-2.403 & 0.377 & 10.520 & 6.043 \\
\hline-2.153 & 0.150 & 10.810 & 6.399 \\
\hline-1.903 & 0.011 & 10.530 & 8.179 \\
\hline-1.653 & -0.127 & 10.530 & 8.140 \\
\hline-1.403 & 0.011 & 10.530 & 8.456 \\
\hline-1.153 & 0.150 & 10.810 & 8.634 \\
\hline-1.403 & 0.011 & 13.640 & 10.266 \\
\hline-1.153 & 0.150 & 13.640 & 10.246 \\
\hline-0.903 & 0.164 & -- & 4.550 \\
\hline-0.653 & 0.179 & 13.790 & 10.385 \\
\hline-0.403 & 0.160 & -- & 12.422 \\
\hline-0.153 & 0.140 & 13.950 & 12.481 \\
\hline 0.097 & 0.006 & 13.480 & 12.728 \\
\hline 0.347 & -0.127 & 13.790 & 12.550 \\
\hline 0.847 & -0.206 & 13.790 & 12.946 \\
\hline
\end{tabular}


Borehole 8E: Ambient, Pump, and Induced Flow Rates Elevation, $\mathrm{m}$ Qa, L/min $Q p, L / \mathrm{min} \quad Q i, L / \mathrm{min}$

$\begin{array}{lrll}-8.393 & -0.108 & 13.640 & -0.078 \\ -6.653 & 0.941 & -- & -- \\ -6.403 & 1.475 & 13.640 & 2.711 \\ -6.153 & 2.009 & 13.640 & 3.057 \\ -5.653 & 2.424 & 13.640 & 3.532 \\ -5.153 & 2.464 & 13.480 & 3.640 \\ -4.653 & 2.464 & 13.480 & 3.818 \\ -4.403 & 2.711 & 13.480 & 3.996 \\ -4.153 & 2.958 & 13.480 & 4.026 \\ -3.903 & 2.765 & 13.480 & 3.631 \\ -3.653 & 2.572 & -- & 3.690 \\ -3.153 & 2.671 & -- & 4.016 \\ -2.653 & 1.406 & -- & 3.907 \\ -2.153 & 0.397 & 13.480 & 4.303 \\ -2.153 & 0.397 & 13.790 & 4.649 \\ -2.153 & 0.397 & 13.560 & 4.441 \\ -1.903 & 0.852 & 13.480 & 6.409 \\ -1.653 & 0.318 & -- & 6.241 \\ -1.653 & 0.318 & 13.560 & 6.399 \\ -1.523 & 0.320 & 13.640 & 6.676 \\ -1.403 & 0.323 & 13.640 & 6.330 \\ -1.153 & 0.328 & -- & 5.252 \\ -1.023 & 0.145 & 13.640 & 2.701 \\ -0.903 & -0.038 & -- & 3.690 \\ -0.773 & -0.221 & 13.640 & 11.285 \\ -0.653 & -0.404 & 13.330 & 11.107 \\ -0.403 & -0.384 & 13.480 & 11.749 \\ -0.153 & -0.345 & 13.640 & 12.293 \\ 0.097 & -0.335 & 13.480 & 12.353 \\ 0.347 & -0.325 & -- & 12.254 \\ 0.597 & -0.236 & 13.640 & 12.185 \\ 0.847 & -0.236 & -- & 11.423\end{array}$


Borehole 10E: Ambient, Pump, and Induced Flow Rates Elevation, $\mathrm{m} Q \mathrm{Q}, \mathrm{L} / \mathrm{min} \quad \mathrm{Qp}, \mathrm{L} / \mathrm{min} \mathrm{Qi}, \mathrm{L} / \mathrm{min}$

\begin{tabular}{|c|c|c|c|}
\hline-9.153 & 0.187 & -- & -- \\
\hline-8.653 & 0.236 & -- & -- \\
\hline-8.153 & -- & -- & -- \\
\hline-7.903 & -- & -- & -- \\
\hline-7.653 & -- & - - & - - \\
\hline-7.403 & - - & - - & -- \\
\hline-7.153 & -- & -- & -- \\
\hline-6.903 & -- & -- & -- \\
\hline-6.653 & 2.062 & -- & - - \\
\hline-6.153 & 2.709 & -- & -- \\
\hline-5.653 & 2.759 & - - & - - \\
\hline-5.153 & 3.083 & -- & - - \\
\hline-4.653 & 3.269 & -- & - - \\
\hline-4.153 & -- & -- & -- \\
\hline-3.653 & 2.994 & 13.790 & 4.555 \\
\hline-3.153 & 3.161 & 14.120 & 4.742 \\
\hline-2.653 & 1.895 & -- & 4.663 \\
\hline-2.153 & 0.206 & 13.640 & 7.147 \\
\hline-1.653 & -0.422 & 13.640 & 9.581 \\
\hline-1.153 & 0.118 & - - & 3.436 \\
\hline-0.653 & -0.648 & 13.790 & 10.426 \\
\hline-0.153 & -0.805 & 13.640 & 12.311 \\
\hline 0.347 & -0.795 & -- & 11.859 \\
\hline 0.847 & 0.187 & 14.120 & 13.498 \\
\hline
\end{tabular}


Borehole 12E: Ambient, Pump, and Induced Flow Rates Elevation, $\mathrm{m}$ Qa, L/min $Q p, L / m i n \quad Q i, L / m i n$

\begin{tabular}{|c|c|c|c|}
\hline-7.153 & 0.565 & 13.330 & 0.783 \\
\hline-7.153 & 0.476 & -- & -- \\
\hline-6.903 & 0.323 & 13.330 & 1.237 \\
\hline-6.653 & 0.169 & 13.330 & 2.276 \\
\hline-6.153 & 2.078 & 13.480 & 2.701 \\
\hline-5.653 & 1.860 & 13.330 & 2.721 \\
\hline-5.153 & 1.930 & 13.330 & 2.691 \\
\hline-4.903 & 1.658 & -- & 1.999 \\
\hline-4.653 & 1.386 & -- & 2.523 \\
\hline-4.403 & 1.307 & -- & 2.286 \\
\hline-4.153 & 1.228 & -- & 2.365 \\
\hline-3.903 & 0.827 & -- & 1.969 \\
\hline-3.653 & 0.427 & -- & 1.040 \\
\hline-3.653 & 0.397 & -- & -- \\
\hline-3.403 & 0.832 & 13.330 & 2.325 \\
\hline-3.153 & 1.267 & 13.330 & 2.325 \\
\hline-2.653 & 0.070 & 13.330 & 2.424 \\
\hline-2.403 & -0.053 & 13.330 & 2.731 \\
\hline-2.153 & -0.177 & 13.330 & 4.946 \\
\hline-1.903 & -0.216 & 13.330 & 6.073 \\
\hline-1.653 & -0.256 & 13.330 & 6.370 \\
\hline-1.403 & -0.083 & 13.330 & 6.558 \\
\hline-1.153 & 0.090 & -- & 3.245 \\
\hline-0.903 & -0.226 & -- & 4.234 \\
\hline-0.653 & -0.543 & 13.330 & 11.008 \\
\hline-0.153 & -0.592 & 13.480 & 11.799 \\
\hline 0.097 & -0.478 & 13.480 & 12.511 \\
\hline 0.347 & -0.365 & -- & 11.393 \\
\hline 0.597 & -0.424 & -- & 12.363 \\
\hline 0.847 & -0.483 & 13.480 & 12.264 \\
\hline
\end{tabular}


Borehole 14E: Ambient, Pump, and Induced Flow Rates Elevation, $\mathrm{Qa}$, L/min Qp, L/min Qi, L/min

$\begin{array}{lccc}-8.153 & 0.634 & 13.790 & 0.723 \\ -7.653 & -- & -- & - \\ -7.153 & 0.347 & 13.790 & 0.713 \\ -6.653 & 1.653 & 13.480 & 2.058 \\ -6.153 & 2.958 & 13.640 & 3.334 \\ -5.653 & 3.017 & 13.640 & 3.532 \\ -5.653 & 3.087 & -- & -- \\ -5.153 & 2.563 & 13.720 & 3.097 \\ -4.653 & 2.790 & 13.790 & 3.443 \\ -4.653 & 2.602 & 13.480 & 3.601 \\ -4.153 & 3.027 & 13.950 & 3.611 \\ -3.573 & 2.602 & 13.720 & 3.067 \\ -3.573 & 2.325 & -- & -- \\ -3.403 & 1.692 & 13.720 & 3.512 \\ -3.233 & 1.059 & 13.720 & 3.195 \\ -2.653 & 0.130 & 13.720 & 3.265 \\ -2.403 & -0.271 & 13.950 & 4.857 \\ -2.153 & -0.671 & 13.480 & 7.359 \\ -1.653 & -0.740 & 13.190 & 8.110 \\ -1.153 & -0.889 & 13.480 & 8.704 \\ -0.903 & -0.884 & 13.400 & 6.755 \\ -0.653 & -0.879 & 13.330 & 10.780 \\ -0.153 & -0.780 & 13.480 & 11.403 \\ 0.347 & -0.721 & 13.480 & 11.631 \\ 0.727 & -0.577 & 13.480 & 11.542 \\ 0.847 & -0.434 & -- & -- \\ & & & \end{array}$




\section{APPENDIX VI \\ Discharge Flow $\left(Q_{i}-Q_{a}\right)$ and Hydraulic Conductivity}


Some Qi-Qa values (in first column) were corrected (to the value in the second column) if they were erroneously low due to poor packer seal. The corrected value in each case was interpolated linearly between more reliable values (achieved with good packer seal) above and below. 
Borehole 16W: Discharge Flow and Hydraulic Conductivity Elevation, $\mathrm{m}$ Qi-Qa, L/min Qi-Qa $\operatorname{corr} \mathrm{K}, \mathrm{m} / \mathrm{s}$

\begin{tabular}{|c|c|c|c|}
\hline-9.653 & -0.059 & -0.059 & - \\
\hline-9.153 & 0.147 & 0.147 & 0.064 \\
\hline-8.653 & 0.245 & 0.245 & 0.030 \\
\hline-8.153 & 0.294 & 0.294 & 0.015 \\
\hline-7.653 & 0.274 & 0.364 & 0.022 \\
\hline-7.153 & 0.176 & 0.433 & 0.022 \\
\hline-6.653 & 0.127 & 0.503 & 0.022 \\
\hline-6.153 & 0.127 & 0.573 & 0.022 \\
\hline-5.653 & 0.088 & 0.643 & 0.022 \\
\hline-5.153 & 0.196 & 0.712 & 0.022 \\
\hline-4.653 & 0.734 & 0.782 & 0.022 \\
\hline-4.153 & 0.852 & 0.852 & 0.022 \\
\hline-3.653 & -- & 0.928 & 0.023 \\
\hline-3.403 & 0.196 & 0.966 & 0.023 \\
\hline-3.153 & 0.411 & 1.004 & 0.023 \\
\hline-2.653 & 0.392 & 1.080 & 0.023 \\
\hline-2.153 & 1.155 & 1.155 & 0.023 \\
\hline-1.653 & 1.488 & 1.488 & 0.103 \\
\hline-1.403 & 1.508 & 1.508 & 0.012 \\
\hline-1.153 & 0.705 & 1.740 & 0.144 \\
\hline-0.903 & 1.973 & 1.973 & 0.144 \\
\hline-0.778 & 4.472 & 4.472 & 3.095 \\
\hline-0.653 & 8.607 & 8.607 & 5.121 \\
\hline-0.403 & 10.580 & 10.580 & 1.222 \\
\hline-0.153 & 5.934 & & -- \\
\hline 0.097 & 8.548 & & -- \\
\hline 0.222 & 9.057 & & -- \\
\hline 0.347 & 10.340 & & -- \\
\hline 0.597 & 8.519 & & -- \\
\hline 0.847 & 8.862 & & $\ldots$ \\
\hline
\end{tabular}


Borehole 14W: Discharge Flow and Hydraulic Conductivity Elevation, $\mathrm{m}$ Qi-Qa, L/min Qi-Qa corr $\mathrm{k}, \mathrm{m} / \mathrm{s}$

$\begin{array}{rrrr}-10.653 & 0.111 & 0.111 & -- \\ -10.153 & 0.192 & 0.192 & 0.025 \\ -9.653 & 0.263 & 0.263 & 0.022 \\ -9.153 & 0.142 & 0.318 & 0.017 \\ -8.653 & -0.081 & 0.372 & 0.017 \\ -8.153 & 0.020 & 0.427 & 0.017 \\ -7.653 & 0.071 & 0.482 & 0.017 \\ -7.153 & -- & 0.536 & 0.017 \\ -6.903 & 0.071 & 0.563 & 0.017 \\ -6.653 & 0.081 & 0.591 & 0.017 \\ -6.153 & 0.101 & 0.645 & 0.017 \\ -5.653 & -- & 0.700 & 0.017 \\ -5.403 & 0.091 & 0.727 & 0.017 \\ -5.153 & 0.081 & 0.755 & 0.017 \\ -4.653 & 0.809 & 0.809 & 0.017 \\ -4.153 & 0.303 & 1.295 & 0.152 \\ -3.653 & 1.780 & 1.780 & 0.152 \\ -3.153 & 1.720 & 2.180 & 0.125 \\ -2.653 & 2.580 & 2.580 & 0.125 \\ -2.153 & 5.938 & 5.938 & 1.050 \\ -1.653 & 6.960 & 6.960 & 0.319 \\ -1.153 & 6.576 & 9.656 & 0.843 \\ -0.653 & 12.352 & 12.352 & 0.843 \\ -0.153 & 7.324 & 12.509 & 0.049 \\ 0.347 & 12.666 & 12.666 & 0.049 \\ 0.847 & 13.252 & 13.252 & 0.183 \\ 1.107 & 13.182 & & --\end{array}$


Borehole 12W: Discharge Flow and Hydraulic Conductivity Elevation, $\mathrm{m}$ Qi-Qa, L/min Qi-Qa corr $\mathrm{K}, \mathrm{m} / \mathrm{s}$

$\begin{array}{lrll}-10.153 & -- & - & - \\ -9.653 & -- & -- & -- \\ -9.153 & 0.333 & 0.333 & -- \\ -8.903 & 0.216 & 0.344 & 0.006 \\ -8.653 & 0.069 & 0.354 & 0.006 \\ -6.403 & 0.020 & 0.447 & 0.006 \\ -6.153 & 0.029 & 0.457 & 0.006 \\ -5.653 & 0.088 & 0.478 & 0.006 \\ -5.153 & 0.118 & 0.498 & 0.006 \\ -4.653 & 0.245 & 0.519 & 0.006 \\ -4.153 & 0.539 & 0.539 & 0.006 \\ -2.903 & 1.069 & 1.069 & 0.066 \\ -2.653 & 4.521 & 4.521 & 2.141 \\ -2.153 & 1.824 & 4.678 & 0.049 \\ -1.903 & 2.731 & 4.756 & 0.049 \\ -1.653 & 4.835 & 4.835 & 0.049 \\ -1.403 & 3.874 & 5.845 & 0.626 \\ -1.153 & 4.335 & 6.855 & 0.626 \\ -0.903 & 7.865 & 7.865 & 0.626 \\ -0.778 & 5.732 & 8.448 & 0.724 \\ -0.653 & 9.032 & 9.032 & 0.724 \\ -0.403 & 10.371 & 10.371 & 0.830 \\ -0.153 & 12.464 & 12.464 & 1.299 \\ 0.097 & 10.704 & 12.504 & 0.024 \\ 0.347 & 7.816 & 12.543 & 0.024 \\ 0.597 & 11.062 & 12.582 & 0.024 \\ 0.847 & 11.199 & 12.621 & 0.024 \\ 1.097 & 12.660 & 12.660 & 0.024\end{array}$


Borehole 10W: Discharge Flow and Hydraulic Conductivity Elevation, $\mathrm{m}$ Qi-Qa, L/min Qi-Qa corr $\mathrm{K}, \mathrm{m} / \mathrm{s}$

$\begin{array}{rrrr}-3.043 & 0.686 & 0.686 & -- \\ -2.653 & 0.575 & 0.717 & 0.012 \\ -2.153 & 0.757 & 0.757 & 0.012 \\ -1.653 & 2.947 & 2.947 & 0.646 \\ -1.153 & 2.372 & 4.532 & 0.468 \\ -1.023 & 0.747 & 4.944 & 0.468 \\ -0.903 & 0.717 & 5.324 & 0.468 \\ -0.778 & 1.201 & 5.721 & 0.468 \\ -0.653 & 6.117 & 6.117 & 0.468 \\ -0.403 & 10.780 & 10.780 & 2.751 \\ -0.153 & 12.102 & 12.102 & 0.780 \\ 0.347 & 12.365 & 12.365 & 0.077 \\ 0.847 & 12.597 & 12.597 & 0.068\end{array}$


Borehole 8w: Discharge Flow and Hydraulic Conductivity Elevation, $\mathrm{Q}$ Q $-\mathrm{Qa}, \mathrm{L} / \mathrm{min} \mathrm{Qi}-\mathrm{Qa} \operatorname{corr} \mathrm{K}, \mathrm{m} / \mathrm{s}$

\begin{tabular}{lrll}
-8.153 & \multicolumn{1}{c}{--} & \multicolumn{1}{l}{-} \\
-7.653 & \multicolumn{1}{c}{--} & \multicolumn{1}{l}{--} \\
-7.153 & \multicolumn{1}{c}{--} & \multicolumn{1}{c}{-} \\
-6.653 & -0.173 & -0.173 & -- \\
-6.153 & -0.227 & 0.205 & 0.113 \\
-5.653 & 0.584 & 0.584 & 0.113 \\
-5.153 & -0.227 & 0.820 & 0.071 \\
-4.653 & 0.162 & 1.056 & 0.071 \\
-4.153 & 0.205 & 1.292 & 0.071 \\
-3.653 & -- & 1.528 & 0.071 \\
-3.553 & 0.432 & 1.575 & 0.071 \\
-3.153 & 0.692 & 1.764 & 0.071 \\
-2.653 & 2.000 & 2.000 & 0.071 \\
-2.153 & 0.519 & 2.667 & 0.200 \\
-1.903 & 3.000 & 3.000 & 0.200 \\
-1.653 & 3.914 & 3.914 & 0.547 \\
-1.403 & 3.616 & 3.975 & 0.037 \\
-1.153 & 3.643 & 4.036 & 0.037 \\
-0.903 & 4.097 & 4.097 & 0.037 \\
-0.653 & 7.741 & 7.741 & 2.181 \\
-0.153 & 9.514 & 9.514 & 0.531 \\
0.097 & 5.806 & 10.036 & 0.313 \\
0.347 & 8.357 & 10.559 & 0.313 \\
0.597 & 11.081 & 11.081 & 0.313 \\
0.847 & 13.762 & 13.762 & 1.605
\end{tabular}


Borehole 6w: Discharge Flow and Hydraulic Conductivity Elevation, $\mathrm{m}$ Qi-Qa, L/min Qi-Qa corr $\mathrm{K}, \mathrm{m} / \mathrm{s}$

$\begin{array}{lrrl}-5.153 & -- & -- & -- \\ -4.653 & -- & -- & -- \\ -4.403 & 0.296 & 0.296 & -- \\ -4.153 & 0.261 & 0.462 & 0.099 \\ -3.653 & 0.796 & 0.796 & 0.099 \\ -3.153 & 1.557 & 1.557 & 0.226 \\ -2.653 & 1.841 & 1.841 & 0.084 \\ -2.153 & 1.432 & 3.154 & 0.390 \\ -1.653 & 4.467 & 4.467 & 0.390 \\ -1.403 & 3.722 & 4.620 & 0.091 \\ -1.153 & 3.933 & 4.774 & 0.091 \\ -0.903 & 4.927 & 4.927 & 0.091 \\ -0.653 & 7.399 & 7.399 & 1.469 \\ -0.403 & 8.786 & 8.786 & 0.824 \\ -0.153 & 10.707 & 10.707 & 1.141 \\ 0.347 & 12.219 & 12.219 & 0.449 \\ 0.597 & 12.042 & 13.185 & 0.574 \\ 0.847 & 14.151 & 14.151 & 0.574\end{array}$


Borehole 4W: Discharge Flow and Hydraulic Conductivity Elevation, $\mathrm{m}$ Qi-Qa,L/min Qi-Qa corr $\mathrm{K}, \mathrm{m} / \mathrm{s}$

$\begin{array}{lccc}-8.153 & 0.287 & 0.287 & -- \\ -7.653 & -- & 0.406 & 0.036 \\ -7.153 & -- & 0.526 & 0.036 \\ -6.653 & 0.645 & 0.645 & 0.036 \\ -6.153 & 0.594 & 0.761 & 0.035 \\ -5.653 & 0.635 & 0.878 & 0.035 \\ -5.153 & -- & 0.994 & 0.035 \\ -4.773 & 0.133 & 1.082 & 0.035 \\ -4.653 & -- & 1.110 & 0.035 \\ -4.403 & 1.168 & 1.168 & 0.035 \\ -4.153 & 1.311 & 1.311 & 0.086 \\ -3.653 & 0.830 & 1.772 & 0.138 \\ -3.153 & 2.233 & 2.233 & 0.138 \\ -2.903 & 1.834 & 2.816 & 0.350 \\ -2.653 & 1.752 & 3.399 & 0.350 \\ -2.403 & 1.941 & 3.982 & 0.350 \\ -2.153 & 2.028 & 4.565 & 0.350 \\ -1.903 & 5.148 & 5.148 & 0.350 \\ -1.653 & 8.318 & 8.318 & 1.902 \\ -1.403 & 8.871 & 8.871 & 0.332 \\ -1.153 & 2.254 & 9.103 & 0.139 \\ -0.903 & 2.208 & 9.334 & 0.139 \\ -0.653 & 1.987 & 9.566 & 0.139 \\ -0.403 & 8.205 & 9.797 & 0.139 \\ -0.153 & 10.029 & 10.029 & 0.139 \\ 0.097 & 7.114 & 10.981 & 0.572 \\ 0.347 & 11.934 & 11.934 & 0.572 \\ 0.597 & 13.102 & 13.102 & 0.701 \\ 0.847 & 14.505 & 14.280 & 0.707\end{array}$


Borehole 2W: Discharge Flow and Hydraulic Conductivity Elevation, $\mathrm{m}$ Qi-Qa, L/m Qi-Qa corr $\mathrm{K}, \mathrm{m} / \mathrm{s}$

$\begin{array}{rrrr}-6.653 & 0.129 & 0.129 & - \\ -6.153 & 0.075 & 0.172 & 0.013 \\ -5.653 & 0.215 & 0.215 & 0.013 \\ -5.153 & 0.333 & 0.333 & 0.035 \\ -4.653 & 0.440 & 0.440 & 0.032 \\ -4.153 & 0.665 & 0.665 & 0.067 \\ -3.903 & -0.622 & 0.919 & 0.152 \\ -3.653 & -- & 1.173 & 0.152 \\ -3.403 & 1.427 & 1.427 & 0.152 \\ -3.153 & 1.513 & 1.513 & 0.051 \\ -2.653 & 1.803 & 1.803 & 0.087 \\ -2.403 & 2.291 & 2.291 & 0.292 \\ -2.153 & 3.916 & 3.916 & 0.971 \\ -1.903 & 5.778 & 5.778 & 1.112 \\ -1.653 & 6.448 & 6.448 & 0.401 \\ -1.403 & 6.915 & 6.915 & 0.279 \\ -1.153 & 3.627 & 6.945 & 0.018 \\ -0.903 & 6.974 & 6.974 & 0.018 \\ -0.653 & 10.043 & 10.043 & 1.833 \\ -0.403 & 10.102 & 10.102 & 0.035 \\ -0.153 & 9.699 & 11.507 & 0.840 \\ 0.097 & 12.913 & 12.913 & 0.840 \\ 0.347 & 11.201 & 13.115 & 0.121 \\ 0.597 & 12.462 & 13.317 & 0.121 \\ 0.847 & 13.519 & 13.519 & 0.121\end{array}$


Borehole IW: Discharge Flow and Hydraulic Conductivity Elevation, $\mathrm{m}$ Qi-Qa, L/min Qi-Qa corr $\mathrm{K}, \mathrm{m} / \mathrm{s}$

\begin{tabular}{|c|c|c|c|}
\hline-10.153 & -- & -- & -- \\
\hline-9.653 & -- & -- & - \\
\hline-9.153 & -- & -- & - \\
\hline-8.653 & - & -- & -- \\
\hline-8.153 & $\ldots$ & $\ldots$ & -- \\
\hline-7.653 & 0.681 & 0.681 & -- \\
\hline-7.153 & -- & 0.697 & 0.005 \\
\hline-6.653 & -- & 0.714 & 0.005 \\
\hline-6.403 & -- & 0.722 & 0.005 \\
\hline-6.303 & 0.725 & 0.725 & 0.005 \\
\hline-6.153 & 1.563 & 1.563 & 0.827 \\
\hline-5.653 & 1.864 & 1.864 & 0.089 \\
\hline-5.153 & 1.897 & 1.897 & 0.010 \\
\hline-4.653 & 2.165 & 2.165 & 0.079 \\
\hline-4.153 & 1.518 & 2.907 & 0.220 \\
\hline-3.653 & 3.650 & 3.650 & 0.220 \\
\hline-3.153 & 3.962 & 3.962 & 0.093 \\
\hline-2.653 & 2.623 & 4.996 & 0.306 \\
\hline-2.403 & 3.722 & 5.512 & 0.306 \\
\hline-2.153 & 3.348 & 6.029 & 0.306 \\
\hline-1.903 & 6.546 & 6.546 & 0.306 \\
\hline-1.653 & 9.431 & 9.431 & 1.710 \\
\hline-1.403 & 9.576 & 9.576 & 0.086 \\
\hline-1.153 & 4.464 & 9.877 & 0.178 \\
\hline-0.903 & 6.512 & 10.177 & 0.178 \\
\hline-0.653 & 7.991 & 10.478 & 0.178 \\
\hline-0.153 & 7.701 & 11.079 & 0.178 \\
\hline 0.097 & 8.627 & 11.380 & 0.178 \\
\hline 0.347 & 9.074 & 11.681 & 0.178 \\
\hline 0.597 & 11.981 & 11.981 & 0.178 \\
\hline 0.847 & 12.869 & 12.869 & 0.526 \\
\hline
\end{tabular}


Borehole 25-5: Discharge Flow and Hydraulic Conductivity Elevation, $\mathrm{m}$ Qi-Qa,L/min Qi-Qa corr

\begin{tabular}{|c|c|c|}
\hline-9.153 & -- & - - \\
\hline-8.903 & -- & -- \\
\hline-8.653 & -- & - \\
\hline-8.403 & -- & -- \\
\hline-8.153 & -. & - \\
\hline-7.903 & -. & -- \\
\hline-7.653 & -- & -- \\
\hline-7.403 & -- & -- \\
\hline-7.153 & -- & - \\
\hline-6.903 & -- & -- \\
\hline-6.653 & -- & -- \\
\hline-6.403 & -- & -- \\
\hline-6.153 & -- & - - \\
\hline-5.903 & -- & -- \\
\hline-5.653 & -- & -- \\
\hline-5.403 & -- & -- \\
\hline-5.153 & -- & -- \\
\hline-4.903 & -- & -- \\
\hline-4.653 & -- & -- \\
\hline-4.353 & -- & - - \\
\hline-4.153 & -- & -- \\
\hline-3.903 & -- & -- \\
\hline-3.653 & -- & -- \\
\hline-3.403 & 2.120 & 2.120 \\
\hline-3.153 & 2.339 & 2.339 \\
\hline-2.903 & 1.115 & 2.408 \\
\hline-2.653 & 2.478 & 2.478 \\
\hline-2.403 & 2.657 & 2.657 \\
\hline-2.153 & 3.563 & 3.563 \\
\hline-1.903 & 4.130 & 4.130 \\
\hline-1.653 & 5.245 & 5.245 \\
\hline-1.403 & 8.499 & 8.499 \\
\hline-1.153 & 5.006 & 9.428 \\
\hline-0.903 & 3.931 & 10.357 \\
\hline-0.653 & 11.286 & 11.286 \\
\hline-0.403 & 7.514 & 11.309 \\
\hline-0.153 & 9.862 & 11.332 \\
\hline 0.097 & 11.355 & 11.355 \\
\hline 0.347 & 11.743 & 11.743 \\
\hline 0.597 & 11.723 & - \\
\hline 0.847 & & -. \\
\hline 1.097 & & -- \\
\hline
\end{tabular}


Borehole 1E: Discharge Flow and Hydraulic Conductivity Elevation, $\mathrm{m}$ Qi-Qa, L/min Qi-Qa corr $\mathrm{K}, \mathrm{m} / \mathrm{s}$

$\begin{array}{rrrr}-8.153 & 0.000 & 0.000 & - \\ -7.653 & 0.022 & 0.022 & 0.006 \\ -7.153 & 0.118 & 0.118 & 0.028 \\ -6.653 & 2.129 & 2.129 & 0.589 \\ -6.153 & 2.849 & 2.849 & 0.211 \\ -5.653 & 3.215 & 3.215 & 0.107 \\ -5.153 & 2.871 & 3.222 & 0.002 \\ -4.653 & 3.193 & 3.229 & 0.002 \\ -4.153 & 3.236 & 3.236 & 0.002 \\ -3.653 & -- & 3.650 & 0.121 \\ -3.403 & 2.871 & 3.857 & 0.121 \\ -3.153 & 4.064 & 4.064 & 0.121 \\ -2.653 & 4.054 & 6.631 & 0.751 \\ -2.153 & 3.828 & 9.197 & 0.751 \\ -1.653 & 11.763 & 11.763 & 0.751 \\ -1.153 & 4.742 & 11.950 & 0.055 \\ -0.653 & 12.064 & 12.136 & 0.055 \\ -0.153 & 12.322 & 12.322 & 0.055 \\ 0.347 & 13.935 & 13.935 & 0.472 \\ 0.847 & 14.620 & 14.620 & 0.201\end{array}$


Borehole 2E: Discharge Flow and Hydraulic Conductivity Elevation, $\mathrm{m}$ Qi-Qa, L/min Qi-Qa corr $\mathrm{K}, \mathrm{m} / \mathrm{s}$

\begin{tabular}{llrl}
-10.653 & -0.098 & -0.098 & 0.001 \\
-10.153 & -- & 0.215 & 0.098 \\
-10.053 & -0.236 & 0.277 & 0.098 \\
-9.653 & -0.275 & 0.528 & 0.098 \\
-9.153 & \multicolumn{1}{l}{--} & 0.841 & 0.098 \\
-8.653 & -- & 1.154 & 0.098 \\
-8.153 & \multicolumn{1}{c}{--} & 1.467 & 0.098 \\
-7.653 & -- & 1.780 & 0.098 \\
-7.153 & -- & 2.093 & 0.098 \\
-6.653 & -- & 2.406 & 0.098 \\
-6.403 & 2.562 & 2.562 & 0.098 \\
-6.153 & 2.994 & 2.994 & 0.271 \\
-5.653 & 2.975 & 3.019 & 0.008 \\
-5.153 & 3.043 & 3.043 & 0.008 \\
-4.653 & 2.916 & 3.051 & 0.002 \\
-4.153 & 2.425 & 3.058 & 0.002 \\
-3.653 & 1.924 & 3.065 & 0.002 \\
-3.403 & 2.994 & 3.069 & 0.002 \\
-3.153 & 3.073 & 3.073 & 0.002 \\
-2.903 & 2.479 & 3.325 & 0.158 \\
-2.653 & 2.749 & 3.577 & 0.158 \\
-2.403 & 3.829 & 3.829 & 0.158 \\
-2.153 & 5.743 & 5.743 & 1.199 \\
-1.653 & 6.685 & 6.685 & 0.295 \\
-1.403 & 9.267 & 9.267 & 1.618 \\
-1.278 & 9.542 & 9.542 & 0.344 \\
-1.153 & 8.875 & 9.788 & 0.309 \\
-0.903 & 5.355 & 10.281 & 0.309 \\
-0.653 & 5.998 & 10.773 & 0.309 \\
-0.403 & 7.854 & 11.266 & 0.309 \\
-0.153 & 6.155 & 11.758 & 0.309 \\
0.097 & 6.754 & 12.251 & 0.309 \\
0.232 & 12.517 & 12.517 & 0.309 \\
0.347 & 13.057 & 13.057 & 0.735 \\
0.597 & 12.684 & & -- \\
0.847 & 2.523 & & -- \\
& & &
\end{tabular}


Borehole 4E: Discharge Flow and Hydraulic Conductivity Elevation, $\mathrm{m}$ Qi-Qa, L/min Qi-Qa corr $\mathrm{K}, \mathrm{m} / \mathrm{s}$

\begin{tabular}{|c|c|c|c|}
\hline-9.153 & -0.158 & -0.158 & $\ldots$ \\
\hline-8.903 & 0.020 & -0.049 & 0.091 \\
\hline-8.653 & 0.059 & 0.059 & 0.091 \\
\hline-8.403 & 0.010 & 0.213 & 0.129 \\
\hline-8.153 & -0.030 & 0.367 & 0.129 \\
\hline-7.903 & -0.109 & 0.521 & 0.129 \\
\hline-7.653 & -- & 0.675 & 0.129 \\
\hline-7.403 & -- & 0.828 & 0.129 \\
\hline-7.153 & -- & 0.982 & 0.129 \\
\hline-6.903 & -- & 1.136 & 0.129 \\
\hline-6.653 & -- & 1.290 & 0.129 \\
\hline-6.403 & 1.444 & 1.444 & 0.129 \\
\hline-6.153 & 1.948 & 1.948 & 0.422 \\
\hline-5.903 & 2.176 & 2.176 & 0.190 \\
\hline-5.653 & 1.889 & 2.197 & 0.018 \\
\hline-5.403 & 2.067 & 2.218 & 0.018 \\
\hline-5.153 & 2.156 & 2.239 & 0.018 \\
\hline-4.903 & 2.166 & 2.260 & 0.018 \\
\hline-4.653 & 1.790 & 2.281 & 0.018 \\
\hline-4.553 & 1.988 & 2.290 & 0.018 \\
\hline-4.403 & 2.077 & 2.302 & 0.018 \\
\hline-4.153 & 1.815 & 2.323 & 0.018 \\
\hline-4.053 & -- & 2.332 & 0.018 \\
\hline-3.903 & 1.844 & 2.344 & 0.018 \\
\hline-3.853 & -- & 2.349 & 0.018 \\
\hline-3.653 & 0.989 & 2.365 & 0.018 \\
\hline-3.403 & 1.088 & 2.387 & 0.018 \\
\hline-3.153 & 1.384 & 2.408 & 0.018 \\
\hline-2.903 & 1.553 & 2.429 & 0.018 \\
\hline-2.653 & 1.938 & 2.450 & 0.018 \\
\hline-2.403 & 1.770 & 2.471 & 0.018 \\
\hline-2.153 & 2.492 & 2.492 & 0.018 \\
\hline-1.903 & 4.203 & 4.203 & 1.430 \\
\hline-1.653 & 3.946 & 4.544 & 0.285 \\
\hline-1.403 & 4.885 & 4.885 & 0.285 \\
\hline-1.153 & 3.837 & 5.231 & 0.289 \\
\hline-0.903 & 3.461 & 5.577 & 0.289 \\
\hline-0.653 & 5.924 & 5.924 & 0.289 \\
\hline-0.403 & 6.487 & 6.487 & 0.471 \\
\hline-0.153 & 8.297 & 8.297 & 1.513 \\
\hline 0.097 & 9.642 & 9.642 & 1.124 \\
\hline 0.347 & 6.369 & 9.794 & 0.127 \\
\hline 0.447 & 9.063 & 9.855 & 0.127 \\
\hline 0.597 & 8.791 & 9.947 & 0.127 \\
\hline 0.847 & 9.395 & 10.099 & 0.127 \\
\hline 1.097 & 8.139 & 10.251 & 0.127 \\
\hline
\end{tabular}


Borehole 6E: Discharge Flow and Hydraulic Conductivity Elevation, $\mathrm{m}$ Qi-Qa, L/min Qi-Qa corr $\mathrm{K}, \mathrm{m} / \mathrm{s}$

$\begin{array}{lrcl}-8.603 & 0.336 & 0.336 & -- \\ -8.153 & 0.049 & 0.603 & 0.123 \\ -7.653 & -- & 0.900 & 0.123 \\ -7.153 & -- & 1.197 & 0.123 \\ -6.653 & 1.493 & 1.493 & 0.123 \\ -6.403 & 3.110 & 3.110 & 1.338 \\ -6.153 & 3.293 & 3.293 & 0.151 \\ -5.903 & 3.619 & 3.619 & 0.270 \\ -5.653 & 3.570 & 3.763 & 0.119 \\ -5.403 & 3.906 & 3.906 & 0.119 \\ -5.153 & 4.114 & 4.114 & 0.172 \\ -4.903 & 3.980 & 4.153 & 0.033 \\ -4.653 & 4.193 & 4.193 & 0.033 \\ -4.403 & 4.158 & 4.262 & 0.057 \\ -4.153 & 4.331 & 4.331 & 0.057 \\ -3.903 & 4.564 & 4.564 & 0.192 \\ -3.653 & -- & 4.638 & 0.061 \\ -3.153 & 4.786 & 4.786 & 0.061 \\ -2.903 & 5.142 & 5.142 & 0.295 \\ -2.653 & 4.727 & 5.405 & 0.217 \\ -2.403 & 5.666 & 5.666 & 0.217 \\ -2.153 & 6.250 & 6.250 & 0.483 \\ -1.903 & 8.168 & 8.168 & 1.588 \\ -1.653 & 8.267 & 8.267 & 0.082 \\ -1.403 & 8.445 & 8.445 & 0.147 \\ -1.153 & 8.485 & 8.485 & 0.318 \\ -0.903 & -- & -- & 0.318 \\ -0.653 & 10.255 & 10.255 & 0.318 \\ -0.403 & 10.097 & 10.757 & 0.318 \\ -0.153 & 4.386 & 11.259 & 0.318 \\ 0.097 & 10.205 & 11.760 & 0.318 \\ 0.347 & 12.262 & 12.262 & 0.318 \\ 0.847 & 12.341 & 12.341 & 0.025\end{array}$


Borehole 8E: Discharge Flow and Hydraulic Conductivity Elevation, $\mathrm{m}$ Qi-Qa, L/min Qi-Qa corr $\mathrm{K}, \mathrm{m} / \mathrm{s}$

$\begin{array}{llll}-8.393 & 0.030 & 0.030 & -- \\ -8.153 & -- & 0.175 & 0.098 \\ -7.653 & -- & 0.478 & 0.098 \\ -7.153 & -- & 0.781 & 0.098 \\ -6.653 & -- & 1.085 & 0.098 \\ -6.403 & 1.236 & 1.236 & 0.098 \\ -6.153 & 1.048 & 1.253 & 0.011 \\ -5.653 & 1.108 & 1.287 & 0.011 \\ -5.153 & 1.177 & 1.321 & 0.011 \\ -4.653 & 1.355 & 1.355 & 0.011 \\ -4.403 & 1.286 & 1.498 & 0.092 \\ -4.153 & 1.068 & 1.642 & 0.092 \\ -3.903 & 0.865 & 1.785 & 0.092 \\ -3.653 & 1.117 & 1.928 & 0.092 \\ -3.153 & 1.345 & 2.215 & 0.092 \\ -2.653 & 2.502 & 2.502 & 0.092 \\ -2.153 & 4.252 & 4.252 & 0.563 \\ -1.903 & 5.558 & 5.558 & 0.840 \\ -1.653 & 6.082 & 6.082 & 0.337 \\ -1.523 & 6.356 & 6.356 & 0.340 \\ -1.403 & 6.008 & 7.180 & 1.105 \\ -1.153 & 4.925 & 8.897 & 1.105 \\ -1.023 & 2.556 & 9.789 & 1.105 \\ -0.903 & 3.728 & 10.613 & 1.105 \\ -0.773 & 11.506 & 11.506 & 1.105 \\ -0.653 & 11.511 & 11.511 & 0.007 \\ -0.403 & 12.134 & 12.134 & 0.401 \\ -0.153 & 12.638 & 12.638 & 0.325 \\ 0.097 & 12.688 & 12.688 & 0.032\end{array}$


Borehole 10E: Discharge Flow and Hydraulic Conductivity Elevation, $\mathrm{m}$ Qi-Qa, L/min Qi-Qa corr

$$
\mathrm{K}, \mathrm{m} / \mathrm{s}
$$$$
-9.153
$$$$
-8.653
$$$$
-8.153
$$$$
-7.903
$$$$
-7.653
$$$$
-7.403
$$$$
-7.153
$$$$
-6.903
$$$$
-6.653
$$$$
-6.153
$$$$
-5.653
$$$$
-5.153
$$$$
-4.653
$$$$
-4.153
$$$$
-3.653
$$$$
-3.153
$$$$
-2.653
$$$$
-2.153
$$$$
-1.653
$$$$
-1.153
$$$$
-0.653
$$$$
-0.153
$$$$
0.347
$$$$
0.847
$$$$
\begin{aligned}
& -- \\
& -- \\
& -- \\
& -- \\
& -- \\
& -- \\
& -- \\
& -- \\
& -- \\
& -- \\
& -- \\
& -- \\
& -- \\
& - \\
& 1.561 \\
& 1.581 \\
& 2.768 \\
& 6.941 \\
& 10.004 \\
& 3.318 \\
& 11.074 \\
& 13.116 \\
& 12.654 \\
& 13.312
\end{aligned}
$$

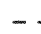$$
-
$$$$
\text { -- }
$$$$
\text { - }
$$$$
-
$$$$
-
$$$$
-
$$$$
-
$$$$
\text { -- }
$$$$
--
$$$$
-
$$$$
\text { -- }
$$$$
\text { 1. } 561
$$$$
1.581
$$$$
2.768
$$$$
6.941
$$$$
10.004
$$$$
10.539
$$$$
11.074
$$$$
13.116
$$$$
13.214
$$$$
13.312
$$ 
Borehole 12E: Discharge Flow and Hydraulic Conductivity Elevation, mQi-Qa, L/min Qi-Qa corr $\mathrm{K}, \mathrm{m} / \mathrm{s}$

$\begin{array}{lrrl}-7.153 & 0.218 & 0.218 & - \\ -6.903 & 0.915 & 0.915 & 0.464 \\ -6.653 & 2.106 & 2.106 & 0.792 \\ -6.153 & 0.623 & 2.137 & 0.010 \\ -5.653 & 0.860 & 2.168 & 0.010 \\ -5.153 & 0.761 & 2.199 & 0.010 \\ -4.903 & 0.341 & 2.215 & 0.010 \\ -4.653 & 1.137 & 2.230 & 0.010 \\ -4.403 & 0.979 & 2.245 & 0.010 \\ -4.153 & 1.137 & 2.261 & 0.010 \\ -3.903 & 1.142 & 2.276 & 0.010 \\ -3.653 & 0.613 & 2.292 & 0.010 \\ -3.403 & 1.493 & 2.307 & 0.010 \\ -3.153 & 1.058 & 2.323 & 0.010 \\ -2.653 & 2.354 & 2.354 & 0.010 \\ -2.403 & 2.784 & 2.784 & 0.286 \\ -2.153 & 5.123 & 5.123 & 1.555 \\ -1.903 & 6.289 & 6.289 & 0.776 \\ -1.653 & 6.626 & 6.626 & 0.224 \\ -1.403 & 6.640 & 6.640 & 0.010 \\ -1.153 & 3.155 & 8.277 & 1.088 \\ -0.903 & 4.460 & 9.914 & 1.088 \\ -0.653 & 11.550 & 11.550 & 1.088 \\ -0.153 & 12.391 & 12.391 & 0.279 \\ 0.097 & 12.989 & 12.989 & 0.398 \\ 0.347 & 11.758 & 13.115 & 0.084 \\ 0.597 & 12.786 & 13.241 & 0.084 \\ 0.847 & 12.747 & 13.368 & 0.084\end{array}$


Borehole 14E: Discharge Flow and Hydraulic Conductivity Elevation, mQi-Qa, L/min Qi-Qa corr $\mathrm{K}, \mathrm{m} / \mathrm{s}$

$$
\begin{aligned}
& -8.153 \\
& -7.153 \\
& -6.653 \\
& -6.153 \\
& -5.653 \\
& -5.153 \\
& -4.653 \\
& -4.153 \\
& -3.573 \\
& -3.403 \\
& -3.233 \\
& -2.653 \\
& -2.403 \\
& -2.153 \\
& -1.653 \\
& -1.153 \\
& -0.903 \\
& -0.653 \\
& -0.153 \\
& 0.347
\end{aligned}
$$

0.089

0.366

0.405

0.376

0.514

0.534

0.999

0.583

0.465

1. 820

2. 136

3. 135

5. 127

8.030

8.851

9.592

7.639

11.659

12.183

12.351
0.089

0.366

0.405

0.460

0.514

0.534

0.999

1. 327

1.708

1.820

2. 136

3.135

5.127

8.030

8.851

9.592

10.626

11.659

12.183

12.351
0.045

0.013

0.018

0.018

0.006

0.151

0.107

0.107

0.107

0.303

0.280

1. 296

1. 887

0.267

0.241

0.672

0.672

0.170

0.055 


\section{APPENDIX VII \\ Flow and Hydraulic Conductivity Profiles}



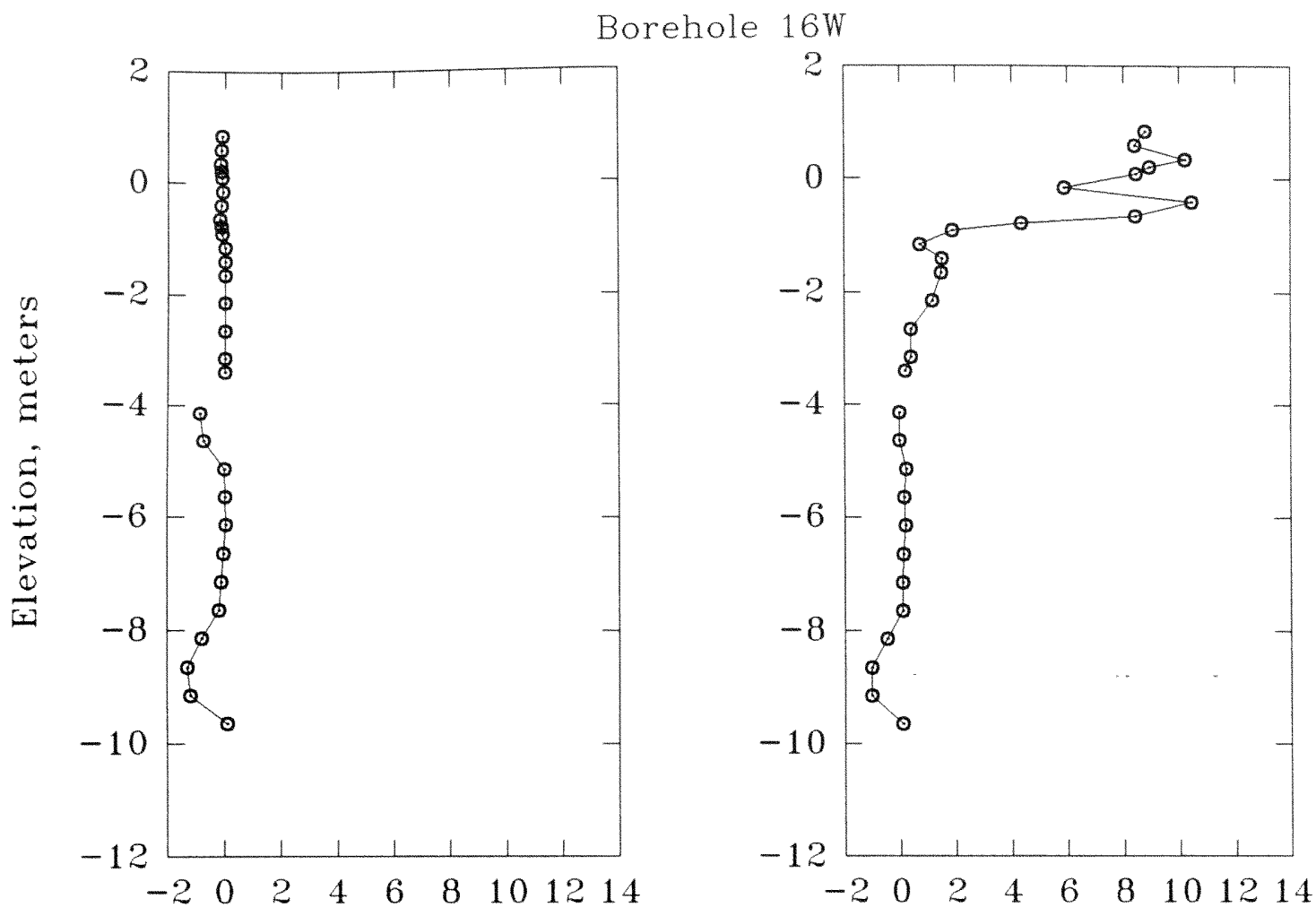

Ambient flow, Qa, L/min

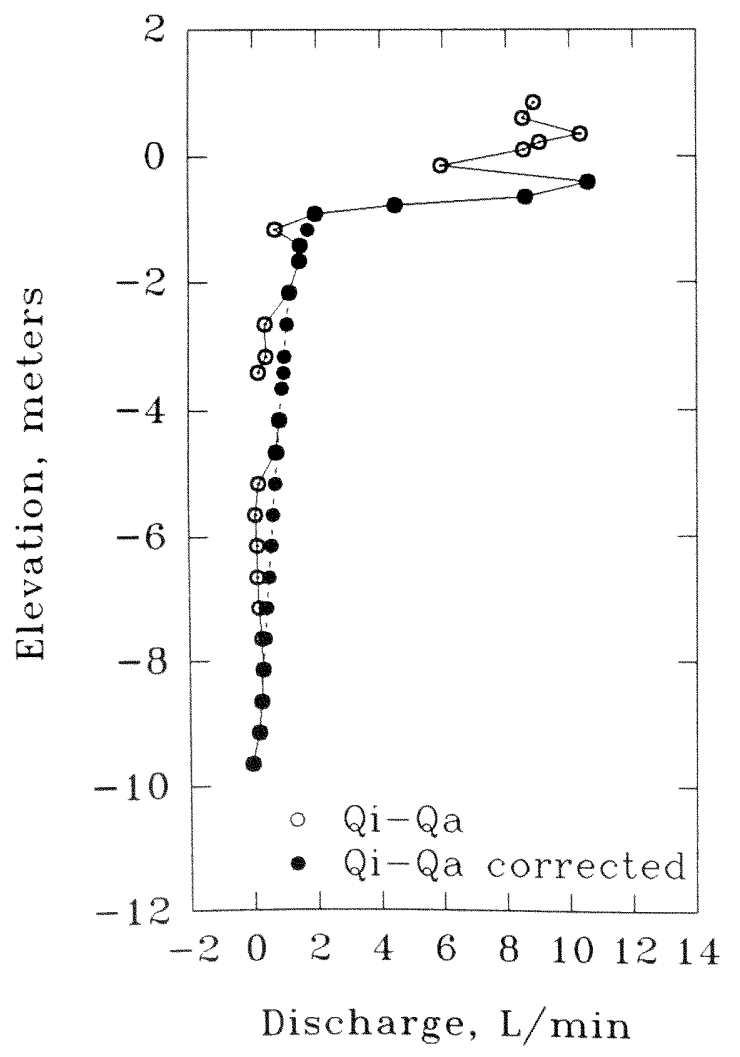

Induced flow, Qi, L/min

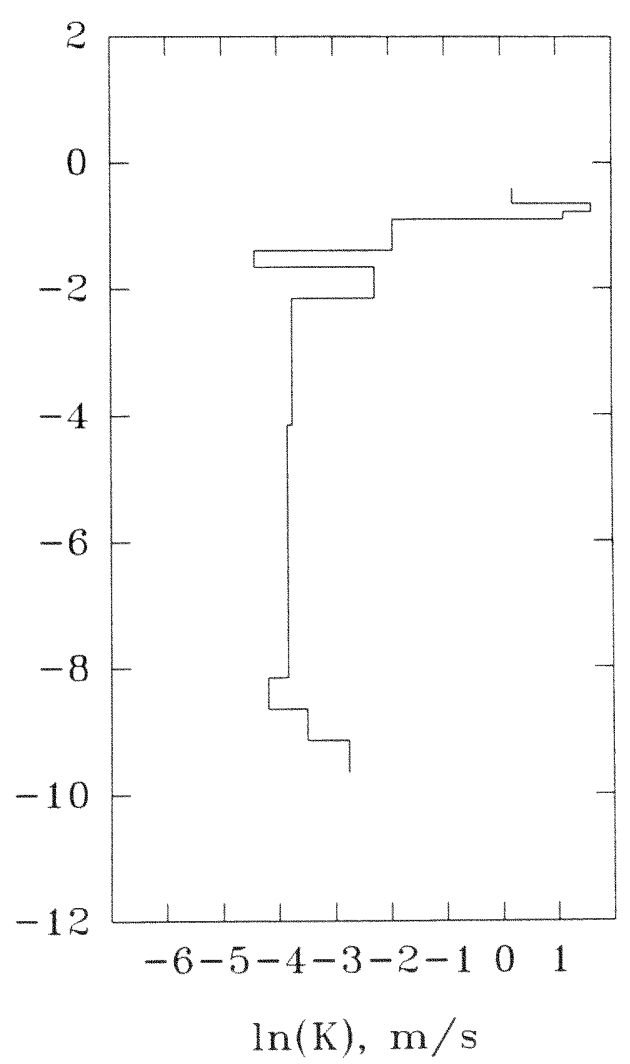


Borehole $14 \mathrm{~W}$
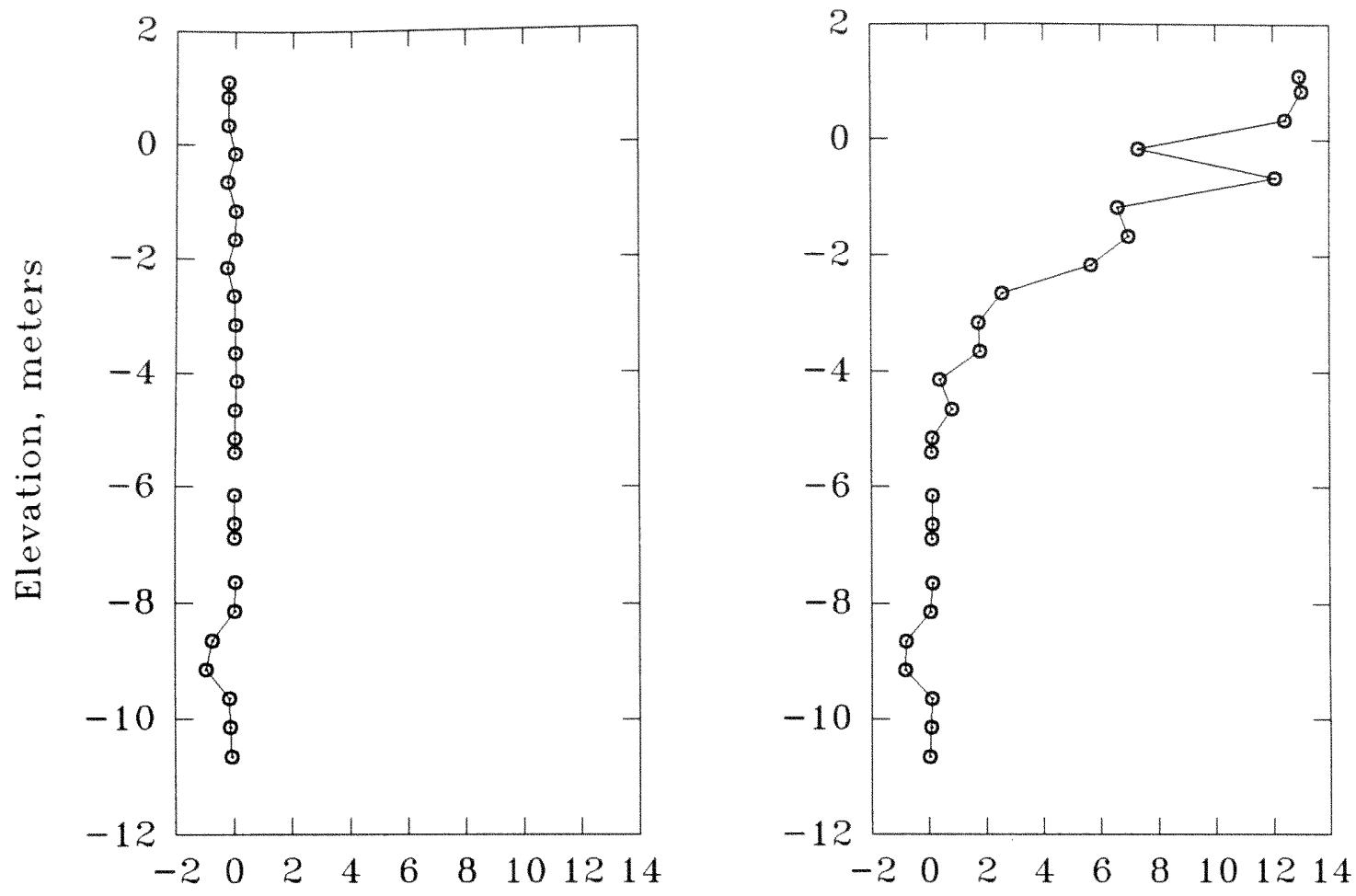

Ambient flow, Qa, L/min

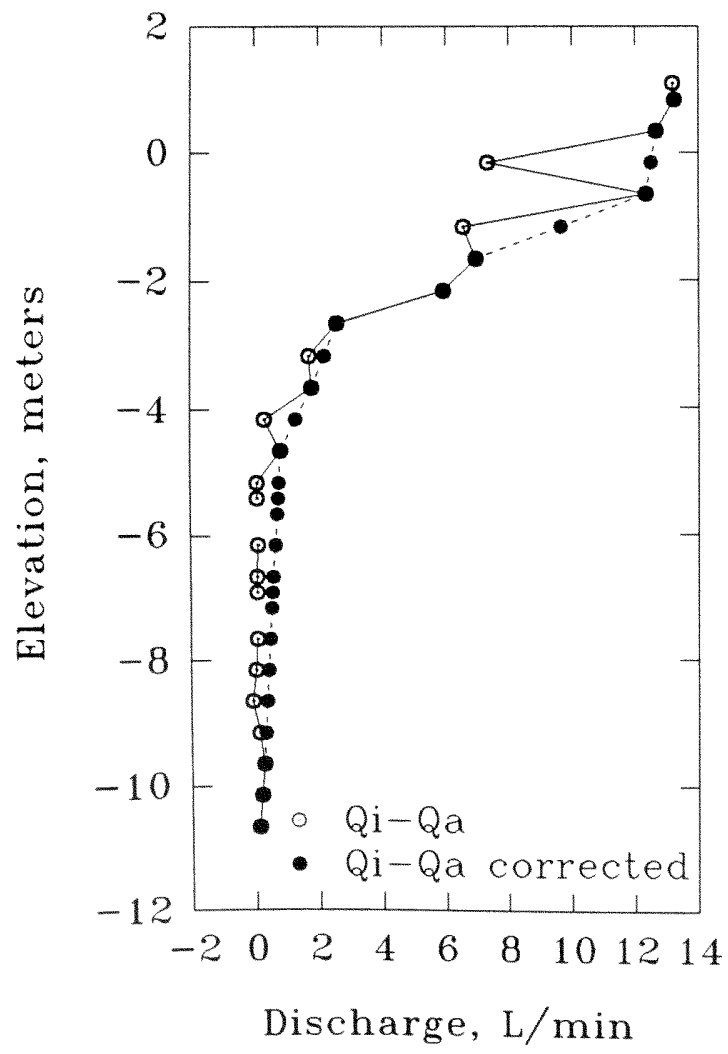

Induced flow, $\mathrm{Qi}, \mathrm{L} / \mathrm{min}$

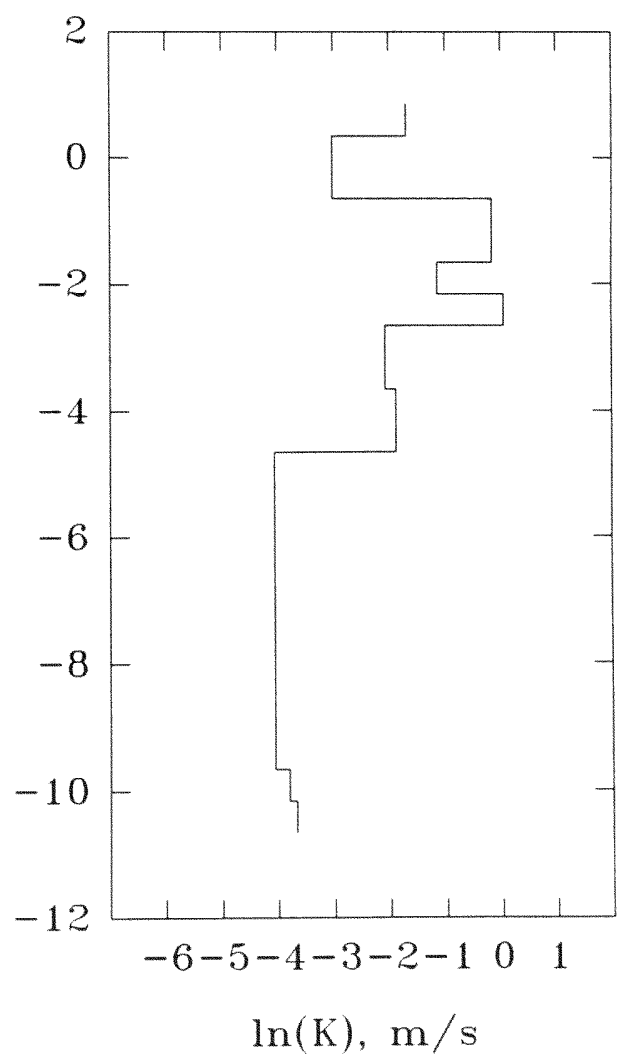


Borehole 12W

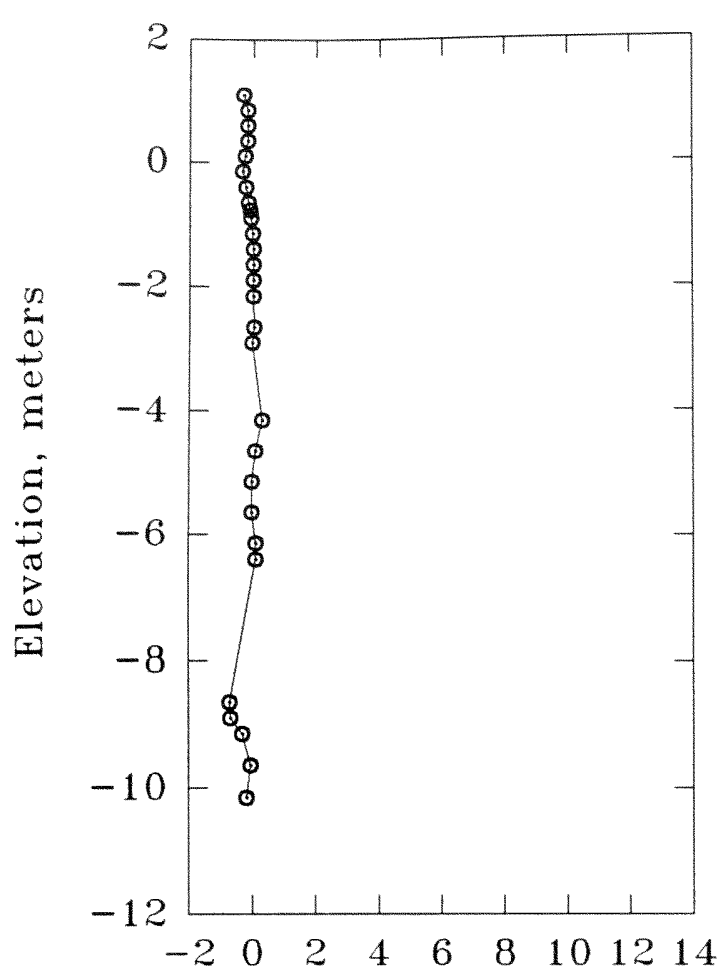

Ambient flow, Qa, L/min

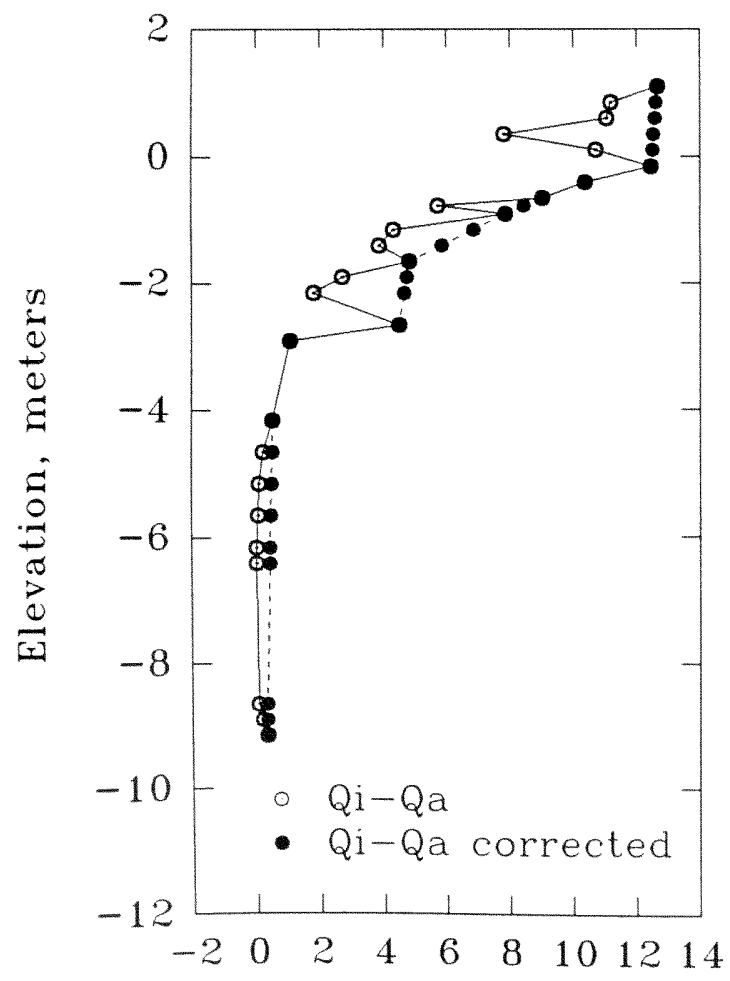

Discharge, L/min

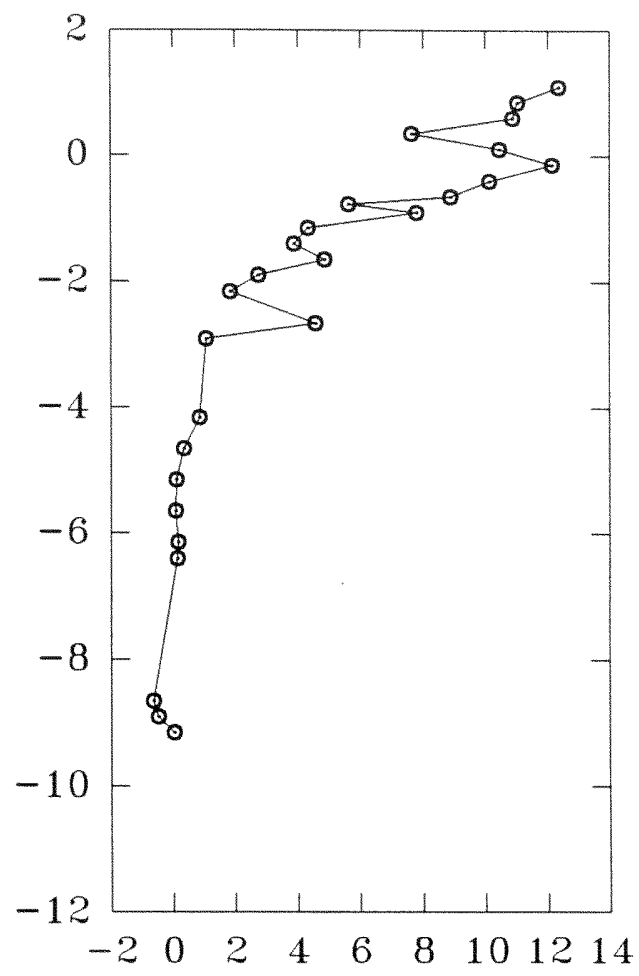

Induced flow, Qi, L/min

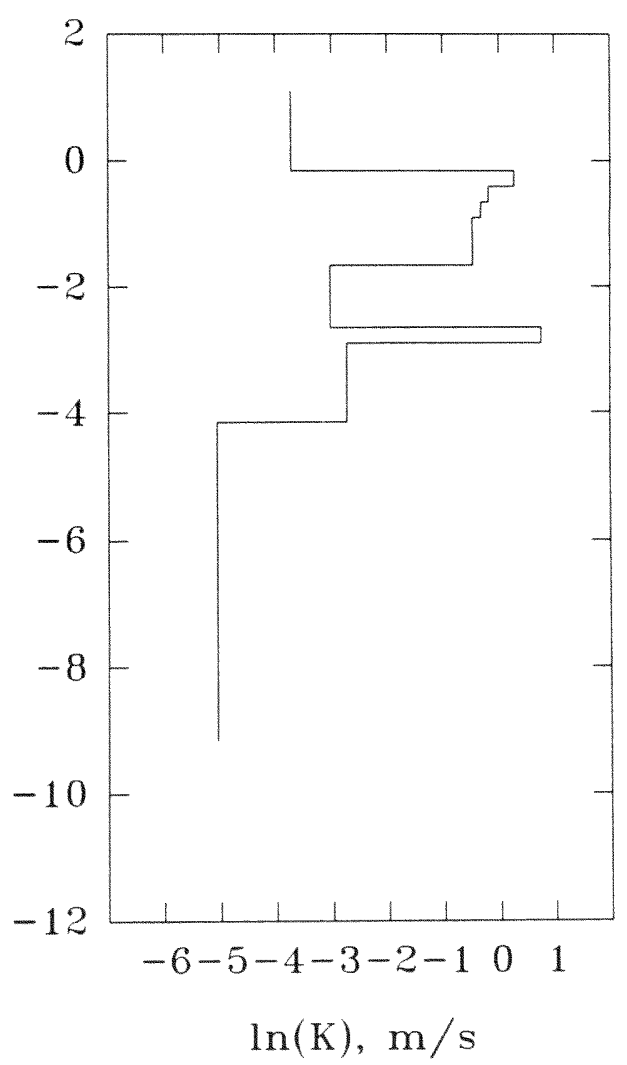



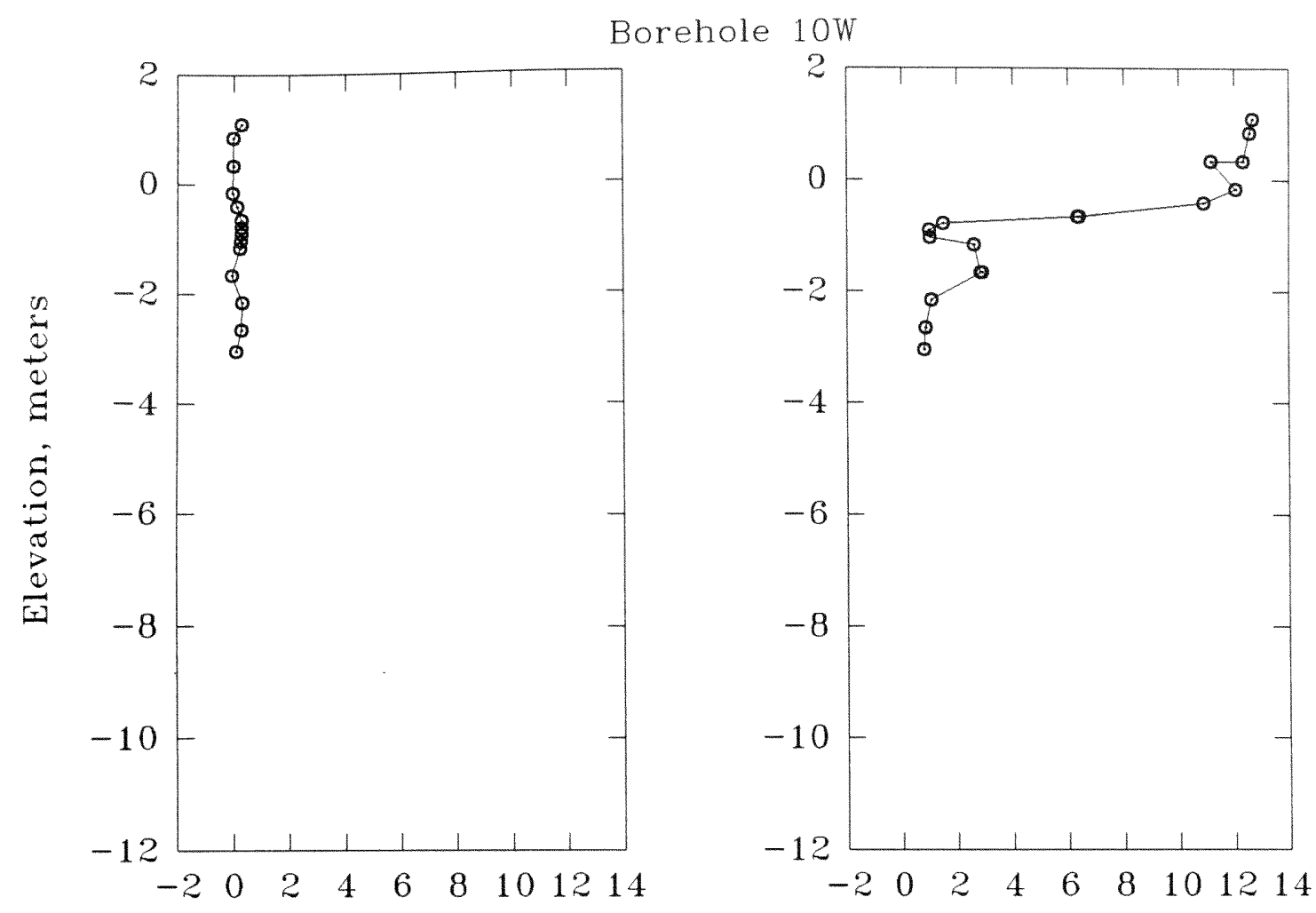

Ambient flow, Qa, L/min

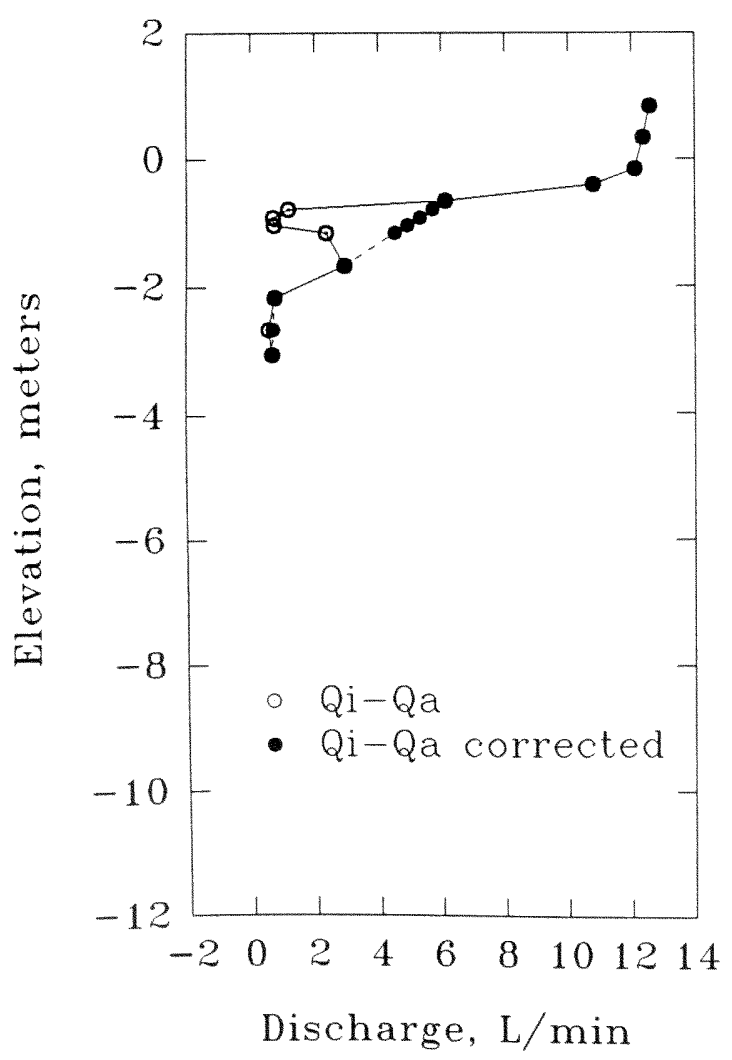

Induced flow, Qi, L/min

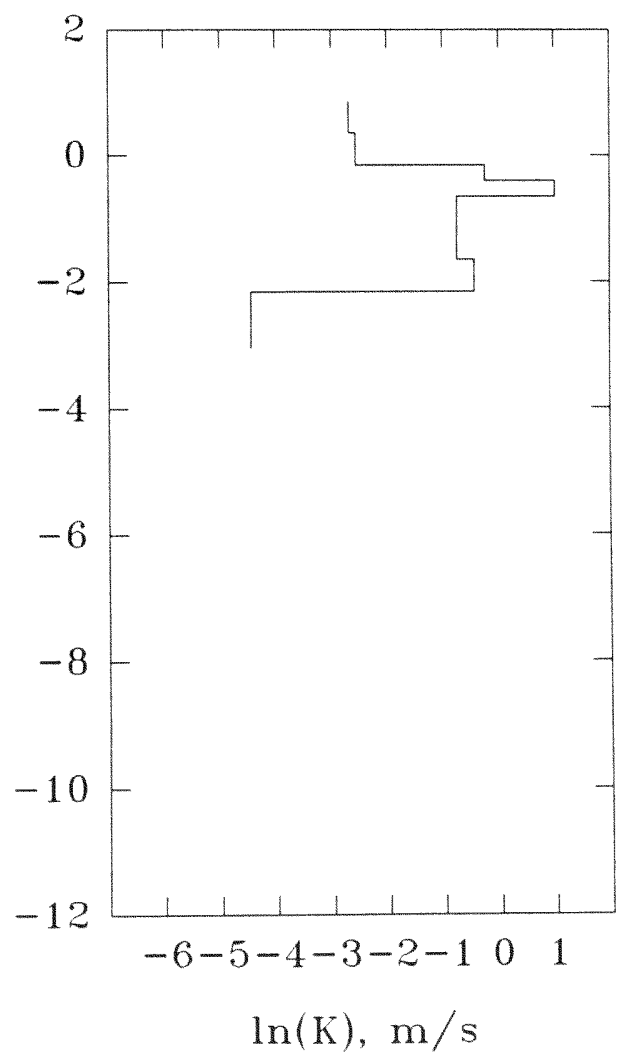


Borehole 8W

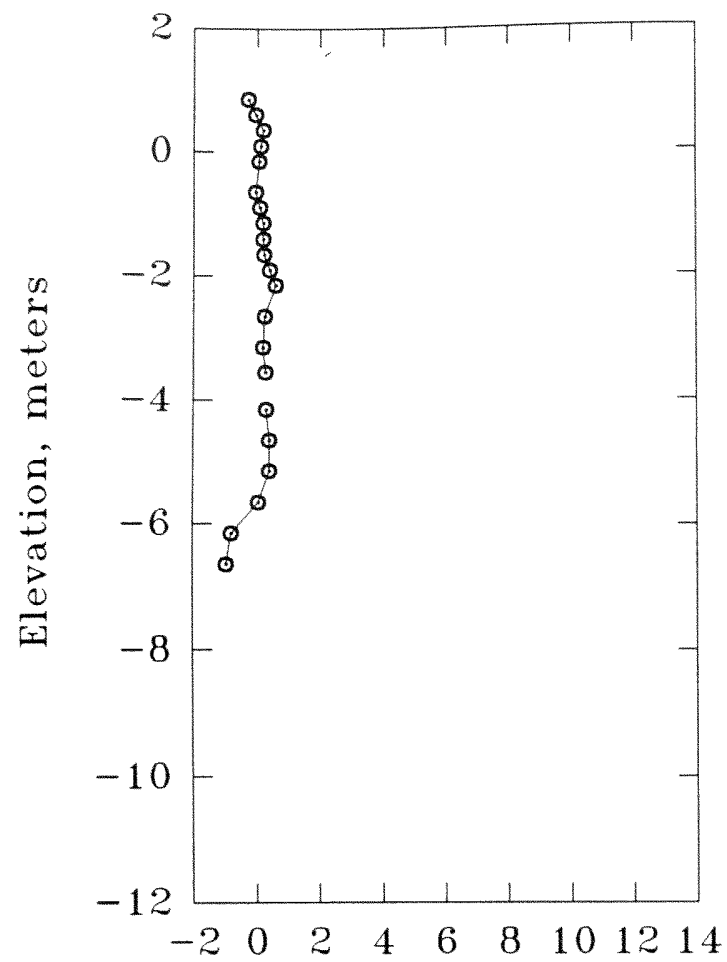

Ambient flow, Qa, L/min

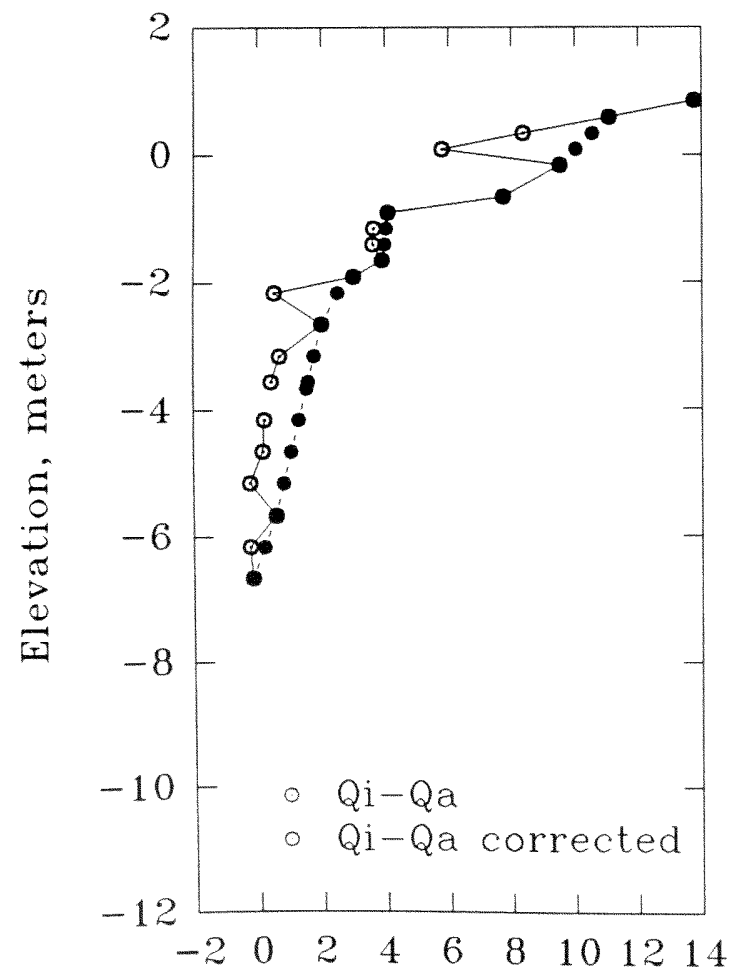

Discharge, $\mathrm{L} / \mathrm{min}$

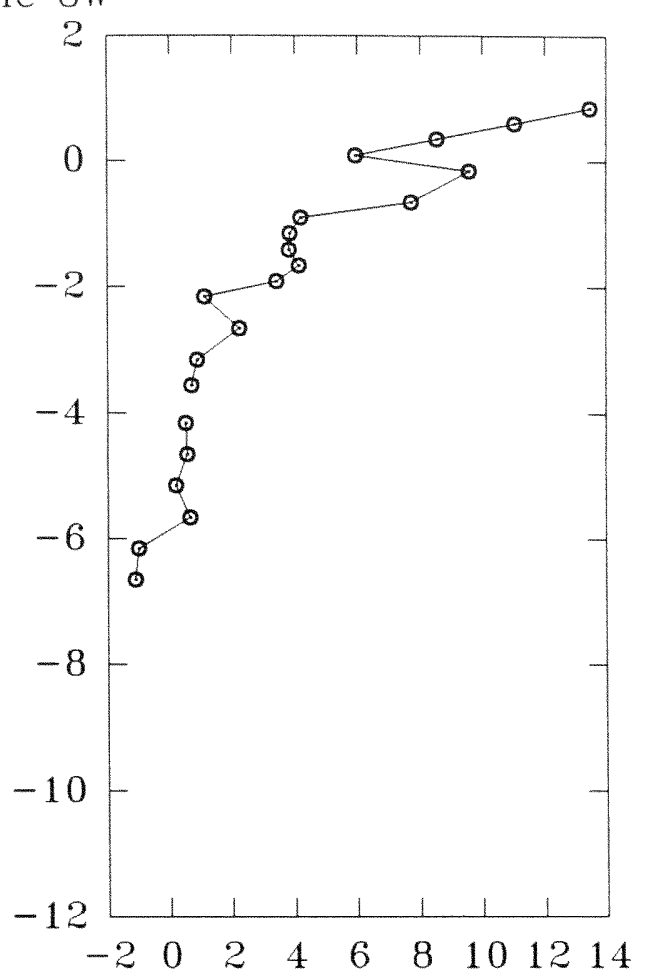

Induced flow, Qi, L/min

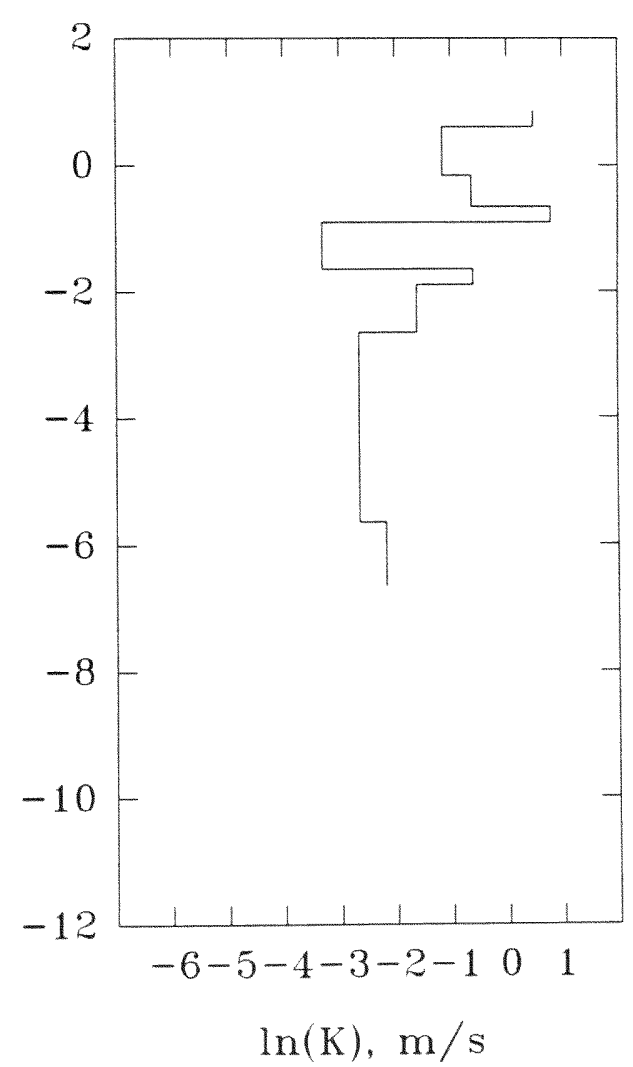




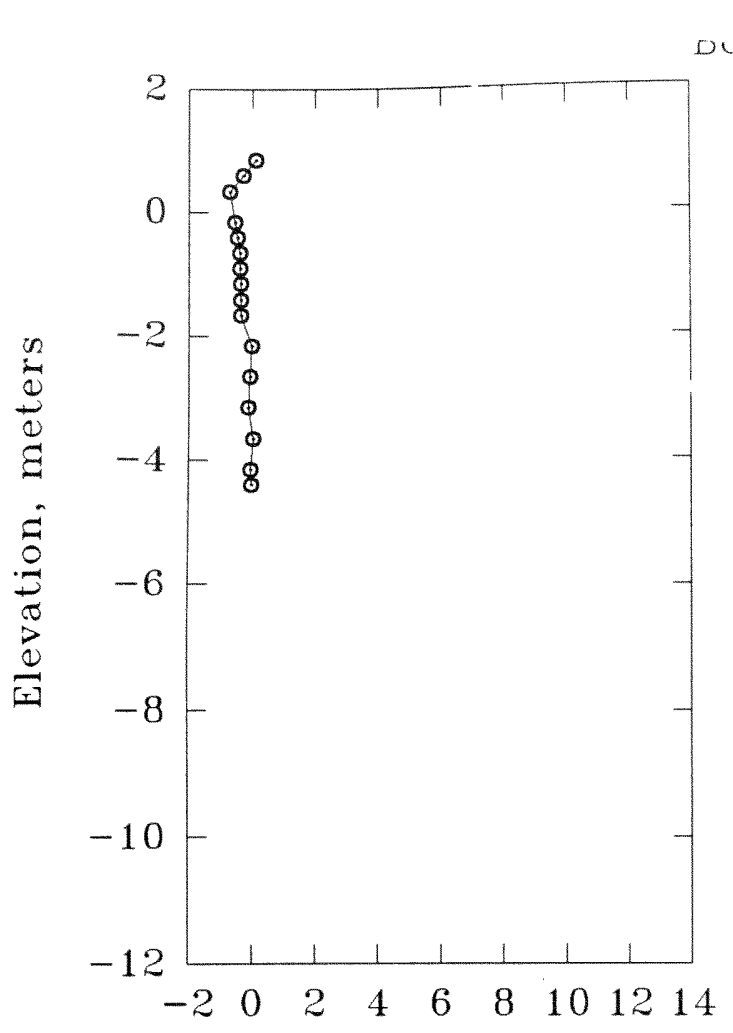

Ambient flow, Qa, L/min

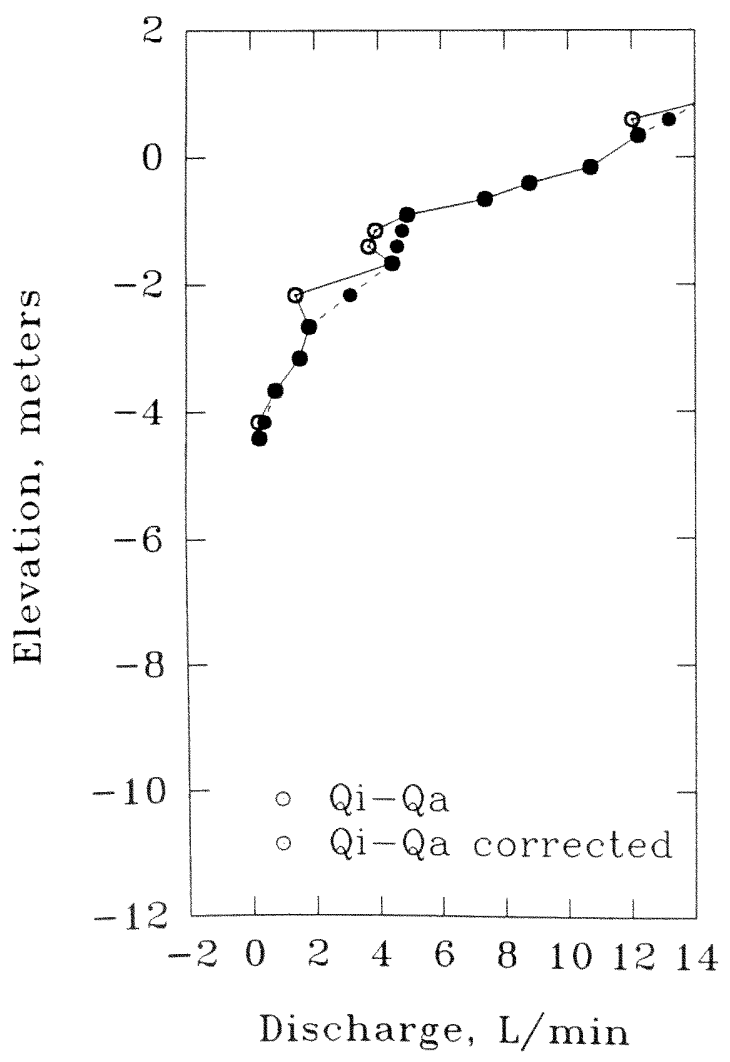

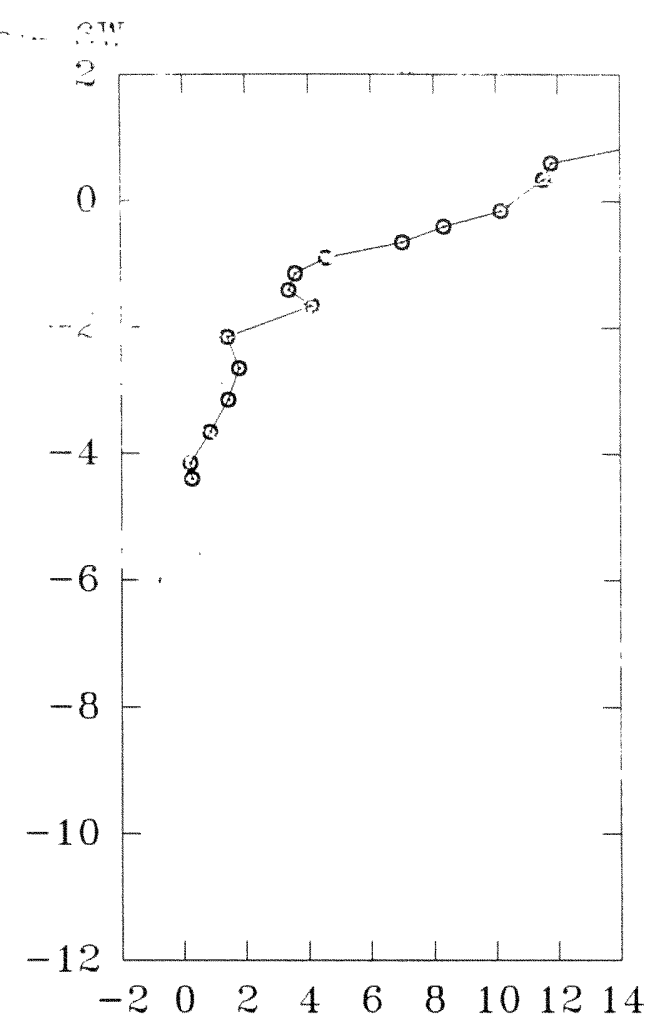

Induced flow, Qi, L/min

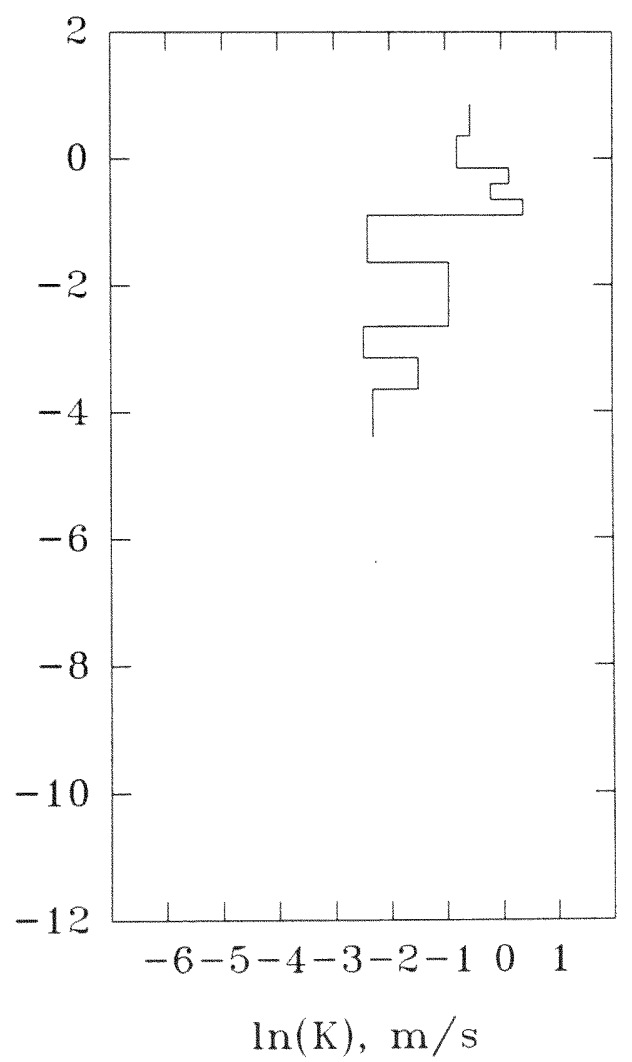


Borehole $4 \mathrm{~W}$
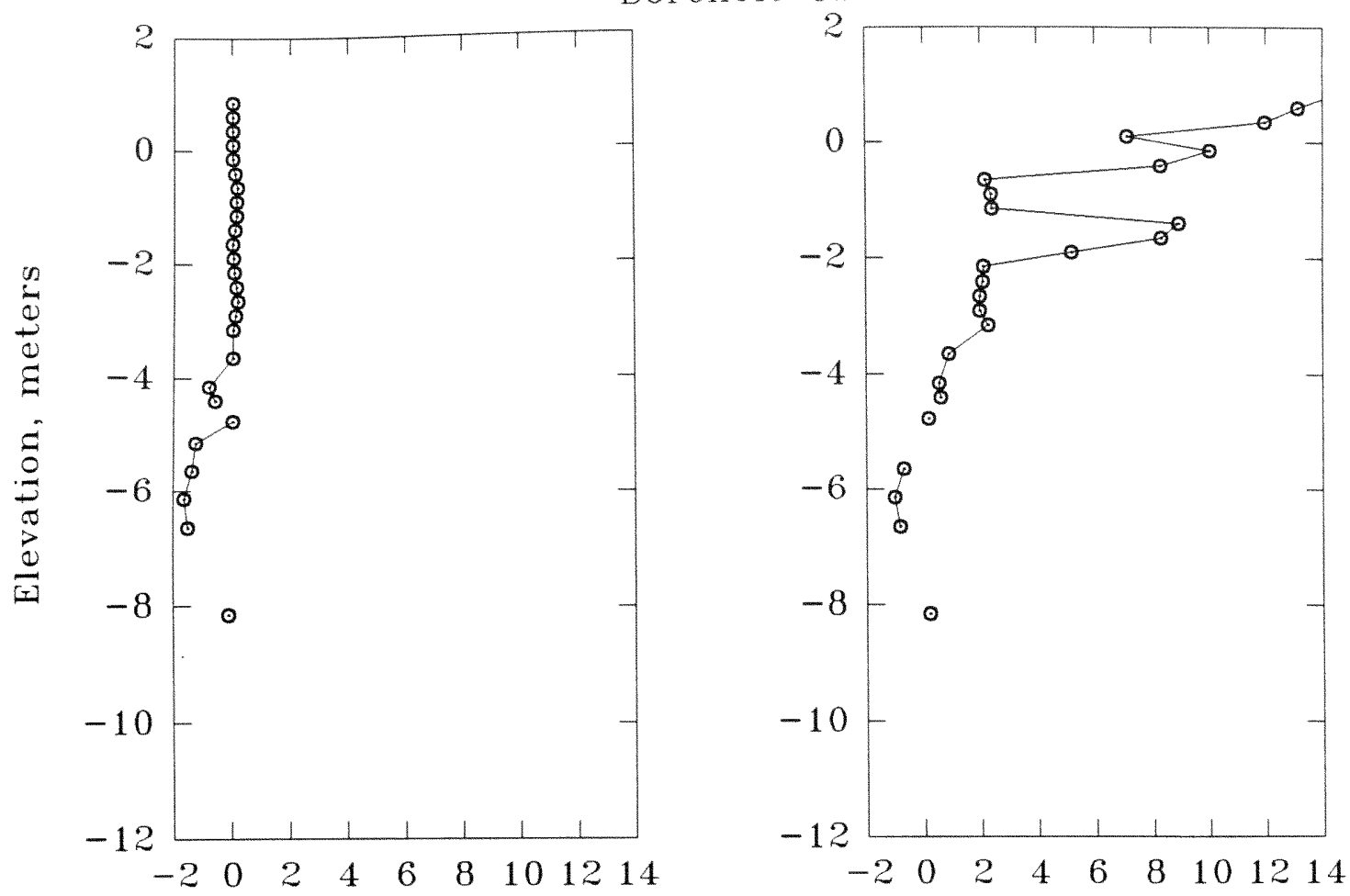

Ambient flow, Qa, L/min
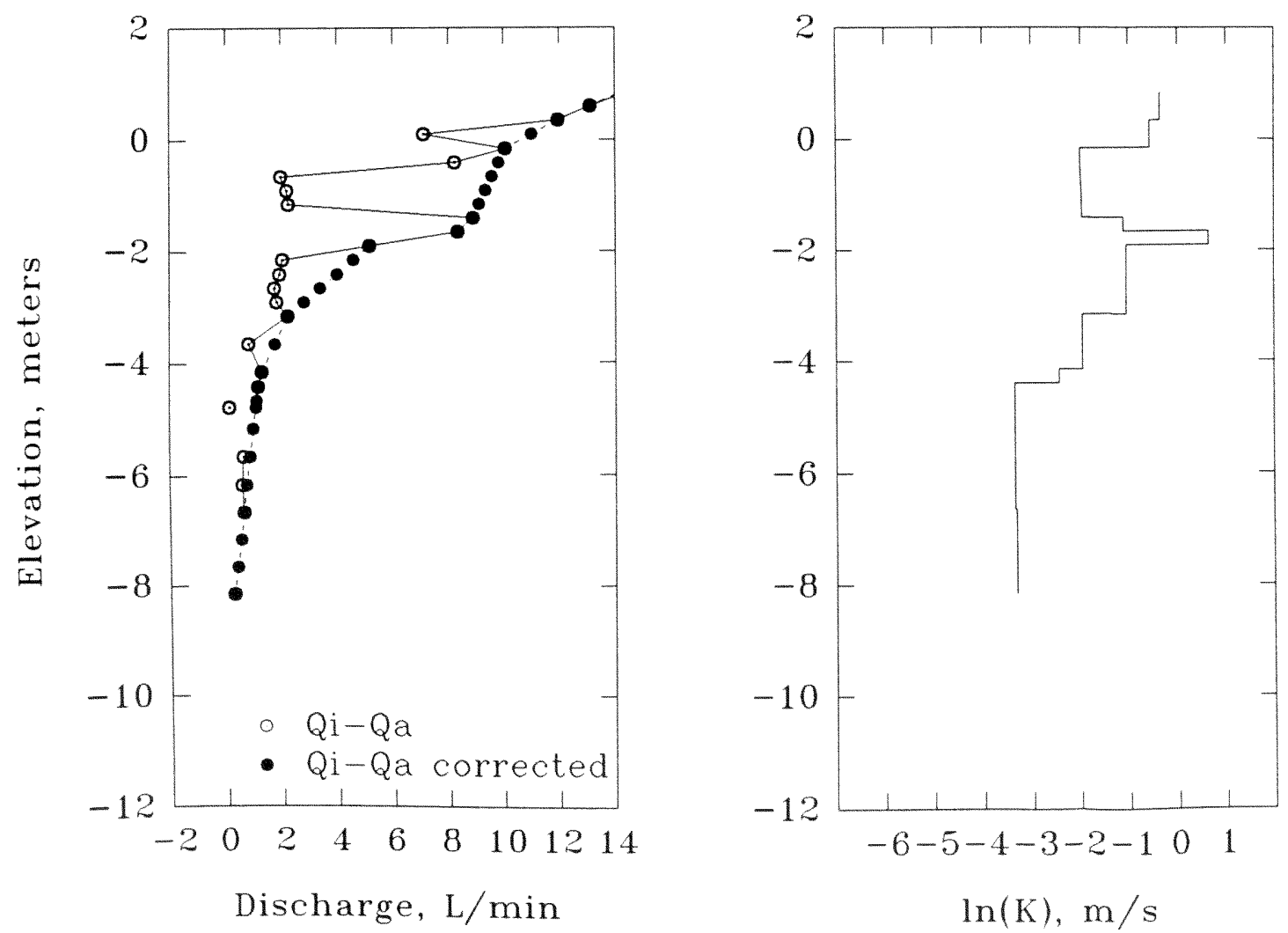
Borehole 2W
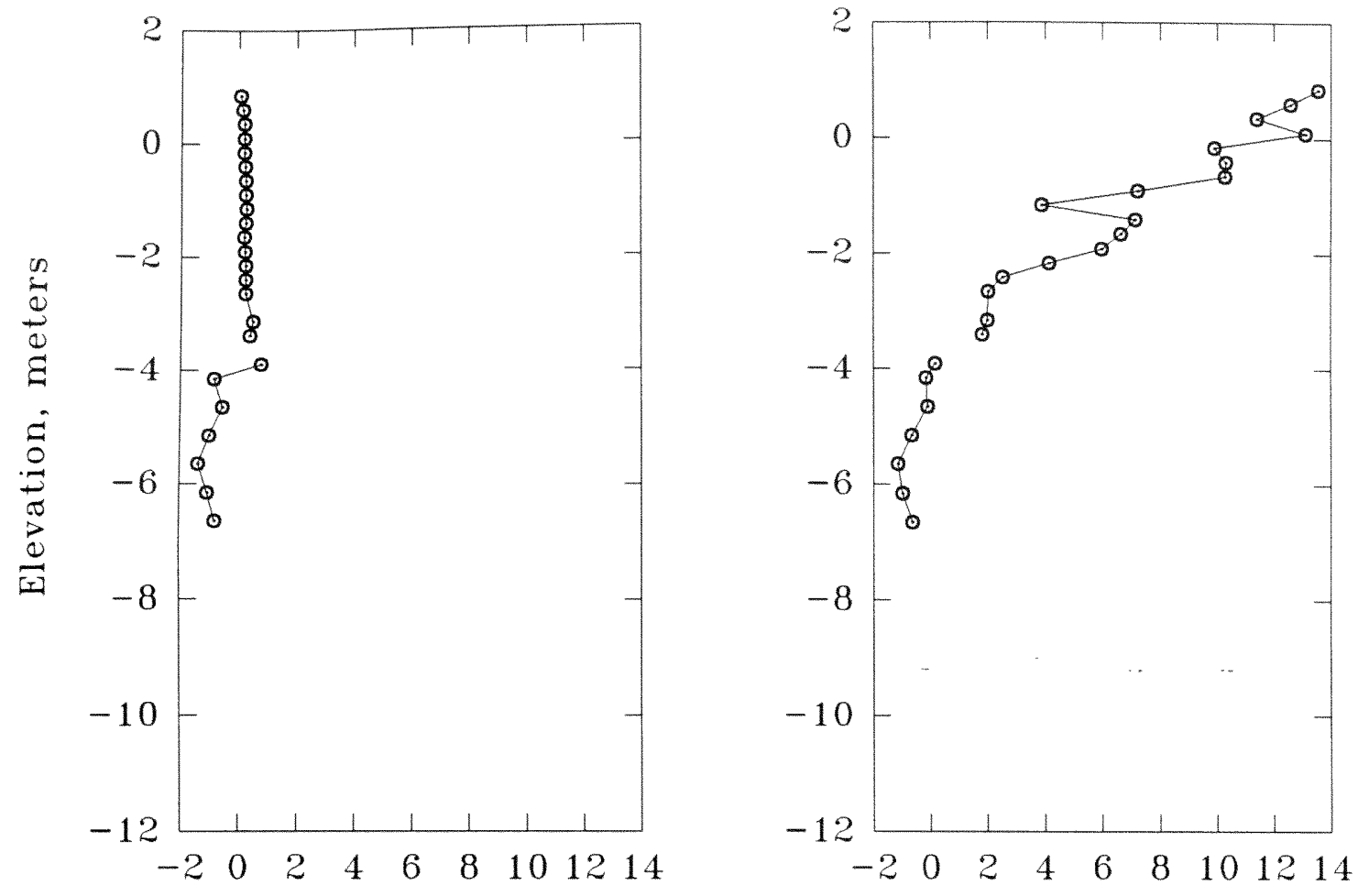

Ambient flow, Qa, L/min

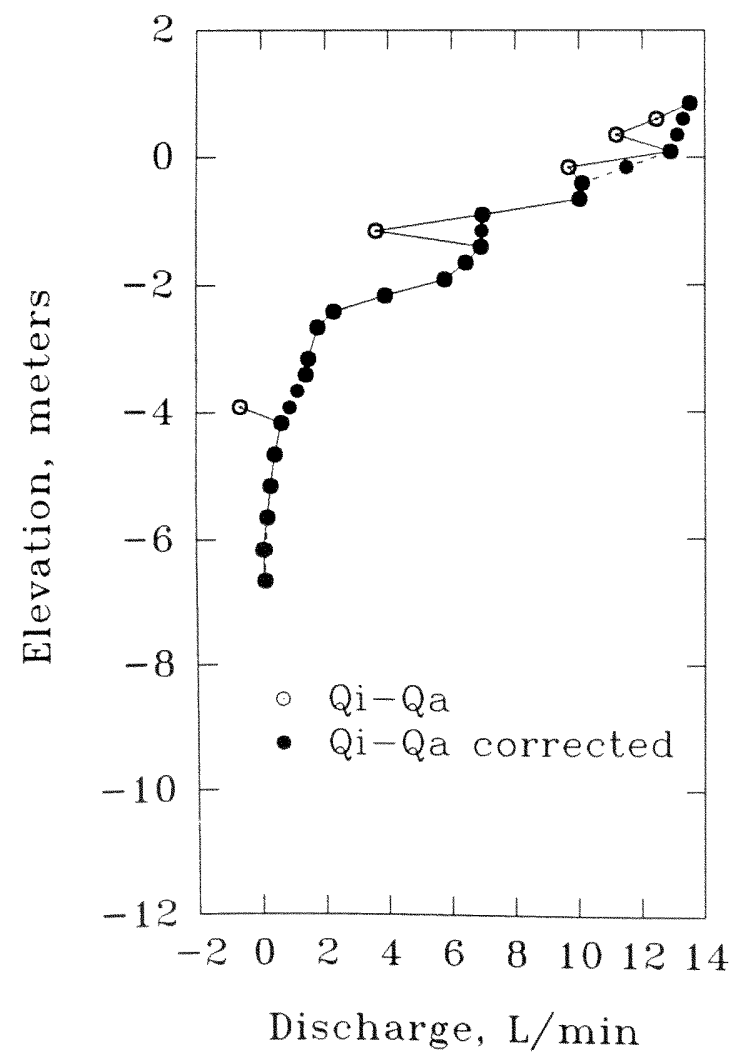

Induced flow, Qi, L/min

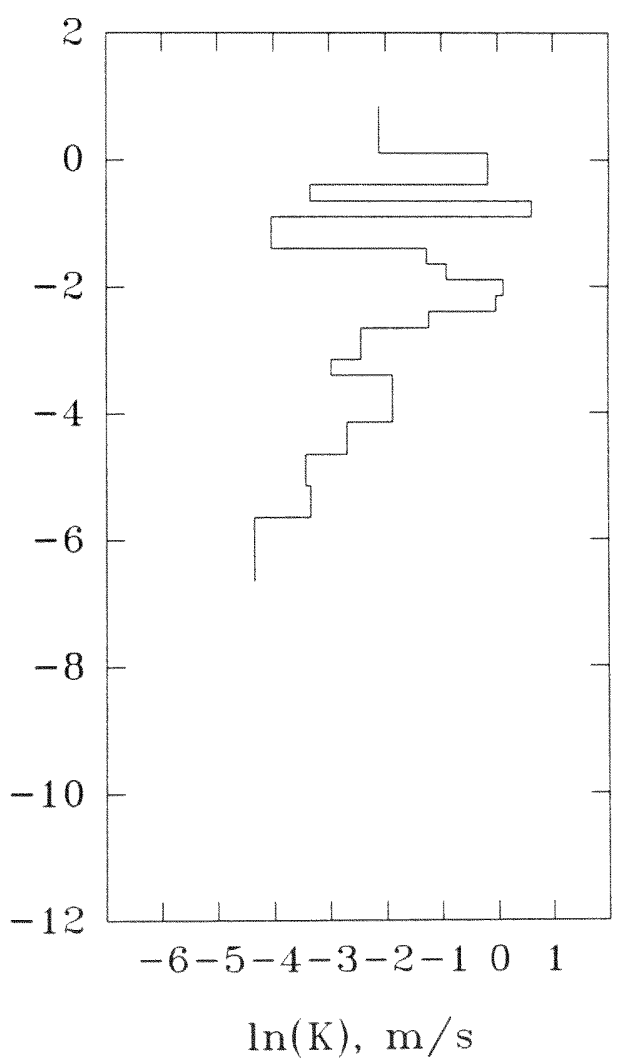



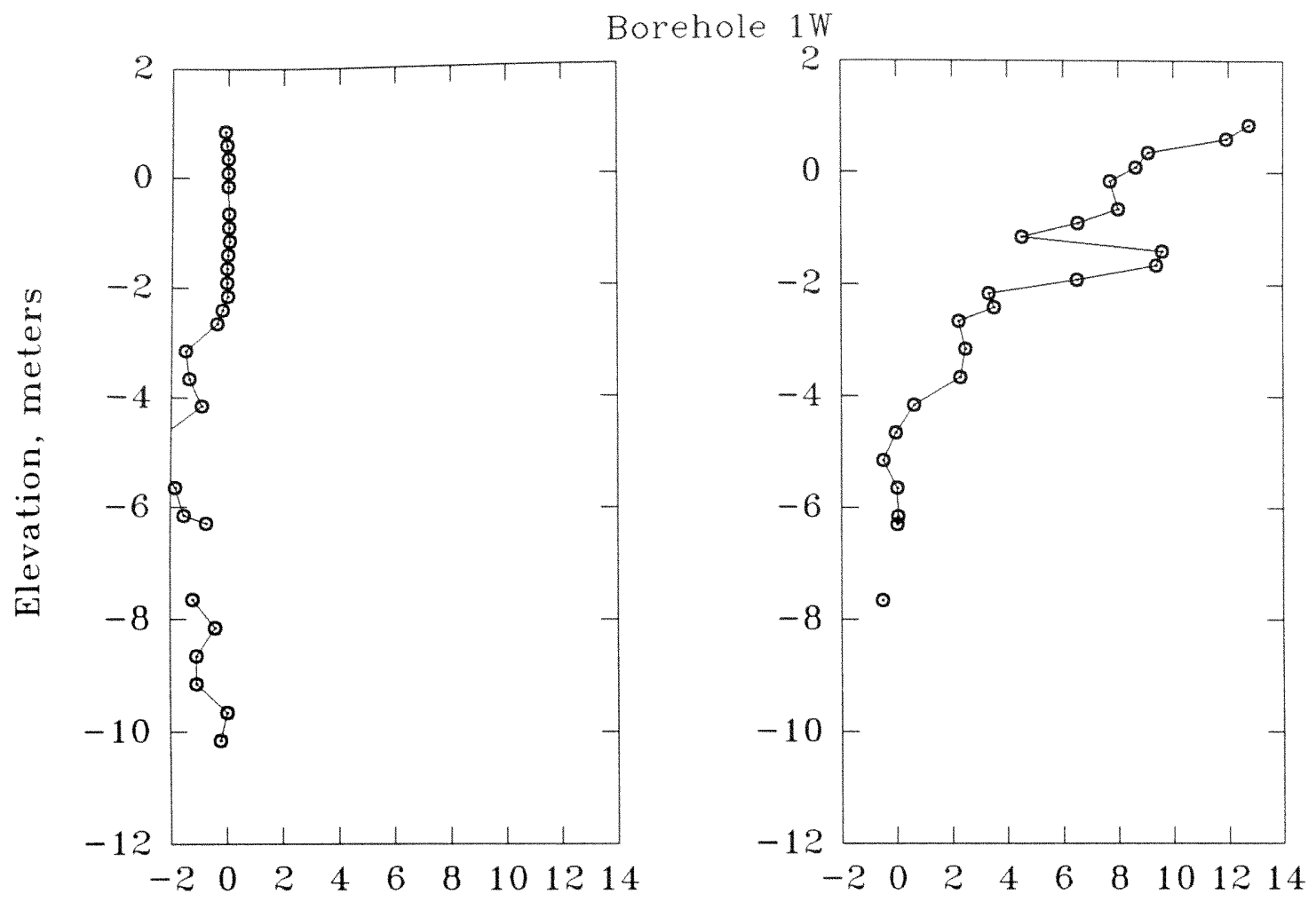

Ambient flow, Qa, L/min

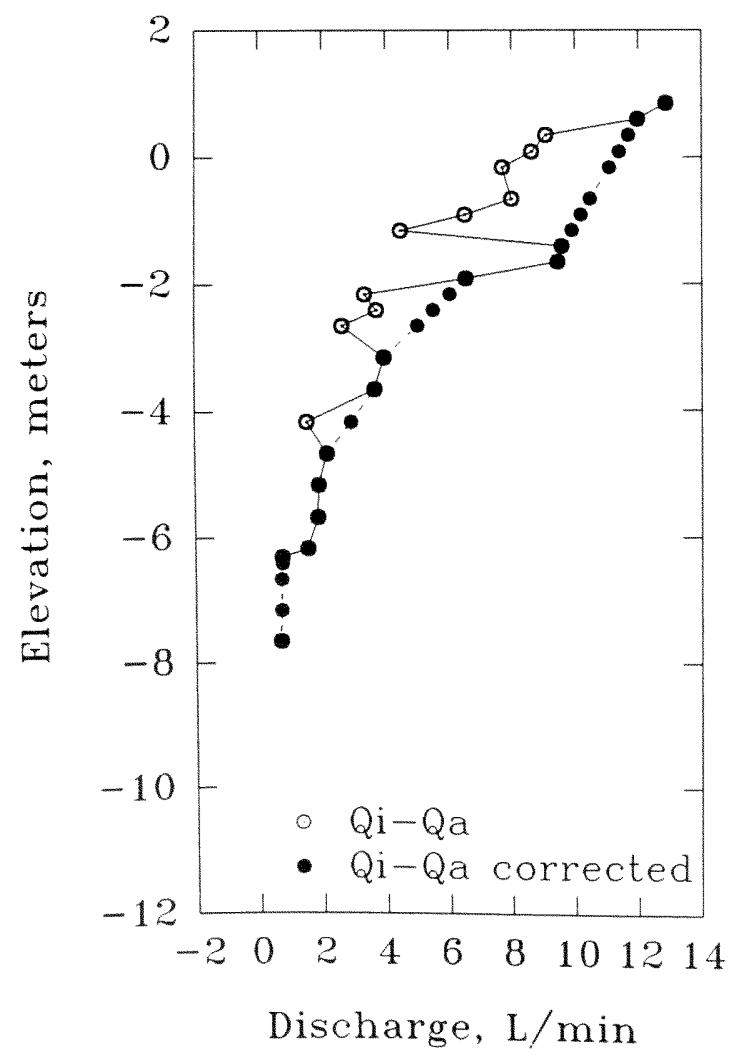

Induced flow, Qi, L/min

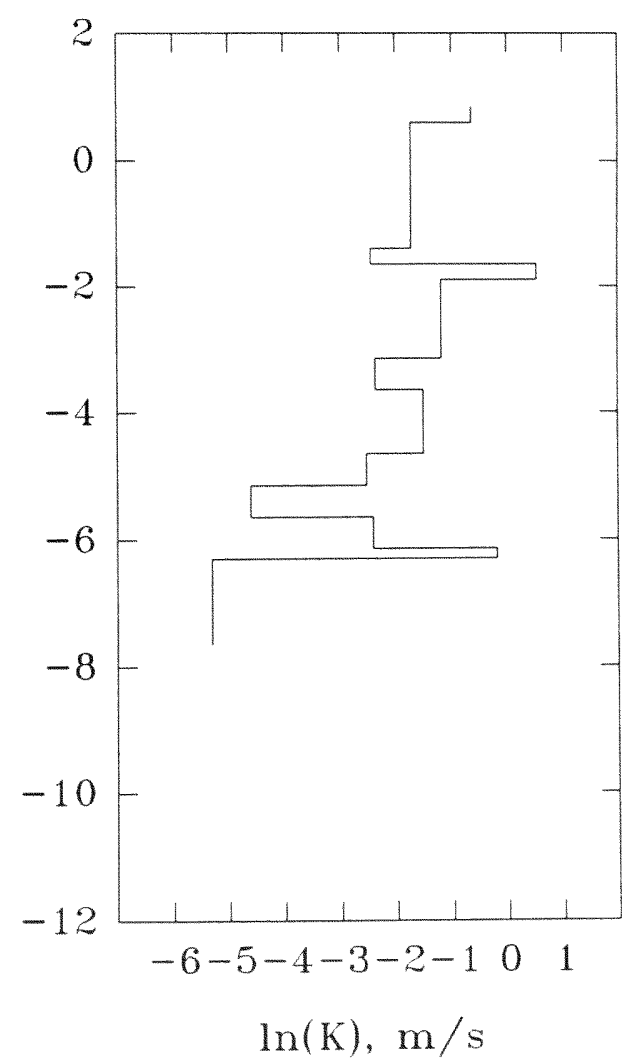


Borehole 25-5
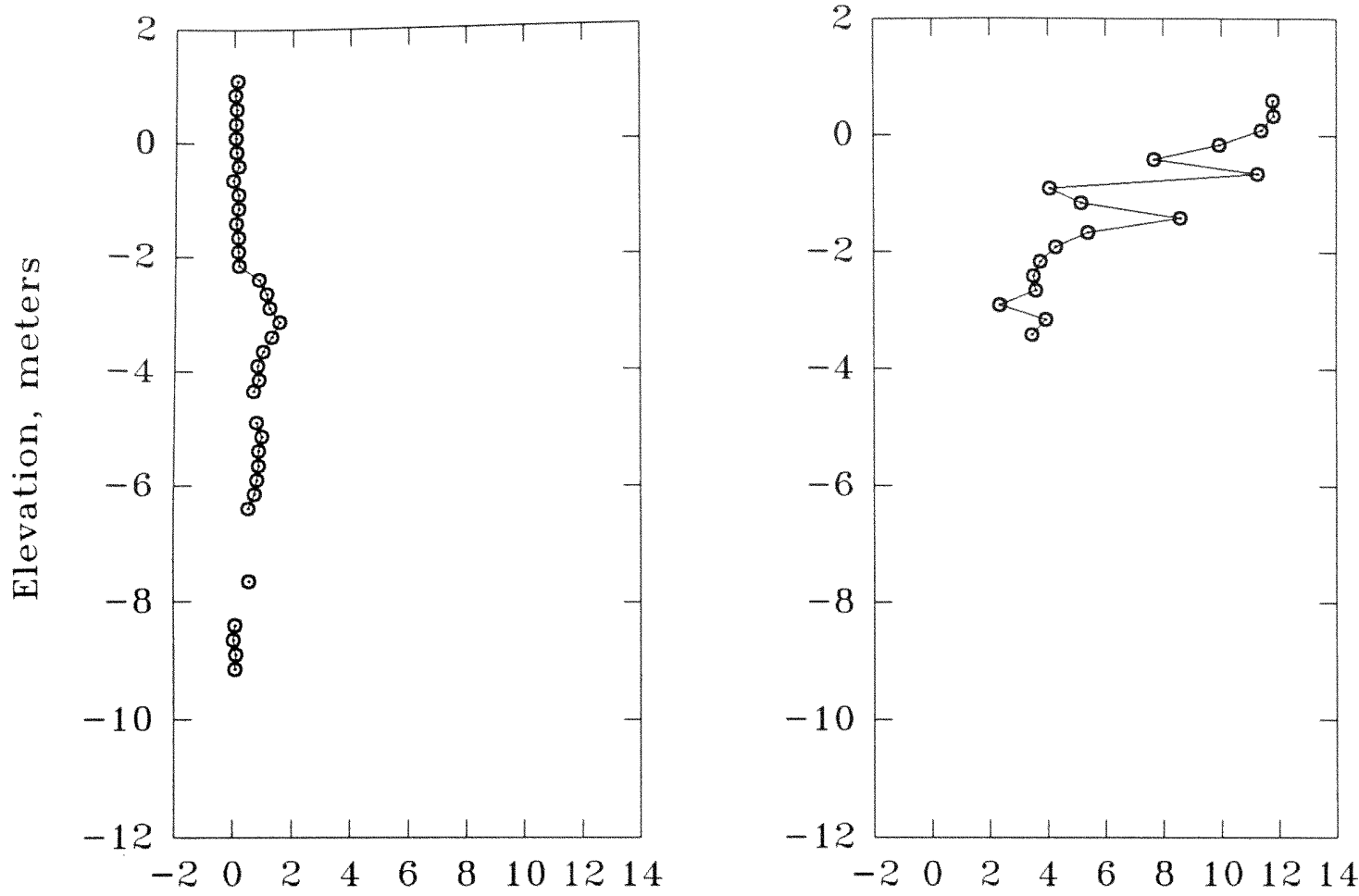

Ambient flow, Qa, L/min

Induced flow, Qi, L/min
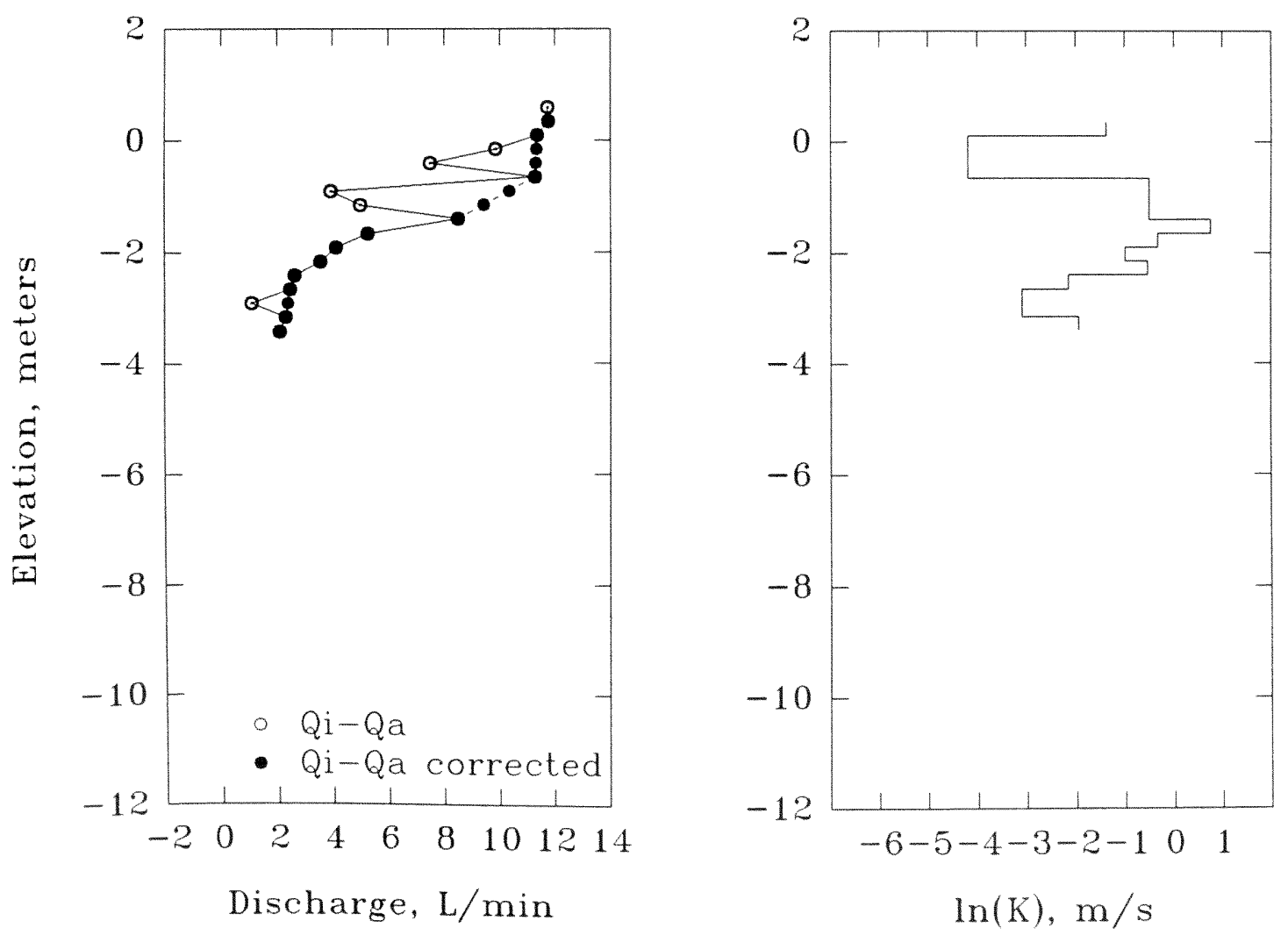


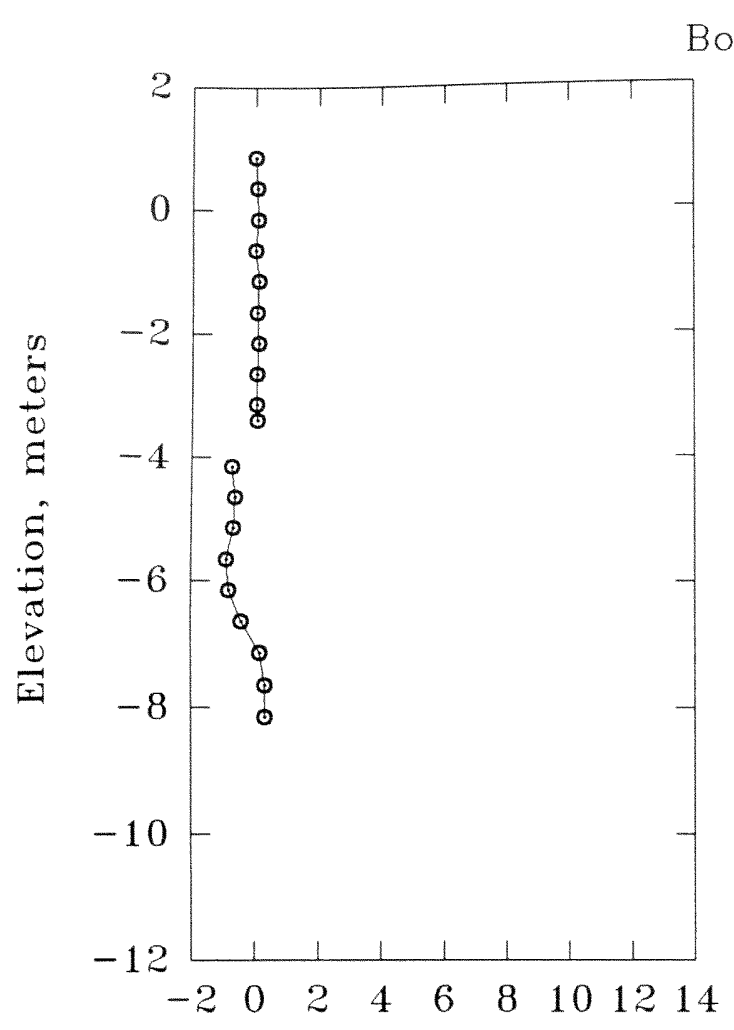

Borehole $1 \mathrm{E}$

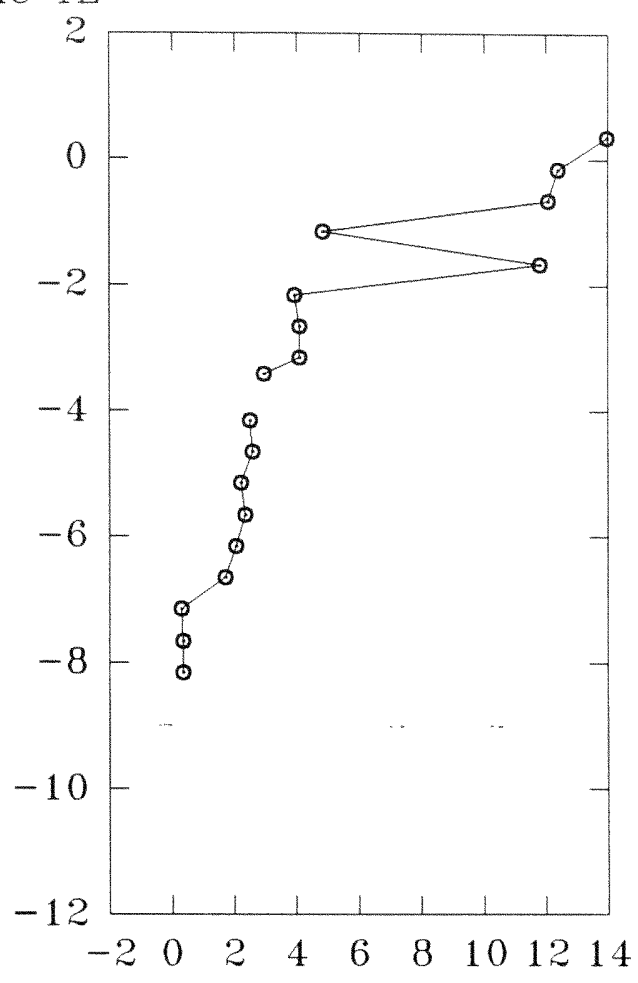

Ambient flow, Qa, L/min

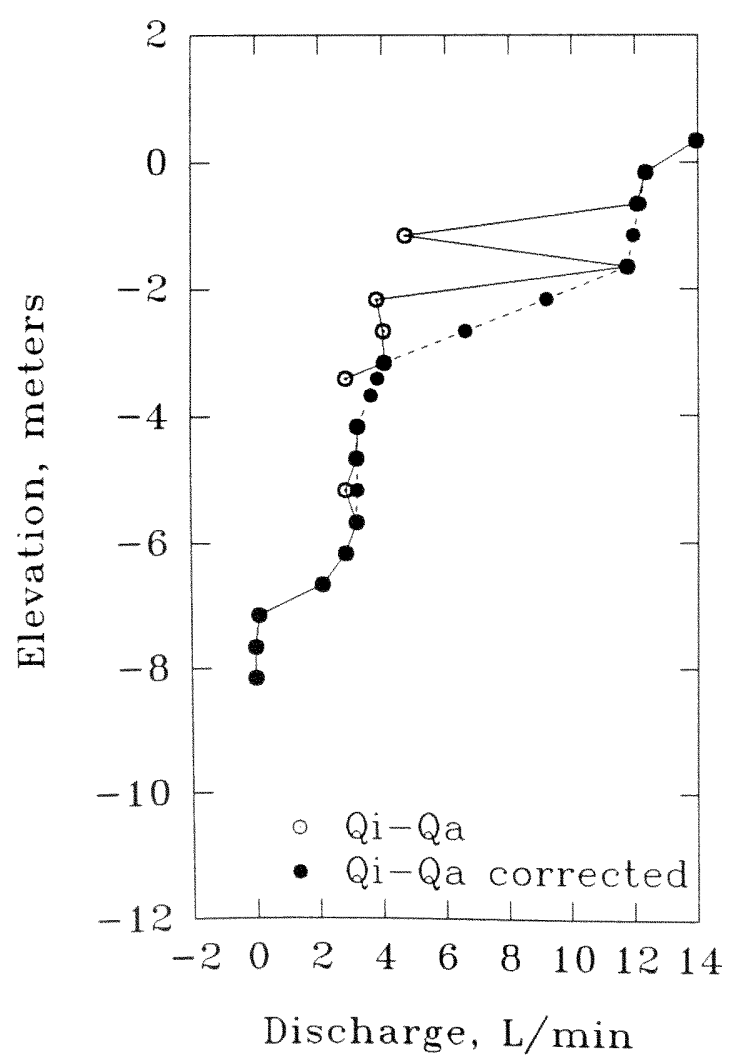

Induced flow, $\mathrm{Qi}, \mathrm{L} / \mathrm{min}$

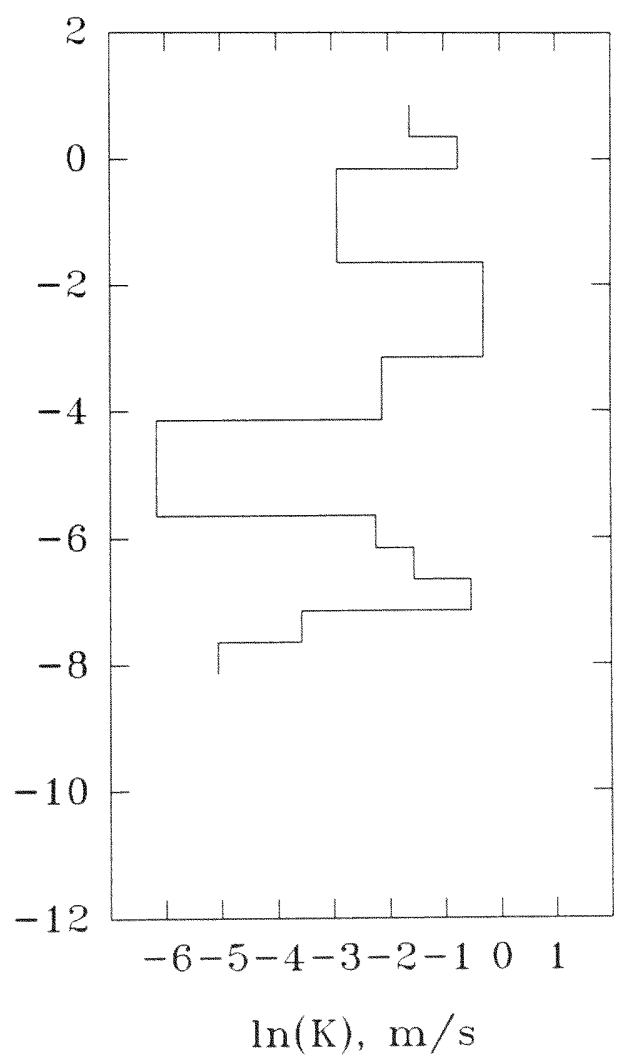


Borehole 2E

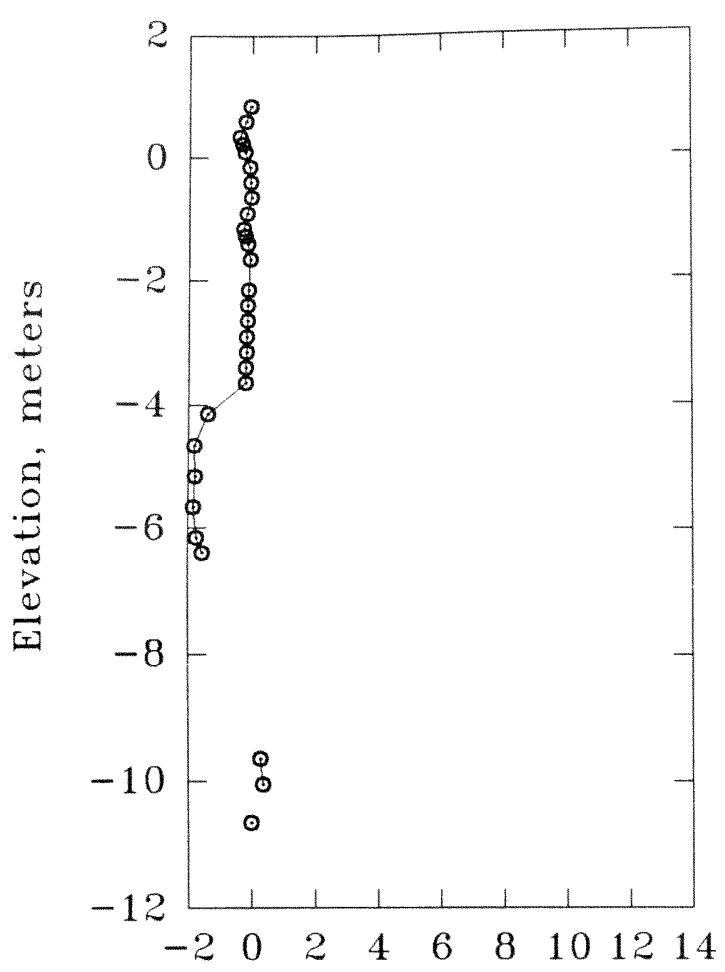

Ambient flow, Qa, L/min

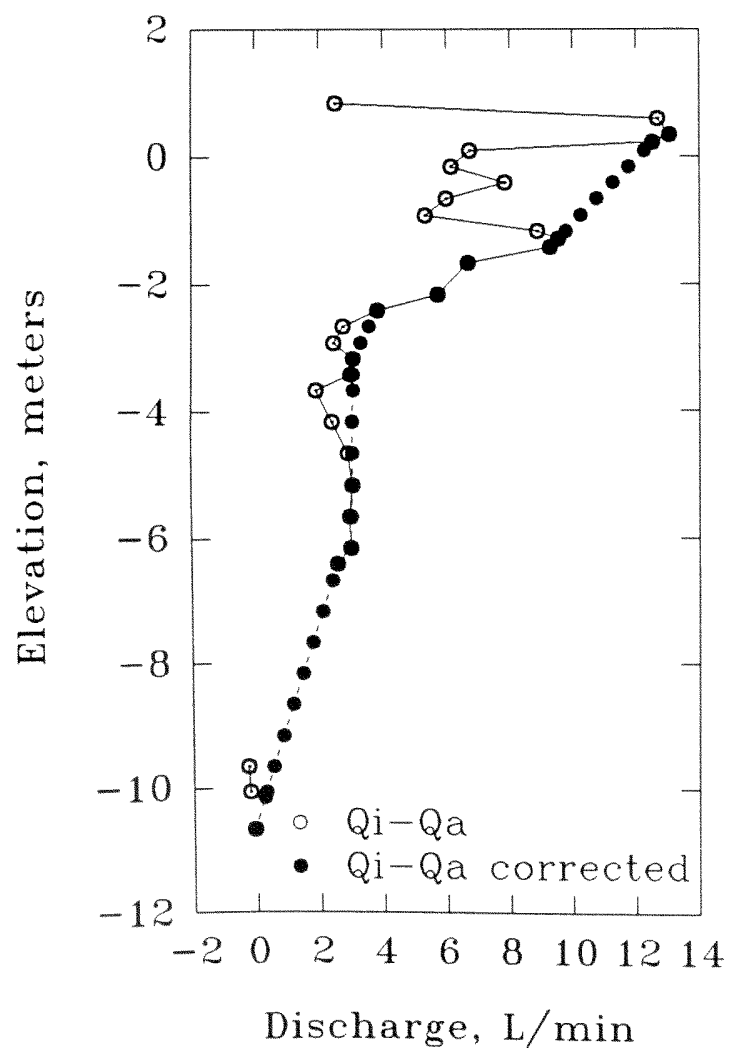

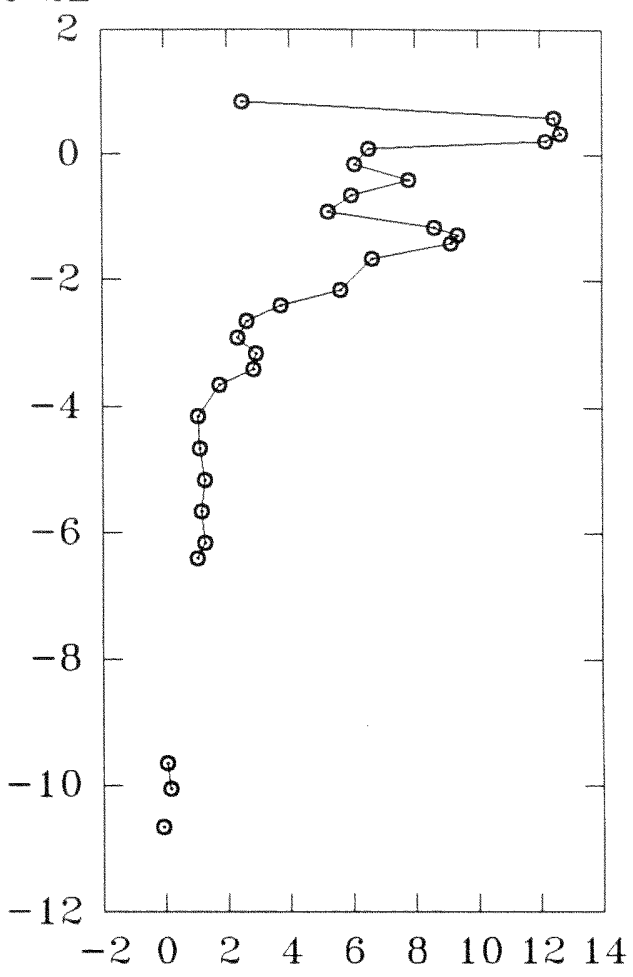

Induced flow, Qi, L/min

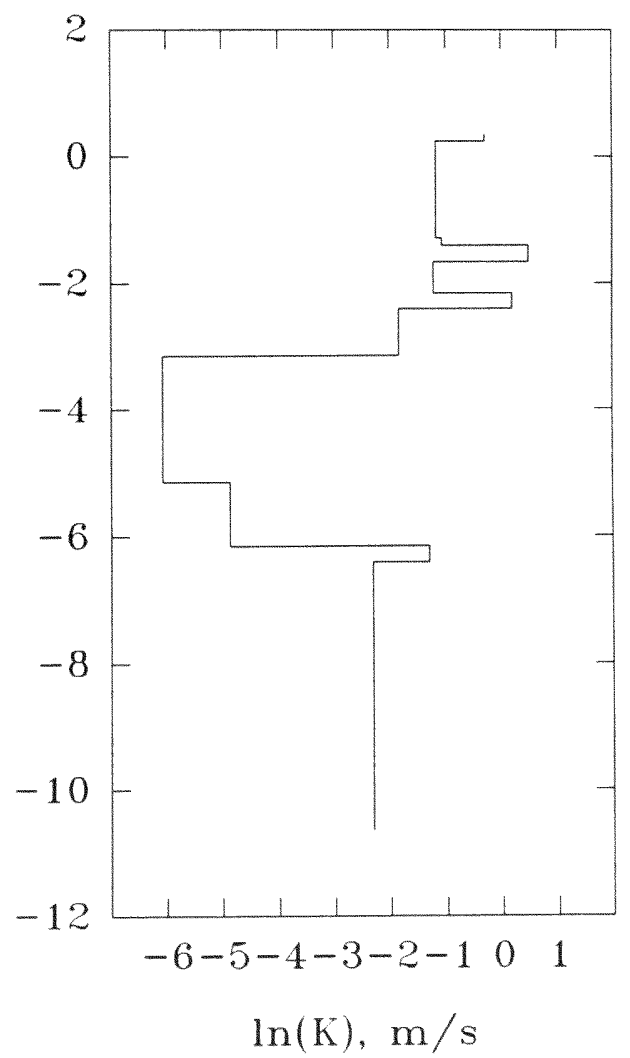


Borehole $4 \mathrm{E}$
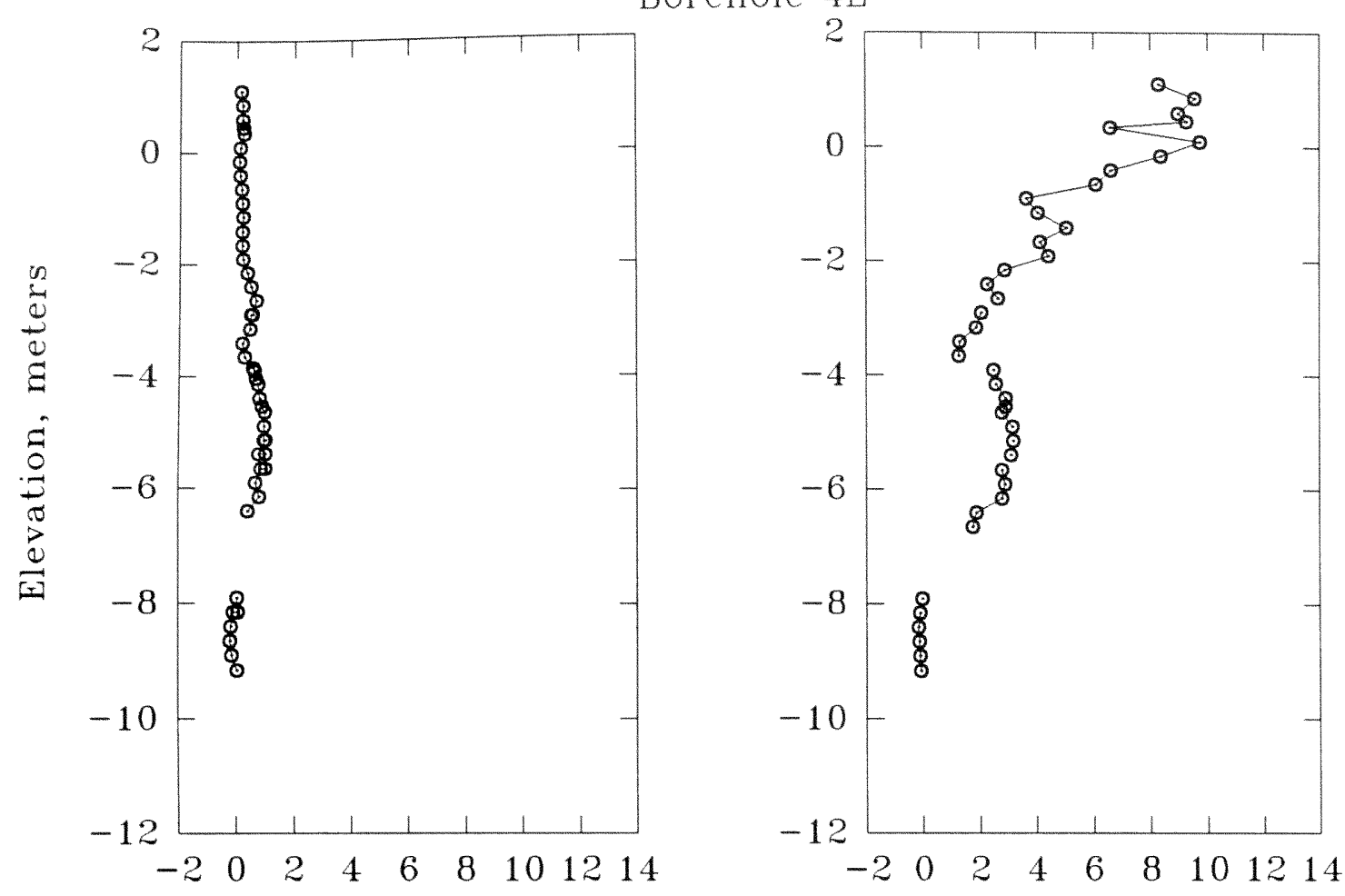

Ambient flow, Qa, L/min
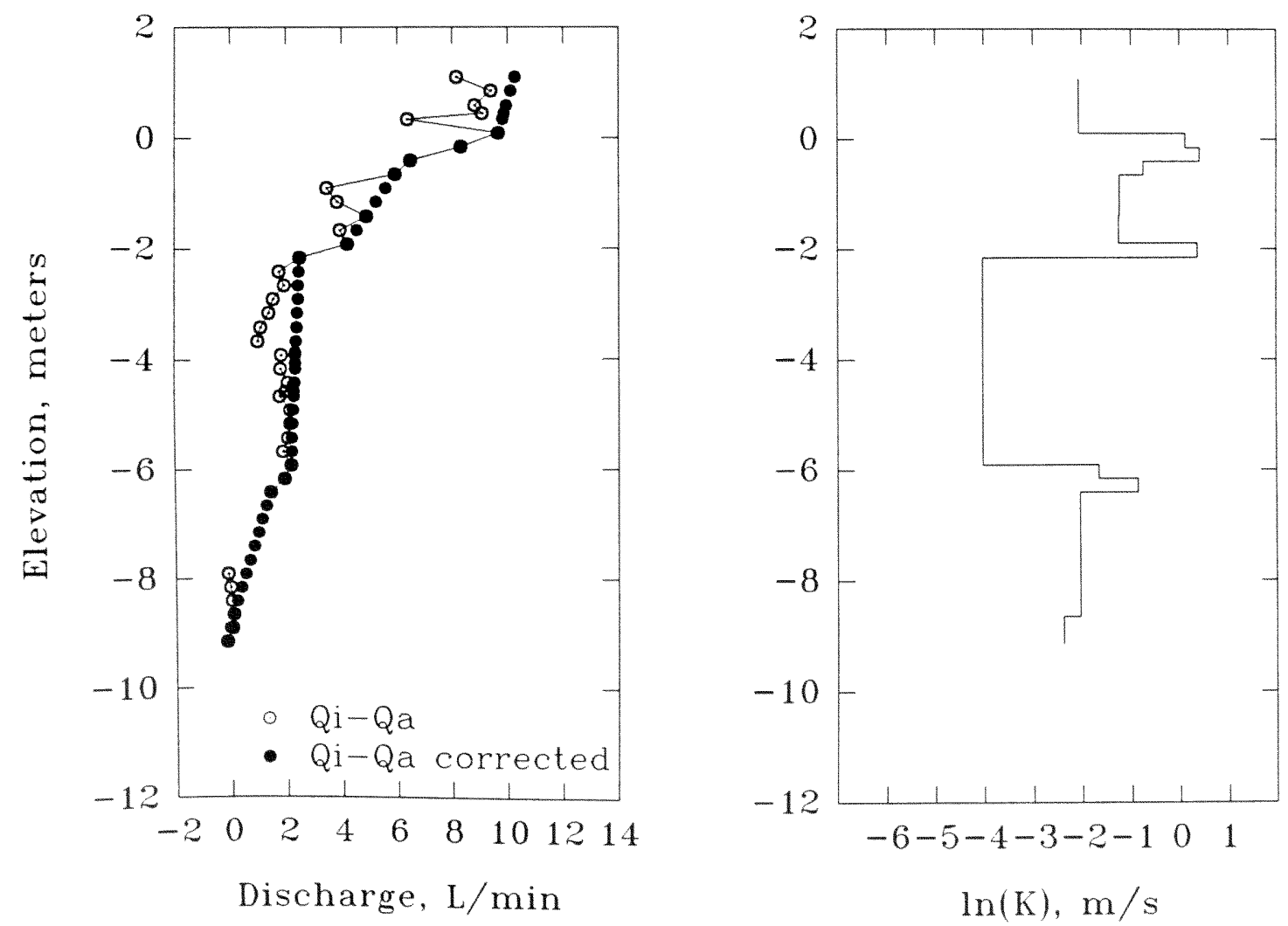
Borehole 6E

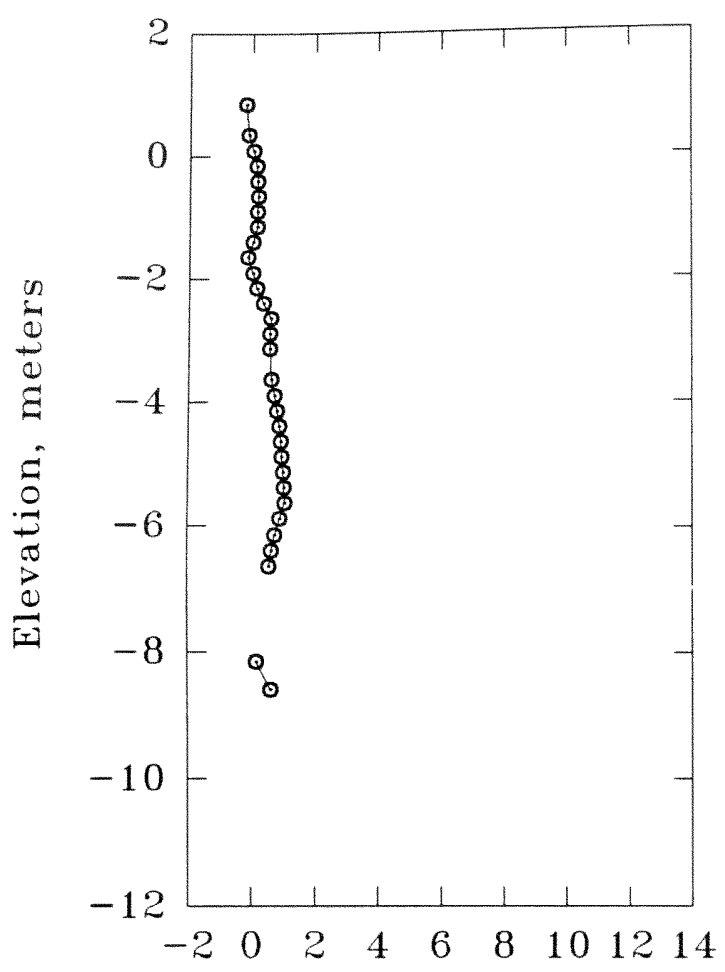

Ambient flow, Qa, L/min

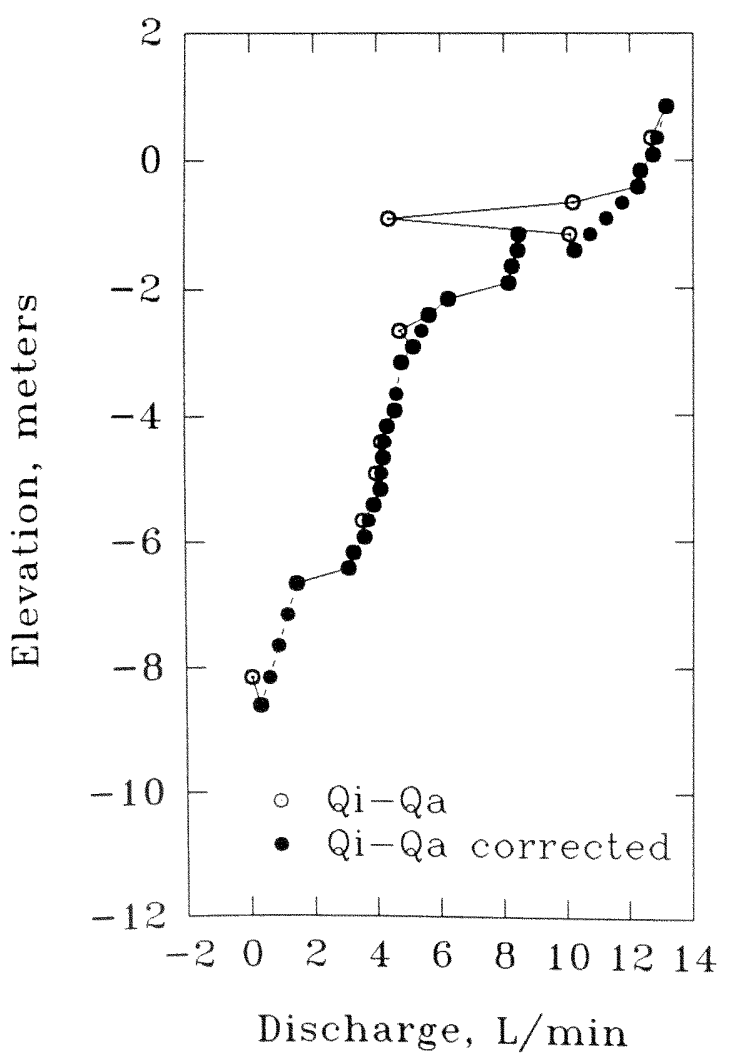

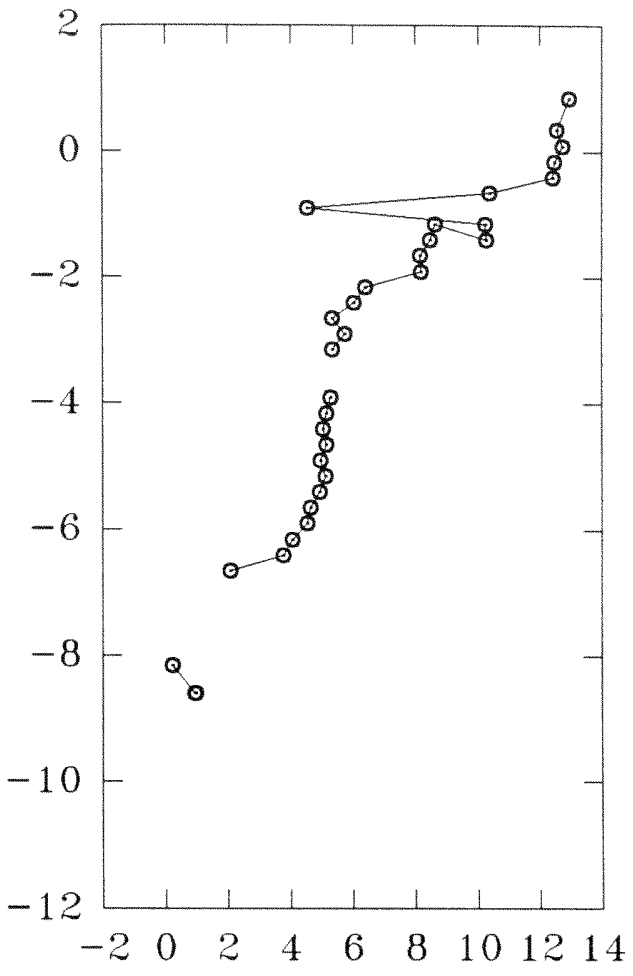

Induced flow, Qi, L/min

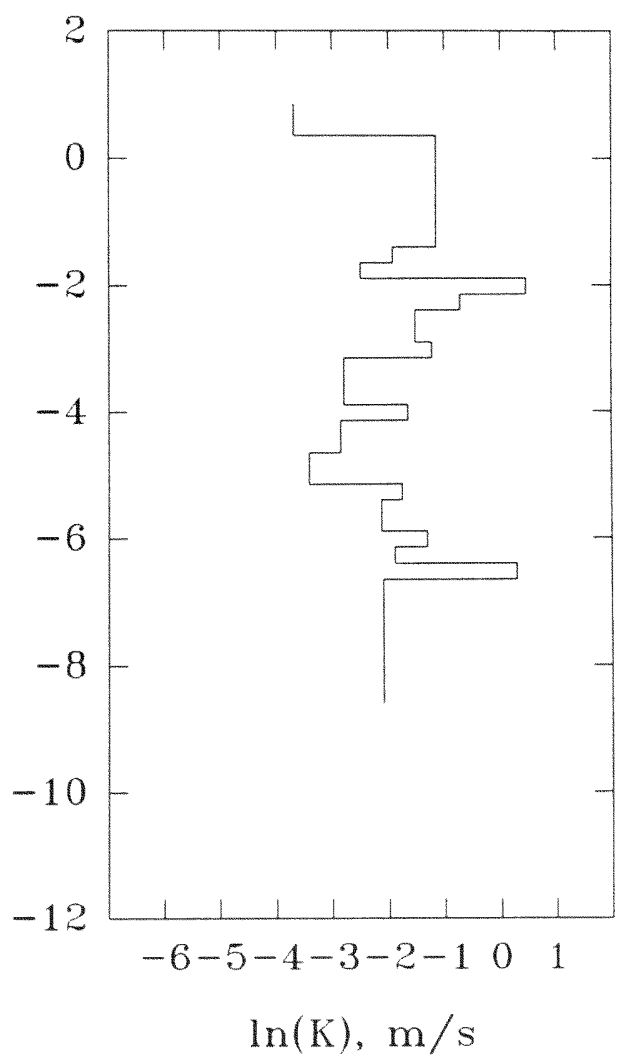


Borehole 8E

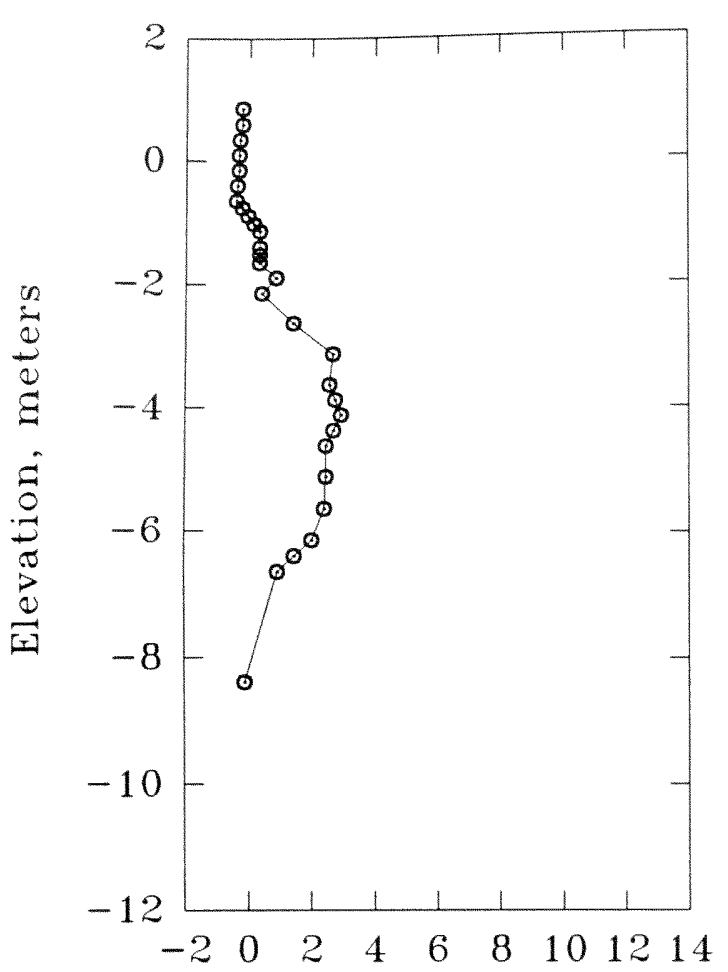

Ambient flow, Qa, L/min

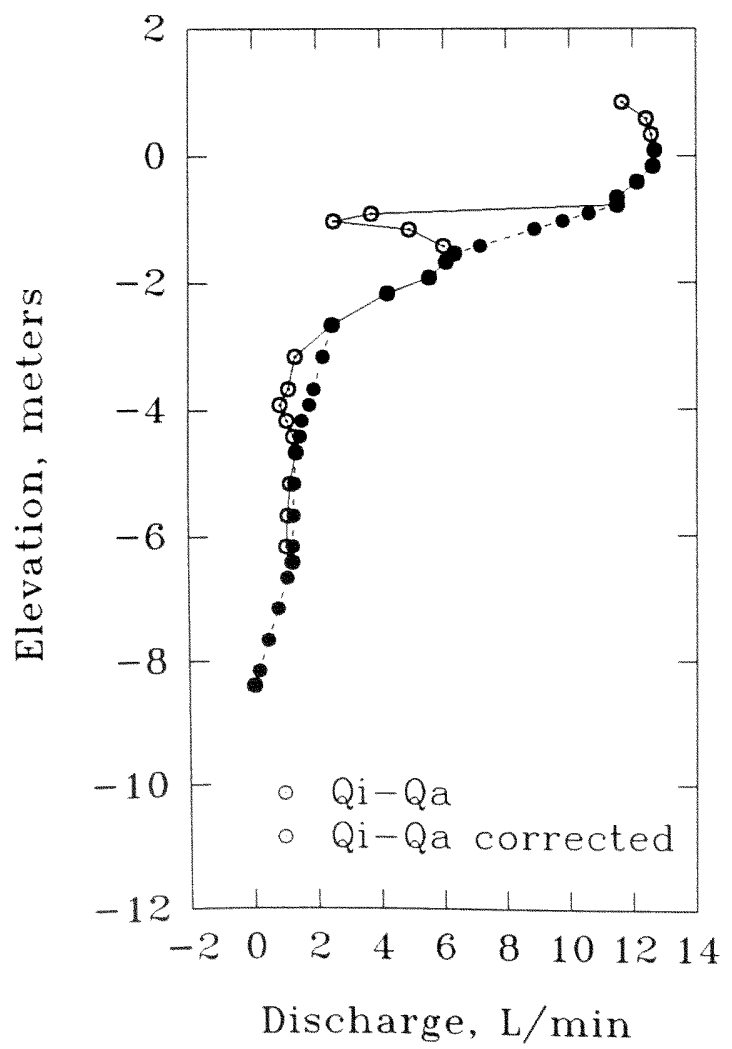

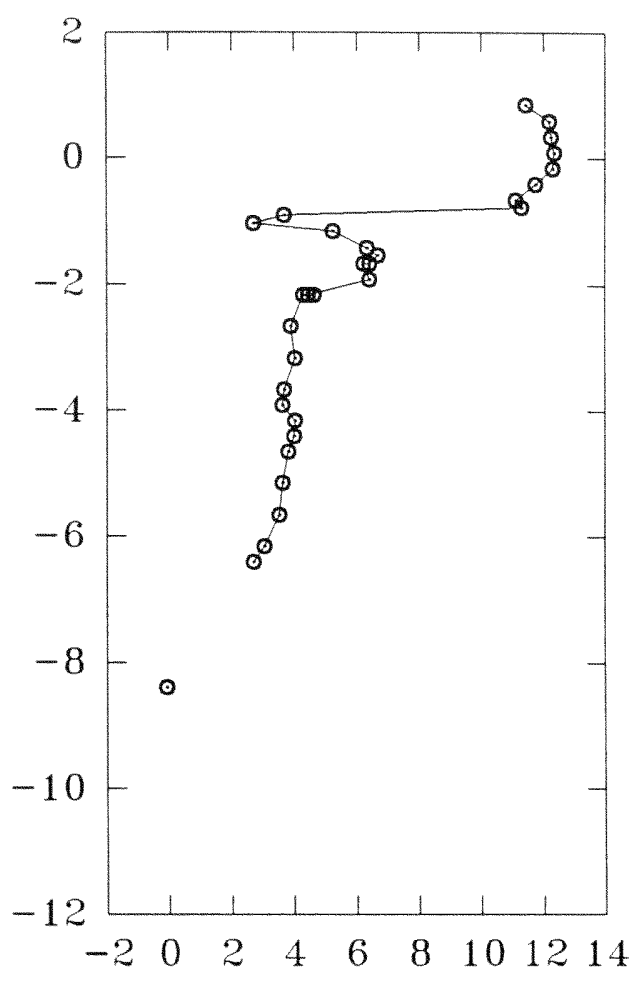

Induced flow, Qi, L/min

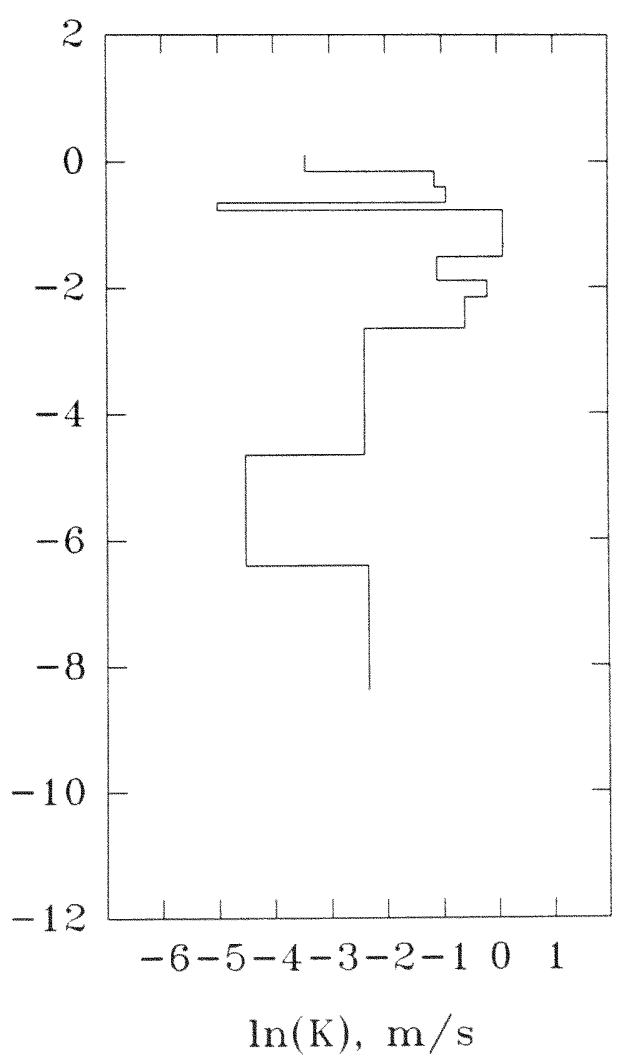




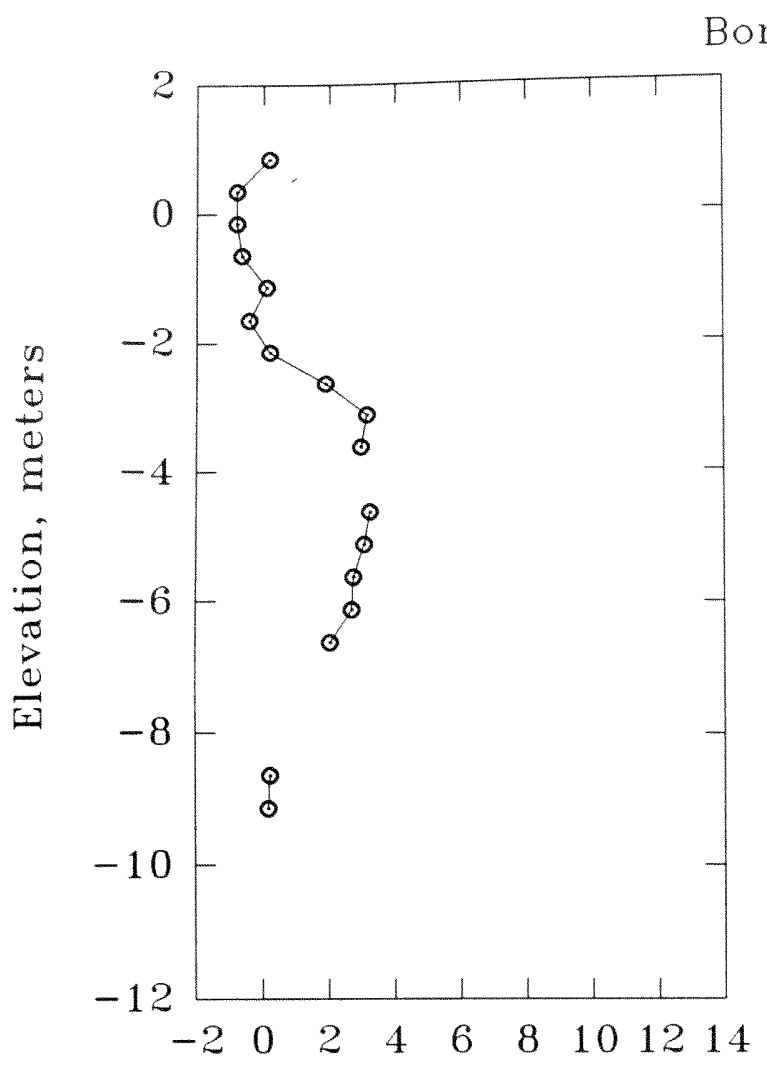

Borehole 10E

Ambient flow, Qa, L/min

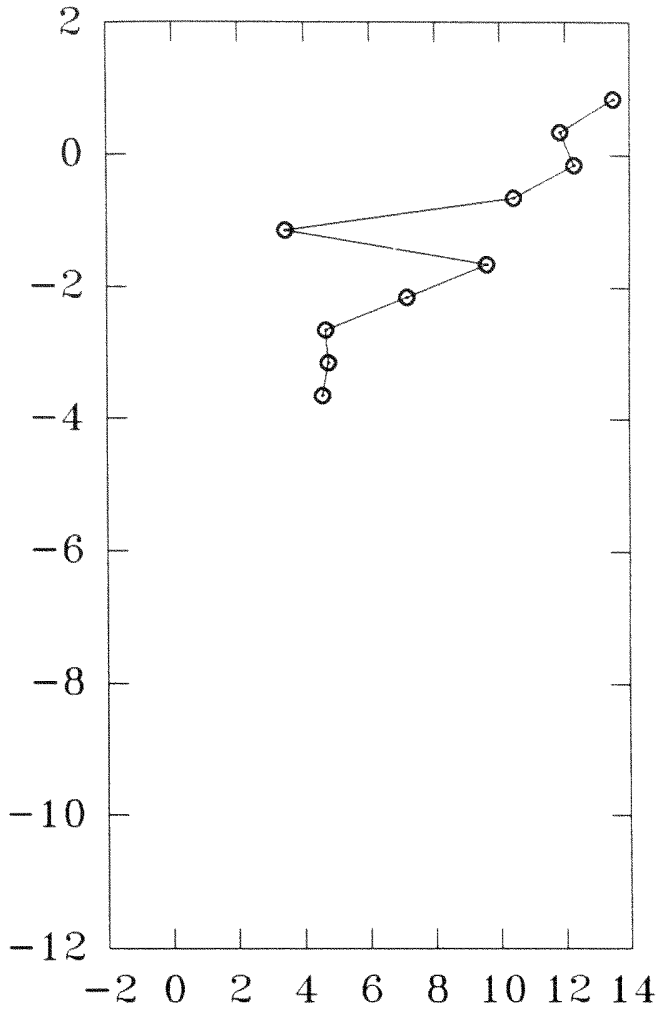

Induced flow, Qi, L/min
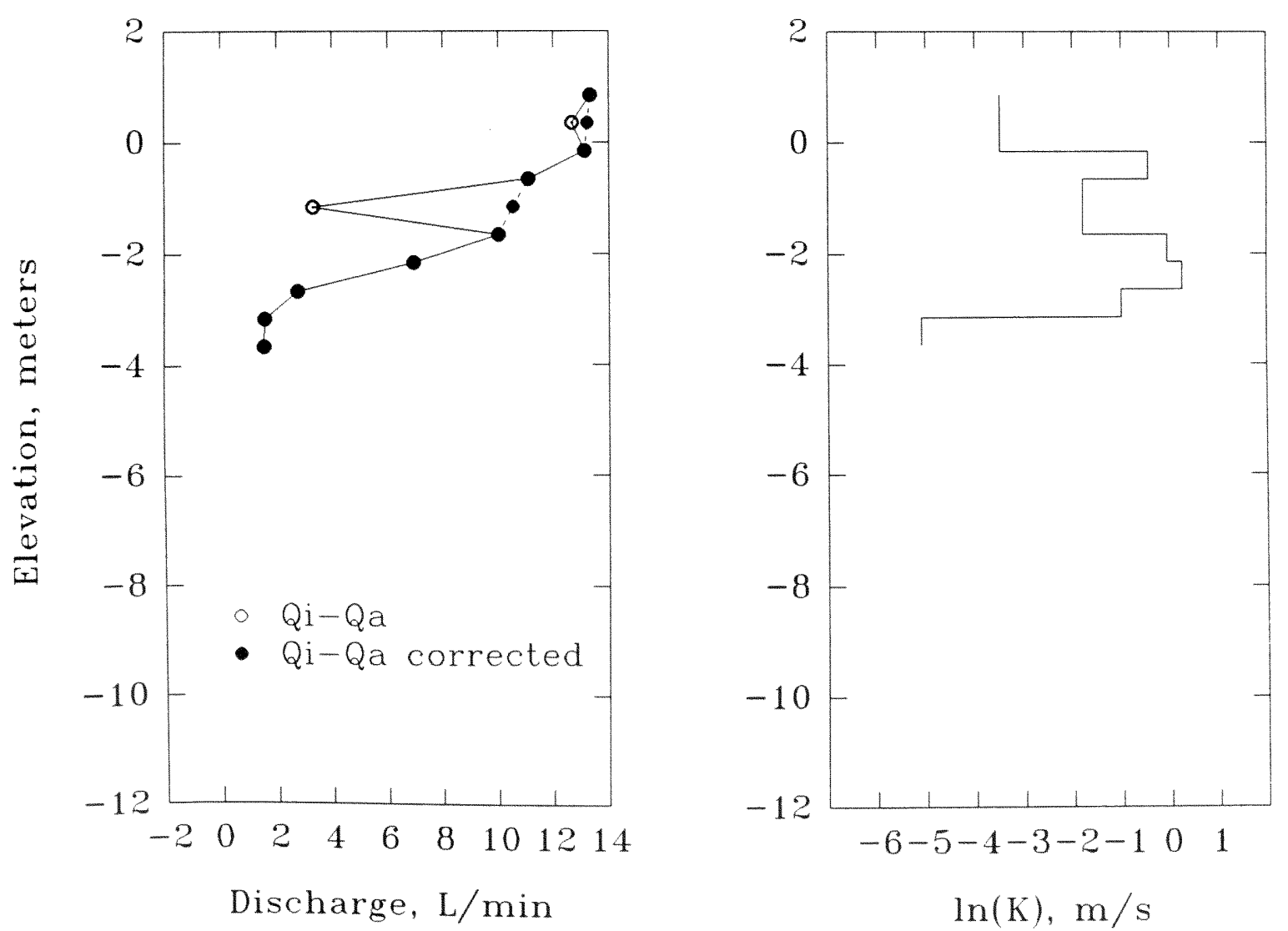
Borehole 12E
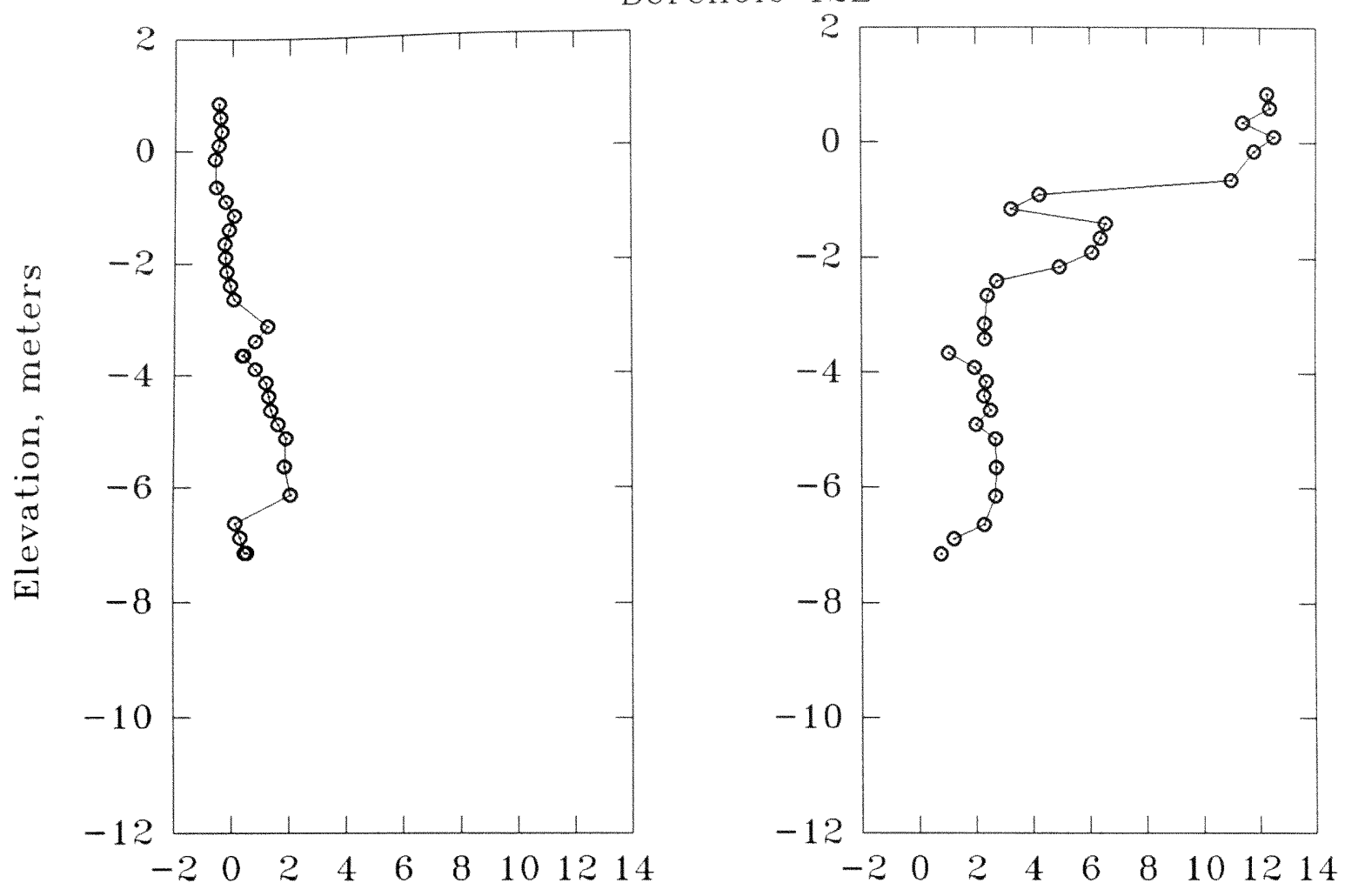

Ambient flow, Qa, L/min

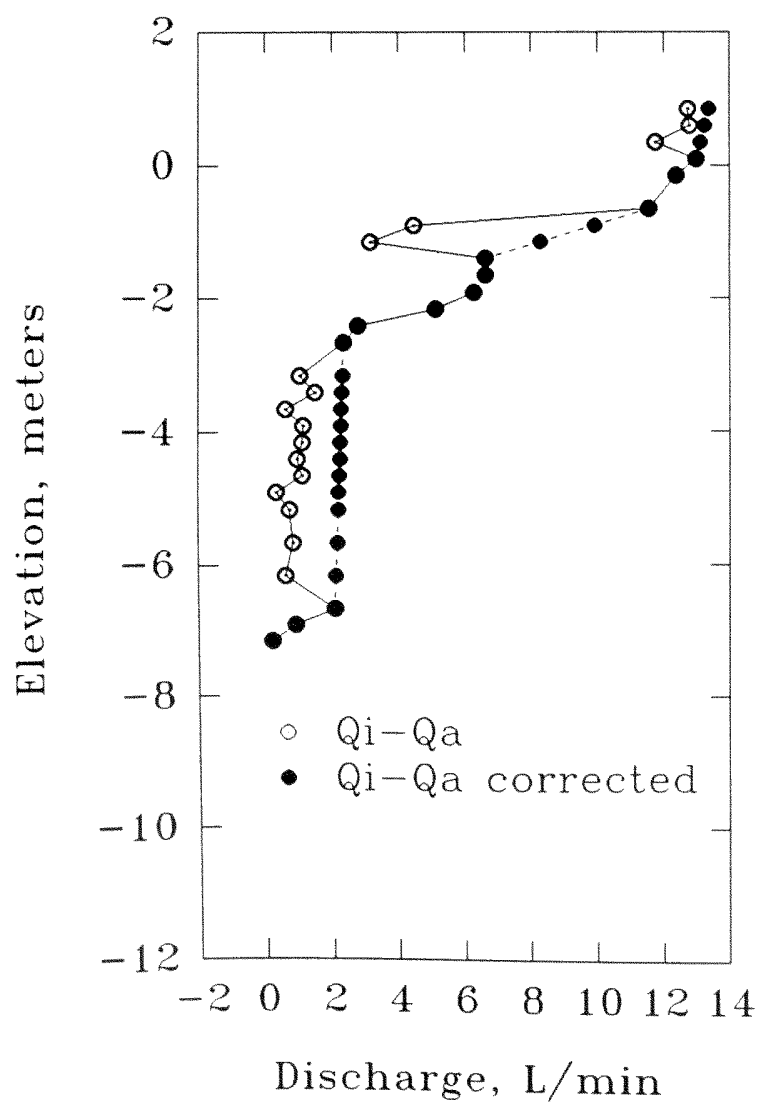

Induced flow, Qi, L/min

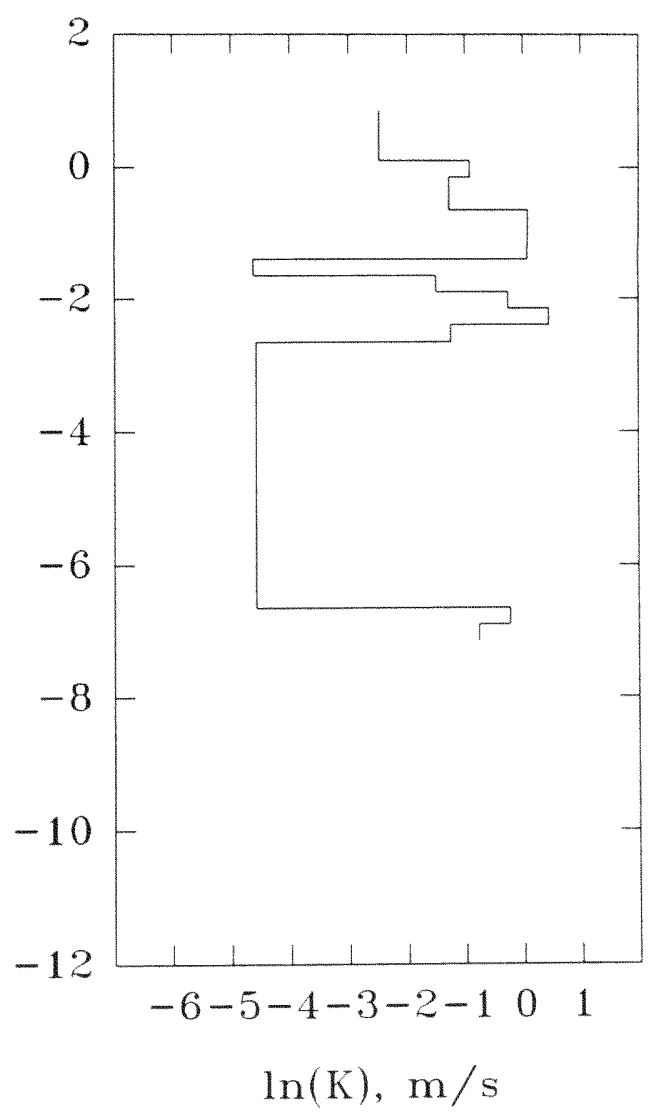


Borehole 14E
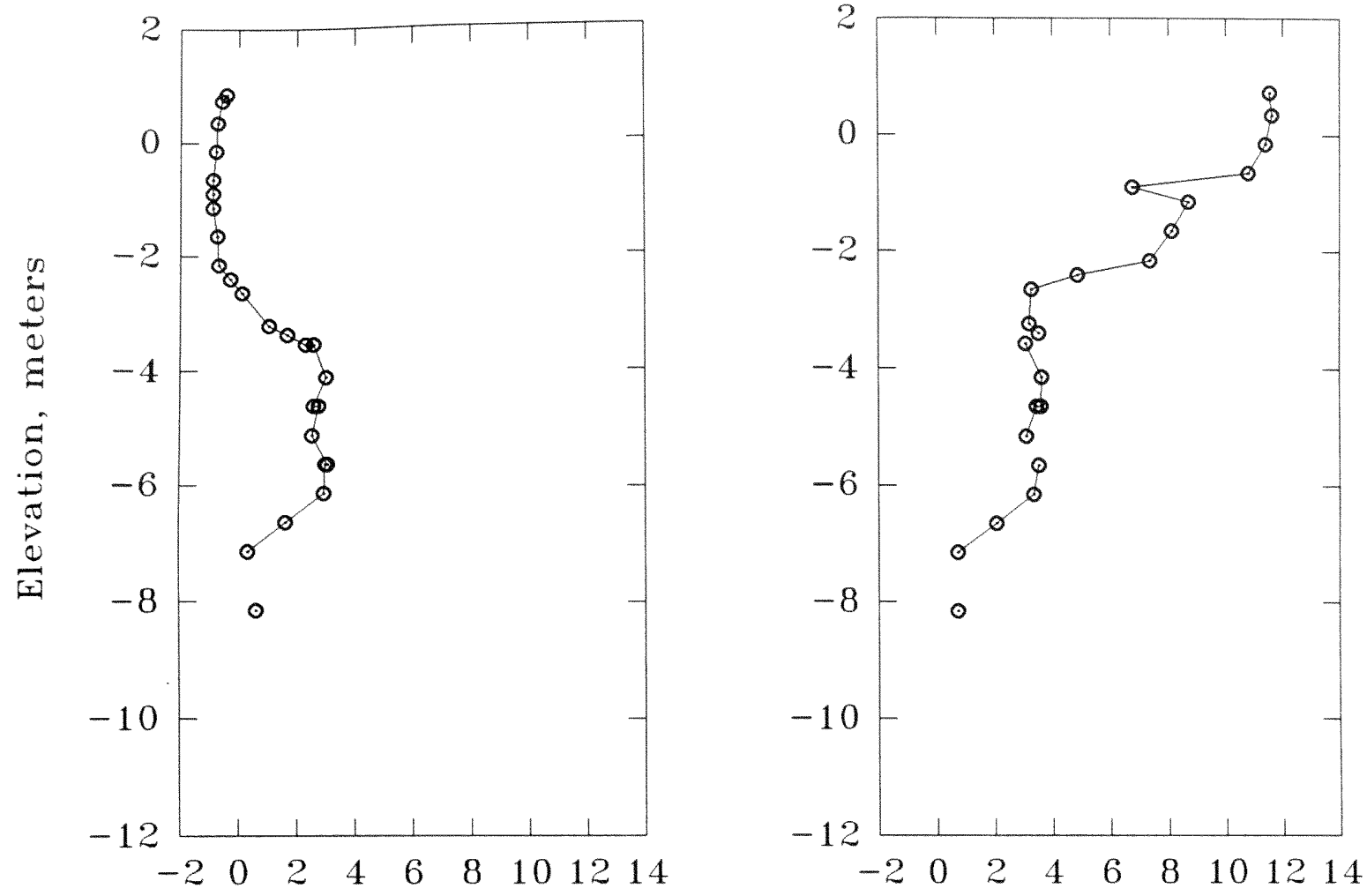

Ambient flow, Qa, L/min
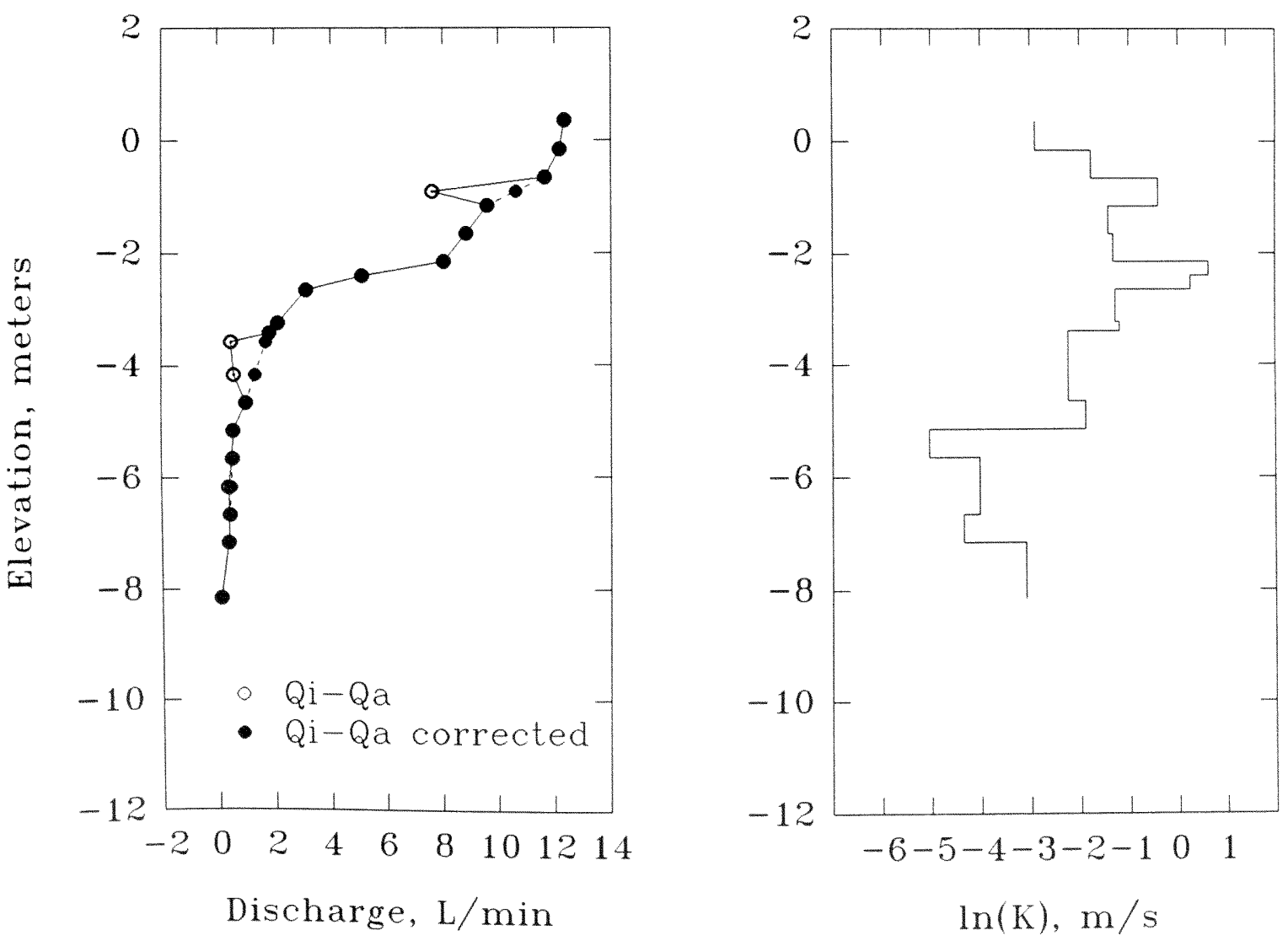


\section{APPENDIX VIII \\ Determination of Pseudo-Steady State Conditions}


The use of Equation 6 in the calculation of the layer hydraulic conductivity assumes that the layer discharge and the pump discharge do not change with time, that the system has attained a pseudo-steady state behavior. Molz and Young (1993) state that the pseudo-steady state conditions occur when:

$$
\mathrm{r}_{\mathrm{w}}^{2} \mathrm{~S} / 4 \mathrm{Tt}<0.01
$$

where,

$$
\begin{aligned}
& \mathrm{r}_{\mathrm{w}}=\text { effective well radius, } 0.0381 \text { meter } \\
& \mathrm{S}=\text { aquifer storage coefficient } \\
& \mathrm{T}=\text { aquifer transmissivity }=\mathrm{K}_{\text {avg }} \mathrm{b} \\
& \mathrm{K}_{\mathrm{avg}}=\text { average aquifer hydraulic conductivity, } 0.16142 \text { meter/second } \\
& \mathrm{b}=\text { aquifer thickness, } 12 \text { meters } \\
& \mathrm{t}=\text { time since pumping started, at least } 30 \text { minutes. }
\end{aligned}
$$

The storage coefficient of unconfined aquifers is the specific yield (Domenico and Schwartz, 1990), said by Freeze and Cherry (1979) to range from 0.01 to 0.30. However, a tabulation presented by Domenico and Schwartz (1990) from Johnson (1967) showed that specific yield of certain materials exceeded 0.30 . The coarser the material, the more closely the specific yield approaches total porosity.

Appel (1973) states that the storage coefficient of the Biscayne Aquifer ranges from 0.10 to 0.35 , and averages 0.20 . The Biscayne Aquifer cores obtained from borehole 25-5 showed that the total porosity for the intact core ranged from 0.03 to 0.47 and averaged 0.28 ; the upper limit for average total porosity, based on core recovery, was 0.69 . Using the above average 
values of total porosity as the specific yield, $3.0 \times 10^{-8}<\mathrm{r}_{\mathrm{w}}{ }^{2} \mathrm{~S} / 4 \mathrm{Tt}<7.2 \mathrm{x}$ $10^{-8}$. These values as far less than 0.01 , indicating that a thirty minute lapse between the start of pumping and induced flow measurements was acceptable. The maximum time required to achieve the pseudo-steady state with these aquifer parameters was 0.0129 second. 


\section{APPENDIX IX \\ Calculation of Macrodispersivity}


Estimation of macrodispersivity (dispersivity at the field scale) was based on the stochastic analysis of Gelhar and Axness (1983), which involved presentation of a series of equations for calculating macrodispersivity from the spatial statistics of $Y$ (the natural log of hydraulic conductivity). Equations $\{65\}$ are the most appropriate for the present analysis (equation numbers in braces refer to equations in Gelhar and Axness (1983), while those in parentheses refer to this report). Eqns. $\{65\}$ were derived for a layered anisotropic medium with $\lambda_{1}=\lambda_{2} \neq \lambda_{3}$ (directions 1 and 2 lying in the plane of the layering or bedding, direction 3 being normal to this plane), $J_{2}$ (head gradient in direction 2) equal to zero, and flow inclined at an angle $\theta$ to the bedding.

$$
\begin{aligned}
& A_{1}=A_{L}=\sigma_{Y}^{2} \lambda_{1} \mu / \gamma^{2} \xi \\
& A_{2}=\frac{\sigma_{Y}^{2} \lambda_{1} \mu J_{3}^{2}}{\left[2(1+\xi)^{2} \gamma^{2} J_{1}^{2}\right]} \\
& A_{3}=\frac{\sigma_{Y}^{2} \lambda_{1} J_{3}^{2}(1+2 \xi)}{\left[2(1+\xi)^{2} \gamma^{2} J_{1}^{2}\right]}
\end{aligned}
$$

where,

$$
\begin{aligned}
& \xi=\left(\sin ^{2} \theta+\mu^{2} \cos ^{2} \theta\right)^{1 / 2} \\
& \beta=\exp \left[\sigma_{Y}^{2}\left(g_{11}-g_{33}\right)\right]
\end{aligned}
$$




$$
\begin{gathered}
g_{11}=\frac{1}{2\left(\rho^{2}-1\right)}\left[\frac{\rho^{2}}{\left(\rho^{2}-1\right)^{1 / 2}} \tan ^{-1}\left(\rho^{2}-1\right)^{1 / 2}-1\right] \\
g_{33}=\frac{\rho^{2}}{\left(\rho^{2}-1\right)}\left[1-\frac{1}{\left(\rho^{2}-1\right)^{1 / 2}} \tan ^{-1}\left(\rho^{2}-1\right)^{1 / 2}\right] \\
\gamma=\frac{\exp \left[\sigma_{Y}^{2}\left(0.5-g_{33}\right)\right]}{\left(\sin ^{2} \theta+\beta \cos ^{2} \theta\right)} \\
\rho=\lambda_{1} / \lambda_{3}=1 / \mu
\end{gathered}
$$

Eqns. $\{53 \mathrm{a}, \mathrm{b}\}$ are applicable when $\rho>1 . \lambda_{1}$ is the correlation length in the horizontal, and was referred to in Table 2 as $\lambda_{\mathrm{h}}$; similarly, $\lambda_{3}$, applicable in the vertical, was designated $\lambda_{v} . \quad \lambda_{1}=\lambda_{2} \neq \lambda_{3}$ is applicable to the common situation (realized in the Biscayne Aquifer) of flat-lying sediments or sedimentary rocks. Such deposits may exhibit small anisotropy in the plane of bedding in some cases (most likely in cases where there are significant directional sedimentary structures, such as the cross-beds found in the Miami Limestone east of our study site on the Coastal Ridge). In the absence of such structures, $\lambda_{1}=\lambda_{2}$ is a reasonable assumption (though it would be best to test this assumption with measurements along transects having different orientations).

For purposes of estimating macrodispersivity we have assumed groundwater flow to be horizontal in the Biscayne Aquifer (i.e., $\theta=0$ ), an 
assumption that is reasonable for this flat-lying, highly permeable, unconfined aquifer. This assumption leads to a value of zero for the horizontal $\left(A_{22}\right)$ and vertical $\left(A_{33}\right)$ transverse macrodispersivities calculated with Eqns. $\{65 b, c\}$, indicating that for flow in the plane of bedding transverse dispersion is governed by the local scale dispersivities (Gelhar and Axness, 1983). In addition, Eqn. $\{65 \mathrm{a}\}$ simplifies to the form it would have in an isotropic medium, given as Eqn. $\{33\}$ in Gelhar and Axness (1983):

$$
A_{L}=\frac{\sigma_{Y}^{2} \lambda_{1}}{\gamma^{2}}
$$

When $\theta=0$ the expression for $\gamma$ also simplifies:

$$
\gamma=\exp \left[\sigma_{Y}^{2}\left(0.5-g_{11}\right)\right]
$$

For an isotropic porous medium the transverse macrodispersivity is:

$$
A_{T}=\frac{\sigma_{Y}^{2} \alpha_{L}\left(1+4 \alpha_{T} / \alpha_{L}\right)}{15 \gamma^{2}}
$$

In a medium where $\lambda_{3} \lambda_{1}=\lambda_{2}$ the transverse macrodispersivity is:

$$
A_{T}=\frac{\sigma_{Y}^{2} \alpha_{L}\left(1+3 \alpha_{T} / \alpha_{L}\right)}{8 \gamma^{2}}
$$

Eqn. $\{65 \mathrm{a}\}$ (equivalent to Eqn. $\{33\}$ when $\theta=0$ ) of Gelhar and Axness (1983) was used to estimate longitudinal macrodispersivity for the full Biscayne Aquifer, and for the Upper and Lower Aquifers separately. The variance $\left(\sigma_{Y}{ }^{2}\right)$ value used in calculations for the model with a nugget effect was the average of the values obatined from horizontal and vertical semi- 
variograms, while for those without a nugget the variance value used was the average of the values obtained from the semi-variograms and the sample variance (sample variance being the square of the standard deviation on the appropriate histogram, Figure 28 or 29, determined independently of semivariogram analysis)(Table IX.1).

Eqns. $\{36\}$ and $\{37\}$ was used to provide a rough estimate of the magnitude of transverse macrodispersivity, $A_{T}$. The ratio $\alpha_{T} / \alpha_{L}$ is called for in Eqns. $\{36\}$ and $\{37\}$ (the ratio of transverse to longitudinal local dispersivity); a value of 0.1 , based on the literature review by Gelhar et al. (1992), was used. The simplified expression given above was used to compute $\gamma$, except for the cases of the full aquifer, multiple interval approach, and the Lower Biscayne Aquifer; in these cases, $\lambda_{3}$ was greater than $\lambda_{1}$, precluding use of the equation involving $\mathrm{g}_{11}$ (as noted above, the expression for $\mathrm{g}_{11}$ is valid only when $\lambda_{1}>\lambda_{3}$ ). For these cases, $\gamma$ was calculated using the expression developed for isotropic media, $\gamma=1+\sigma_{\mathrm{Y}}{ }^{2} / 6$ (the vertical and horizontal correlation lengths are quite similar for the model without nugget, suggesting that calculating $\gamma$ with the isotropic model is acceptable; Gelhar and Axness, 1983, page 164, Equation 37 and related discussion). Results are presented and discussed in Table 3, in section 5.3. of the report text. 


\begin{tabular}{|c|c|c|c|c|c|}
\hline & $\mathbb{N}$ & $\sigma_{y}^{2}$ & $\sigma_{n}^{2}$ & $o_{s}^{2}$ & $\sigma_{\mathrm{Y}}^{2}$ \\
\hline \multicolumn{6}{|l|}{ Full Biscayne Aquifer } \\
\hline \multicolumn{6}{|l|}{ multiple interval } \\
\hline with nugget & 425 & 3.51 & 1.80 & - & 2.66 \\
\hline without nugget & 425 & 3.66 & 1.80 & 2.61 & 2.69 \\
\hline \multicolumn{6}{|l|}{ single interval } \\
\hline with nugget & 207 & 1.47 & 1.42 & - & 1.44 \\
\hline without nugget & 207 & 2.56 & 1.81 & 2.49 & 2.29 \\
\hline \multicolumn{6}{|l|}{ Upper Biscayne Aquifer } \\
\hline \multicolumn{6}{|l|}{ multiple interval } \\
\hline with nugget & 258 & 2.34 & 1.17 & - & 1.76 \\
\hline without nugget & 258 & 2.53 & 1.85 & 2.09 & 2.157 \\
\hline \multicolumn{6}{|l|}{ single interval } \\
\hline with nugget & 145 & 2.05 & 1.40 & - & 1.72 \\
\hline without nugget & 145 & 2.05 & 1.82 & 1.87 & 1.91 \\
\hline \multicolumn{6}{|l|}{ Lower Biscayne Aquifer } \\
\hline \multicolumn{6}{|l|}{ multiple interval } \\
\hline with nugget & 167 & 1.99 & 0.86 & - & 1.42 \\
\hline without nugget & 167 & 1.90 & 1.81 & 1.69 & 1.80 \\
\hline \multicolumn{6}{|l|}{ single interval } \\
\hline with nugget & 62 & 2.45 & 0.76 & - & 1.60 \\
\hline without nugget & 62 & 2.45 & 2.25 & 2.11 & 2.27 \\
\hline
\end{tabular}

Table IX.1. Values of variances obtained from the vertical ("v") and horizontal ("h") semi-variograms, and direct calculation ("s") based on $\operatorname{lnK}$ values. The average variance $\left(\sigma_{Y}^{2}\right)$ was used to estimate the macrodispersivity. 
APPENDIX X

Logistical References 
Borehole video:

Yuhr, Lynn, General Manager-Vice President, Technos Inc., 3333 Northwest $21^{\text {st }}$ Street, Miami, Florida 33142, Telephone (305) 634-4507, Fax (305) 635-4109

Drilling equipment and supplies:

Toney Drilling Supplies, Inc., $14060 \mathrm{NW} 19^{\text {th }}$ Avenue, Miami, Florida 33054, Telephone (305) 685-2453, Fax (305) 687-5231

Electromagnetic flowmeter:

Bozeman, Ed, Tisco, Inc., 1050 Northfield Court, Suite 240, Roswell, Georgia 30076-3826, Telephone (404) 664-0859, Fax (404) 664-9070

Everglades National Park:

Fennema, Robert. Daniel Beard Research Center, Everglades National Park, Homestead, Florida, Telephone (305) 242-7826

Rubber hoses and clamps:

Amazon Rubber Company, 3950 N. Miami Avenue, Miami, Florida 33137, Telephone (305) 576-1640, Fax (305) 573-8063

Variogram software:

Rockware, Inc., 4251 Kipling Street, Suite 595, Wheat Ridge, Colorado 80033, Telephone (800) 775-6745, Fax (303) 423-6171

Ingram, Phillip. SRIE Pty. Ltd. P.O. Box 1189. Dee Why, N.S.W., 2099, Australia 